\title{
MICROFÓSSEIS CONTIDOS NO CÁLCULO DENTÁRIO COMO EVIDÊNCIA DO USO DE RECURSOS VEGETAIS NOS SAMBAQUIS DE JABUTICABEIRA II (SC) E MORAES (SP)
}

\author{
Instituto de Biociências \\ Universidade de São Paulo
}




\title{
MICROFÓSSEIS CONTIDOS NO CÁLCULO DENTÁRIO COMO EVIDÊNCIA DO USO DE RECURSOS VEGETAIS NOS SAMBAQUIS DE JABUTICABEIRA II (SC) E MORAES (SP)
}

\author{
Instituto de Biociências \\ Universidade de São Paulo
}

Dissertação apresentada ao Instituto de Biociências da Universidade de São Paulo, para a obtenção de Título de Mestre em Ciências, na Área de Genética e Biologia Evolutiva.

Orientadora: Profa. Dra. Sabine Eggers 


\title{
MICROFÓSSEIS CONTIDOS NO CÁLCULO DENTÁRIO COMO EVIDÊNCIA DO USO DE RECURSOS VEGETAIS NOS SAMBAQUIS DE JABUTICABEIRA II (SC) E MORAES (SP)
}

\author{
Instituto de Biociências \\ Universidade de São Paulo
}

Dissertação apresentada ao Instituto de Biociências da Universidade de São Paulo, para a obtenção de Título de Mestre em Ciências, na Área de Genética e Biologia Evolutiva 


\section{Ficha Catalográfica}

Boyadjian, Célia Helena Cezar

Microfósseis contidos no cálculo

dentário como evidência do uso de recursos vegetais nos sambaquis de Jabuticabeira II (SC) e Moraes (SP).

$147 \mathrm{pps}$

Dissertação (Mestrado) - Instituto de Biociências da Universidade de São Paulo. Departamento de Genética e Biologia Evolutiva.

1. Paleodieta 2.Bioarqueologia 3. Cálculo dentário I. Universidade de São Paulo. Instituto de Biociências. Departamento de Genética e Biologia Evolutiva.

\section{Comissão Julgadora:}

Prof(a). Dr.(a).

Orientador(a) 
Dedico este trabalho à minha mãe, Ivany, exemplo de força e dignidade, pelo carinho, apoio e amor incondicional. Sem ela, nada disso teria sido possível. 
"You have never been in love Until you've seen the sun light thrown Over smashed human bone"

Morrissey, First of the gang to die 


\section{Agradecimentos}

À Sabine Eggers, pela orientação (não só em assuntos relacionados ao mundo acadêmico), encorajamento, compreensão e, principalmente, por ter sido um grande exemplo durante todos estes sete anos.

A Karl Reinhard, por ter participado do início deste processo, por todos os ensinamentos, por ter me aberto tantas portas e, principalmente, pelas horas sempre agradáveis e divertidas.

À FAPESP, pela bolsa concedida.

A Matthias Kucera e Doris Pany, por terem me acolhido durante a o estágio na Austria, pelo carinho, paciência e pelo trabalho em colaboração, essencial para parte desta pesquisa.

A Wolfgang Neubauer e Martin Fera do VIAS (Vienna Institute for Archaeological Science), por terem me concedido o estágio de escavação em Schwarzenbach.

A Paulo De Blasis e Levy Figuti (MAE-USP), por terem possibilitado a minha ida a campo, o acesso às informações relacionadas aos sítios estudados, pelo carinho e atenção durante as etapas de escavação. À Paula Nishida e Daniela Klökler, por terem me ensinado muito em campo e pelas horas divertidas.

Á Carol (Borges) pelas maravilhosas conversas e esclarecimentos sobre arqueologia, pelo incentivo e pela grande amizade que começou em meio às reviravoltas de um ciclone extra-tropical.

Á Carol (Góes) por ter me ajudado com o processamento das amostras, etapa essencial deste trabalho, pelo carinho e amizade.

À Profa. Maria Luiza Salatino, por ter permitido acesso ao Laboratório de Fitoquímica (IB-USP), sem o qual não poderia ter realizado este trabalho. À Mayumi pelo auxílio em seu laboratório e pelas horas de esclarecimento sobre questões práticas e espirituais. Á Lu Witovski, por esclarecer dúvidas básicas sobre botânica e me fascinar com suas histórias.

À Verônica Wesolowski, pelo esclarecimento de dúvidas, pelas valiosas conversas e pelo pioneirismo nos estudos sobre microfóssies em cálculo dentário no Brasil.

À Paula Amaral (IGC-USP), por me ajudar com as diatomáceas.

Aos amigos do LAB, Camila Frochtengarten, Ligia e Rafael Bartolomucci, Dalva Hashimoto, Roberto Perrota, Katharina Brandt, Alan Besbordco, pela curadoria, trabalho em conjunto, apoio e alegria. À Ciça, pela amizade, pelos ensinamentos valiosíssimos e por ter sido tão companheira durante os anos que trabalhamos juntas. A José Filippini, amigo e companheiro de viagens e aventuras. À Mercis, amiga e exemplo de pesquisadora.

A todos os meus amigos, que souberam me amar e compreender minha ausência durante todo este período.

A meus avós, Aparecida e Palmiro, pelo amor, carinho, incentivo, exemplo de vida e por terem sido parte tão importante no meu processo de crescimento e aprendizagem. Á meus tios, Walter e Erica pelo carinho, apoio e por terem demonstrado grande interesse sobre minhas pesquisas.

A meu irmão, Victor, que seguiu meus passos durante sua infância e agora é um grande exemplo pra mim. A meu pai, que mesmo longe, está tão próximo.

A Davi C. Elias, por ter me auxiliado nas etapas finais deste trabalho, pela assistência técnica, pelo apoio, compreensão, paciência, carinho e, principalmente, por seu amor e companheirismo.

Á todos que contribuíram para a realização deste trabalho. 


\section{Apresentação}

O trabalho desenvolvido durante o período do Mestrado foi um exercício de extrema importância na exploração de possibilidades de recuperação de informações sobre o consumo de vegetais por grupos humanos associados aos sambaquis; informações estas, ainda muito escassas e pouco abordadas (de maneira geral) para estes sítios. Ele se vale da utilização de um método tradicional para recuperação de microfósseis vegetais aderidos ao cálculo dentário, mas trata, especialmente, do esforço referente ao desenvolvimento de uma técnica alternativa para obtenção de informações quando as mesmas são muito raras e/ou permanecem encobertas.

Esta dissertação consiste de Introdução na qual, com base em uma revisão bibliográfica, se discorre sobre os principais assuntos relacionados ao tema da pesquisa e se abordam as questões cruciais que motivaram o desenvolvimento do trabalho. Nos Objetivos enfocam-se as questões abordadas pelo presente trabalho. Em Material e Métodos, trata-se da exposição da forma como foram estudados os objetos de pesquisa e como foram obtidos e tratados os dados.

Como os resultados obtidos foram muitos, e de naturezas muito distintas, já que uma parte do trabalho se refere a testes de uma nova metodologia, optou-se por manter um tópico único de Resultados e Discussão, para que a leitura pudesse ficar mais clara. Dessa forma, cada um dos resultados é discutido à medida que é exposto, de forma a facilitar o entendimento de cada dado obtido no contexto estudado. Entretanto, para uma compreensão mais global, foram acrescentados resumos no final dos grandes capítulos. Além do tópico abordando as Conclusões, discorre-se brevemente sobre as dificuldades enfrentadas, algumas das quais impediram a realização de determinados testes, nas Limitações do trabalho. Por fim, as Considerações Finais abordam o trabalho que será executado no futuro, além de apresentar possíveis soluções para alguns dos problemas observados. 


\section{Índice}

1 - Introdução

1.2Dieta no passado 11

1.3Sambaquis 12

1.3.1Sambaqui Jabuticabeira II 16

1.3.1.1Locus II 17

1.3.1.2Bioantropologia e Jabuticabeira II 18

1.4Sambaquis fluviais $\quad 20$

1.4.1Sambaqui do Moraes $\quad 22$

1.5Paleoetnobotânica 23

1.5.1Fitólitos $\quad 24$

1.5.2Grãos de amido $\quad 27$

1.5.3Outros microfósseis vegetais $\quad 30$

1.6Formação do Cálculo dentário

1.6.1Análise de Cálculo dentário 32

1.6.2Preservação de Cálculo dentário 33

2 - Objetivos $\quad 39$

3 - Material e Métodos $\quad 40$

3.1 - Processamento do Cálculo dentário: Método Tradicional 41

3.2 - Processamento do Cálculo dentário: Método "Dental Wash" 41

3.4 - Preparação das lâminas

3.5 - Contabilização dos Microfósseis 42

3.6 - Testes do "Dental Wash"

3.6.1 - Microscópio Eletrônico de Varredura (MEV) 44

4 - Resultados e Discussão 45

4.1 - Análise "tradicional" de cálculo dentário em Jabuticabeira II 45

4.1.1 - Amido $\quad 46$

4.1.1.1 - Comparações entre dentição anterior e posterior 47

4.1.1.2 - Comparação entre sexos $\quad 48$

4.1.1.3 - Tamanho e peso do cálculo dentário, concentração de amido e idade de óbito 48

4.1.1.4 - Concentração de amido versus cáries $\quad 51$

4.1.1.5 - Amidos modificados: evidências sobre preparo alimentar 51

4.1.2 - Outros microfósseis vegetais 53

4.1.3 - Análise de microfósseis in loco através do microscópio eletrônico de varredura (MEV) 53

4.1.4 - Fitólitos $\quad 54$

4.1.4.1 - Comparação entre sexos 56

4.1.4.2 - Tamanho e peso do cálculo dentário, concentração de fitólito e idade de óbito 56

4.1.4.3 - Comparações entre dentição anterior e posterior 57

4.1.4.4 - Fitólitos versus desgaste dentário $\quad 57$

4.1.5 - O Lócus 2 de Jabuticabeira II $\quad 58$

4.1.5.1 - Amido $\quad 59$

4.1.5.1.1 - Sexo e idade 59

4.1.5.1.2 - Lócus 2 versus outros loci 59

$\begin{array}{ll}\text { 4.1.5.2 - Fitólitos } & 60\end{array}$

4.1.5.2.1 - Sexo e idade $\quad 60$

4.1.5.2.2 - Lócus 2 versus outros loci 60

4.1.6-Resumo $\quad 61$

4.2 - "Dental Wash"

4.2.1 - Testes do Dental Wash: Comparabilidade $\quad 84$

4.2.1.1 - Verificando a possibilidade de comparação $\quad 85$

4.2.1.2 - Comparação das concentrações entre ambos os métodos 87

4.2.1.2.1 - Comparações entre dentição anterior e posterior $\quad 87$

4.2.1.2.2 - Sexo e idade $\quad 88$

4.2.2 -Testes do Dental Wash: Efeitos sobre o Microdesgaste (MEV) 88 
4.2.3 - Resumo 89

4.3 - Análise de Cálculo em Moraes ("dental wash") 102

4.3.1 - Amido 102

4.3.1.1 - Sexo e idade 103

4.3.1.2 - Comparações entre dentição anterior e posterior 104

4.3.1.3 - Concentração de amido versus cáries 104

4.3.1.4 - Grãos de amido modificados em Moraes 105

4.3.2 - Fitólitos $\quad 106$

4.3.2.1 - Sexo e idade 107

4.3.2.2 - Comparações entre dentição anterior e posterior 107

4.3.2.3 - Fitólitos versus desgaste dentário 107

$\begin{array}{ll}4.3 .3 \text { - Peso e índice de cálculo } & 108\end{array}$

$\begin{array}{ll}\text { 4.3.4 - Resumo } & 108\end{array}$

4.4 - A dieta vegetal dos sambaquieiros de Moraes e Jabuticabeira II 119

4.4.1 - Concentrações de microfósseis, cáries, formação dos depósitos de cálculo 119

4.4.2 - Diferenças entre sexos e idade de óbito quanto à alimentação 124

$\begin{array}{ll}4.4 .3 \text { - Outros microfósseis vegetais } & 125\end{array}$

4.5 - Paleodieta sambaquieira $\quad 125$

5 - Conclusões 127

6 - Limitações do trabalho 129

7 - Considerações finais 132

Resumo 133

$\begin{array}{ll}\text { Abstract } & 135\end{array}$

Apêndice $\quad 137$

Referências Bibliográficas 139 


\section{Introdução}

\section{2 - Dieta no Passado}

O estudo da paleodieta visa elucidar padrões alimentares em populações pretéritas, incluindo distribuição geográfica e temporal de tipos e mudanças de estratégias de subsistência.

Diferentes ferramentas são utilizadas para a compreensão da dieta no passado. A análise química dos ossos (através da determinação de isótopos estáveis, por exemplo) possibilita reconstruir a proporção de recursos animais e vegetais ingeridos, o que indica o que era preponderante, a caça, a pesca ou a coleta de vegetais de um ou outro tipo (Scarre, 2005). Já por meio da análise de macro vestígios vegetais, é possível conhecer as espécies utilizadas como recursos alimentares e agrupá-las em selvagens ou domesticadas. Isso possibilita inferir se houve, em determinado horizonte geográfico e cultural, a prática do cultivo de plantas (Smith, 1989 apud Scarre, 2005). A prática da domesticação de plantas e animais tem, por sua vez, inúmeras causas e conseqüências de enorme valor para a reconstrução do modo de vida e da relação saúde-doença em agrupamentos humanos do passado, sua adaptação e adaptabilidade. Os vestígios de dieta em sítios arqueológicos são, inclusive, importantes para a reconstrução do paleoambiente.

Contudo, o conhecimento sobre a subsistência no passado também fornece embasamento para a compreensão do presente. A mudança de uma economia baseada na caça e coleta para a agricultura representa um marco crucial na história da nossa espécie, que levou ao aumento populacional, à complexificação da organização interna das sociedades, ao aparecimento das cidades, à evolução da escrita, à criação do estado (Scarre, 2005). Entretanto, como acreditam alguns autores, estas transformações ocorreram em paralelo com a domesticação, ou ainda, na ausência dela, em alguns casos. Mas, a origem, o desenvolvimento e a dispersão da agricultura ainda são questões um tanto controversas, sendo extensa a lista de teorias e hipóteses a seu respeito (Scarre, 2005). Embora algumas dessas teorias sejam bastante distintas, verifica-se o descortinar de um cenário cada vez mais complexo de estratégias de subsistência, sendo que algumas delas, como as baseadas em caça, pesca e coleta, são consideradas, hoje, 
como promovedoras de adensamento demográfico e complexificação social, antes atribuídas, apenas, a agricultura (Kelly, 1995).

Nas Américas a origem da agricultura é uma questão discutida veementemente. $\mathrm{O}$ andamento das pesquisas, o desenvolvimento de novas técnicas e a mudança no foco dos estudos e no tipo de evidência arqueológica analisada desencadearam um recuo na datação dos vestígios de vegetais cultivados mais antigos (Dickau, 2007; Iriarte et al, 2004; Piperno et al, 2000; Piperno et al, 2004; Sandweiss, 2007). Atualmente, as evidências mais antigas da domesticação de vegetais no Novo Mundo datam de 9240 e 7660 anos AP para abóbora, 7840 anos AP para amendoim, 8000 e 7660 anos AP para quinoa e 5490 anos AP para o algodão (Dillehay et al, 20007). Estes dados provêm de macro-vestígios vegetais obtidos em sítios do Norte do Peru e demonstram que "a horticultura e a complexidade cultural se desenvolveram nas Américas quase tão precocemente quanto em muitas regiões do Velho Mundo" (Dillehay et al, 2007). No entanto, dentre alguns dos sítios arqueológicos mais antigos (datados entre 5000 e 4000 anos $A P$ ) da América do Sul em que foram encontradas evidências de vegetais cultivados, estas não provém de macrovestígios (como tubérculos carbonizados, sementes, entre outros), mas sim de microvestígios botânicos, como fitólitos e grãos de amido (Iriarte et al, 2004), abordados mais adiante.

Apesar dos sambaquis representarem o tipo de sítio arqueológico melhor estudado no Brasil, dieta e subsistência de seus construtores ainda são parcialmente desconhecidas. Todavia, estudos com novas abordagens e técnicas inovadoras vem obtendo resultados interessantes que têm contribuído para as mudanças de hipóteses nessa área. Com os resultados obtidos no presente trabalho, almeja-se complementar as informações sobre subsistência nos sambaquis, especialmente no que diz respeito à utilização dos recursos vegetais.

\section{3 - Sambaquis}

Em quase toda a costa do Brasil, principalmente nas regiões Sul e Sudeste, foram encontrados sambaquis. Até o presente existem mais de 1000 sambaquis registrados e mais de 300 trabalhos, dissertações e teses elaboradas sobre sambaquis e seus construtores. Esses sítios arqueológicos, que datam de 8000 a 600 anos AP, são montes artificiais em forma de calota e podem atingir dimensões variadas, chegando à $70 \mathrm{~m}$ de altura (De Blasis et al, 2007; Lima 2000; Prous, 1991). Eles são compostos, principalmente, por conchas de moluscos, contendo, também, restos de fauna, artefatos 
ósseos e líticos, estruturas de habitação, restos de fogueiras e, inclusive, sepultamentos humanos (Gaspar, 1998).

Mas a exploração do ambiente de costa não se deu apenas através dos indivíduos associados aos Sambaquis. "Há cerca de 7000 anos AP a ocupação da costa é um evento global e a presença de sítios semelhantes aos sambaquis é um traço comum" (Figuti, 1993) em vários países. Em Portugal se observam os concheiros mesolíticos; os shellmounds no litoral dos Estados Unidos; os conchales no Peru, Chile, Argentina e Guianas. Sítios semelhantes também existem em outras regiões como na costa da África (Egito, Senegal, África do sul, Madagascar), Europa, Malásia, Japão, Austrália, entre outros (Lima, 2000). Todos esses são exemplos de sítios costeiros de subsistência baseada em recursos aquáticos, caracterizados pelo acúmulo de conchas em sua estrutura. Estes tipos de sítios arqueológicos apareceram em diferentes momentos durante o Holoceno e estavam relacionados a distintas culturas.

Por muito tempo acreditou-se que a enorme quantidade de conchas dos sambaquis seria proveniente de restos alimentares e os indivíduos associados a esses sítios eram vistos como nômades coletores de moluscos. Estudos zooarqueológicos e de isótopos estáveis têm demonstrado que a subsistência dos sambaquieiros, no entanto, era baseada na pesca enquanto a coleta de moluscos teria um papel secundário na alimentação (Bandeira, 1992; de Masi, 1999; Figuti, 1993; Klökler, 2000). Porém, hoje é consenso que as conchas constituíam material primordial de construção. Além disso, atualmente, reinterpretações arqueológicas retratam os sambaquieiros como grupos sedentários vivendo em altas densidades demográficas de maneira socialmente mais complexa do que se imaginava anteriormente (De Blasis et al., 1998; Gaspar et al, 1999). Hoje a visão "impressionista" (Scheel-Ybert et al, 2003) de pequenos bandos nômades de comedores de moluscos não mais se aplica aos pescadores-coletores-caçadores dos sambaquis da costa brasileira (Lima, 2000).

Esses sítios arqueológicos, em geral, quando ativos, estavam estrategicamente localizados próximos ao mar, a lagoas ou rios, mangues e restingas, todas elas áreas ricas e previsíveis quanto aos recursos alimentares, facilitando a sedentarização da população (Scheel-Ybert, 2001). Tais ambientes apresentam alta disponibilidade e alta densidade de peixes, crustáceos e moluscos, não sendo muito dispendiosa a aquisição desse tipo de fauna (Figuti, 1993). Em contrapartida, a caça de animais terrestres nos ecossistemas costeiros não seria tão vantajosa, já que nesses ambientes a fauna de mamíferos apresenta uma densidade por espécie/área baixa, uma vez que "predominam 
animais solitários, pequenos, arborícolas e noturnos" (Vickers, 1984 appud Figuti, 1993; Vickers, 1988). Os resultados dos estudos zooarqueológicos têm evidenciado esse "papel preponderante da pesca como fonte de alimentação se comparada aos produtos da caça" (Figuti, 1993). Nesse contexto, a pesca (e não a caça) seria, então, a principal fonte de subsistência, sendo complementada pela coleta de moluscos. Isso porque a coleta de moluscos é uma atividade de baixo rendimento nutricional, e que, portanto, não poderia ser a principal fonte de alimentação desses grupos, mas poderia, por outro lado, ser mantida com constância, devido à alta disponibilidade desses organismos no ambiente (Figuti, 1993), sendo uma segura fonte de alimento tanto em épocas de abundância quanto de baixa dos outros recursos (Klökler, 2000). Os moluscos teriam, então, maior valor por suas conchas, utilizadas como material de construção, do que por seu valor nutritivo.

O ecossistema de restinga apresenta uma grande diversidade de recursos vegetais como frutos e sementes, além de muitas plantas tuberosas (Scheel-Ybert et al, 2003). Os indivíduos que viviam nesse ambiente podem ter utilizado "tubérculos de Gramineae e Cyperaceae, assim como de taboa (Thypha domingensis) e de carás (Discorea spp)" para complemento de sua alimentação, podendo, alguns desses vegetais, ter sido, inclusive, cultivados (Scheel-Ybert et al, 2003).

Entretanto, ainda pouco se sabe sobre o consumo, cultivo e domesticação de vegetais por esses grupos sambaquieiros, já que caça e pesca deixam vestígios muito mais conspícuos no registro arqueológico do que a coleta de plantas. Isso se deve a características químicas específicas do solo e ao clima da região, fatores que dificultam a preservação de vestígios vegetais nestes contextos arqueológicos. As evidências da utilização de plantas nos sambaquis restringiam-se, até pouco tempo atrás, a sementes, coquinhos e objetos líticos atribuídos ao processamento de vegetais (De Blasis et al, 1998; Garcia, 1972; Kneip, 1994; Lima, 2000; Tenório, 1991).

Mas, através de estudos antracológicos (analise de carvão arqueológico), tem-se demonstrado cada vez mais a importância da utilização de vegetais (Scheel-Ybert, 2000; 2001; Scheel-Ybert et al, 2003). Scheel-Ybert e colaboradores (2003) afirmam que os sambaquieiros utilizavam grande variedade de plantas selvagens em sua dieta e sugerem que, inclusive, o manejo ou cultivo incipiente de espécies tuberosas e árvores poderia ter sido praticado em certos sítios estudados no sudeste e sul do país. Além dos estudos antracológicos, o presente trabalho, assim como o doutorado de Verônica Wesolowski (Wesolowski, 2007), está demonstrando o enorme potencial que o estudo do cálculo 
dentário tem para a reconstrução da utilização de plantas pelos sambaquieiros, na tentativa de compensar a falta de informações devida ao escasso registro deixado por macro vestígios vegetais.

É importante frisar que a utilização de plantas não se restringe apenas ao consumo alimentar. Elas também são utilizadas como material de construção (Villers et al, 1981) e para a confecção de artefatos tão variados como cestos, remos, cordas, redes, armas e tecidos (Alcorn, 1995). Ainda, são utilizadas como material de combustão (Alcorn, 1995, Scheel-Ybert, 2000; 2001; Scheel-Ybert et al, 2003), como material em rituais funerários ou xamânicos e, diretamente como ervas medicinais (Alcorn, 1995). Para os grupos construtores dos sambaquis, além de fonte de alimento, as plantas poderiam servir como combustível, para construção de habitações, cercas e canoas, para a execução de trabalhos manuais (Scheel-Ybert et al, 2003) e até, para a delimitação e elementos de sustentação em contextos funerários, como é demonstrado pelas marcas de estaca dispostas em torno dos sepultamentos no sítio Jabuticabeira II (Figura 1).

Outro indício da utilização de plantas pelos sambaquieiros seria o fato de que, em alguns dos sambaquis localizados na região Sul do Brasil, pode-se observar a presença de restos de cerâmica, relacionados a ocupações mais recentes dos sítios. Isso poderia sugerir que, nesse período, a horticultura teria sido introduzida na área (Beck, 1972), já que se acreditou, por muito tempo, que a tradição da cerâmica pudesse estar relacionada à prática do cultivo de vegetais (Schmitz, 1988; Tiburtius et al, 1951;). Curiosamente, esses sambaquieiros ceramistas apresentam índices de cáries mais baixos (Wesolowski, 2000) do que o esperado para populações agricultoras (Turner II, 1979), o que leva a crer que, pelo menos nos grupos sambaquieiros, a cerâmica não esteve, necessariamente, relacionada à horticultura e vice-versa (Wesolowski, 2000). Inclusive, recentemente, Dickau e colaboradores (2007) observaram em sítios arqueológicos das porções oeste e central do Panamá, evidências da adoção de plantas domesticadas e produção de alimento vegetal antes da utilização da cerâmica. Há indício de que isto tenha ocorrido, também, em outras regiões da América do Sul (Iriarte et al, 2004; Perry et al, 2006; Piperno et al, 2000), como está sendo aventado para os sambaquis.

O que corrobora tal interpretação é que, vestígios cerâmicos no topo dos sambaquis, em geral, não vem acompanhados de outras mudanças tecnológicas (Lima, 2000). Então, tais vestígios parecem mais representar a utilização de sambaquis desocupados por populações ceramistas (Beck, 1978) ou então, a utilização de cerâmica 
por parte dos sambaquieiros sem que isso tenha mudado substancialmente seu modo de vida e subsistência (Lima, 2000).

O cultivo e o consumo de plantas por esses grupos sambaquieiros permanecem, ainda, incompreendidos. Muitas questões necessitam ser respondidas. Diversas análises e a utilização de novas técnicas fazem-se necessárias para elucidar esse problema.

\subsection{1 - Sambaqui Jabuticabeira II}

Os sambaquis da região Sul do país apresentam características peculiares, como dimensões monumentais (com registro de sambaqui de $400 \mathrm{~m}$ de extensão e até $70 \mathrm{~m}$ de altura - De Blasis et al., 1998), presença de artefatos líticos em forma de animal, conhecidos como zoólitos, exclusivos dos sambaquis meridionais (Prous, 1991), e grande número de sepultamentos humanos, o que confere a alguns deles a denominação de sítios cemitérios (Fish et al., 2000).

Um grupo multidisciplinar de pesquisadores vem estudando sistematicamente a formação e o padrão de assentamento de um conjunto de mais de sessenta sambaquis localizados nas proximidades da Lagoa do Camacho, em Jaguaruna, SC, desde 1997 ("Processos Formativos nos Sambaquis do Camacho, SC: Padrões Funerários e Atividades Cotidianas"1 e "Sambaquis e Paisagem: Modelando a Inter-relação entre Processos Culturais e Naturais no Litoral Sul de Santa Catarina" ${ }^{2}$ ).

Dentre os sambaquis dessa região, merece destaque o Jabuticabeira II (Figura 2), o sambaqui melhor datado do Brasil. Este sítio localiza-se no município de Jaguaruna (latitude $28^{\circ} 36^{\prime} \mathrm{S}$ e $48^{\circ} 57^{\prime} \mathrm{W}$ ) e possui, aproximadamente, $400 \mathrm{~m}$ de comprimento, $200 \mathrm{~m}$ de largura e $6 \mathrm{~m}$ de altura (De Blasis et al, 1998). Foram obtidas dezenas de datações radiocarbônicas, que indicam um período contínuo de ocupação de mais de 1000 anos, datado entre 2890 +/- 55 e 1805+/- 65 anos BP (De Blasis et al, 2007).

Jabuticabeira II se caracteriza pela deposição repetitiva de camadas de conchas e areia, intercaladas por lentes de solos ricos em matéria orgânica, com coloração diferenciada e numerosas marcas de estaca em associação com sepultamentos (Fish et al, 2000, Klökler, 2000). Isso, em conjunto com a ausência de evidências de habitação, leva a crer que a construção desse sambaqui foi decorrente de rituais funerários (De Blasis et al, 2004).

\footnotetext{
${ }^{1}$ FAPESP 03/02059-0

${ }^{2}$ FAPESP 04/11038-0
} 
Há uma enorme quantidade de sepultamentos em Jabuticabeira II, o que indica, a priori, uma alta densidade demográfica na região. Fish e colaboradores (Fish et al, 2000), através de uma abordagem conservadora, estimaram a existência de mais de 43.000 pessoas sepultadas em Jabuticabeira II, a julgar pela densidade de sepultamentos nas áreas até então escavadas e pelo volume total do sítio. Eles são, em grande parte, recobertos por conchas e acompanhados por fogueiras, seixos, marcas de estacas e restos de fauna, principalmente peixes (Klökler, 2003).

Os principais componentes da matriz estratigráfica deste sambaqui são conchas e areia, mas as camadas dominadas por conchas são recobertas por um solo orgânico escuro, denominado terra preta. As datações obtidas indicam continuidade de ocupação do sítio mesmo nessa área de transição estratigráfica e, nessas camadas de terra preta, o ritual mortuário parece apresentar poucas mudanças em relação aos estratos anteriores (Fish et al, 2000). Além disso, nessas camadas mais recentes foram observados bolsões preenchidos com "materiais típicos de espaços funcionais de ocupação, tais como grande quantidade de carvões (incluindo madeira e sementes)" (Fish et al, 2000).

Como mencionado anteriormente, há vestígios que apontam para o manejo ou cultivo incipiente de vegetais em alguns dos sambaquis. Levando em conta as características da camada de terra preta, é interessante investigar se o grupo associado ao sambaqui de Jabuticabeira II teria praticado algum tipo de cultivo vegetal nas fases mais tardias de ocupação do sítio.

Apesar dessa questão da prática de horticultura ainda estar em aberto, há evidências sobre a importância da utilização de recursos vegetais nesse sambaqui. Em Jabuticabeira II foram encontrados artefatos líticos como almofarizes, socadores e mãos de mó (Figura 3), cuja função estaria relacionada ao processamento de plantas (ScheelYbert, et al 2003). Além disso, a análise antracológica revelou que esse sambaqui se encontrava em região de mata de restinga e de restinga aberta (Scheel-Ybert, et al 2003) caracterizando uma região muito rica em recursos vegetais.

\subsubsection{1 - Lócus 2}

No Lócus 2 de Jabuticabeira II (Figura 1), há um conjunto de sepultamentos associados estratigraficamente de forma que parecem pertencer a um grupo distinto dos demais sepultamentos do sítio (De Blasis et al, 2004). Por esse motivo ele foi denominado grupo de afinidade. Datações muito próximas entre um sepultamento na superfície e outro 
na base da camada desse lócus (2340 e $2320 \pm 50$ BP respectivamente) confirmam a concomitância deles, indicando, indiretamente, tratar-se de um grupo que foi sepultado com poucas décadas de diferença.

A natureza de tal "afinidade", se é que não se trata de um artefato arqueológico, ainda está em aberto. Os indivíduos poderiam ter sido agregados por realizarem alguma atividade específica comum, por serem membros de uma mesma família ou clã ou ainda, por representarem uma parcela da população submetida a alguma situação específica. Se esses indivíduos realmente faziam parte de um grupo especial, é possível, inclusive, que houvesse diferenças quanto à sua dieta em comparação com os indivíduos dos outros loci.

Assim, o Lócus 2 é mais um aspecto desafiador do sambaqui de Jabuticabeira II e necessita ser melhor investigado. Até agora foram estudadas sistematicamente duas hipóteses: a dos indivíduos do Lócus 2 terem desempenhado atividades distintas dos demais indivíduos e de serem aparentados entre si. Não há indícios que dêem suporte a hipótese de parentesco, pois estudos de biodistância com variáveis não métricas cranianas (Filippini, 2004) e dentárias (Bartolomucci, 2006) não encontraram qualquer diferença estatisticamente significativa entre os indivíduos pertencentes ao grupo de afinidade e aqueles escavados em outras áreas do Jabuticabeira II. Analogamente, Petronilho (2005) não encontrou diferenças importantes quanto a padrão, distribuição e gravidade de degeneração articular dos indivíduos de dentro versus de fora do grupo de afinidade.

Contudo, um aspecto interessante que não foi abordado, até o momento, diz respeito à comparação de restos alimentares dos indivíduos sepultados no Lócus 2 com indivíduos dos demais sepultamentos de Jabuticabeira II, para verificação de possíveis diferenças na dieta destes grupos. Isso será discutido no presente trabalho.

\subsubsection{2 - Bioantropologia e Jabuticabeira II}

A bioantropologia estuda aspectos da vida humana como nutrição, dieta, estado de saúde, atividade e afinidade biológica entre populações. Para estudar a bioantropologia em grupos pretéritos analisam-se coleções osteológicas e dentárias.

Diversos estudos bioantropológicos já foram realizados com os restos humanos provenientes do sambaqui de Jabuticabeira II (Bartolomucci, 2006; Filippini, 2004; Filippini \& Eggers, 2005; Perrota \& Eggers, 2005; Petronilho, 2005; Petronilho \& Eggers, 2005; 
Okumura \& Eggers, 2005; Scheel-Ybert et al, 2003; Storto et al, 1999), inclusive alguns relacionados a presença de exostose auditiva (anomalia óssea no canal auditivo externo) provocada por atividades realizadas em contato com água e temperatura ambiental frias e ventos fortes como por exemplo mergulho, remo e natação (Boyadjian \& Eggers, 2002; Boyadjian \& Eggers, 2003a; b; Boyadjian et al, 2005; Eggers, et al 2006; Okumura et al, 2005; Okumura et al, 2005/6; Okumura et al, 2007 a, b).

Dentre os principais achados de Jabuticabeira II estão a ocorrência elevada de infecções, a baixa incidência de osteoartrite, os raros traumatismos, sejam eles acidentais ou violentos, a baixa estatura, (Okumura \& Eggers, 2005; Storto et al, 1999), a baixa freqüência de exostose auditiva (Boyadjian et al, 2005; Eggers et al, 2006; Okumura et al, 2007a) e a diferença morfológica marcante em relação a sambaquieiros provenientes do Vale do Ribeira (Filippini, 2004), mais tarde reavaliada e, desde então, sendo considerada ausente (Okumura \& Neves, 2005; Bartolomucci, 2006). Com relação aos dentes dos indivíduos desse sítio, observa-se uma incidência de cáries praticamente nula e um alto grau de desgaste dentário (Storto et al, 1999), o que seria característico de populações de caçadores-coletores, segundo Turner II (1979). No entanto, já foram obtidas baixas freqüências de lesões cariosas em grupos agricultores, cuja dieta era rica em carboidratos, como os consumidores de arroz do sudeste asiático (Tayles et al., 2000).

De qualquer forma, a cárie é uma doença infecciosa (provocada por bactérias da flora bucal) e multifatorial (Wesolowski, 2007). Sua associação com a horticultura é indireta e baseada no fato de que a dieta, embora tenha forte influência na forma e na intensidade com que a doença se manifeste, é apenas um dos fatores envolvidos em sua expressão (Tayles et al, 2000, Wesolowski, 2007). Dietas ricas em carboidratos normalmente causam um aumento na freqüência de cáries (Cohen \& Armelagos, 1984; Klinberg, 2002 Turner II, 1979), especialmente dependendo da freqüência e forma com que são ingeridos (Mandel, 1970). Alimentos ricos em carboidratos que permanecem por mais tempo na boca, ou que são mais adesivos, estão relacionados ao aparecimento da doença com maior grau de gravidade (Kleinberg et al, 1981; White, 1975).

Outros fatores que influenciam na formação de cáries são: a patogenicidade da flora bacteriana da boca, o $\mathrm{pH}$ salivar, procedimentos de higiene, a composição química da água consumida (Klinberg, 2002; White, 1975; Scheel-Ybert et al, 2003) e até a predisposição genética. Alguns destes fatores atuam, inclusive, contra a formação das cáries, ou até, retardando o processo carioso, impedindo o aumento do grau de gravidade. 
Uma proteção contra essas lesões pode estar associada, por exemplo, à ingestão de flúor e cálcio (Klinberg, 2002; White, 1975). Assim, a dependência de recursos marinhos na dieta teria efeito cariostático, já que flúor e cálcio estão presentes em peixes e mariscos, sendo, portanto, ingeridas em grandes quantidades (Steckel \& Rose, 2002). Somado a isso, o desgaste dentário provocado pela abrasividade desse tipo de dieta (juntamente com o alimento acabam sendo mastigados grãos de areia e fragmentos de conchas (Mendonça de Souza, 1995)), também atua contra a formação de cáries, diminuindo o relevo da superfície oclusal, eliminando sulcos onde as bactérias se instalariam, podendo, inclusive, eliminar a própria lesão cariosa (Mendonça de Souza, 1995; Wesolowski, 2007). Não somente a subsistência baseada em recursos marinhos, mas também outros tipos de dieta, como aquelas ricas em plantas com abundância de certos tipos de fitólitos, são abrasivas e podem causar desgaste dentário (Danielson \& Reinhard, 1998), dificultando a formação de cáries. Além disso, o acúmulo do próprio cálculo dentário também pode promover uma espécie de barreira, protegendo os dentes da ação danosa das bactérias cariogênicas (Greene et al, 2005).

Então, a baixa freqüência de cáries em Jabuticabeira II poderia ter ocorrido por alguns desses fatores em conjunto, como o alto grau de desgaste e de cálculo dentários, além da intensa utilização de recursos aquáticos marinhos. Desta forma, mesmo que houvesse uma grande ingestão de carboidratos na dieta, isso não poderia ser detectado, de forma indireta, pela ausência de cáries.

Por outro lado, apesar da baixa freqüência de cáries e, principalmente, da clara dependência de recursos aquáticos marinhos (Eggers et al, 2007; Klökler, 2000;), a presença da terra preta e dos artefatos líticos relacionados ao processamento de vegetais, bem como os dados antracológicos, apontam para uma grande importância dos recursos vegetais em Jabuticabeira II. Faz-se necessária, portanto, uma investigação mais detalhada sobre a utilização e consumo de plantas pelos indivíduos associados a esse sambaqui, para que seja possível avaliar melhor a sua dieta. O presente trabalho pretende contribuir com essa investigação através da análise de micro resíduos vegetais nesse sítio arqueológico.

\section{4 - Sambaquis fluviais}

Além dos sambaquis da costa, existem ainda aqueles que se encontram no interior, próximos a rios. Estes sítios são chamados sambaquis fluviais, ou "concheiros", e foram 
pouco estudados até o final da década de 90 (Prous, 1991). No vale do Ribeira (região sudeste do Brasil) os sambaquis fluviais são freqüentes, sendo que até a década de 80 , haviam sido identificados 28 deles (Barreto, 1988). Este contingente vem aumentando devido a um projeto realizado na região ${ }^{3}$.

Sabe-se que há semelhanças e diferenças entre os sambaquis costeiros e fluviais, mas as informações que se têm, até o momento, ainda são insuficientes para que se possa afirmar qualquer coisa concreta sobre sua inter-relação (Figuti, 2004). Os sítios do interior têm dimensões menores do que os do litoral e, embora suas camadas não sejam tão espessas e tão estratificadas quanto às dos sítios litorâneos, a densidade de conchas é muito parecida (Barreto, 1988). As conchas utilizadas nos sambaquis costeiros são de moluscos bivalves (na maioria deles, Anomalocardia brasiliana) (Prous, 1991) enquanto nos fluviais predominam as de moluscos terrestres (Megalobulimus $s p$ ) (Barreto, 1988; Figuti, 2004). Os artefatos encontrados nesses sítios diferem, principalmente, pela matéria prima utilizada. No interior são comuns as pontas de flecha de sílex e no litoral as feitas em osso (Figuti, 2004).

Mas, adornos feitos de caninos de animais (mais freqüentes como acompanhamento funerário em sepultamentos de criança do que de adultos), sepultamentos com ocre (Edwards et al, 2001) e anzóis, em ambos os tipos de sítios, são alguns aspectos que sugerem um contato ou identidade cultural entre esses tipos de sambaquis (Figuti, 2004). Evidências como espinhas de raias e dentes de tubarões, encontrados em sambaquis fluviais da região do Vale do Ribeira (Figuti, 2004), fornecem suporte a essa semelhança. Outros dados que apóiam essa interpretação incluem a elevação do nível do mar anterior há 6000 anos AP (Angulo \& Lessa, 1997; Bissa et al, 2000) e as datações antigas encontradas recentemente para sambaquis costeiros

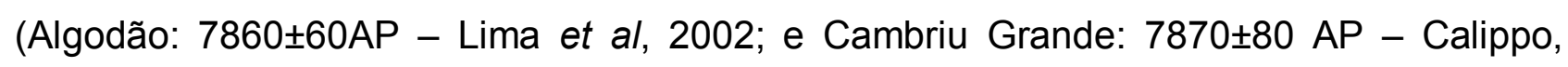
2004), com a ressalva de que nem todos os autores levam essas datas em consideração.

As semelhanças encontradas entre os sítios fluviais e os costeiros levam a crer que houve uma importante comunicação entre os seus construtores. Uma real possibilidade de contato entre os representantes de grupos costeiros e fluviais seria o próprio Vale do Ribeira, uma vez que representa uma das poucas regiões onde a Serra do Mar não é tida como barreira geográfica (Barreto, 1988; Okumura \& Neves, 2005). Assim, acredita-se que os construtores de sambaquis costeiros tenham utilizado o vale do Ribeira para

\footnotetext{
${ }^{3}$ Investigações Arqueológicas e Geofísicas nos sambaquis Fluviais do Vale do Ribeira de Iguape, Estado de São Paulo" (FAPESP N99/12684-2).
} 
chegar ao interior, numa tentativa de escapar das pressões causadas por alterações climáticas, ambientais e, talvez, demográficas ocorridas na costa.

Entretanto, os restos humanos mais antigos de sambaqui datam de 9000AP e são provenientes de um indivíduo exumado do sítio Capelinha, um sambaqui fluvial do Vale do Ribeira, não de um sambaquieiro da costa. O mais interessante é que estudos craniométricos demonstraram grande semelhança deste indivíduo com os paleoamericanos que habitaram o interior antes do aparecimento dos grupos mongolóides que construíram os sambaquis da costa (Neves et al, 2005). Isso poderia sugerir uma origem interiorana para os sambaquis fluviais, com um posterior contato com os grupos da costa, a priori (Eggers, 2006). Mas essa ainda é uma questão em debate.

\subsection{1 - Sambaqui do Moraes}

Dentre os sambaquis do Vale do Ribeira encontra-se o sambaqui do Moraes (latitude $24^{\circ} 17^{\prime} \mathrm{S}$ e longitude $47^{\circ} 28^{\prime} \mathrm{W}$ ), situado a $130 \mathrm{~km}$ de São Paulo, na periferia da cidade de Miracatú (ao lado da BR116), distando apenas $35 \mathrm{~km}$ em linha reta do atual litoral (Figura 4).

Esse sítio conta, até o momento, com cerca de 40 sepultamentos para 37 quadras avaliadas e apresenta datações para 4 indivíduos, entre $5895 \pm 45$ e $4511 \pm 32$ AP (Figuti, 2003).

Alguns estudos bioantropológicos também têm sido realizados com o material osteológico proveniente desse sítio (Eggers et al, 2003a; 2003b; Giardini \& Eggers, 2003; Filippini, 2004; Filippini \& Eggers, 2005; Okumura e Neves, 2005; Bartolomucci, 2006) e, embora numa análise regional, os indivíduos associados a este sambaqui tenham sido interpretados como morfologicamente distintos dos costeiros (Filippini, 2004; Filippini \& Eggers, 2005/2006), há trabalhos que apontam para uma semelhança morfológica deles com os sambaquieiros da costa do Paraná (Bartolomucci, 2006; Okumura e Neves, 2005) e de São Paulo (Okumura e Neves, 2005). Inclusive, a freqüência de exostose auditiva observada em Moraes (22\%) é muito alta para um sítio do interior, ficando dentre as freqüências máximas observadas para os sítios costeiros (Okumura et al, 2007a). Dentre as patologias detectadas importantes para o presente trabalho, podem-se citar as cáries, com uma taxa de 18\%, e um tipo de desgaste dentário que refletiria um modo de vida caçador-coletor baseado largamente em componentes vegetais, pelo menos em parte, cariogênicos (Eggers et al, 2003a). 
Assim como em Jabuticabeira II, ainda há muito a ser investigado sobre a utilização das plantas (principalmente quanto à dieta) pelo grupo associado ao Sambaqui do Moraes. Uma ferramenta útil para essa empreitada é a Paleoetnobotânica.

\section{5 - Paleoetnobotânica}

A Paleoetnobotânica, termo introduzido por Helbaek (1959), trata da elucidação das relações "planta - ser humano" no passado, através de estudos de vestígios arqueológicos de vegetais (vestígios arqueobotânicos) como grãos de pólen, fitólitos, grãos de amido, sementes, carvão (Pearsall, 2000). Dados botânicos vêm auxiliando na formação de teorias a respeito de estilo de vida, história social e econômica e saúde das populações do passado (Alcorn, 1995).

Essa "subdisciplina" da arqueologia está fortemente relacionada à botânica, ecologia, antropologia, e pode ter vários enfoques, como o estudo sobre o impacto da utilização das plantas pelos humanos sobre elas e sobre o próprio homem (Pearsall, 2000), ou a investigação das mudanças nos sistemas de subsistência e assentamento das populações pré-históricas (Piperno, 1998).

Estudos de antracologia (carvão arqueológico) são utilizados para investigar padrões de seleção de lenha para fogueira, ou ainda, como indicativo de distúrbio ambiental (queimadas, por exemplo). Outra subárea muito frutífera na paleoetnobotanica é a palinologia. O estudo dos grãos de pólen provenientes de sedimentos de sítios arqueológicos, de coprólitos (fezes fósseis), da superfície interna de utensílios de cerâmica, entre outros, permite descobrir quais vegetais eram consumidos e se havia a prática da agricultura (Bryant, 1974; Dimbleby, 1985; Reinhard, 1993; Leyden et al, 1998).

Não somente os grãos de pólen, mas outros micro-resíduos vegetais vêm recebendo cada vez mais atenção nos estudos paleoetnobotânicos. Até pouco tempo atrás, as evidências diretas do uso de vegetais se restringiam apenas aos macro-restos (Sandweiss, 2007), como tubérculos e outras porções macroscópicas preservadas das plantas. A análise de fitólitos e grãos de amido, partículas que têm sido estudadas mais sistematicamente para propósitos arqueológicos apenas nas três últimas décadas (Piperno, 2006; Torrence, 2006), tem imenso valor na investigação da sua presença, por exemplo, em ferramentas diversas ou recipientes de cerâmica, contribuindo com a identificação da função de tais objetos (Pearsall, 1987; Piperno \& Holst, 1998; Shafer \& 
Holloway, 1979; Zarrillo \& Kooyman, 2006). Por serem constituídos de uma substância mais dura do que o esmalte, os fitólitos podem levar a abrasão e ao desgaste dos dentes de animais que se alimentam de plantas com alta concentração dos mesmos (Walker et al., 1978). Dessa forma, o estudo do padrão de microdesgaste também em dentes humanos pode contribuir com a reconstrução da dieta em populações passadas (Lalueza \& Pérez-Pérez, 1993, Danielson \& Reinhard, 1998).

Uma outra área de utilização da microbotânica, a qual será tratada abordada no presente trabalho, é a análise de micro-restos presentes no cálculo dentário, no intuito de avaliar a importância do uso de vegetais, principalmente, como recurso alimentar (Middleton \& Rovner, 1994; Fox et al, 1996; Reinhard et al, 2001).

Nos capítulos seguintes são tratados, com detalhes, diferentes microfósseis que podem ser encontrados no cálculo dentário.

\section{5 .1 - Fitólitos}

Existe um grupo de microfósseis vegetais que apresentam todos os atributos necessários para merecer destaque na paleoetnobotânica e paleoecologia: produção em grande número, durabilidade em sedimentos antigos e especificidade morfológica suficiente para permitir identificação de um amplo espectro de taxa (Piperno, 1988). Essas micro partículas, os fitólitos (Figura 5), são compostas de sílica hidratada $\left(\mathrm{SiO}_{2} . n \mathrm{H}_{2} \mathrm{O}\right)$ (Piperno and Pearsall, 1993), formadas nas células das plantas vivas e liberadas no meio ambiente quando os vegetais morrem ou se deterioram.

A origem do termo fitólito é grega e significa "pedra de planta". Ele é utilizado, muitas vezes, para descrever todas as formas de substâncias mineralizadas secretadas pelas plantas, sejam elas constituídas de sílica ou oxalato de cálcio (Danielson \& Reinhard, 1998; Esau, 1977 apud Jones \& Bryant, 1992). Mas alguns autores preferem restringir o termo a corpos de sílica (Pearsall, 2000; Piperno, 1988), excluindo os cristais de oxalato de cálcio, já que os últimos raramente contribuem para a identificação de uma família de plantas, muito menos de um gênero ou espécie particular, enquanto os corpos silicosos, em muitas plantas, auxiliam na sua identificação, por serem distintos de táxon pra táxon (Piperno, 1988). Além disso, os fitólitos podem fazer parte de uma nomenclatura mais generalizada, os biólitos ou sílica biogênica, que se referem à sílica proveniente de organismos vivos e não sílica de origem pedológica. Como o presente trabalho é uma análise quantitativa e não qualitativa, o termo fitólito será utilizado sem restrição quanto à 
composição do microfóssil, referindo-se tanto a corpos de sílica quanto aos cristais de oxalato de cálcio.

A formação e desenvolvimento dos fitólitos dependem de fatores como a idade da planta, o clima do ambiente em que a planta cresce e a quantidade de água disponível bem como a natureza do solo em que a planta se desenvolve. Através da raiz, a planta absorve sílica solúvel da água do solo, que é, então, transportada através do xilema até os órgãos aéreos, em um processo que termina com a deposição de sílica sólida em células específicas, os idioblastos (Esau, 1965 apud Pearsall, 2000) ou em espaços extracelulares ou intracelulares (Fox \& Pérez-Pérez, 1994; Piperno, 1988). Esses corpos de sílica costumam ocorrer especialmente em folhas, caules, raízes e sementes (Fox \& Pérez-Pérez, 1994).

"As pesquisas sobre os padrões de silicificação e produção de fitólitos têm demonstrado que há uma forte influência genética governando sua formação" (Piperno \& Pearsall, 1993) o que faz com que "a produção de muitos tipos de fitólitos seja consistente dentro do mesmo táxon crescendo sob condições ambientais muito diferentes" (Pearsall, 2000). Dessa forma, certos tipos de fitólitos são característicos de uma família, gênero ou até espécie (Piperno \& Pearsall, 1993). Portanto, a análise desses microfósseis é de grande valia em áreas como a arqueologia, bioantropologia e paleoetnobotânica, já que permite a investigação do passado através da reconstrução paleoambiental ou do estudo das espécie vegetais utilizadas na agricultura em sociedades pré-históricas.

Mas por que as plantas produzem os fitólitos? Até algumas poucas décadas atrás pouco se sabia sobre a função dos fitólitos, por isso, diversos estudos foram e têm sido realizados na tentativa de se desvendar seu significado adaptativo. Hoje se sabe que diversas plantas obtêm benefícios quanto a crescimento e reprodução, que estão diretamente relacionados à presença de sílica (Epstein, 1994 Appud Piperno, 2006). As principais funções dos fitólitos seriam, assim, estruturais, de proteção e fisiológicas (Sangster et al, 2001 Appud Piperno, 2006). Como exemplo de função estrutural tem-se o caso do arroz, cujas folhas ricas em sílica ficam mais eretas, permitindo a chegada da luz nas folhas baixas, aumentando a atividade fotossintética (Okuda \& Takahashi, 1961). Com relação à proteção, os fitólitos são uma boa estratégia contra a herbivoria e a ação de fungos patogênicos (Piperno, 2006). Por fim, as funções fisiológicas envolvem a interação da sílica com outras substâncias que ocorrem na planta ou no ambiente em que a mesma cresce. Assim, alguns estudos têm demonstrado que a sílica pode, entre outras 
coisas, neutralizar os efeitos danosos sobre o crescimento provocados por metais pesados absorvidos junto com a água (Sangster et al, 2001 Appud Piperno, 2006).

Embora a utilização dos fitólitos na bioantropologia seja recente, o início do estudo dessas partículas remonta a quase dois séculos atrás. Piperno (1988) divide as pesquisas sobre os fitólitos em quatro períodos. As primeiras pesquisas se deram por volta de 1835 até o final do século XIX, quando os fitólitos foram observados em plantas vivas e no solo e foram classificados. Mas, por muitos anos essas partículas vegetais não receberam muita atenção como vestígios em investigações arqueobotânicas (Piperno, 1988).

Depois se seguiu o "período botânico" (iniciado por volta de 1895 até aproximadamente1936), no qual, principalmente os investigadores alemães, deram início a explorações sistemáticas da produção, taxonomia e variação intra-específica dos fitólitos. Segundo Piperno (1988), durante esse período, foram realizados estudos quantitativos do conteúdo de sílica em plantas modernas e propostos mecanismos de deposição de sílica nas células vegetais. Contudo, a instauração do regime nazista e a Segunda Grande Guerra levaram ao fim deste "período botânico" de estudos dos corpos de sílica.

A partir de 1955 as pesquisas relacionadas aos fitólitos foram retomadas, mas através de uma abordagem ecológica, na qual as análises dessas estruturas vegetais eram utilizadas como um indicativo do histórico ambiental. Estudos foram realizados em várias regiões do mundo, e não somente na Europa. Nessa fase os fitólitos também foram descobertos em contextos diferentes, incluindo deposições calcáreas (Jones et al, 1963), rochas sedimentares e outros materiais geológicos (Baker, 1960a; Gill, 1967), assim como na poeira atmosférica (Baker, 1960b appud Piperno, 1988). A ocorrência de fitólitos em formações geológicas de milhões de anos deixou claro que a partícula de sílica de origem vegetal era estável por longos períodos sob processos de intemperismo químico e mecânico (Piperno, 1988). Neste período Ecológico (de 1955 até aproximadamente 1975) também foram realizadas descrições de fitólitos em plantas vivas, sobre as quais se tinha conhecimento que estivessem presentes em estratos geológicos. Isso estabeleceu a base comparativa moderna para identificação de plantas fósseis. Os últimos anos desse período apresentaram um decréscimo no estudo de fitólitos no solo e em sedimentos, mas ainda continuaram sendo realizadas pesquisas relacionadas ao estudo de estágios de desenvolvimento da silicificação, características ultraestruturais das células silicificadas e suas funções morfológicas (Hodson et al, 1984; Perry et al, 1984; Sangster, 1985 appud Piperno, 1988). 
Somente nas últimas décadas é que a utilização dos fitólitos com a abordagem arqueológica tem recebido mais atenção. No período moderno de pesquisa arqueológica, a partir de 1978, os arqueobotânicos começaram a investigação sistemática da produção e morfologia dos fitólitos em plantas modernas e descreveram sua freqüência e distribuição em sedimentos arqueológicos e geológicos (Piperno, 1988).

O estudo dos fitólitos é importante, pois, em certos ambientes, como é o caso de regiões de floresta tropical, que dificultam a preservação de grãos de pólen e macrorestos vegetais (Piperno \& Holst, 1998), esses microfósseis são alguns dos poucos vestígios que restam para reconstrução do paleoambiente e da paleodieta vegetal. 0 principal motivo para tanto é sua extrema resistência a danos mecânicos e químicos (Piperno, 1988; Pearsall, 2000).

Além disso, quando se encontram fitólitos de certas frutas ou sementes em contexto arqueológico, isso é uma evidência de que tais estruturas de uma espécie vegetal foram exploradas por uma população humana naquela região. Caso fossem encontrados grãos de pólen no mesmo contexto, nem sempre seria possível obter-se tal precisão (Piperno, 1988). Isso porque grãos de pólen são muito leves e pequenos, podendo ser transportados através do vento (estratégia reprodutiva comum em algumas espécies), acumulando-se em uma área diferente da região de origem. Assim, encontrar pólen de uma dada espécie vegetal em um sítio arqueológico, não significa, necessariamente, que aquela espécie foi explorada pelo grupo que ali vivia, mas pode ser resultado do acaso.

Vale ainda dizer que, como a análise de fitólitos na paleoetnobotânica é um recurso relativamente novo, há lacunas no conhecimento sobre a produção destas partículas em algumas famílias vegetais. Além disso, as chaves e guias para identificação de fitólitos ainda são poucos, referindo-se a poucas regiões e a escassos grupos taxonômicos (Piperno \& Pearsall, 1993). No Brasil, inclusive, até o momento não foi feita nenhuma chave de identificação para os fitólitos encontrados nas plantas nativas.

\section{$\underline{1.5 .2 ~-~ G r a ̃ o s ~ d e ~ a m i d o ~}$}

Os tubérculos não carbonizam bem, produzem poucos grãos de pólen e deixam como micro vestígio poucos fitólitos ou fitólitos não identificáveis (Piperno \& Holst, 1998). Além disso, estas estruturas vegetais são quase sempre consumidas inteiramente, tendendo a deixar poucos macrovestígios, mesmo em condições favoráveis de 
preservação (Sandweiss, 2007). Uma forma de identificar os tubérculos utilizados por uma dada população seria, portanto, através da análise de grãos de amido que ficaram retidos em artefatos líticos durante o preparo de alimentos (Piperno \& Holst, 1998; Piperno et al, 2000; Zarrilo \& Kooyman, 2006).

Em contrapartida, diferentemente dos fitólitos, os grãos de amido são menos resistentes, sendo susceptíveis à ação do calor e da umidade, podendo intumescer, deformar ou destruir-se. Em caso de amostras dessecadas, o amido pode sofrer ação de fungos ou até, romper-se por ação da desidratação (Cortella \& Pochettino, 1994; Pearsall, 2000). Todos esses fatores impediriam a identificação desse material em amostras arqueológicas.

Entretanto, trabalhos como o de Piperno e Holst (1998), indicam que em certas condições, os grãos de amido em material arqueológico podem durar por até milhares de anos. Em ferramentas encontradas em sítios arqueológicos da América central, região tropical, em que os macro vestígios de tubérculos e raízes não costumam se preservar (Sandweiss, 2007), grãos de amido se mantiveram conservados por pelo menos 7000 a 8000 anos, já que se encontravam protegidos em pequenas depressões e fendas intersticiais na superfície dos artefatos líticos. Inclusive, segundo Torrence (2006), grãos de amido já foram encontrados em depósitos com mais de 2 milhões de anos. Quando aderidos ao cálculo dentário, como descrito mais adiante, os grãos de amido permanecem protegidos por camadas mineralizadas de sua matriz por milhares de anos, podendo ser estudados e identificados através de análises microscópicas.

O amido antigo, aquele encontrado em material arqueológico, é observado em duas formas (Torrence, 2006): a forma nativa, não modificada e melhor estudada; e a forma modificada, resultante de processos tanto tafonômicos quanto relacionados à manipulação de vegetais (normalmente relacionados a conservação e ao preparo de alimentos como congelamento, dessecamento, aquecimento, maceração, abrasão). Estes processos provocam mudanças físico-químicas nos produtos que contêm amido, alterando a estrutura de alguns grãos, fazendo até com que os mesmo cheguem a perder algumas de suas características mais marcantes, tornando a sua identificação mais difícil. Entretanto, tais alterações podem fornecer pistas sobre os hábitos e as tecnologias do passado (Babot, 2006). Por exemplo, a desidratação, seja ela provocada por frio, calor ou pela exposição ao ar, altera e reduz a birrefringência dos grãos, enquanto a moagem pode provocar rompimento de grãos ou separação de grãos compostos (Babot, 2006). 
Analisando-se o tipo e o grau de alteração, é possível inferir quais os métodos empregados no preparo e conservação do alimento (Babot, 2006).

Os grãos de amido são polímeros de carboidratos que servem como principal forma de armazenamento de energia das plantas (Lehninger et al, 1993; Piperno \& Holst, 1998). Dentro das plantas há dois tipos de amido: o amido de reserva, que é encontrado em abundância em órgãos de armazenamento como tubérculos, raízes e sementes (Gott et al, 2006; Lehninger et al, 1993; Pearsall, 2000; Piperno \& Holst, 1998) e o amido de transição, pequeno e com formato indeterminado, que é formado a partir do açúcar produzido na fotossíntese e que pode ser transformado novamente quando a planta precisa mobilizar energia, ou ser convertido em amido de reserva para ser armazenado (Gott et al, 2006). O amido de transição é comumente encontrado em folhas e outras partes das plantas que contém cloroplastos. Estrutura, tamanho e forma dos grãos de amido de reserva variam consideravelmente entre as espécies, permitindo a distinção de amidos de plantas diferentes (Cortella \& Pochetino, 1994). Por isso, esse tipo de amido é de grande importância para a identificação taxonômica. Já os grãos de amido de transição não são diagnósticos de taxa, porque seu formato não é espécie-específico. Felizmente, o amido mais encontrado em contexto arqueológico é o de reserva, na forma nativa ou modificada, já que ele provém dos órgãos vegetais mais explorados pelos humanos em muitas partes do mundo.

Dois polímeros orgânicos compõem o grão de amido: amilose e amilopectina. Dentro de plastídios, organelas das células vegetais, os grãos vão crescendo devido ao acréscimo de camadas (lamelas) desses polímeros ao redor do hilo, e essas lamelas são visíveis ao microscópio ótico em muitos amidos (Pearsall, 2000). Em certos casos, é possível observar-se uma "cruz de interferência" (cujo ponto de cruzamento se dá na região do hilo) sob luz polarizada, devido às diferenças na densidade e estrutura dos componentes do grão de amido (Pearsall, 2000).

As camadas, a presença do hilo e a cruz de interferência são características diagnósticas de grãos de amido (Figura 6), ou seja, características que servem para identificar um microfóssil como grão de amido. O desenvolvimento e morfologia do grão se dão, em grande parte, através de determinação genética (Loy, 1994 apud Pearsall, 2000), e isso torna as características dos grânulos consistentes com agrupamento taxonômico. Para a identificação de táxon, é necessário observar detalhes do formato e localização do hilo, a espessura das camadas de deposição e outras características (Loy, 1994 apud Pearsall, 2000). Há, inclusive, variação na morfologia e tamanho de grãos de 
amido dentro de uma mesma espécie e, até mesmo, entre os diferentes órgãos de armazenamento de uma mesma planta (Gott et al, 2006). As formas também mudam com o tempo, de acordo com a maturidade do grão e com a idade do tecido ou órgão vegetal em que os grãos estão localizados (Shannon \& Garwood, 1984 appud Gott et al, 2006) e isso deve ser levado em consideração durante a identificação dos mesmos.

A maioria das chaves de identificação de amido foi desenvolvida por pessoas interessadas no seu uso econômico visando, portanto, os grãos domesticados e não as espécies selvagens. Isso dificulta a identificação de amido em material arqueológico proveniente de espécies ou gêneros nativos e sem importância econômica atual. Embora o potencial arqueológico do amido antigo tenha sido reconhecido há um século (Wittmack, 1905 appud Torrence, 2006), seu estudo sistemático na arqueologia é relativamente recente (Piperno \& Holst, 1998; Torrence, 2006) e de grande importância. Isso porque, ao contrário de outros microfósseis vegetais, o amido está diretamente ligado à alimentação (Torrence, 2006) podendo fornecer informações sobre origem e desenvolvimento da agricultura e domesticação das plantas, principalmente no Novo Mundo, região tropical em que os macro vestígios vegetais dificilmente se preservam.

Levando isso em consideração, é extremamente informativa, portanto, a análise dos grânulos preservados no cálculo dentário de indivíduos pré-históricos de regiões tropicais. Os sambaquieiros representam o grupo humano pré-histórico brasileiro mais numeroso, contudo, há apenas escassa informação a respeito dos vegetais amiláceos consumidos por eles. Portanto, análises de grãos de amido são necessárias para a desmistificação da visão impressionista que ainda impera sobre a dieta (animal) e, logo, sobre a subsistência deste grupo como um todo.

Entretanto, para possibilitar a identificação das plantas utilizadas por eles, coleções de referência e/ou chaves de identificação são imprescindíveis (veja Piperno \& Holst, 1998) e, infelizmente, esse material não existe ainda para as plantas da região Sul do país.

\section{5 .3 - Outros microfósseis vegetais}

Além dos fitólitos e grãos de amido, outros resíduos vegetais de grande importância nos estudos paleoetnobotânicos são fibras, células epidérmicas e derivados epidérmicos (Reinhard et al, 2001). Segundo Shafer \& Holloway (1979), os fragmentos de epiderme são os microfósseis cuja identificação é mais informativa entre todos os vestígios vegetais encontrados, pois seus padrões, em conjunto com o arranjo e a 
distribuição dos estômatos, podem ser comparados com epidermes de espécies frescas, levando a identificação até o gênero.

Esses resíduos são potencialmente preservados em superfícies e fissuras de ferramentas líticas devido ao manejo e utilização das mesmas (Shafer \& Holloway, 1979), e tal preservação depende das condições do micro ambiente da superfície da ferramenta juntamente com as características dos tipos específicos de tecidos vegetais (Pearsall, 2000).

Assim como ocorre com grãos de amido e fitólitos, é possível encontrar tais microvestígios no cálculo dentário (Reinhard et al, 2001). Entretanto, nesse tipo de material eles não são tão comuns. A maneira como todos estes micro-restos vegetais ficam retidos no cálculo é descrita a seguir.

\section{6 - Formação do Cálculo dentário}

O cálculo dentário (Figura 7), também conhecido como tártaro, é um depósito mineralizado aderido à superfície do dente (Adde \& Duarte, 1990; Jin \& Yip, 2002; Greene et al, 2005). Esse material é 79-80\% inorgânico, sendo composto, principalmente, por sais cristalinos. A porção orgânica consiste de proteínas, carboidratos e lipídios (Greene et al, 2005, Adde \& Duarte, 1990) provenientes das bactérias presentes na boca e de seus produtos, da saliva, de células epiteliais, de elementos sangüíneos, entre outros (Adde \& Duarte, 1990). Bernimoulin (2003) descreve que a placa dentária, um biofilme produzido por bactérias presentes na boca, se mineraliza ao longo do tempo, formando o cálculo. Inicialmente, após a erupção dos dentes, ou após a profilaxia (apenas 30 minutos depois, segundo MacPhee \& Cowley, 1975 (Appud Middleton and Rovner, 1994)), as proteínas presentes na saliva formam uma película que recobre todo o interior da boca. Então, as bactérias presentes na flora bucal penetram nessa película, formando a placa dentária (Jin \& Yip, 2002; Greene et al, 2005). Essa placa é, portanto, a conglomeração de bactérias e uma matriz, composta em parte por proteínas da saliva e em parte produzida pelas próprias bactérias (Adde \& Duarte, 1990; Greene et al, 2005). Os tipos de placas produzidas variam, já que a flora bucal também varia entre espécies e de acordo com a dieta, mas o processo de formação é basicamente o mesmo para todas as espécies já estudadas (Dent \& Marsh, 1981).

A placa dentária absorve cálcio e fosfato da saliva e do fluido crevicular, iniciando o processo de mineralização (Greene et al, 2005; Jin \& Yip, 2002; Poff et al, 1997). Os 
minerais do cálculo dentário incluem, principalmente, apatita, whitlockita, bruxita e octacálcio (Adde \& Duarte, 1990; Kani et al., 1983), estando o carbonato de cálcio quase sempre presente (Hazen, 1995). De acordo com Ânerud e colaboradores (1991) o acúmulo de cálculo dentário é progressivo, havendo, na ausência de tratamento dental, um aumento dos depósitos conforme a idade.

Há dois tipos de cálculo, o supragengival e o subgengival. O cálculo supragengival é formado a partir de minerais provenientes da saliva, e se encontra, principalmente, na superfície lingual dos dentes anteriores e na superfície bucal dos dentes posteriores, locais próximos aos orifícios dos ductos salivares (Greene et al, 2005; Jin \& Yip, 2002; Poff et al, 1997; Larsen et al, 1999). O cálculo supragengival é mais comum e apresenta coloração amarelada ou esbranquiçada.

Já o cálculo subgengival é composto por minerais provenientes do fluído crevicular (o qual flui continuamente do sulco gengival). Esse tipo de cálculo, de coloração marrom ou esverdeada, é menos aparente do que o primeiro tipo em pessoas vivas, já que se encontra coberto pela gengiva.

Diversos fatores podem influenciar na formação do cálculo dentário. Sabe-se, por exemplo, que dietas ricas em proteína inibem a formação do cálculo nos dentes, ao passo que dietas ricas em carboidrato têm o efeito contrário (Greene et al, 2005). A elevação do $\mathrm{pH}$ da saliva, a presença de certas substâncias que auxiliam o processo de mineralização na mesma (Adde e Duarte, 1990) e a ausência de higiene bucal devida, que impede a retirada mecânica da placa bacteriana são outros fatores que influenciam na formação do tártaro.

Entretanto, como exatamente o cálculo se desenvolve ainda não é muito bem compreendido (Middleton \& Rovner, 1994; Hazen, 1995), pois o padrão morfológico do cálculo dentário varia consideravelmente, não apenas entre indivíduos, mas também de um cálculo para outro em um mesmo indivíduo. No entanto, ele pode ser classificado como lamelado ou homogêneo (Anneroth et al., 1977), dependendo de seu grau de mineralização (Kani et al., 1983).

\subsection{1 - Análise de Cálculo dentário}

O estudo do cálculo dentário é muito importante para complementar estudos paleopatológicos, porque, a "medida de sua gravidade em uma população nos ajuda a entender melhor a expressão das patologias dentais que são afetadas por ela" (Greene et 
al, 2005). Hoje em dia, a maioria dos autores acredita na relação entre o índice de cálculo e doença periodontal (Adde \& Duarte, 1990). Conforme o cálculo se forma e acumula, ele desloca o epitélio ao redor da linha da gengiva, permitindo com que as bactérias da placa bacteriana contaminem o alvéolo (Greene et al, 2005), provocando inflamação e infecção. Ainda, o cálculo dentário guarda relação com outras patologia dentárias, como por exemplo, a cárie. Conforme o cálculo se expande, ele forma uma espécie de barreira protetora ao redor dos dentes, o que impediria a atuação dos ácidos bacterianos na superfície dos dentes e, portanto, dificultaria a formação de cáries (Greene et al, 2005), principalmente aquelas não oclusais. Além disso, o cálculo dentário também é importante por prover evidências diretas sobre a dieta de uma população, pois sua freqüência aumenta em relação ao aumento da ingestão de carboidratos (Turner II, 1979; Larsen, 1997).

Somado a isso, está o fato de que, quando as plantas são mastigadas ou raspadas com os dentes, para ingestão como alimento, para fins medicinais, ou durante a produção de artefatos (Alt \& Pickler, 1998, Reinhard et al, 2001) elas podem deixar vestígios. Graças à rapidez com que a deposição das camadas da placa dentária ocorre, esses vestígios ficam retidos na superfície do dente e são, então, incorporados (Middleton \& Rovner, 1994) pela matriz do cálculo durante a deposição de cálcio e fosfato. É, portanto, nessa matriz de carbonato de cálcio do cálculo que ficam aderidos os fitólitos e grãos de amido (Fox et al, 1996), além das outras micro-partículas. Dessa forma, o processamento e análise do cálculo proveniente de dentes de populações pré-históricas permite a investigação sobre os tipos vegetais utilizados (Fox et al 1996; Reinhard et al., 2001; Piperno, 1998, Boyadjian et al, 2006).

O presente trabalho é focado nesse último modo de análise de cálculo dentário, que utiliza uma abordagem relativamente recente na tentativa de reconstrução da dieta de populações passadas (Reinhard et al, 2001).

\subsection{2 - Preservacãa de Cálculo dentário}

Ao contrário do que ocorre em Jabuticabeira II e em muitos sambaquis costeiros, nem sempre é possível encontrar grandes depósitos de cálculo dentário nos indivíduos de todas as coleções osteológicas. Isso se aplica, por exemplo, ao sítio fluvial Moraes. Esse fato impede as análises mencionadas acima e dificulta as discussões sobre o significado dos vestígios vegetais nesses sítios arqueológicos. 
Os processos que poderiam ter levado os cálculos dentários dos indivíduos exumados em Moraes a não se preservarem bem incluiriam os seguintes: a) abrasão da dentição com o sedimento do sítio, b) processos químicos de dissolução parcial da camada externa do cálculo por ácido húmico da terra muito mais orgânica em Moraes do que em Jabuticabeira II e c) preservação precária dos dentes que, durante o transporte, tornam-se paulatinamente mais friáveis, rompendo-se juntamente com os depósitos de cálculo. Estes fatores fazem com que restem apenas alguns pontos em que o cálculo permanece fortemente aderido ao dente (Boyadjian et al, 2007a) e que dificilmente pode ser removido mecanicamente (Canis et al., 1979). Assim, em algumas coleções arqueológicas preservam-se apenas marcas do antigo depósito de cálculo (Figura 8).

Para esses casos, é interessante desenvolver uma técnica que permita a recuperação de microfósseis a partir de depósitos escassos de cálculo dentário, possibilitando, assim, estudos sobre o uso de vegetais em populações com esta característica. 


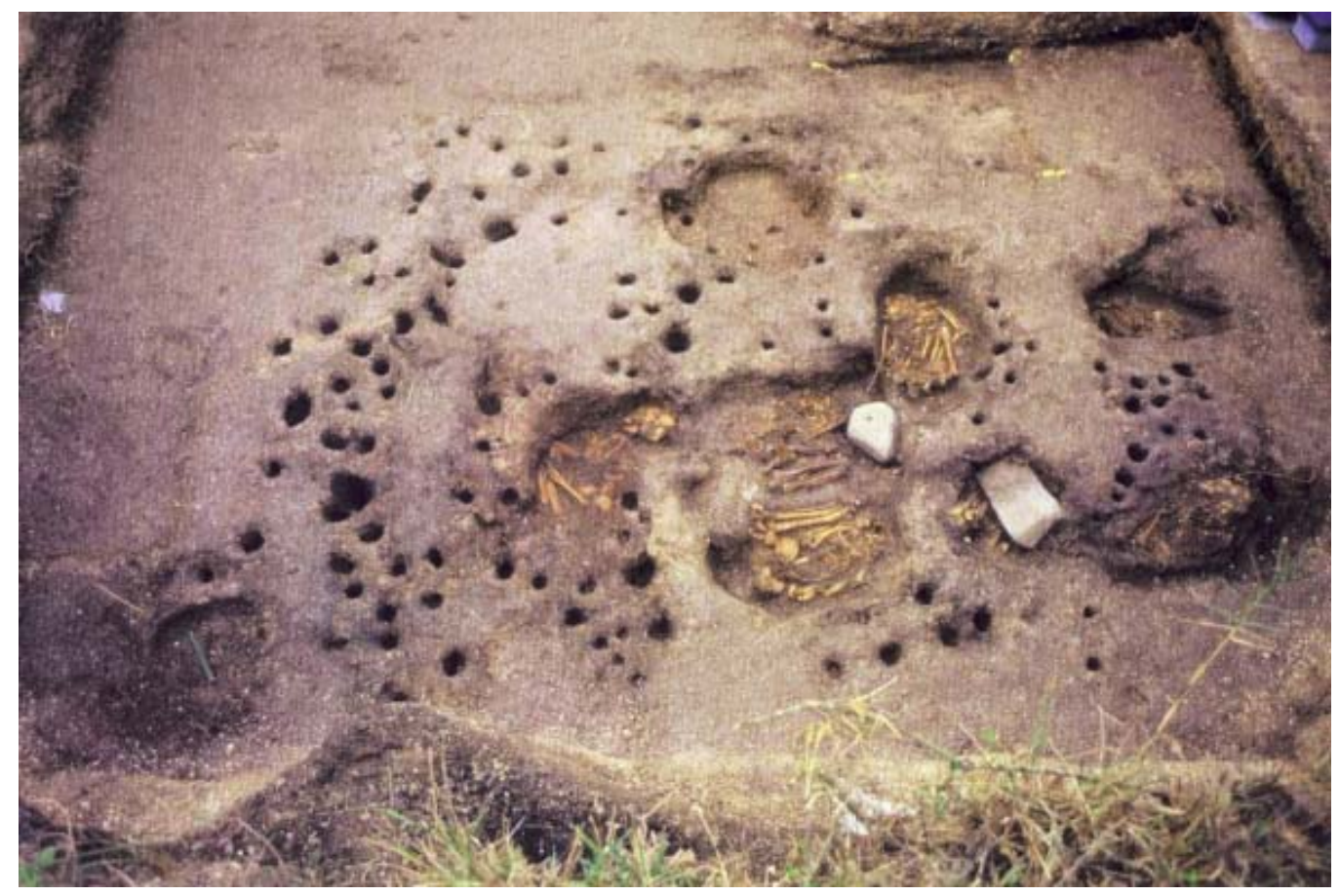

Figura 1: Marcas de estaca ao redor dos sepultamentos do Lócus 2 do sítio arqueológico de Jabuticabeira II.

Foto: Paulo DeBlasis 

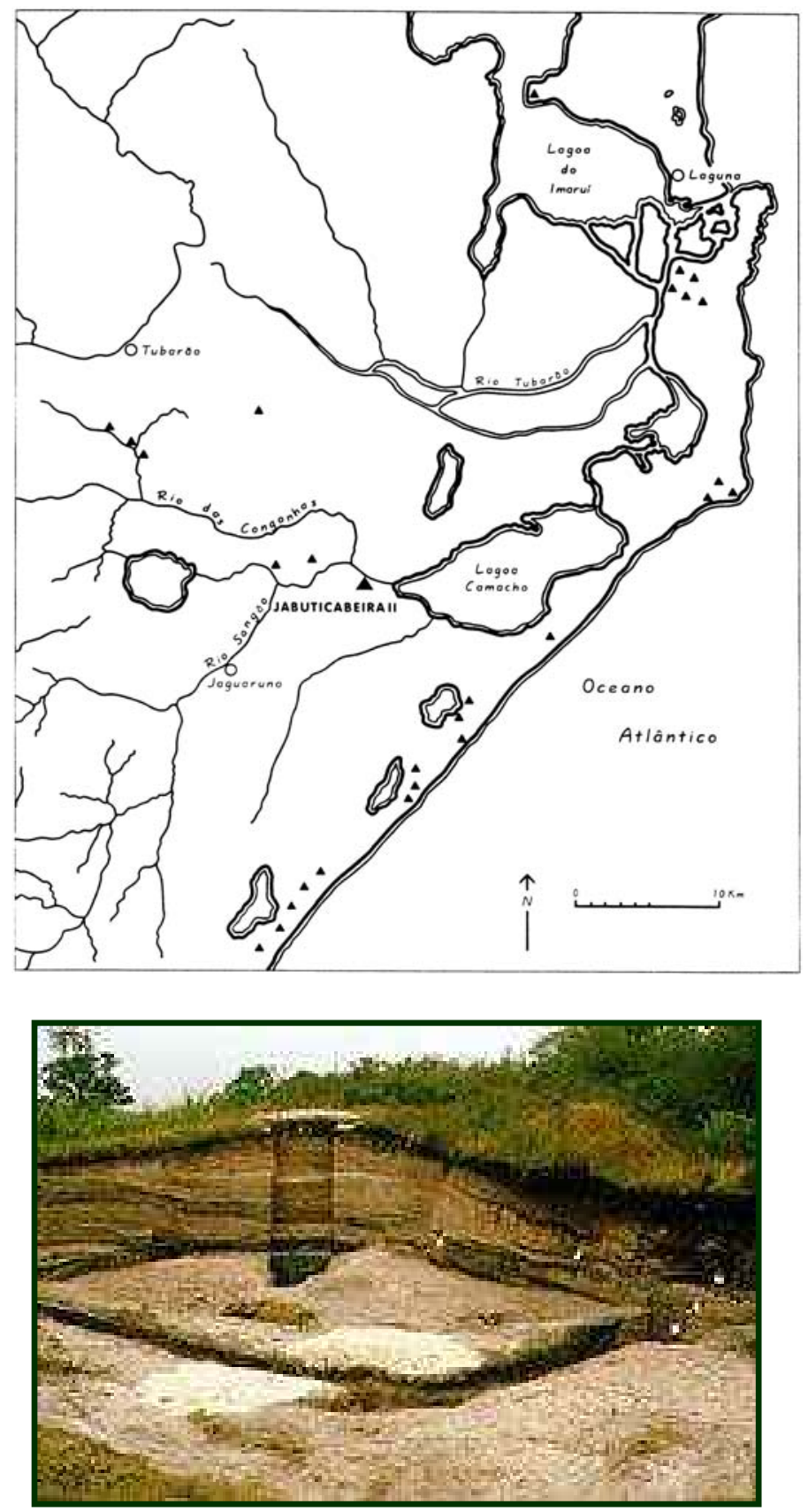

Figura 2: Localização do sítio Jabuticabeira II, no complexo arqueológico do Camacho e imagem do perfil deste sítio.

Mapa adaptado de Fish et al, 2000 


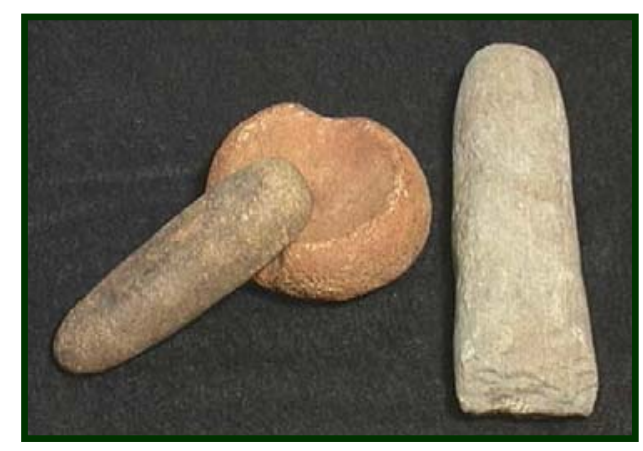

Figura 3: Artefatos líticos associados ao preparo de alimentos encontrados no sítio Jabuticabeira II.

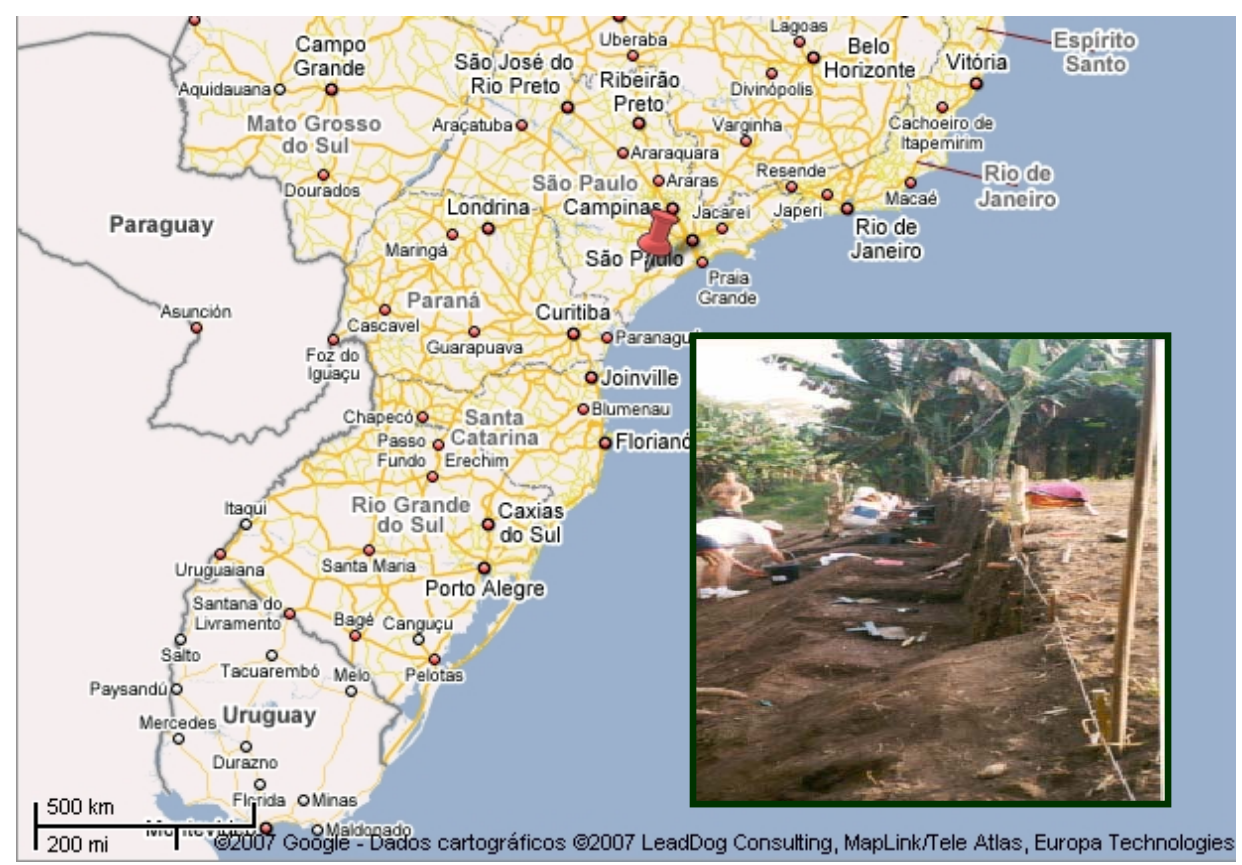

Figura 4: Imagem do sítio arqueológico Moraes e mapa mostrando a sua localização.

Foto: J. Filippini 


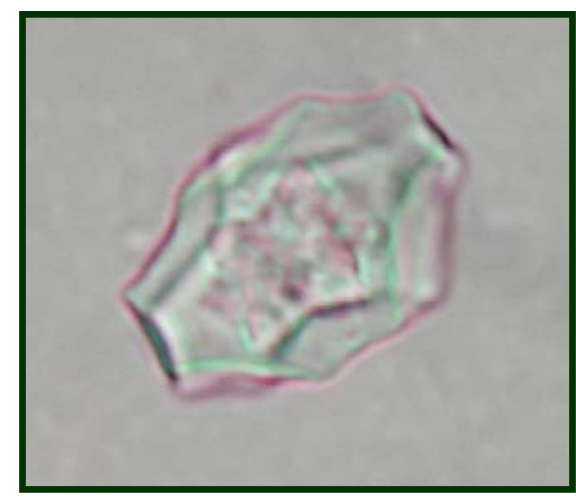

Figura 5: imagem de um fitólito não identificado encontrado em amostras de cálculo de Jabuticabeira II. Infelizmente nesta figura não há escala porque quando as primeiras amostras foram analisadas o Laboratório de Antropologia Biológica ainda não possuía o retículo para mensuração em seu microscópio óptico.

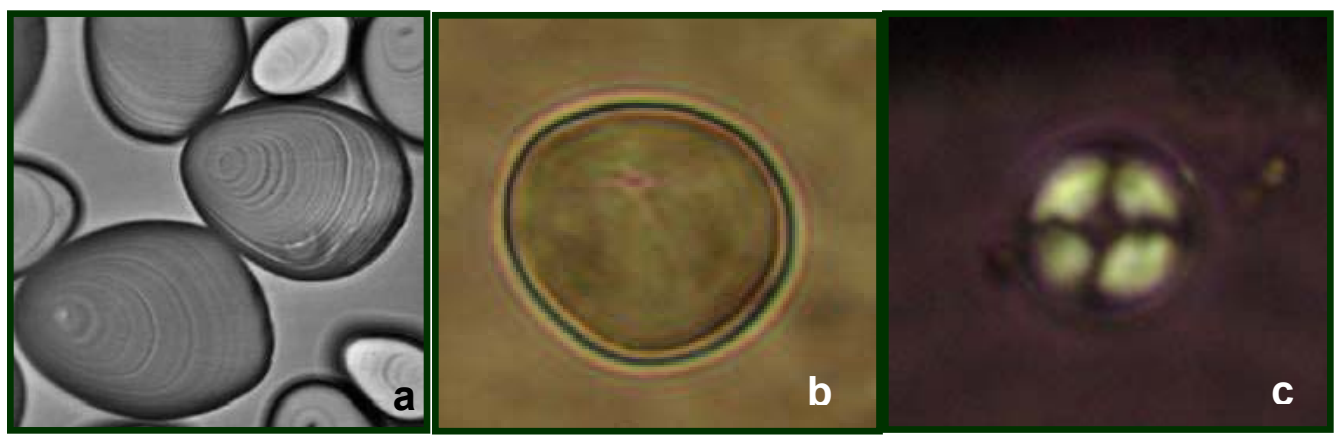

Figura 6: imagens de diferentes grãos de amido evidenciando as diferentes características: a) lamelas; b) hilo c) cruz de interferência.

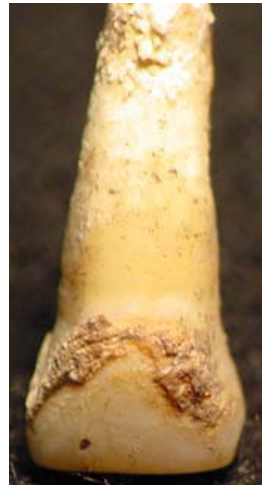

Figura 7: Típica camada espessa de cálculo dentário observada em incisivo de sepultamento do sítio arqueológico Jabuticabeira II

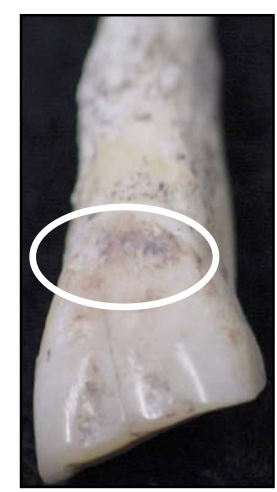

Figura 8: dente com pouco depósito de cálculo dentário, próprio para a aplicação do "dental wash". 


\section{Objetivos}

O presente trabalho teve por objetivo principal contribuir com novos dados sobre a utilização dos recursos vegetais por sambaquieiros dos sítios Jabuticabeira II e Moraes. Para possibilitar comparações entre esses dois sítios arqueológicos foi necessário desenvolver uma técnica para que se pudesse recuperar informação sobre paleodieta a partir de escassos restos de cálculo dentário. Isso era necessário, pois, diferentemente de Jabuticabeira II, onde os depósitos de calculo dentário são bem preservados, na coleção osteológica de Moraes eles se constituem apenas de marcas, o que inviabilizava a utilização do método tradicional de análise de cálculo.

Para tanto, foram realizadas as seguintes análises:

\section{Jabuticabeira II:}

- Processamento e análise do cálculo dentário (método tradicional);

- Classificação e quantificação dos microfósseis encontrados nas amostras;

- Verificação de diferenças quanto a sexo, idade, dentição, entre outros, quanto aos microfósseis encontrados;

- Verificação de diferenças ente os loci, quanto aos microfósseis encontrados;

- Testes de comparabilidade entre os resultados obtidos através do método tradicional e o alternativo;

- Teste para verificação das conseqüências do uso do método novo sobre os dentes.

\section{Moraes:}

- Obtenção de microfósseis, aplicando o novo método;

- Classificação e quantificação dos microfósseis;

- Verificação de diferenças quanto a sexo e idade quanto aos microfósseis encontrados;

\section{Jabuticabeira II e Moraes:}

- Comparação dos resultados obtidos entre os dois sítios estudados. 


\section{Material e Métodos}

Duas coleções osteológicas foram utilizadas para a execução do presente trabalho: a coleção referente ao sambaqui costeiro Jabuticabeira II (SC) e aquela escavada no sambaqui fluvial Moraes (SP). A coleção osteológica humana de Jabuticabeira II (alocada no Laboratório de Antropologia Biológica do IBUSP) apresenta restos de mais de 120 indivíduos, escavados durante as etapas de campo realizadas nos anos 1997, 1998, 1999, 2004, 2005 e 2006. A coleção osteológica humana exumada de Moraes encontrase, desde 2005, no Museu de Arqueologia e Etnologia da USP, contando com cerca de 40 indivíduos, aos quais a equipe do Laboratório de Antropologia Biológica teve acesso.

No presente estudo foram utilizados 68 dentes dos indivíduos de Jabuticabeira II e 63 de Moraes. As amostras foram obtidas de no mínimo 1 e no máximo 5 dentes por indivíduo. Não sendo utilizados todos os dentes de cada indivíduo para a obtenção da amostra, são preservados alguns depósitos de cálculo, possibilitando análises futuras, caso surjam novos métodos investigativos. Segundo Reinhard et al (2001), com depósitos fartos de calculo dentário de apenas um único dente por indivíduo já é possível obter resultados satisfatórios. Entretanto, nos casos em que havia muito poucos vestígios do deposito de cálculo nos dentes, foi necessário obter-se material de mais de um dente para que fosse possível processar alguma amostra.

Elaborou-se uma planilha de dados (Excel), contendo as seguintes informações sobre cada uma das amostras: número do sepultamento a partir do qual foi obtida; sexo e idade do indivíduo do qual é proveniente; patologias dentárias, grau de desgaste, número e tipos de cáries que esse indivíduo apresenta; a partir de qual dente a amostra de cálculo foi obtida; as características desse dente (grau de desgaste; presença de cárie); o peso do fragmento de cálculo retirado; entre outras. Nessa planilha também foram lançados os valores das concentrações de cada tipo de microfóssil encontrado nas amostras, determinados de acordo com os métodos descritos mais adiante. Então, esses dados foram utilizados em testes estatísticos (Chi-quadrado, Spearman's rho, Mann-Whitney, Wilcoxon) com o intuito de analisar as diferenças entre as amostras dentro de um mesmo sítio ou entre os sítios. Deve ficar claro que, tanto em Jabuticabeira II quanto em Moraes, houve algumas amostras com valores de concentrações bastante discrepantes (outliers), que foram excluídas para a realização dos testes estatísticos. 


\section{1 - Processamento do Cálculo dentário: Método Tradicional}

Nos casos em que há depósito espesso de cálculo (em Jabuticabeira II), fragmentos deste foram retirados com o auxílio de um explorador dentário (cureta). Esse material foi pesado em uma balança de precisão e, posteriormente, tratado quimicamente de acordo com os métodos descritos em Reinhard et al (2001) objetivando a obtenção da amostra (Protocolo 1 - Apêndice). Nos casos em que foram obtidos depósitos de cálculo de mais de um dente para obtenção de uma única amostra, os fragmentos foram pesados em conjunto.

A técnica tradicional consiste, basicamente, na dissolução da matriz do cálculo dentário através da ação de $\mathrm{HCl}$ a $10 \%$ e a lavagem com água destilada e centrifugação da solução repetidas vezes. Após a última centrifugação, a água destilada é descartada e substituída por etanol. A solução final consiste, portanto, dos microfósseis (grãos de amido, fitólitos e outros) imersos em etanol. A montagem das lâminas elaboradas com essa solução para análise dos microfósseis será descrita mais adiante.

\section{2 - Processamento do Cálculo dentário: Método "Dental Wash"}

Nos casos em que há escassos restos de cálculo dentário, foi aplicada uma nova técnica para obtenção de microfósseis, desenvolvida em colaboração com o Prof. Dr. Karl Reinhard, da Universidade de Nebraska, EUA. Tal técnica foi baseada em um procedimento utilizado para obtenção de pólen a partir de recipientes de cerâmica, chamada de "Pollen Wash" (Bryant \& Morris 1986), e por isso, ela passou a ser chamada de "dental wash" (Boyadjian et al, 2007a).

Ao contrário da técnica tradicional, que consiste na retirada de fragmentos de cálculo dentário mecanicamente, o "dental wash" consiste na lavagem direta dos dentes com solução de ácido clorídrico a uma concentração de 2\% (Protocolo 2 - Apêndice), para que o cálculo remanescente seja dissolvido e os microfósseis vegetais se desprendam da superfície do dente. Através de lavagens com água destilada e centrifugações repetidas obtém-se a amostra de microfósseis a ser analisada. 


\section{4 - Preparação das Lâminas}

As lâminas foram preparadas com uma gota de glicerina (50\% água e 50\% glicerina) e $10 \mu \mathrm{L}$ de amostra e foram seladas com uma mistura de cera de abelha com breu (também $50 \%$ de cada um). Foram montadas 5 lâminas para cada amostra, totalizando um volume de $50 \mu \mathrm{L}$ para análise de cada uma delas. Os mesmos procedimentos de montagem das lâminas foram utilizados tanto para as amostras obtidas a partir do método tradicional, quanto para as originárias de "dental wash".

Posteriormente essas lâminas foram varridas sistematicamente sob microscópio ótico de luz transmitida (em aumento de 200 e 400 vezes - aumento de 20x ou 40x da objetiva e 10x da ocular) e com luz polarizada, para que fosse possível reconhecer e contabilizar os microfósseis. A luz polarizada é utilizada para a identificação positiva do amido, já que através dela, a cruz de interferência, característica diagnóstica desses grãos, se torna visível (Piperno \& Holst, 1998, Moss, 1976) e o grão pode ser reconhecido.

llustrações e fotografias foram confeccionadas para cada estrutura encontrada (Ficha para catalogação de microfósseis - Apêndice). Esse procedimento é de extrema importância, pois, apesar de no presente trabalho o objetivo ser a contabilização dos tipos de microfósseis, posteriormente, através das imagens obtidas, será possível a identificação de cada um deles. A identificação destes micro-restos (família, gênero ou, por vezes, até espécie) somente será possível com auxílio de chaves de identificação elaboradas a partir da análise das micro-partículas de plantas vivas coletadas na região e, que se saiba terem existido no local há aproximadamente três mil anos. Este estudo será objetivo de trabalho futuro.

\section{5 - Contabilização dos Microfósseis}

Durante a varredura sistemática das lâminas os microfósseis encontrados foram classificados nas seguintes categorias: fitólitos, grãos de amido e fibras/traqueídes. Algumas estruturas que não se enquadravam nestas categorias também foram registradas, mas estes dados não foram apresentados em tabelas, foram apenas descritos nos resultados. Para cada microfóssil encontrado foi aberta uma ficha contendo sua descrição, ilustração e fotos, independentemente do fato de outro microfóssil com as mesmas características já ter sido observado em amostra anterior. 
A concentração das micro-partículas por amostra foi obtida através da adaptação da fórmula descrita por Pearsall (Pearsall, 2000):

(n. de microfsseis/n. de esporos de Lycopodium)Xn. de esporos de Lycopodium por tablete

volume da amostra

, onde o número de esporos

de Lycopodium sp. referido é conhecido e proveniente dos tabletes de Lycopodium sp. adicionados durante a preparação das amostras (como descrito nos protocolos Apêndice). Esses esporos são essenciais para a contabilização dos microfósseis (Pearsall, 2000; Warnock \& Reinhard, 1992).

\section{6 - Testes do "Dental Wash"}

Como nesse projeto havia, também, o intuito de testar a comparabilidade do método do "dental wash" com o método "tradicional" de análise do cálculo dentário, foi realizada, concomitantemente com a extração do cálculo dos indivíduos de Jabuticabeira II, a obtenção de material para o método a ser testado. O dente tratado com cureta para obtenção tradicional de cálculo dentário foi, posteriormente, submetido à "lavagem" e, então, uma segunda amostra foi obtida a partir dele.

Com as duas amostras de cada indivíduo de Jabuticabeira II foram feitas lâminas (seguindo os mesmos procedimentos citados anteriormente), as quais foram analisadas sob o microscópio ótico. Então, a concentração de microfósseis de cada uma delas foi estimada através da fórmula já citada.

De posse desses dados, passou-se a realizar análises estatísticas para verificar se os resultados obtidos através de ambos os métodos são comparáveis. Deve ficar claro aqui, que para as análises estatísticas referentes a este teste, apenas as concentrações de grãos de amido foram levadas em consideração, apesar de outros microfósseis terem sido observados com a aplicação de ambos os métodos. As implicações desta estratégia serão discutidas mais adiante. 


\subsection{1 - Microscópio Eletrônico de Varredura (MEV)}

As amostras de cálculo dentário de Moraes tiveram de ser coletadas através do "dental wash" em um espaço de tempo curto demais, antes mesmo de serem finalizadas as análises preliminares do novo método. Isso ocorreu devido à devolução da coleção osteológica deste sítio para o Museu de Arqueologia e Etnologia da USP ter sido exigida antes do previsto (em 2005). Entretanto, análises posteriores dos dentes de Jabuticabeira II que haviam sofrido o processo do "dental wash" revelaram alterações na cor e no brilho dos dentes (Boyadjian et al, 2007a). A investigação deste processo tornou-se, portanto, um objetivo a mais do presente estudo.

Durante o andamento do projeto, iniciamos uma colaboração com o Vienna Institute for Archaeological Science da Universidade de Viena (Matthias Kucera) e o Museu de História Natural de Viena (Doris Panny). Em visita a estas instituições foi possível analisar sob microscópio eletrônico de varredura (MEV) um pré-molar pertencente ao sepultamento 41 a de Jabuticabeira II, com grande depósito de cálculo. $\mathrm{O}$ tipo de microscópio utilizado possibilita a formação de imagens de superfície sem necessidade do uso de ouro, o que é crucial para amostras arqueológicas a serem tratadas quimicamente. $O$ dente foi colocado diretamente sob o microscópio, sem nenhuma preparação prévia, e a superfície do cálculo dentário foi observada cuidadosamente a procura de microfósseis. Algumas das imagens obtidas serão apresentadas a seguir.

Graças a este contato, realizou-se um novo teste (com a utilização do MEV) para avaliação dos efeitos causados pelo "dental wash" à estrutura externa dos dentes. Assim, 6 dentes de Jabuticabeira II em diferentes estados de conservação e com diferentes graus de desgaste dentário foram analisados sistematicamente sob o MEV antes e após a aplicação da lavagem com ácido clorídrico. Foram registradas imagens das mesmas áreas da superfície oclusal de cada dente antes e depois do "dental wash", o que permitiu a observação do grau de alteração microscópica ocasionada pelo método na superfície dos dentes.

Os resultados preliminares deste teste foram apresentados no XVI Congresso da SAB (Boyadjian et al, 2007b) e serão discutidos mais adiante. 


\section{Resultados e Discussão}

Os resultados apresentados e discutidos a seguir visam contribuir com informações a respeito da utilização dos recursos vegetais por sambaquieiros dos sítios Jabuticabeira II e Moraes. Primeiramente são tratados os dados obtidos através do método tradicional de recuperação de microfósseis em Jabuticabeira II, depois são apresentados os resultados dos testes do "dental wash", seguidos pelos resultados obtidos para Moraes e, finalmente, discute-se a comparação do dados de dieta obtidos para os dois sítios em questão.

\section{1 - Análise "tradicional" de cálculo dentário em Jabuticabeira II}

Através do método tradicional, foram obtidas 54 amostras, referentes a 34 indivíduos, sendo 17 delas de homens, 20 de mulheres e 17 de indivíduos cujo sexo não pode ser avaliado (Tabela 1). De maneira geral, os indivíduos do sítio Jabuticabeira II apresentam muito cálculo dentário, embora exista certa variação. De acordo com a metodologia descrita em Brothwell (1981) há dentes com índice 1 (depósito de cálculo pequeno/índice de cálculo leve) até 3 (depósito de cálculo grande/índice de cálculo severo) e, inclusive, dentes em que restam apenas marcas de cálculo dentário, como é o caso em Moraes (índice de cálculo 4). Como muitos dos indivíduos estudados nesse trabalho apresentavam a dentição quase completa e o depósito de cálculo estava presente em muitos dentes (Figura 9), foi possível a obtenção de duas amostras por indivíduo em muitos deles, sendo uma delas oriunda de dentes anteriores e outra de dentes posteriores (Tabela 1 e Gráfico 1).

Nessas amostras foram observados, ao todo, 169 grãos de amido, 127 fitólitos e 9 fibras vegetais/traqueídes. As últimas se referem a estruturas que não são grãos de amido, nem fitólitos, e estão relacionadas à sustentação (fibras) ou condução (traqueídes) nas plantas. Apesar de apresentarem funções diferentes, fibras e traqueídes foram computadas numa mesma categoria por terem sido observadas raramente. As concentrações de cada um destes tipos de microfóssil encontram-se na Tabela 1.

Foram observadas, também, 3 diatomáceas na amostra 103 (Figura 10) e outras 3 estruturas não identificadas, que, entretanto, parecem ser fragmentos de epiderme ou cutícula vegetal, nas amostras 57, 78 e 101 (Tabela 1). Além disso, alguns fragmentos 
escuros de origem vegetal, sugestivos de carvão (Piperno, 2006; Wesolowski, 2007) foram encontrados na amostra 73.

Algumas das imagens obtidas dos microfósseis mais interessantes observados nas amostras de Jabuticabeira II encontram-se em anexo (Figura 11). Dentre elas se encontram fotografias de fitólitos e estruturas ainda não identificadas.

É importante frisar que, neste trabalho, em Jabuticabeira II, somente foram considerados para os testes estatísticos os grãos de amido e os fitólitos, pois tanto as diatomáceas, quanto as fibras/traqueídes, os fragmentos escuros e os fragmentos sugestivos de epiderme ou cutícula vegetal foram detectados apenas esporadicamente.

\subsection{1 - Amido:}

Os grãos de amido encontrados mediam de $5 \mu \mathrm{m}$ a $30 \mu \mathrm{m}$ de diâmetro. Seus formatos também variavam. Foram observados grãos esféricos, ovóides, poligonais e com formato de sino (Figura 12). Alguns desses grãos apresentavam fissuras na região do hilo e outros não apresentavam o hilo visível. Em duas amostras foram encontrados grãos de amido compostos: um na amostra 68 e dois na amostra 95. Nota-se que os valores das concentrações desse microfóssil vegetal variam muito entre as amostras (de 0 a 100 grãos/ $\mu$ l, sendo este último valor bem destoante dos demais e correspondente à amostra 83), apresentando uma média de 8,24grãos/ $\mu$ (Gráfico 1).

A existência de grãos de amido em quase $80 \%$ das amostras de Jabuticabeira II sugere que os indivíduos desse sítio arqueológico possuíam uma dieta vegetal fortemente baseada em órgãos de reserva, que são ricos em amido, como tubérculos ou raízes. Por serem muito energéticos, estes órgãos vegetais são as maiores fontes de alimento em muitas partes do mundo (Gott et al, 2006). É interessante notar, que uma identificação preliminar, baseada apenas em semelhança com microfósseis encontrados em outros contextos (Torrence e Barton, 2006; Wesolowski, 2007), sugere que batata doce (Ipomoea batatas) era um dos principais órgãos de reserva consumidos pelos indivíduos de Jabuticabeira II, mas, também, foi possível observar grânulos sugestivos da família das Aráceas.

Como mencionado anteriormente, a concentração de amido da amostra 83 é muito diferente das demais (Tabela 1), além de representar uma das poucas amostras deste sítio que apresentaram fitólitos (20 fitólitos/ $\mu$ l). Outro fato que chama a atenção é que essa amostra pertence ao mesmo indivíduo (XLlaE3-4) que a amostra 82, cuja 
concentração de amido é muito mais baixa (8,52 grãos/ $\mu l)$, encontrando-se entre os valores das concentrações da maioria das amostras de Jabuticabeira II. Isso pode ter ocorrido porque houve uma contagem de esporos de Licopódio muito baixa, comparada às demais amostras deste sítio, além de uma contagem bastante elevada de grãos de amido (25 esporos de licopódio e 10 grãos de amido). Colocando esses valores na fórmula de contabilização, o valor da concentração resulta muito alto.

Infelizmente, mesmo com uma investigação detalhada das fichas individuais e do material de campo do sepultamento XLla do qual provém essas amostras (82 e 83), não foi obtida nenhuma informação específica que pudesse fornecer alguma pista sobre o porque deste indivíduo apresentar tamanha diferença em relação aos demais quanto aos grãos de amido (para uma discussão mais abrangente deste assunto vide tópico 6 Limitações do trabalho).

\subsubsection{1 - Comparações entre dentição anterior e posterior}

A priori esperava-se uma concentração diferente de microfósseis na dentição anterior em relação à posterior, já que, durante a mastigação, principalmente de vegetais, utiliza-se preferencialmente a dentição posterior (Pough et al, 2003). Por este motivo, quando era possível, foram coletadas amostras tanto de dentes anteriores como posteriores para cada indivíduo (totalizando 20 indivíduos com duas amostras diferentes). Entretanto, quando se compara a concentração de amido entre as dentições, tanto visualmente (Gráfico 1) quanto estatisticamente (teste de Mann-Whitney: $p=0,637$ ), não se verifica maior concentração de grãos na dentição posterior. Este resultado é corroborado pela semelhança entre os pesos dos fragmentos de cálculo destacados de dentes anteriores e posteriores (Mann-Whitney: $p=0,139$ ), apesar da variação de peso nos dentes posteriores ser aparentemente maior (Gráfico 2).

Greene e colaboradores (2005) observaram mais cálculo na dentição superior (maxilar) posterior do que na superior anterior, em suas amostras do Egito antigo, ao passo que na dentição inferior (mandibular) ocorria o inverso. Postula-se que isso tenha ocorrido devido à maior proximidade destas regiões (dentição superior posterior e inferior anterior) com a saída dos dutos salivares (Jin e Yip, 2002).

No presente trabalho, no entanto, não foi feita a separação entre cálculos provenientes da dentição superior e inferior, o que poderia explicar a ausência de diferença do peso do cálculo encontrado entre as amostras posteriores e anteriores. 
Levando isto em consideração, se a quantidade de cálculo acumulada não é diferente entre as dentições anterior e posterior, é de se esperar que a quantidade de microfósseis também não seja diferente (como foi demonstrado previamente pelo teste estatístico). Isso porque, pode se imaginar que, quanto maior o depósito de cálculo, maior é a quantidade de micro-restos alimentares aderidos a ele durante o processo de acúmulo e mineralização de sua matriz.

\subsubsection{2 - Comparação entre sexos}

O Gráfico 3 representa a distribuição das concentrações de grãos de amido por sexo dos indivíduos de Jabuticabeira II (excluindo-se aqueles com sexo indeterminado). Os dados sugerem que as amostras com maior concentração de amido, excluindo-se a amostra 83 destoante (Sepultamento XLla), correspondem a indivíduos do sexo feminino. As diferenças de concentração de amido entre os sexos poderiam ser reflexo de uma diferenciação de gênero na alimentação, mas isso não é confirmado pelo teste estatístico (teste de Mann-Whitney: $p=0,519$ ). Da mesma forma, a diferença entre os pesos dos fragmentos de cálculo dos homens em relação aos das mulheres (Gráfico 4), não é estatisticamente significativa (Mann-Whitney: $p=0,503$ ), como poderia se esperar, visto que em populações modernas, são averiguadas diferenças entre os sexos quanto a formação de cálculo (Ânerud et al, 1991) .

Diferenças de dieta podem influenciar a formação e o aumento dos depósitos de cálculo dentário (Greene et al, 2005; Klinberg et al, 1981). Entretanto, os resultados acima demonstram que não há diferença no acúmulo de cálculo entre os sexos em Jabuticabeira II, sugerindo semelhança de dieta vegetal entre homens e mulheres.

\subsubsection{3 - Tamanho e peso do cálculo dentário, concentração de amido e idade de óbito}

O Gráfico 5 (confeccionado mediante exclusão dos indivíduos com idade indeterminada) mostra uma tendência de aumento na concentração de grãos de amido, com o aumento da idade. De acordo com Ânerud e colaboradores (1991) o acúmulo de cálculo dentário é progressivo, havendo, na ausência de tratamento dental, um aumento dos depósitos conforme a idade avança. Isto leva a crer que haveria, também, um acúmulo cada vez maior de microfósseis no cálculo dentário com o passar dos anos. 
Entretanto, o teste estatístico não demonstrou correlação significativa entre a concentração de amido e a idade nos indivíduos de Jabuticabeira II (Spearman's rho: $p=0,214$, coeficiente de correlação: 0,216; Tabela 2).

Por outro lado, o Gráfico 6 demonstra uma relação positiva e estatisticamente significativa entre o peso dos fragmentos de cálculo e a idade dos indivíduos (Spearman's rho: $p=0,008$, coeficiente de correlação=0,440). Além disso, também é observada uma relação positiva e estatisticamente significativa entre o peso do cálculo e as concentraçôes de amido obtidas nas amostras (Spearman's rho $p=0,024$, coeficiente de correlação =0,309) (Gráfico 7,Tabelas 3 e 2). Daí pode-se afirmar que, em Jabuticabeira II, os depósitos de cálculo aumentam conforme o avançar da idade (haja visto que o peso destes depósitos aumenta, e também, ocorre maior concentração de amido em fragmentos de cálculos mais pesados).

A constatação de correlações positivas da concentração de grãos de amido com o peso do cálculo dentário e, do peso do cálculo com a idade, parece contradizer a ausência de correlação entre idade e concentração de grãos de amido. Contudo, o padrão do cálculo dentário varia de um indivíduo para outro, e até mesmo, de um dente para outro, em um mesmo indivíduo (Anneroth et al., 1977). Esta variação se refere ao grau de mineralização, compactação e de aderência do cálculo ao esmalte dentário (Anneroth et al., 1977; Kani et al., 1983; Adde e Duarte, 1990), causada por diferenças em fatores como dieta, $\mathrm{pH}$ da saliva, bactérias, substâncias presentes na placa bacteriana, entre outros (Adde e Duarte, 1990; Jin e Yip, 2002). Desta forma, até mesmo a composição dos microfósseis aderidos a estes depósitos pode variar entre os indivíduos e, inclusive, ao longo da vida de cada indivíduo.

Para melhor compreender a formação do cálculo, também foram testados os dados de índices de cálculo dentário dos indivíduos analisados (variando de 1- pequeno a 3 grande). Para tanto foram excluídas as amostras com índice 4, correspondente aos dentes que apresentavam apenas marcas de cálculo. Espera-se que depósitos mais "fartos" de cálculo (ou seja, com índices maiores) apresentem maior peso e, portanto, o aumento do índice de cálculo dos dentes utilizados para preparo das amostras deveria ser acompanhado pelo aumento da concentração de amido e da idade, como foi observado anteriormente para o peso. No entanto, não é isso o que ocorre. Embora haja relação positiva do aumento do peso com o índice do cálculo dentário (Speraman's rho: $p=0,001$, coeficiente de correlação=0575), não há relação entre o aumento da concentração de amido e o aumento do tamanho do depósito de cálculo dentário (Spearman's rho: 
$p=0,484$, coeficiente de correlação=0,131), como o Gráfico 8 sugere, mesmo que o "outlier" correspondente à amostra 83 fosse incluído. Tampouco há correlação entre idade e índice de cálculo (Spearman's rho: $p=0,157$; coeficiente de correlação=0,320).

Esses dados tornam os resultados um tanto controversos (Tabela 2), especialmente porque contrariam o que foi observado por Wesolowski (2007). Em um trabalho com abordagem semelhante, a autora observa, ao contrário do que foi notado aqui, uma correlação negativa significante em que, quanto maior o peso dos fragmentos de cálculo, menor a concentração de microfósseis obtida a partir dele. Os outros pares de variáveis (peso $\mathrm{x}$ idade; idade $\mathrm{x}$ concentração de microfósseis; índice de cálculo $\mathrm{x}$ concentração de microfósseis; índice x idade; índice x peso) não foram levados em consideração em seu trabalho. No entanto, enquanto aqui foram analisados apenas os dados de um único sítio através de 54 amostras, Wesolowski (2007) avaliou a relação entre a concentração de microfósseis e o peso dos fragmentos de cálculo dentário em 4 sítios distintos, totalizando 53 amostras, ora separados, ora em conjunto (como se fossem parte de uma única amostragem).

Segundo a autora, a grande ingestão de proteínas por sambaquieiros da costa ocasiona o aumento da alcalinidade do $\mathrm{pH}$ salivar, aumentando a precipitação de sais, o que leva a um aumento da velocidade de mineralização da placa dentária (Kleinberg, 1961; Jin e Yip, 2002), acarretando menor retenção de micro-resíduos na matriz do cálculo. Dessa forma, indivíduos com dietas muito ricas em proteína tenderiam a apresentar depósitos de cálculos mais pesados, mas com menor concentração de microrestos, o que explicaria satisfatoriamente a correlação negativa entre peso e concentração de micro-resíduos observada por ela em suas amostras. Entretanto, outros autores consideram que o alto consumo de proteínas levam a uma menor formação de cálculo dentário (Greene et al, 2005).

Portanto, todos estes resultados devem ser avaliados com ressalva, já que ainda não estão esclarecidas todas as questões a respeito do desenvolvimento do cálculo dentário (Middleton \& Rovner, 1994; Hazen, 1995) e, principalmente, ainda são raros os estudos que avaliam a inclusão de micro-resíduos provenientes da dieta na matriz do cálculo e sua recuperação a partir de amostras arqueológicas.

De acordo com os resultados do presente trabalho e os dados conflitantes da literatura, pode-se sugerir que os indivíduos de Jabuticabeira II alimentavam-se de uma dieta rica em proteínas e em vegetais amiláceos de forma que fosse mantido um $\mathrm{pH}$ salivar equilibrado, ocasionando uma velocidade de mineralização da placa dentária 
média, o que implicaria no aumento do peso do cálculo conforme o avançar da idade, como de fato foi observado aqui.

\subsubsection{4 - Concentração de amido versus cáries}

Devido a grande quantidade de amido encontrada nas amostras de Jabuticabeira II, seria de se esperar que houvesse, também, um aumento do índice de cáries neste sítio, já que, muitas vezes, a presença de cáries está associada a dietas ricas em hidratos de carbono (Cohen \& Armelagos, 1984; Klinberg, 2002 Turner II, 1979). Entretanto, dentre os indivíduos estudados deste sítio, somente 2 apresentavam lesões cariosas: o indivíduo IbE2L6C (amostra 71) com duas cáries oclusais e o indivíduo XV (amostras 66 e 67), com uma cárie oclusal. Ainda assim, as amostras destes dois indivíduos não apresentaram concentração de grãos de amido maior que a encontrada nos indivíduos sem cáries.

De fato, há um baixo índice de cáries registrado para os indivíduos de Jabuticabeira II (0,44\% - Okumura \& Eggers, 1995). Índices e freqüências igualmente baixas são comuns para a maioria das coleções esqueletais provenientes de sambaquis (Uchoa, 1973; Mendonça de Souza, 1995; Wesolowski, 2000). Assim, a priori, em Jabuticabeira II há uma baixa freqüência de cáries relacionada a uma dieta com aporte amiláceo importante. Entretanto, é somente à luz da comparação com outros sítios e outros dados deste sitio que esta relação pode ser esclarecida (vide Tópico 4.4.1).

\subsubsection{5 - Amidos modificados: evidências sobre preparo alimentar}

A forma modificada dos grãos de amido resulta de processos tafonômicos e de procedimentos relacionados à conservação e ao preparo de alimentos, fatores que promovem modificações na estrutura dos grânulos. Embora isso torne a identificação destas micro partículas mais difícil (Cortella e Pochettino, 1994), os procedimentos adotados para o preparo dos vegetais causam alterações específicas nos grãos que, por sua vez, possibilitam discernir o método utilizado (Babot, 2006).

Dentre os 169 grãos de amido encontrados nas amostras de Jabuticabeira II, é interessante notar que 37 (ou seja, 21,90\%) deles se encontravam modificados (Figuras 13 e 14 e Tabela 4). Estes apresentam deformações, quebras e até um aumento do tamanho do hilo em comparação com grãos de amido do mesmo tipo não modificados. Inclusive, em alguns casos, esses grãos não formavam mais a cruz de interferência sob 
luz polarizada, característica diagnóstica primordial de um grão de amido. As modificações de estrutura do grão de amido observadas em Jabuticabeira II podem ter sido decorrentes de altas temperaturas usadas no preparo de alimentos através de cocção (Beck \& Torrence, 2006), método mais comum de modificação de amido (Samuel, 2006).

Separando as amostras de Jabuticabeira II por sexo, observa-se que nas amostras masculinas $38,89 \%$ dos grãos de amido são modificados, enquanto nas femininas somente $24,39 \%$ dos grãos obtidos são modificados. No entanto, esta diferença não atinge significância estatística $\left(X^{2}=2,3298 ; p=0,1269\right.$; $p$ Fischer $\left.=0,1377\right)$, sugerindo não haver diferença entre o modo de preparo de alimentos ingeridos por homens e mulheres.

Não é difícil imaginar que em Jabuticabeira II os indivíduos poderiam ter o hábito de consumir alimentos ricos em amido processados previamente, já que a prática do processamento de plantas antes de sua ingestão tem grandes benefícios quanto a remoção de substâncias nocivas e a facilitação da digestão (Beck \& Torrence, 2006). Esta idéia é corroborada pelo fato de que aproximadamente $10 \%$ dos artefatos líticos encontrados em Jabuticabeira II eram utilizados para o processamento de vegetais (Scheel-Ybert et al, 2003), porcentagem semelhante à encontrada em vários outros sambaquis (Beck, 1972; Garcia, 1972; Kneip, 1994; Uchoa, 1973). Além disso, a presença de fragmentos escuros relatados anteriormente em algumas das amostras de cálculo de Jabuticabeira II pode ser proveniente de carvão utilizado para o preparo do alimento, já que é prática comum assar tubérculos e outras porções vegetais em contato direto com o solo e o carvão em fornos escavados (Wesolowski, 2007).

Por outro lado, há numerosas evidências diretas da produção de fogo pelos construtores de Jabuticabeira II durante os rituais de enterramento, como, por exemplo, para a produção de cal disperso sobre os ossos de um dos indivíduos de Jabuticabeira II. Possivelmente, o cal foi utilizado na tentativa de agilizar o processo de decomposição do tecido mole e/ou para reduzir a produção de odores desagradáveis (Edwards et al, 2001). Corroborando a importância do fogo como coadjuvante em várias atividades diárias, consta ainda dos resultados da análise antracológica de material proveniente de alguns sambaquis das regiões sul e sudeste do país, incluindo Jabuticabeira II, a coleta aleatória de madeira morta como fonte de lenha (Scheel-Ybert et al, 2003). 


\subsection{2 - Outros microfósseis vegetais:}

Além dos grãos de amido também foram encontradas células de tecido vascular vegetal (vide coluna [ ] de fibras/traqueídes na Tabela 1) e estruturas que parecem ser epiderme vegetal. Essas são estruturas típicas de órgãos vegetais como caules e folhas. Assim, esses achados podem indicar que nesse sítio os indivíduos também utilizavam caules e folhas de plantas em sua dieta. Alternativamente, a adesão dessas estruturas ao cálculo dentário desses indivíduos pode ser resultado da manipulação de caules ou folhas com os dentes para a produção de artefatos como cordas, cestos ou redes (Brothwell, 1981; Hilson, 1996; Scott \& Turner II, 1988).

Um dado importante que corrobora indiretamente esta última interpretação é o da presença de desgaste para-mastigatório em vários dos indivíduos de Jabuticabeira II, que nada mais é do que um desgaste provocado por atividades não associadas à mastigação alimentar.

Entretanto, a concentração de fibras/traqueídes não se correlaciona ao grau de desgaste dentário médio dos indivíduos (Spearman's rho: coeficiente de correlação=0,059, $p=0,671)$, nem tampouco há diferença entre as concentrações de fibras/traqueídes em indivíduos com e sem desgaste para-mastigatório (Mann-Whitney: $p=0,161)$. Em consonância com estes resultados, também não se encontrou associação significativa entre desgaste para-mastigatório e presença de fibra/traqueídes $\left(X^{2}=0,8413\right.$, $p=0,3590 ; p F i s h e r=0,4394$ ). Daí conclui-se que possivelmente as fibras/traqueídes não são provenientes de material utilizado para a produção de artefatos com auxílio dos dentes, mas sim, provenientes de caules e folhas ingeridos na dieta.

\subsection{3 - Análise de microfósseis in loco através do microscópio eletrônico de varredura (MEV):}

Ao observar as imagens da superfície do cálculo do pré-molar do indivíduo XLla, obtidas através do microscópio eletrônico de varredura (MEV), foram observadas três estruturas sugestivas de diatomáceas (Figura 15). Estruturas semelhantes a estas $(n=3)$ também foram registradas durante a varredura das lâminas referentes à amostra 103 (sepultamento CX - Figura 10). Essas diatomáceas são mais uma evidência da dieta rica em recursos aquáticos dos pescadores-caçadores-coletores de Jabuticabeira II, já que são encontradas tanto em hábitat marinho, quanto em águas continentais (Lee, 1989). 
Entretanto, somente em dois dos 34 indivíduos analisados foram observadas diatomáceas.

A raridade inesperada deste tipo de microfóssil nas amostras de cálculo dentário de um grupo com subsistência baseada em recursos aquáticos sugere que as diatomáceas estejam sub-representadas por algum problema metodológico. Como suas carapaças são compostas de sílica, este problema não poderia estar relacionado à utilização de ácido clorídrico para a produção das amostras, já que o mesmo não dissolve sílica. Então, este problema poderia estar relacionado ao meio utilizado para montagem das lâminas (V. Wesolowski, comunicação pessoal). Sabe-se que, o "rendimento do microscópio óptico aumenta", se são utilizados, para montagem das lâminas, meios de índice de refração mais elevados (Ferreira \& Carvalho, 1972) do que o do objeto a ser observado. Como o índice de refração das diatomáceas equivale a 1,43, seria necessário, para sua adequada visualização, um meio com índice de refração mais alto do que este. Segundo P.G.C. Amaral (comunicação pessoal) um meio com índice de 1,70 é o ideal para a visualização de diatomáceas. Porém, no presente trabalho, as lâminas foram montadas com uma solução simples de água e glicerina (a 50\%), que apresenta índice de refração em torno de 1,41 (Ferreira \& Carvalho, 1972), permitindo a visualização de fitólitos e grânulos de amido, principais objetos de estudo deste trabalho, mas não de diatomáceas.

Nas imagens de MEV também é possível notar estruturas semelhantes a fitólitos, as quais não foram observadas sob microscópio óptico (Figura 15). Além disso, apesar das proporções observadas de fitólitos e grãos de amido (número total de cada um destes microfósseis somando-se todas as amostras do sítio) em Jabuticabeira II não serem tão diferentes entre si (Gráfico 9), o número de fitólitos se concentrou em apenas 13 das 54 amostras (Tabela 1, Gráfico 10), enquanto que os grãos de amido foram observados em quase todas elas (42 de 54 amostras, ou seja 78\%). No entanto, em outro trabalho realizado com a análise de cálculo dentário de indivíduos provenientes de sambaquis, estes microfósseis foram freqüentemente observados nas lâminas e sua distribuição pelas amostras foi equilibrada (Wesolowski, 2007). A seguir serão tratados os resultados a respeito dos fitólitos das amostras de Jabuticabeira II.

\subsection{4 - Fitólitos}

A ausência de alguns tipos de fitólitos nas lâminas e presença destes mesmos tipos somente sob o MEV, assim como a presença de fitólitos em apenas 24,07\% das 
amostras, se explicaria se os fitólitos observados sob MEV fossem compostos de oxalato de cálcio (Esau, 1977 apud Jones \& Bryant, 1992). Como os cristais de oxalato de cálcio não resistem à ação do ácido clorídrico (Pearsall, 2000), tais microfósseis seriam, portanto, destruídos durante o processamento químico do cálculo dentário. Entretanto, não foram ainda realizadas análises suficientes para detectar se, de fato, os fitólitos somente observados através do MEV são compostos por oxalato de cálcio. Quando isto for constatado, entretanto, seria imprescindível adaptar o método de extração de microfósseis a partir de cálculo dentário em sambaquis, no intuito de preservar tais estruturas.

De qualquer forma, os fitólitos que foram observados sob o microscópio óptico não puderam, ainda, ser devidamente identificados, pois não existe, até o presente momento, chave de identificação para fitólitos das plantas da região. Por outro lado, as informações e figuras obtidas na bibliografia (Rapp \& Mulholland, 1992; Pearsall, 2000; Piperno, 2006) não foram suficientes para fazer o diagnóstico para o material observado aqui, pelo simples fato dos trabalhos existentes se referirem a outras regiões fitogeográficas. Entretanto, a identificação dos fitólitos já contabilizados no presente trabalho será realizada em trabalho futuro. Por enquanto, apenas é possível dizer que dentre os fitólitos observados existem estruturas das mais variadas, como druzas, esclereides, estruturas alongadas e lisas e alongadas e granulosas.

Outra explicação mais plausível para essa relativa escassez de amostras contendo fitólitos ( $24 \%$ das amostras) poderia estar relacionada a diferenças de dieta dos indivíduos deste sitio. Eventualmente, uma parcela dos indivíduos de Jabuticabeira II poderia ter uma dieta vegetal baseada, preferencialmente, em raízes e tubérculos, órgãos vegetais que, em geral, não contem fitólitos (Gott et al, 2006) e que são extremamente ricos em grãos de amido, enquanto outra parcela desse grupo poderia alimentar-se de uma maior quantidade de folhas, caules e frutos (órgãos vegetais ricos em fitólitos). Dessa forma, as diferenças de distribuição de fitólitos observados nas amostras de cálculo dentário estariam refletindo distintos padrões alimentares (pelo menos no que tange a utilização de alimentos de origem vegetal).

Em busca de maiores informações a respeito de cada um dos indivíduos que apresentaram fitólitos na composição dos microfósseis dentais, as fichas de campo, fichas osteológicas e paleopatológicas dos sepultamentos, assim como os croquis, foram analisados detalhadamente. Entretanto, nenhuma das informações obtidas sobre esses 
sepultamentos, por mais interessantes que fossem, foi suficiente para compreender o que estes indivíduos tinham de distinto dos demais (vide Tópico 6 - Limitações do trabalho).

\subsubsection{1 - Comparação entre sexos}

Uma vez constatada a presença de fitólitos somente em um quarto dos indivíduos de Jabuticabeira II analisados, passou-se a investigar se esta diferença estava ligada ao sexo. De fato, de acordo com o Gráfico 11, as mulheres tendem a apresentar valores mais altos de concentração de fitólitos que os homens, excluindo-se o "outlier" correspondente à amostra 78 (com 64,88 fitólito/ $\mu \mathrm{L}$ ). Entretanto esta tendência não é confirmada estatisticamente (teste de Mann-Whitney: $p=0,863$ ). Tampouco se verifica uma associação entre sexo e presença de fitólitos (Qui-quadrado = 0,0675; $p=0,7949$ ). Desta maneira, conclui-se que a presença de fitólitos em apenas uma parcela de indivíduos de Jabuticabeira II não está relacionada ao sexo.

\subsubsection{2 - Tamanho e peso do cálculo dentário, concentração de fitólito e idade} de óbito

Embora o Gráfico 12 aparente um aumento da concentração de fitólitos com o aumento da idade (excluindo-se indivíduos com idade indeterminada e o "outlier"), o teste estatístico não demonstrou correlação entre estas duas variáveis (Spearman's rho: $p=0,454$, coeficiente de correlação: 0,133 , tabela 5), da mesma forma como ocorreu para a concentração de amido.

No entanto, diferentemente do observado em relação aos grânulos de amido, não foi demonstrada correlação entre as concentrações de fitólitos e o peso das amostras analisadas (Spearman's rho: $p=0,544$, coeficiente de correlação: 0,084 - tabela 5, Gráfico 13) (vide Tópico 4.1.1.3 para uma melhor discussão).

Analogamente à falta de correlação entre a concentração de amido e o índice de cálculo dentário, não se observou tampouco correlação significativa (Spearman's rho: $p=0,662$, coeficiente de correlação=0,083, excluindo amostras outliers 78 e 89, tabela 5) entre a concentração de fitólitos e o índice de cálculo dentário (Gráfico 14).

Entretanto, como as concentrações de fitólitos estão presentes em somente algumas das amostras de Jabuticabeira II, os resultados destes testes podem estar sujeitos a enviesamento ou então, podem apenas indicar que o consumo de porções 
vegetais ricas em fitólitos é bem menor do que o consumo de vegetais ricos em amido, não havendo uma retenção significativa destas primeiras partículas no cálculo dentário, independente da velocidade de mineralização da placa dentária (Kleinberg, 1961; Jin e Yip, 2002).

\subsubsection{3 - Comparações entre dentição anterior e posterior}

No intuito de melhor compreender a formação do cálculo dentário buscou-se analisar a diferença de concentração de fitólitos entre as amostras provenientes de dentição anterior e posterior (Gráfico 10). Corroborando os resultados já obtidos para as concentrações de amido, também não há diferença significativa entre concentração de fitólito proveniente de dentes anteriores e posteriores (teste de Mann-Whitney: $p=0,784$ ). Seria plausível supor que isto estivesse relacionado à semelhança entre o peso dos fragmentos de cálculo de amostras de dentes anteriores com amostras de dentes posteriores (Mann-Whitney: $p=0,139$ ).

\subsubsection{4 - Fitólitos versus desgaste dentário}

Dentre diversos fatores, um dos principais responsáveis pelo desgaste dentário é o conteúdo abrasivo do alimento, causado por areia, fragmentos ósseos e corpos de sílica. Além disso, o desgaste pode estar associado, também, a utilização dos dentes para processamento de matéria-prima, incluindo fibras vegetais (Brothwell, 1981; Scott \& Turner II, 1988; Hilson, 1996).

A associação entre desgaste dentário e consumo de vegetais ricos em fitólitos foi observada por vários autores (Armitage, 1975; Middleton, 1990, 1992; Ciochon et al, 1990; Danielson e Reinhard, 1998). Assim, grandes concentrações de fitólitos deveriam ser encontradas nos cálculos dentários de indivíduos com alto grau de desgaste, como é o caso de Jabuticabeira II. Embora as amostras com fitólitos deste sítio tenham se restringido a somente poucas amostras, somando-se o conteúdo de todas elas, a quantidade de fitólitos obtida é grande. Portanto, essa questão necessita ser discutida.

Apesar de no Gráfico 15 constar um aumento de concentração de fitólitos com o aumento do grau de desgaste dentário médio, esta correlação não atingiu significância estatística (Spearman's rho: coeficiente de correlação=0,021, $p=0,885$ ), excluindo-se os "outliers" referentes às amostras 78 e 89. Da mesma forma, não foi observada relação 
entre a intensidade do desgaste dentário e a concentração de fitólitos em séries esqueletais provenientes de sambaquis da região norte de Santa Catarina (Wesolowski, 2007).

Também, cogitou-se a possibilidade de que os fitólitos que estavam presentes nas amostras de cálculo dentário fossem provenientes de órgãos vegetais trabalhados com os dentes para serem utilizados como artefatos, e não ingeridos na dieta. Assim, avaliou-se a associação entre a concentração de fitólitos e a presença de desgaste para-mastigatório, mas, a mesma não foi significativa (Mann-Whitney: $p=0,192$ ), assim como não foi significativa a diferença do número de amostras com e sem fitólitos, dentre aquelas provenientes de indivíduos com desgaste para-mastigatório ( $X^{2}=1,7088, p=0,1911$; pFisher=0,3035). Igualmente, não foi verificada correlação entre desgaste paramastigatório e as concentrações de fitólitos para as séries analisadas do litoral Norte Catarinense (Wesolowski, 2007).

No entanto, os resultados obtidos aqui estão relacionados a amostras pequenas, 0 que pode refletir num viés nos testes estatísticos. Além disso, como foi discutido, é possível que tenha ocorrido uma sub-estimativa do número de fitólitos nestas amostras, já que, através do microscópio eletrônico de varredura foram observados fitólitos outros que não os obtidos através da análise sob microscópio óptico. Vale lembrar, ainda, que neste trabalho, o grau de desgaste dos indivíduos não foi analisado de forma detalhada, visto que não era objetivo deste trabalho. Um estudo mais pormenorizado será realizado, futuramente, para que a associação entre desgaste e a presença de fitólitos possa ser esclarecida.

\subsection{5 - O Lócus 2 de Jabuticabeira II:}

O Locus 2 do sítio Jabuticabeira II apresenta características especiais que levam a crer que os indivíduos lá sepultados faziam parte de um grupo de "afinidade" (vide Tópico 1.3.1.1 da Introdução). Essa suposta afinidade poderia, hipoteticamente, ser mediada por semelhanças biológicas ou parentesco; por atividades compartilhadas relacionadas à subsistência e a dieta; à preferências ritualísticas ou outros. Algumas destas hipóteses já foram testadas, entretanto, a análise exaustiva dos dados obtidos não demonstrou haver diferenças significativas entre os indivíduos do grupo de afinidade e os demais (Bartolomucci, 2006; Filippini, 2004; Petronilho, 2005). 
Assim, conjecturou-se investigar se a dieta poderia representar um fator discriminante do grupo de afinidade em relação aos demais indivíduos deste sambaqui cemitério.

\subsubsection{1 - Amido:}

Ao todo, 17 amostras analisadas pertenciam a indivíduos sepultados no Lócus 2, sendo que destas, 6 foram obtidas a partir de esqueletos do sexo masculino, 7 de indivíduos do sexo feminino e 4 de indivíduos cujo sexo não pôde ser determinado. No Gráfico 1 constam as concentrações de grãos de amido obtidas para as amostras do Lócus II. Os resultados dos testes estatísticos para amido se encontram na Tabela 6.

\subsubsection{1 - Sexo e idade}

Quando são aplicados os testes estatísticos somente para as amostras do Lócus 2 (excluindo-se o "outlier" amostra 83), demonstra-se que não há diferença significativa entre homens e mulheres quanto à concentração de grãos de amido (Mann-Whitney: $p=0,321$, Tabela 6). Também não é observada correlação entre idade e concentração de amido para essas amostras (Spearman's rho: $p=0,765$; coeficiente de correlação=0,109, Tabela 6).

\subsubsection{2 - Lócus 2 versus outros loci}

Comparando-se as amostras do suposto grupo de afinidade com as amostras pertencentes a indivíduos dos outros loci, também não se verifica diferença significativa entre as concentrações de amido (Mann-Whitney: $p=0,489$, Tabela 6). A semelhança entre o suposto grupo de afinidade e os demais indivíduos sepultados em Jabuticabeira II é corroborada, ainda, através da comparabilidade dos valores da concentração de amido entre os homens (Mann-Whitney: $p=0,568$ ) e entre as mulheres (Mann-Whitney: $p=0,174$ ) de todas as regiões escavadas do sítio (Tabela 6). 


\subsubsection{2 - Fitólitos:}

No Gráfico 10 constam as concentrações de fitólitos obtidas para as amostras do Lócus 2. Infelizmente, as amostras nas quais foram observados fitólitos são escassas (apenas 6 em 17) a ponto de impossibilitar muitas análises estatísticas. Os resultados de alguns dos testes estatísticos para fitólitos se encontram na Tabela 7.

\subsubsection{1 - Sexo e idade}

Das seis amostras provenientes do Lócus 2 em que foram detectados fitólitos, há três $(50 \%)$ retiradas de esqueletos do sexo masculino e duas $(33,33 \%)$ de sexo feminino. Evidentemente, esta pequena diferença não chega a ser estatisticamente significativa $\left(X^{2}\right.$ $=0,6268, p=0,4285$ e pFisher=0,5921), nem quando se compara a diferença de concentração destes micro-restos entre os sexos (Mann-Whitney: $p=0,847$ ).

As análises sobre a concentração de fitólitos versus idade de óbito também ficaram prejudicadas pelo pequeno espaço amostral, uma vez que metade das já escassas seis amostras tiveram de ser excluídas por serem provenientes de indivíduos com idade indeterminada. Assim, sobraram 3 amostras, sendo uma de adulto jovem, uma de adulto médio e a última proveniente de adulto velho. Como esperado, o teste de correlação entre a idade e as concentrações de fitólitos não resultou significante (Spearman's rho: $p=$ 0,705 ; coeficiente de correlação $=0,138$ ). Para que se possa afirmar qualquer coisa sobre a relação entre idade de óbito e acúmulo de fitólitos no Lócus II é necessário escavar e estudar mais indivíduos.

\subsubsection{2 - Lócus 2 versus outros loci}

Comparando-se as amostras do suposto grupo de afinidade com as amostras pertencentes a indivíduos dos outros loci, percebe-se que, das 13 amostras de Jabuticabeira II que apresentam fitólitos, 46,15\% são provenientes do Lócus 2, enquanto $53,84 \%$ provém de outros loci. Evidentemente, esta diferença de concentração de fitólitos entre os dois grupos não é estatisticamente significativa (Mann-Whitney: $p=0,267$; sum of ranks: Locus II=464 and outros loci=914) excluindo-se as amostras discrepantes de 95,45 e 64,88 fitólitos/ $\mu \mathrm{L}$, que correspondem, respectivamente, a um indivíduo de cada uma das regiões escavadas. 
Curiosamente, estes dados contrariam os resultados de isótopos estáveis que indicam que os indivíduos do Lócus 2 subsistiam com uma dieta comparativamente mais rica em proteínas do que os outros indivíduos de Jabuticabeira II (Eggers, et al, 2007). Contudo, estudos de isótopos estáveis de mais indivíduos de dentro e de fora do Locus 2 necessitam ser realizados para que se possa afirmar se, de fato, a dieta vegetal entre os indivíduos sepultados nesses loci era semelhante, enquanto apenas a protéica era mais relevante para os indivíduos sepultados no Lócus 2.

Quando os dois grupos são comparados com relação aos sexos, dentre as amostras masculinas de Jabuticabeira II $(n=17), 17,64 \%$ são amostras com fitólitos pertencentes ao Lócus 2 e 5,88\% são amostras com fitólitos pertencentes aos outros loci. Já dentre as amostras femininas ( $n=20), 10 \%$ são amostras com fitólitos pertencentes ao Lócus 2 e 10\% são amostras com fitólitos pertencentes aos outros loci. A maior proporção de fitólitos encontrados dentre os homens do Locus 2 poderia indicar uma diferença no consumo de vegetais ricos em fitólitos. Várias análises foram realizadas para testar a veracidade desta afirmação (vide Tabela 7). Todavia, nenhum dos testes estatísticos acusou diferenças significativas quanto a presença e concentração de grãos de amido e fitólitos entre homens e mulheres de dentro do Lócus 2, assim como entre o Lócus 2 e os demais loci de Jabuticabeira II.

Todos esses resultados apresentados, tanto para fitólitos quanto para grãos de amido, sugerem, em concordância com os resultados de biodistância (Filippini, 2004; Bartolomucci, 2006) e osteoartrose (Petronilho, 2005), que o suposto grupo de afinidade é, mais provavelmente, um artefato arqueológico do que uma realidade. Contudo, uma ressalva deve ser feita com relação aos dados referentes aos fitólitos, visto que o tamanho amostral muito reduzido de amostras com estes microfósseis no Lócus 2 poderia estar causando um enviesamento dos testes estatísticos.

\subsection{6 - Resumo:}

Em suma, com relação às amostras de cálculo dentário provenientes de Jabuticabeira II, pode-se afirmar que:

Embora as proporções de fitólitos e grãos de amido obtidos no total das amostras não sejam tão diferentes entre si, os primeiros foram observados em praticamente todas as amostras ( $80 \%$ delas), enquanto que os fitólitos foram encontrados em apenas $24 \%$ das amostras, o que demonstra um 
aporte expressivo de alimentos amiláceos na dieta da maioria dos indivíduos de Jabuticabeira II.

Não houve diferença estatisticamente significativa dos pesos dos fragmentos de cálculo obtidos entre amostras de dentes anteriores e posteriores, nem das concentrações de amido ou de fitólitos entre ambos os tipos de dentição, o que pode ser explicado por não ter sido feita distinção entre amostras provenientes de dentição superior ou inferior;

Não houve diferença significativa entre as amostras provenientes de homens e de mulheres quanto ao peso dos fragmentos de cálculo utilizados, nem quanto às concentrações de amido ou de fitólitos, o que sugere não ter havido distinção na dieta entre os sexos em Jabuticabeira II;

Embora não tenha sido observada correlação entre as concentrações de amido e a idade de óbito dos indivíduos, o peso dos fragmentos de cálculo se correlaciona positivamente com a idade de óbito e com as concentrações de amido. Para fitólitos, não há correlação da concentração com a idade de óbito nem com peso dos fragmentos de cálculo dentário. Isso pode ser explicado pelo fato de que, como há variações na formação, compactação, composição e velocidade de mineralização dos depósitos de cálculo, além de haver variações na dieta entre os indivíduos e ao longo da vida de cada indivíduo, os tipos e quantidades de microfósseis que se aderem a estes depósitos podem variar entre os indivíduos e ao longo da vida de cada um;

Apesar de ter sido observada correlação positiva entre índice de cálculo dentário e peso dos fragmentos de cálculo, não foi observada correlação entre o índice de cálculo e idade de óbito, nem ao menos entre o índice de cálculo e as concentrações de amido ou de fitólitos. Portanto, através deste estudo não foi possível avançar sobre o processo de formação do cálculo.

A relação entre cáries e concentração de amido não pôde ser testada devido ao pequeno número de indivíduos acometidos por esta patologia. A principio isso parece contraditório, visto que o aporte amiláceo na dieta de Jabuticabeira II parece ser significativo, sendo esperada freqüência alta de indivíduos afetados por lesões cariosas. No tópico 4.4.1 a relação de 
cáries com o aporte amiláceo será discutido sob uma perspectiva mais ampla.

Foram observados grãos de amido modificados, o que, juntamente com outras evidências, sugere que havia preparo de alimentos amiláceos em Jabuticabeira II antes do seu consumo.

Não foi observada relação do grau de desgaste dentário, ou do desgaste para-mastigatório com as concentrações de fitólitos obtidas nas amostras. Diante dos raros indivíduos que apresentaram evidências de fitólitos não é possível, entretanto, excluir que folhas e caules tenham sido trabalhados com os dentes para produção de artefatos, assim como não se pode afirmar que os fitólitos provenientes da dieta não tinham poder abrasivo.

Outros microfósseis, além de fitólitos e grãos de amido, foram observados.

Estes incluem diatomáceas, fragmentos de epiderme, fibras vegetais, traqueídes, fragmentos escuros, todos eles em quantidades reduzidas. Estas evidências sugerem um padrão alimentar diversificado, sendo que as diatomáceas confirmam a dependência de recursos aquáticos (inferida até então por estudos zooarqueológicos, dados preliminares proveninetes de análises de isótopos estáveis e investigações sobre o padrão de assentamento deste grande sambaqui cemitério).

Não foi observada correlação entre a concentração de fibras e o desgaste para-mastigatório dos indivíduos analisados, assim como ocorreu para os fitólitos. Diante dos raros indivíduos que apresentaram evidências de fibras, não é possível, entretanto, excluir que folhas e caules tenham sido trabalhados com os dentes para produção de artefatos..

A busca de informações complementares sobre o indivíduo com concentração discrepante de grãos de amido, e sobre os poucos indivíduos que apresentaram fitólitos em suas amostras de cálculo dentário não foram satisfatórias. Apesar de terem sido obtidas informações interessantes em alguns casos, nenhuma delas foi, ainda, suficiente para que pudesse se chegar a alguma conclusão a respeito do porque estes indivíduos apresentavam concentrações de microfósseis vegetais diferente dos demais.

Os resultados obtidos para dieta vegetal, não corroboraram a hipótese de que o Lócus 2 seja um "grupo de afinidade". 
Apesar de terem sido avaliados cálculos dentários de apenas um terço $(n=34)$ dos indivíduos até agora exumados de Jabuticabeira II $(n=110)$, acredita-se que as generalizações acima enumeradas sejam possíveis. Justificativas para tanto incluem bom grau de homogeneidade entre os indivíduos exumados de diferentes loci e camadas estratigráficas de Jabuticabeira II. Esta homogeneidade se refere a variáveis não métricas cranianas (Filippini, 2004) e dentárias (Bartolomucci, 2006), assim como semelhanças de grau e distribuição de degeneração articular (Petronilho, 2005). Esta homogeneidade, embora não se estenda, necessariamente, à dieta, sugere, por outro lado, que uma amostra de um terço do total possa representar bem o grupo como um todo. Entretanto, várias áreas do sambaqui Jabuticabeira II não foram escavadas e nem tampouco avaliadas osteologicamente. Assim, não é de se excluir que, no futuro e de posse de mais dados, sejam encontrados padrões alimentares distintos desses acima discutidos. 


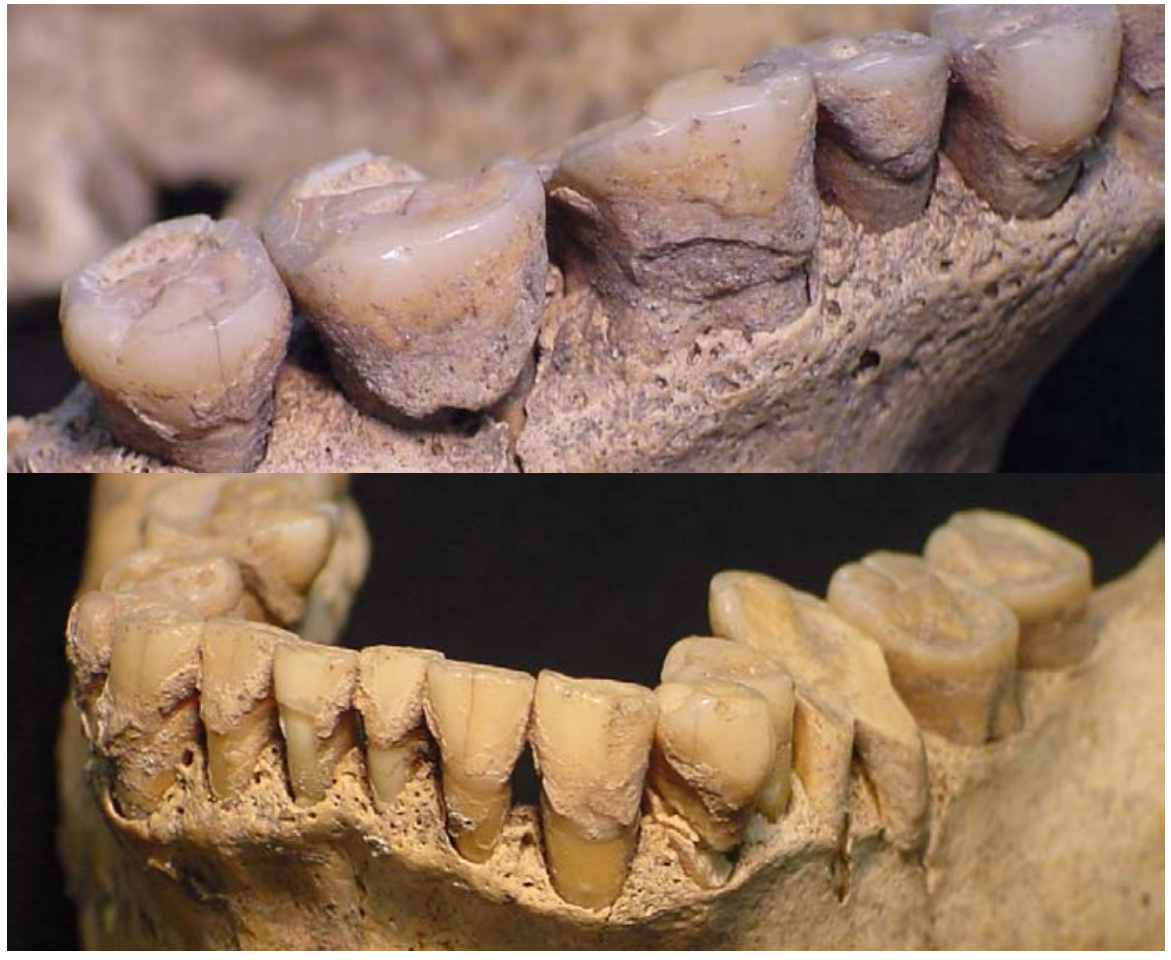

Figura 9: Indivíduo 17a de Jabuticabeira II com dentição completa e com farto depósito de cálculo dental.

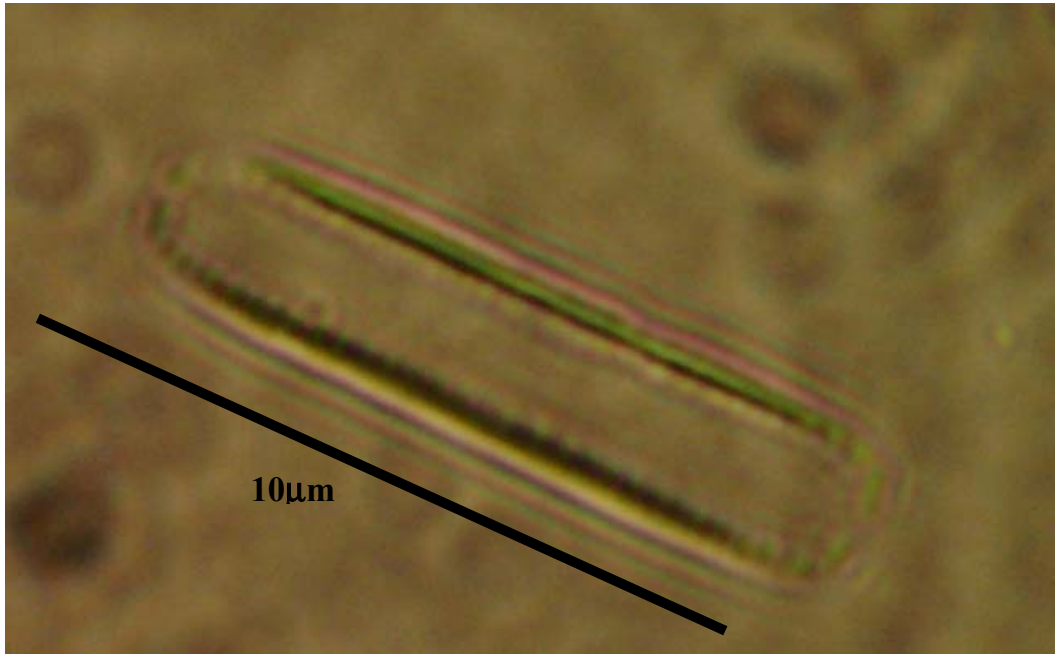

Figura 10: Possível diatomácea encontrada na amostra 103 de cálculo dental de Jabuticabeira II. Aumento de 400x. 

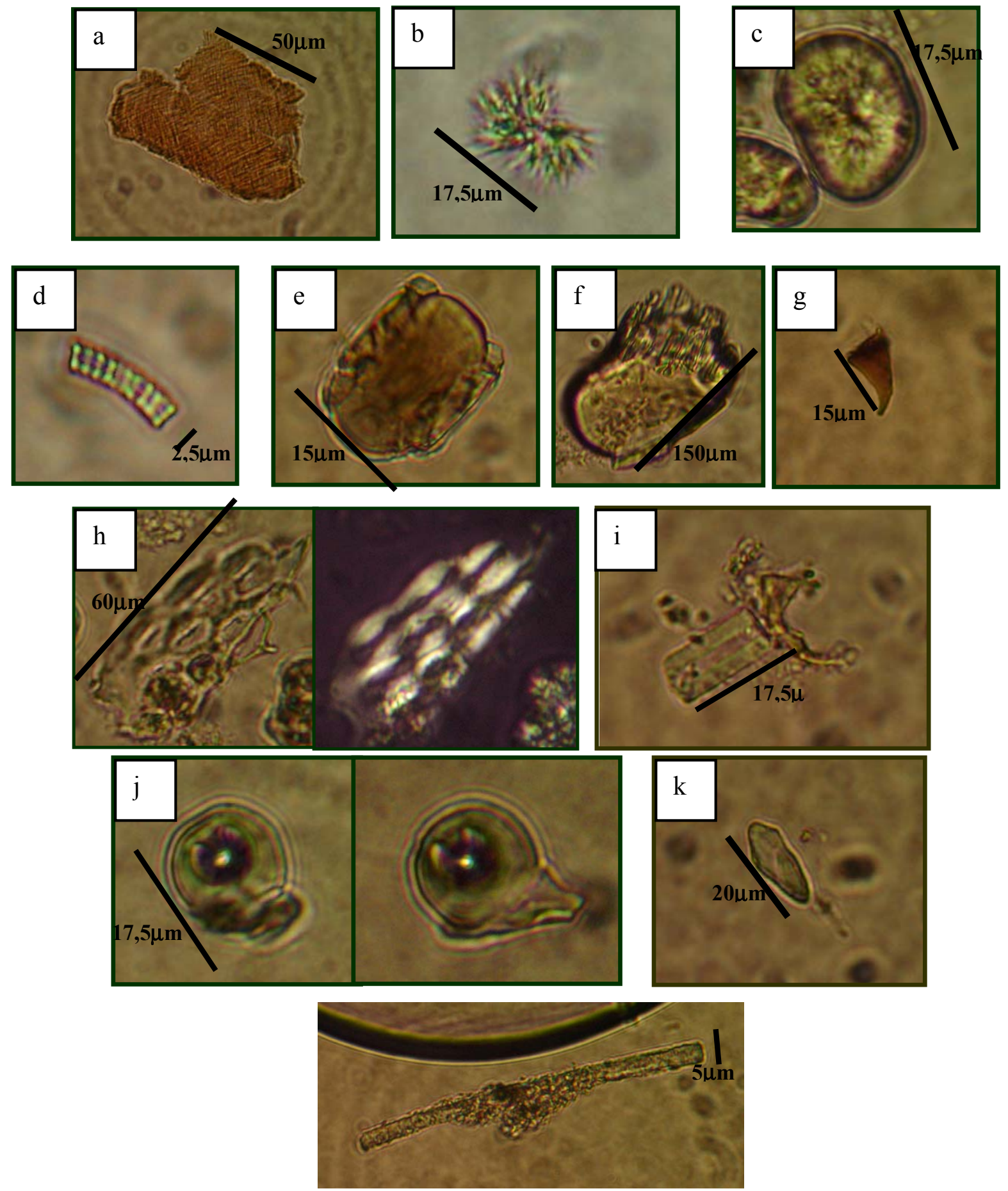

Figura 11: Estruturas peculiares encontradas nas amostras de Jabuticabeira II: a-h) estruturas ainda não identificadas (h: imagem à direita obtida sob luz polarizada), sendo a)possivelmente epiderme b) e c)possivelmente fungos $h$ ) possivelmente epiderme $i-k$ ) possíveis fitólitos (j: mesma estrutura fotografada em diferentes ângulos). I) fitólito alongado de sessão cilíndrica não identificado Aumento de 400x 

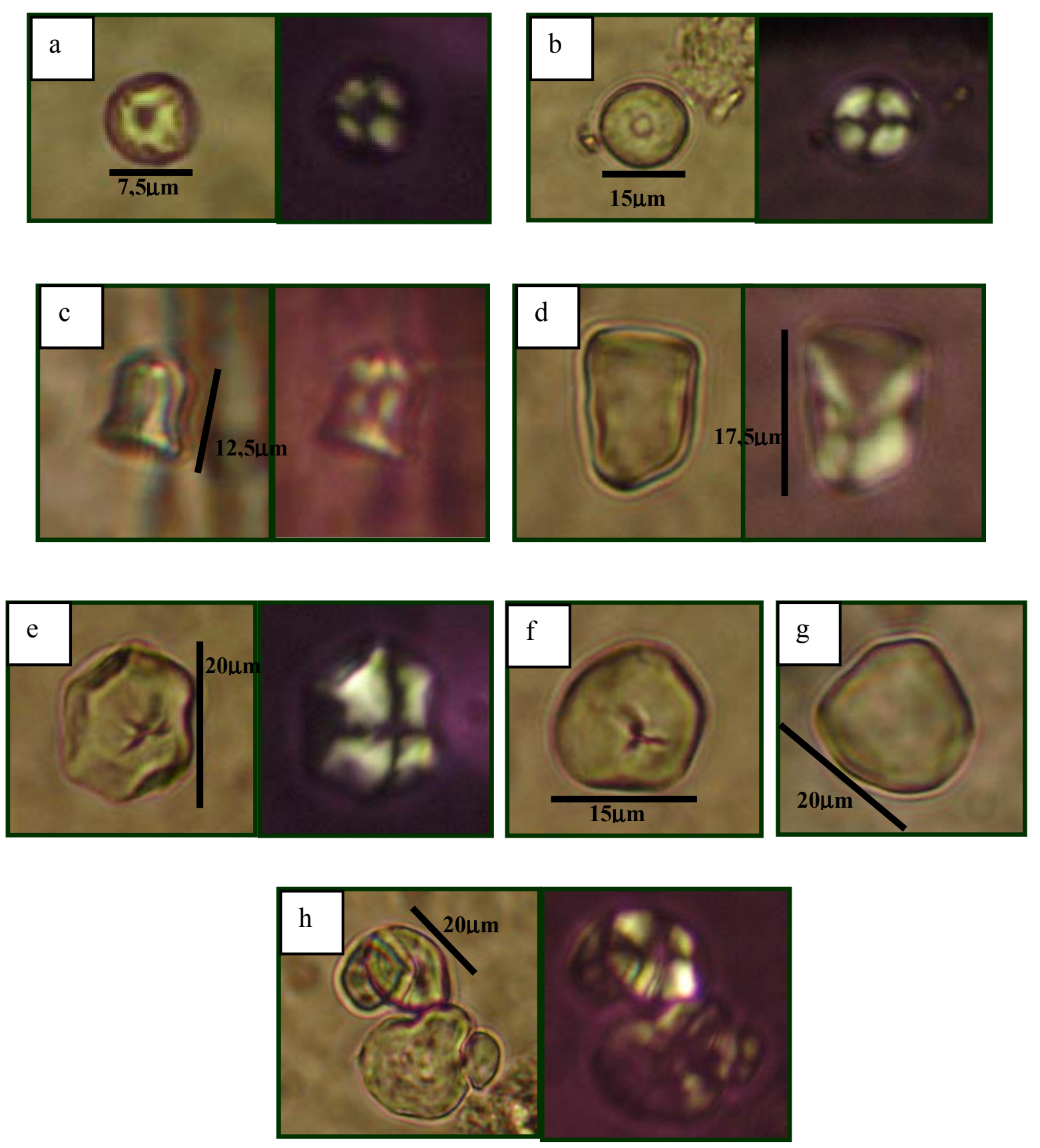

Figura 12: Alguns dos grãos de amido observados nas amostras de cálculo dentário de Jabuticabeira II. a-b) grãos esféricos, c)grão em formato de sino, d-e)grãos poligonais, f)grão com fissura no hilo, g)grão sem hilo visível, h)grão de amido composto. Nas figuras em que aparecem duas imagens do mesmo grão, a imagem à direita foi obtida sob luz polarizada e mostra a cruz de interferência. Aumento de 400x. 

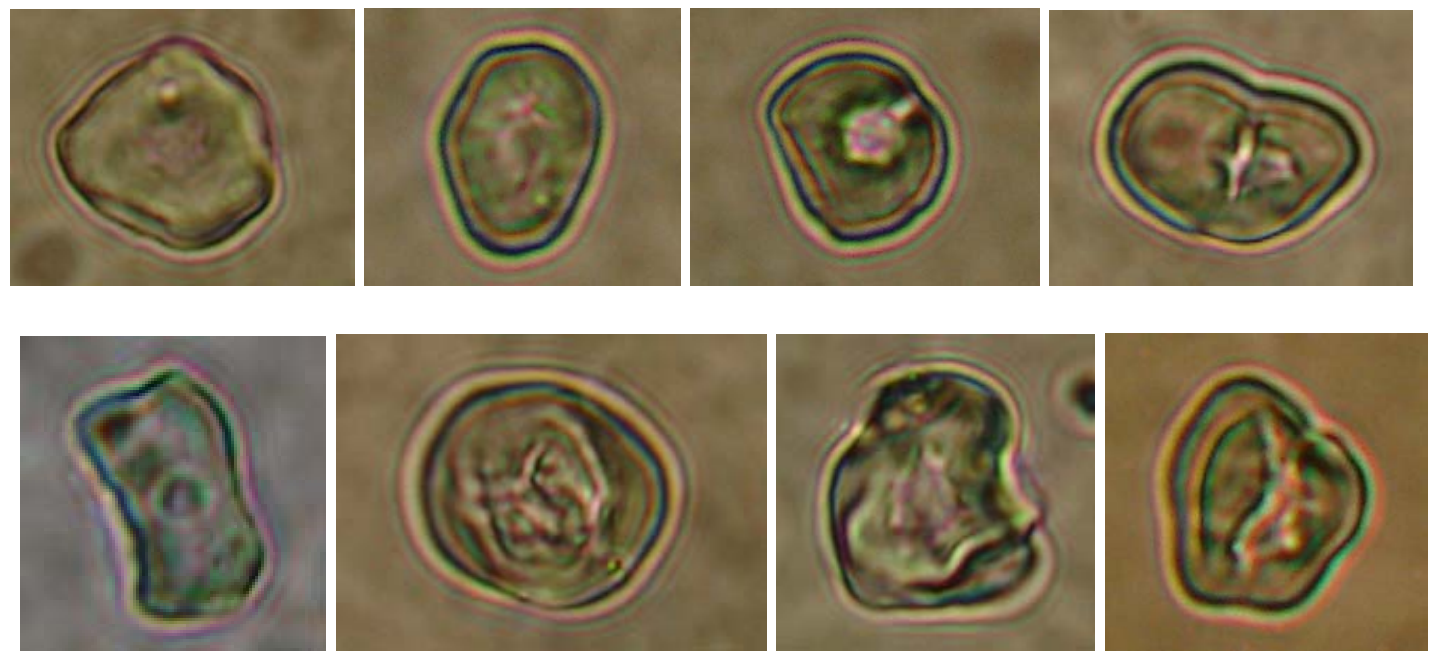

Figura 13: Grãos de amido modificados observados nas amostras. Aumento de 400x Obs.: Na figura não há escala porque quando essas amostras foram analisadas o Laboratório de Antropologia Biológica ainda não possuía o retículo para mensuração em seu microscópio óptico.
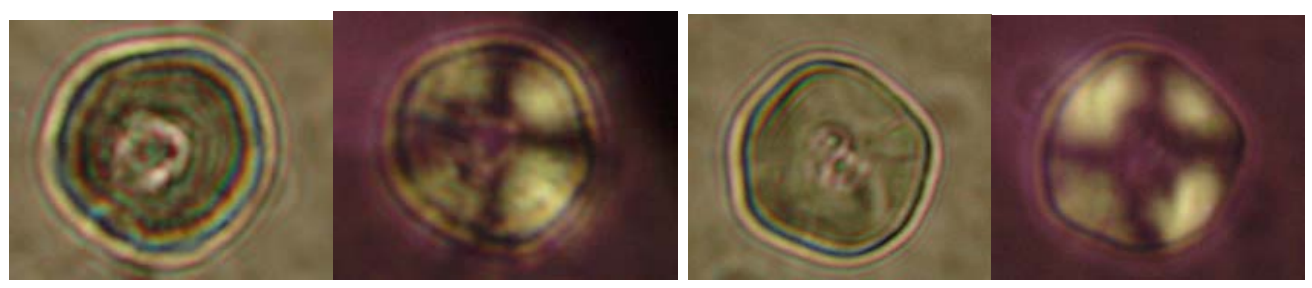

Figura 14: Grãos de amido modificados observados nas amostras de cálculo dentário em que ainda é possível se observar a cruz de interferência sob luz polarizada. Aumento de 400x

Obs.: Na figura não há escala porque quando essas amostras foram analisadas o Laboratório de Antropologia Biológica ainda não possuía o retículo para mensuração em seu microscópio óptico. 


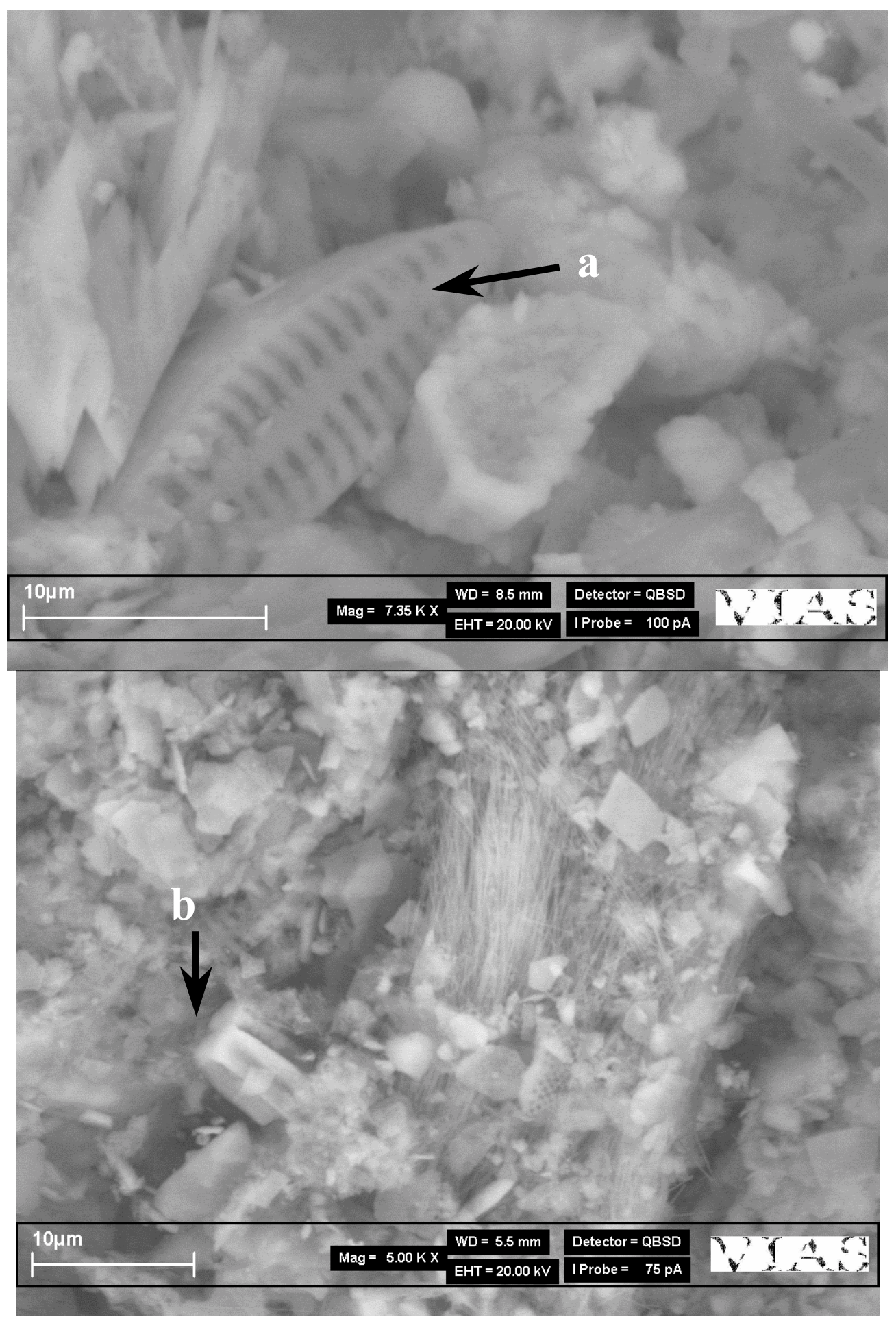

Figura 15: Imagens obtidas através de microscópio eletrônico de varredura (MEV) da superfície do cálculo dental do indivíduo 41a de Jabuticabeira II. a) possível diatomácea b) possível fitólito. 


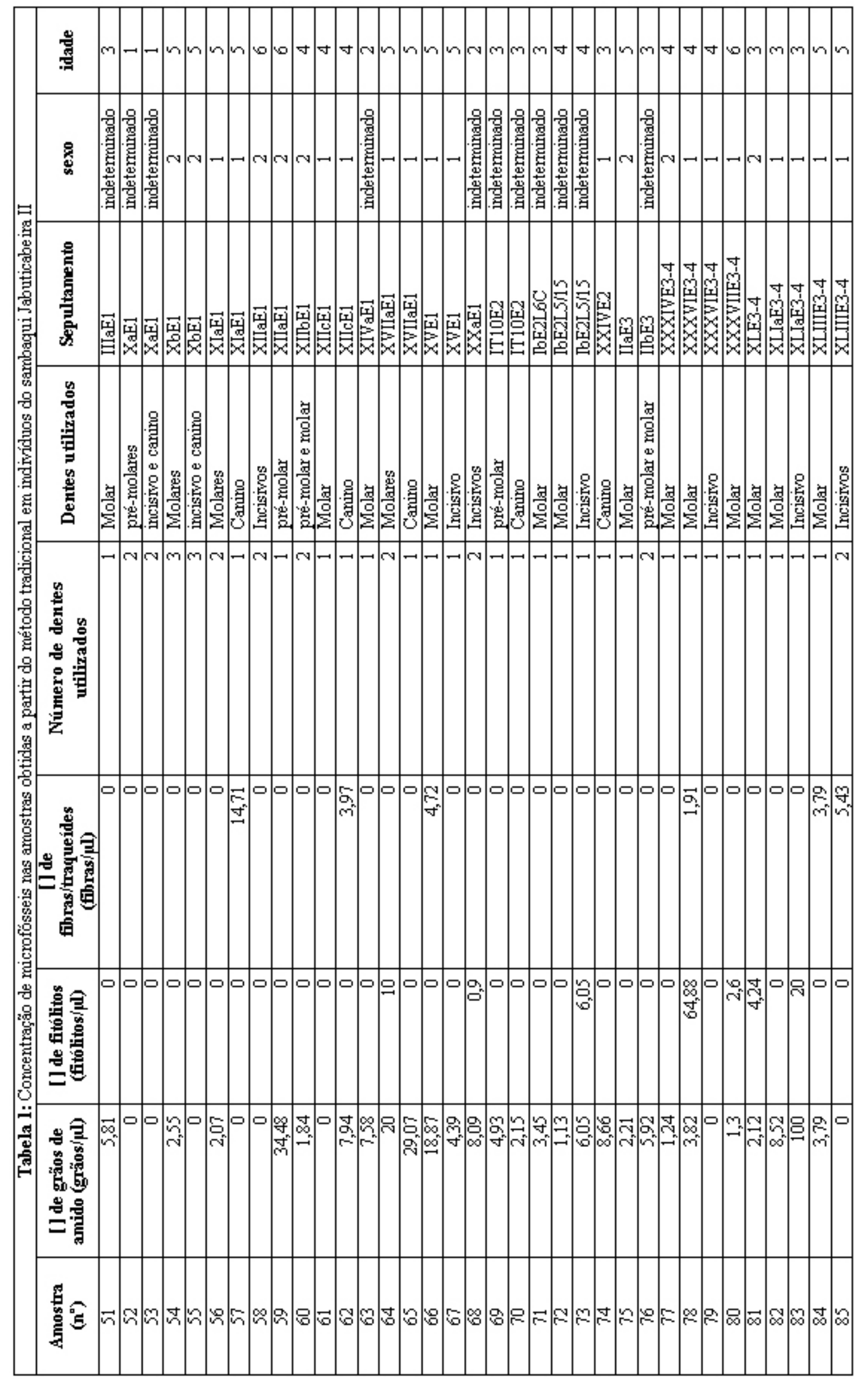




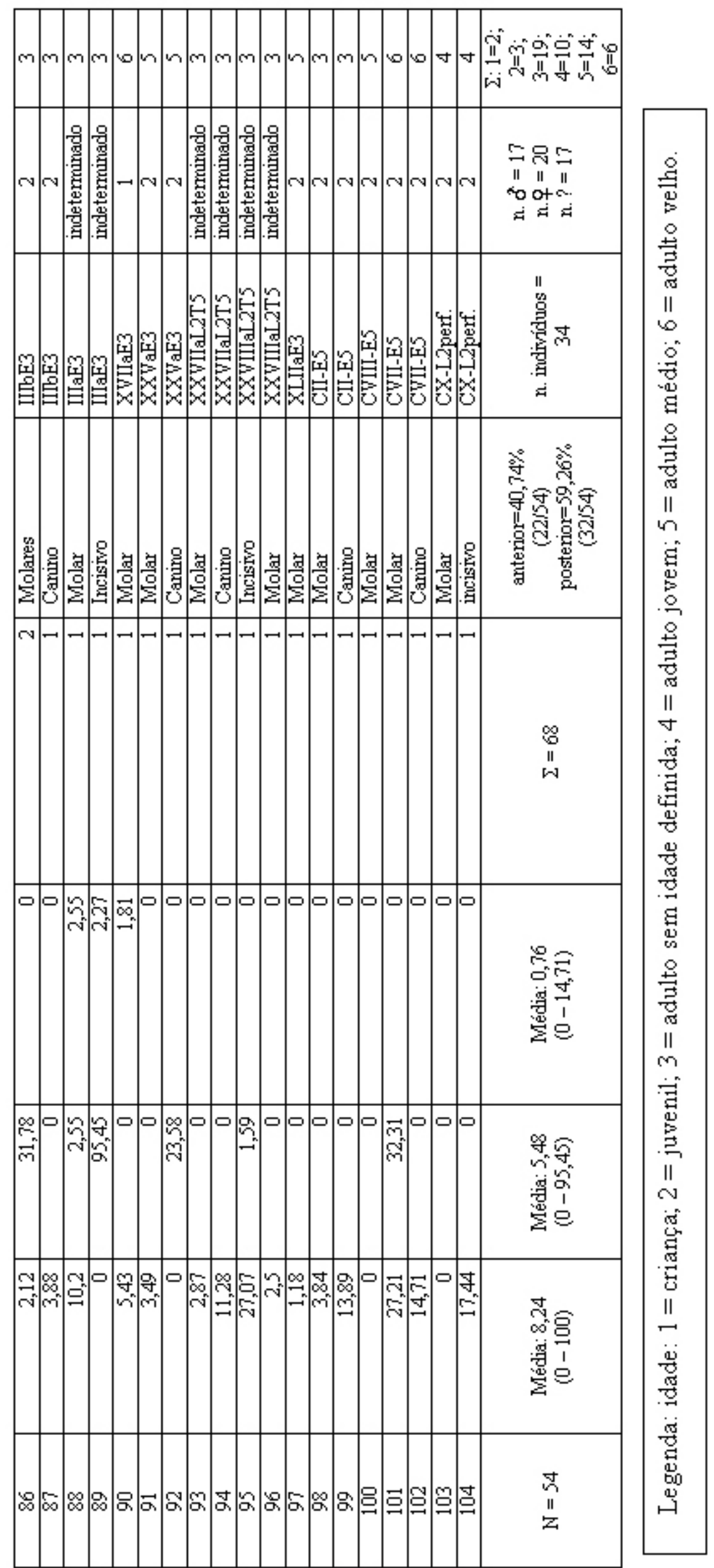




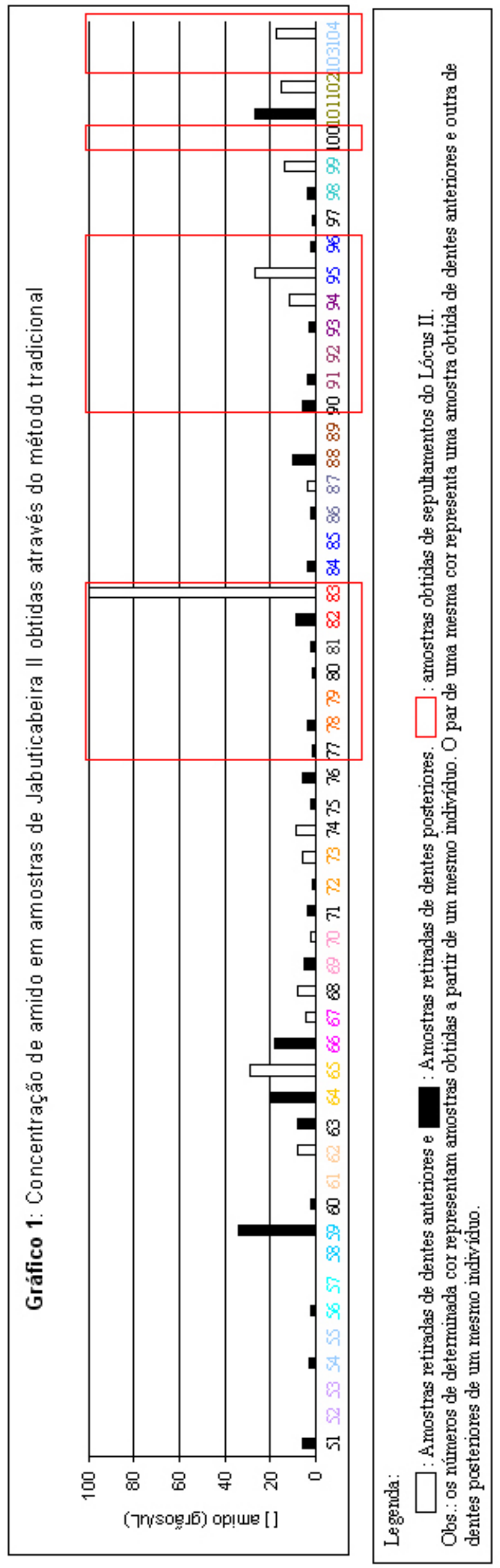



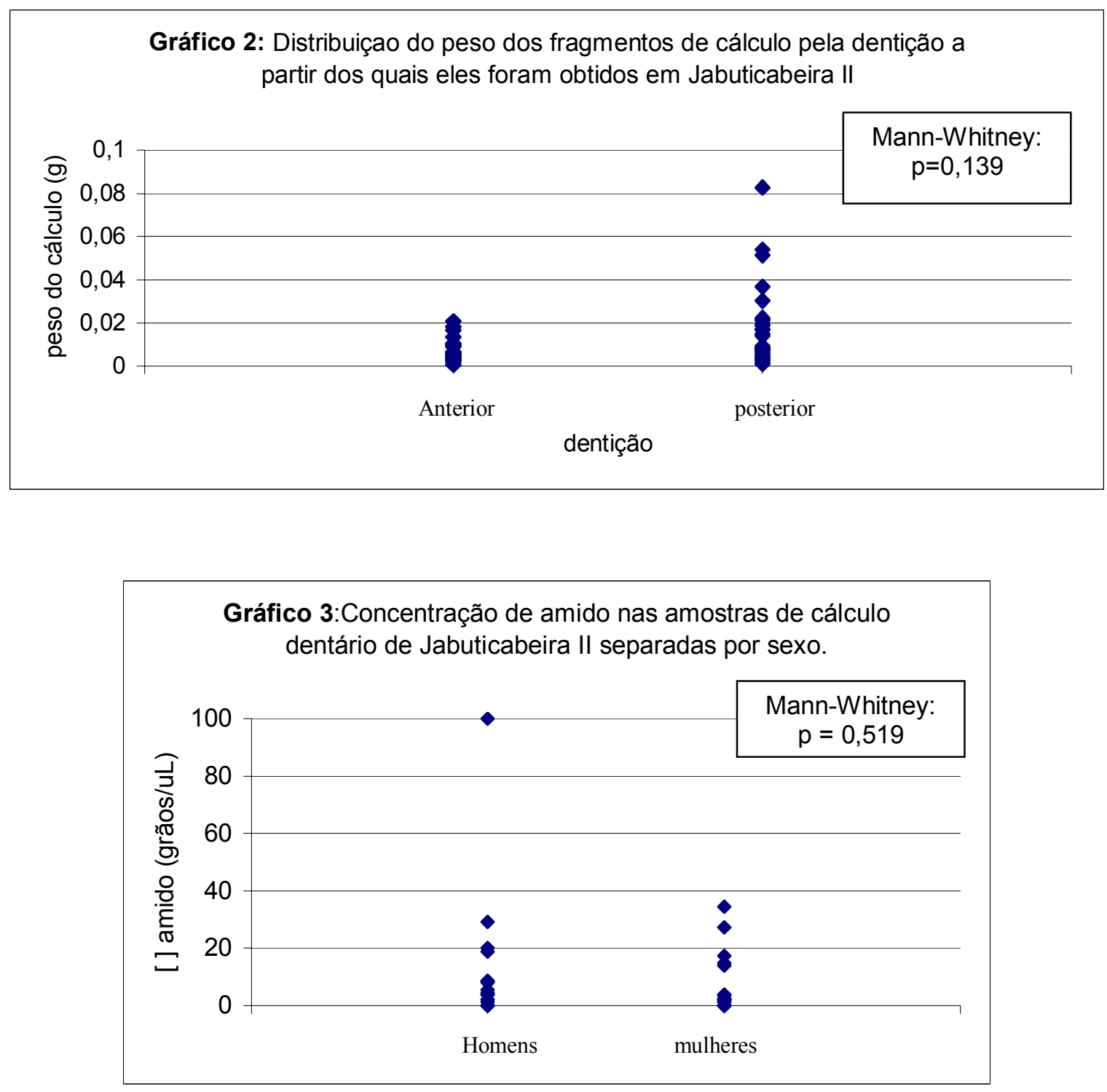

Gráfico 4: Distribuição do peso dos fragmentos de cálculo pelo sexo dos indivíduos analisados em Jabuticabeira II

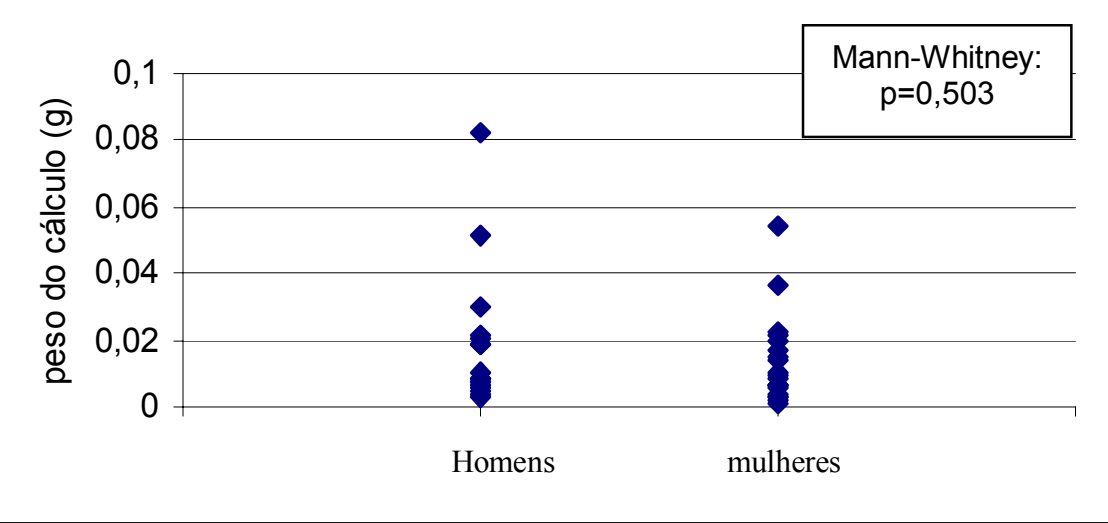




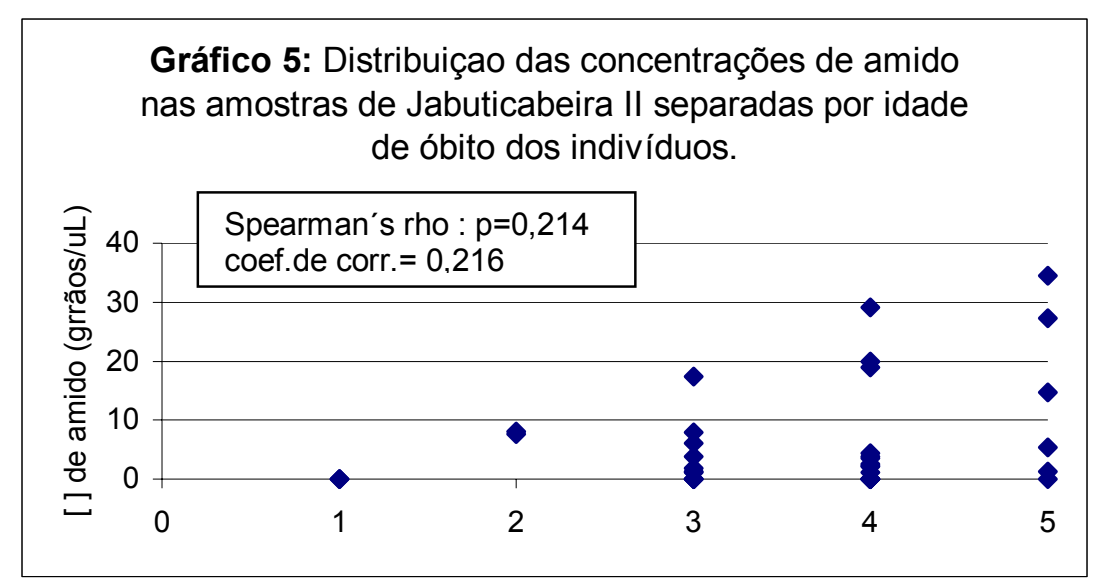

Legenda: $1=$ criança, $2=$ juvenil, $3=$ adulto jovem, $4=$ adulto médio, $5=$ adulto velho.

\begin{tabular}{|c|c|c|}
\hline \multirow{3}{*}{ Pares de variáveis } & & \\
\hline & \multicolumn{2}{|c|}{ resultado } \\
\hline & coeficiente de correlação & valor do $\mathrm{p}$ \\
\hline Concentração de amido x Idade & 0,216 & 0,214 \\
\hline Peso $x$ Idade & 0,440 & $0,008^{*}$ \\
\hline Peso x Concentração de amido & 0,309 & $0,024 *$ \\
\hline Concentração de amido x índice de cálculo & 0,131 & 0,484 \\
\hline Índice de cálculo $\mathrm{x}$ idade & 0,320 & 0,157 \\
\hline Indice de cálculo x peso & 0,575 & $0,001^{*}$ \\
\hline
\end{tabular}

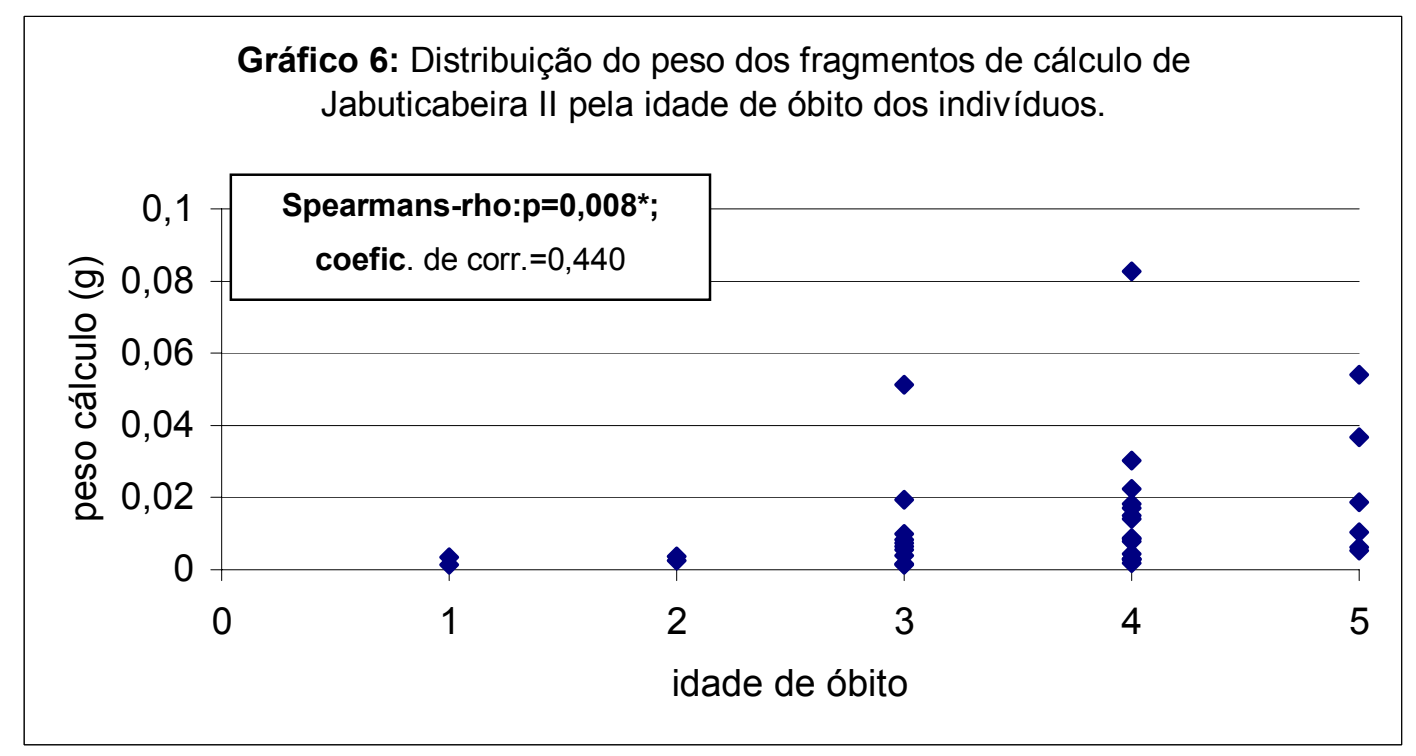

Legenda: $1=$ criança, $2=$ juvenil, $3=$ adulto jovem, $4=$ adulto médio, $5=$ adulto velho. 


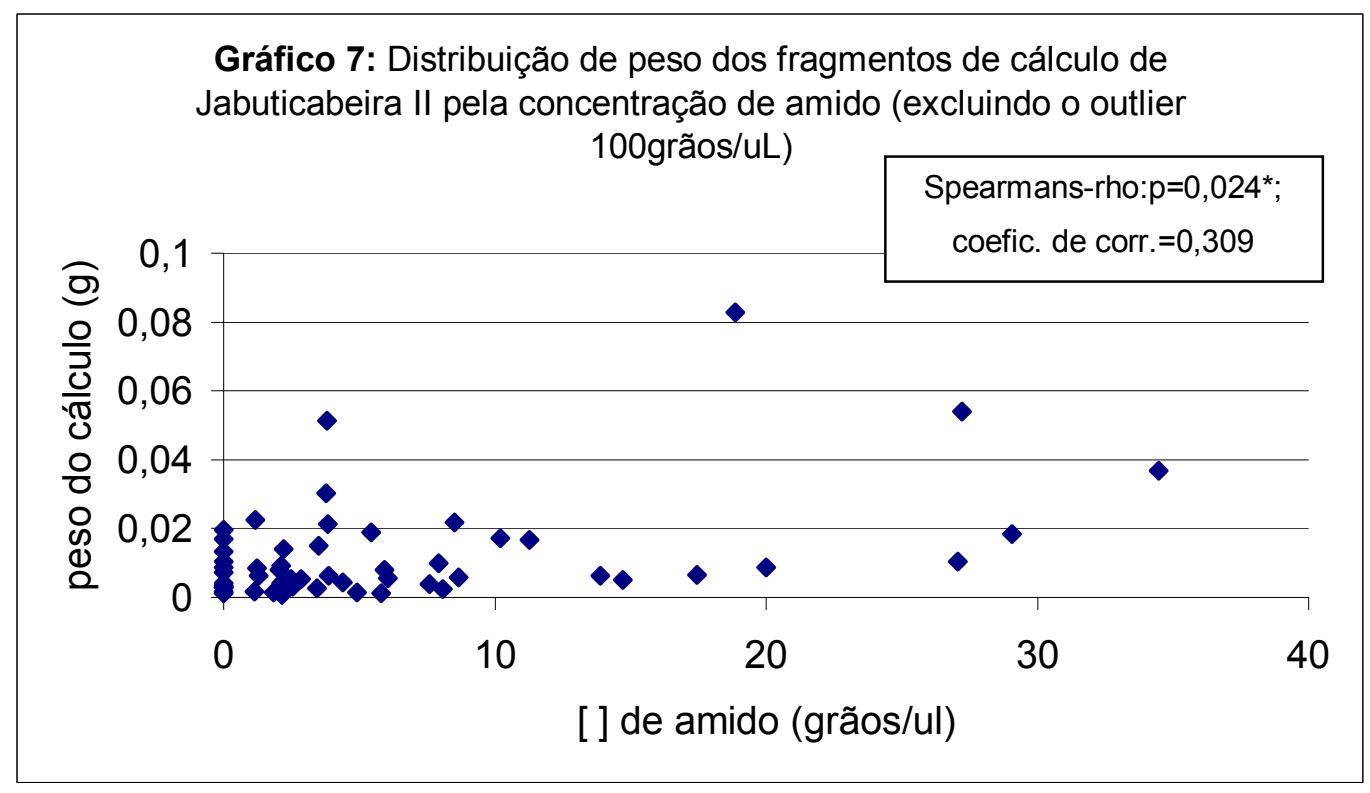

\begin{tabular}{|c|c|c|c|c|c|c|c|}
\hline amostra & idade & [ ] amido & $\begin{array}{c}\text { Peso do calculo coletado } \\
\text { (g) }\end{array}$ & amostra & idade & [ ] amido & \begin{tabular}{|c|} 
Peso do calculo coletado \\
$(\mathrm{g})$
\end{tabular} \\
\hline 51 & Indeterminado & 5,81 & 0,0013 & 78 & Ad. jovem & 3,82 & 0,0513 \\
\hline 54 & Ad. Médio & 2,55 & 0,0031 & 80 & Ad. Velho & 1,3 & 0,0063 \\
\hline 56 & Ad. Médio & 2,07 & 0,0079 & 81 & Indeterminado & 2,12 & 0,0093 \\
\hline 59 & Ad. Velho & 34,48 & 0,0368 & 82 & Indeterminado & 8,52 & 0,0217 \\
\hline 60 & Ad. jovem & 1,84 & 0,0014 & 83 & Indeterminado & 100 & 0,0209 \\
\hline 62 & Ad. jovem & 7,94 & 0,01 & 84 & Ad. Médio & 3,79 & 0,0303 \\
\hline 63 & Juvenil & 7,58 & 0,0038 & 86 & Indeterminado & 2,12 & 0,0042 \\
\hline 64 & Ad. Médio & 20 & 0,0086 & 87 & Indeterminado & 3,88 & 0,0064 \\
\hline 65 & Ad. Médio & 29,07 & 0,0183 & 88 & Indeterminado & 10,2 & 0,0173 \\
\hline 66 & Ad. Médio & 18,87 & 0,0827 & 90 & Ad. Velho & 5,43 & 0,0188 \\
\hline 67 & Ad. Médio & 4,39 & 0,0043 & 91 & Ad. Médio & 3,49 & 0,015 \\
\hline 68 & juvenil & 8,09 & 0,0025 & 93 & Indeterminado & 2,87 & 0,0054 \\
\hline 69 & Indeterminado & 4,93 & 0,0014 & 94 & Indeterminado & 11,28 & 0,0166 \\
\hline 70 & Indeterminado & 2,15 & 0,0007 & 95 & Indeterminado & 27,07 & 0,0103 \\
\hline 71 & Indeterminado & 3,45 & 0,0026 & 96 & Indeterminado & 2,5 & 0,0054 \\
\hline 72 & Ad. jovem & 1,13 & 0,0016 & 97 & Ad. Médio & 1,18 & 0,0224 \\
\hline 73 & Ad. jovem & 6,05 & 0,0056 & 98 & Indeterminado & 3,84 & 0,0212 \\
\hline 74 & Indeterminado & 8,66 & 0,0059 & 99 & Indeterminado & 13,89 & 0,0064 \\
\hline 75 & Ad. Médio & 2,21 & 0,0141 & 101 & Ad. Velho & 27,21 & 0,054 \\
\hline 76 & Indeterminado & 5,92 & 0,0079 & 102 & Ad. Velho & 14,71 & 0,0052 \\
\hline 77 & Ad. jovem & 1,24 & 0,0084 & 104 & Ad. jovem & 17,44 & 0,0065 \\
\hline
\end{tabular}




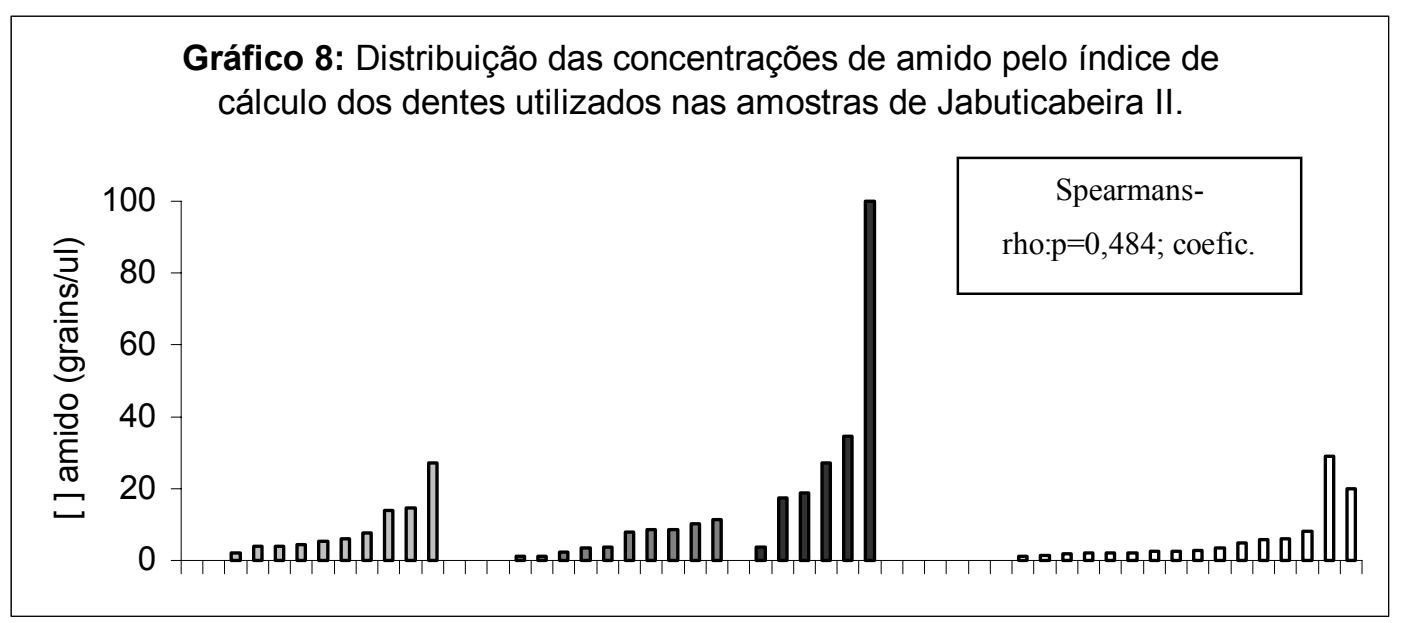

Legenda:

$\square$ :Cálculo leve (1) $\square$ Cálculo moderado (2) $\square$ :Cálculo grande(3) $\square$ :Marcas de cálculo(4)

Tabela 4: Amostras de cálculo dentário de Jabuticabeira II em que foram observados grãos de amido modificados.

\begin{tabular}{|c|c|c|}
\hline amostra & sepultamento & Número de grãos de amido modificados \\
\hline 59 & XIIaE1 & 4 \\
\hline 62 & XIIcE1 & 1 \\
\hline 65 & XVIIaE1 & 4 \\
\hline 66 & XVE1 & 4 \\
\hline 67 & XVE1 & 1 \\
\hline 69 & IT10E2 & 1 \\
\hline 70 & IT10E2 & 1 \\
\hline 73 & IbE2 & 1 \\
\hline 76 & IIbE3 & 1 \\
\hline 77 & XXXIVE3-4 & 1 \\
\hline 78 & XXXVIE3-4 & 1 \\
\hline 82 & XLIaE3-4 & 3 \\
\hline 83 & XLIaE3-4 & 9 \\
\hline 91 & XvaE3 & 2 \\
\hline 101 & CVIIE5 & 3 \\
\hline $\mathbf{N}=\mathbf{1 5}$ & $\mathrm{N}$. indivíduos $=12$ & $\mathbf{N}=\mathbf{3 7}$ \\
\hline
\end{tabular}




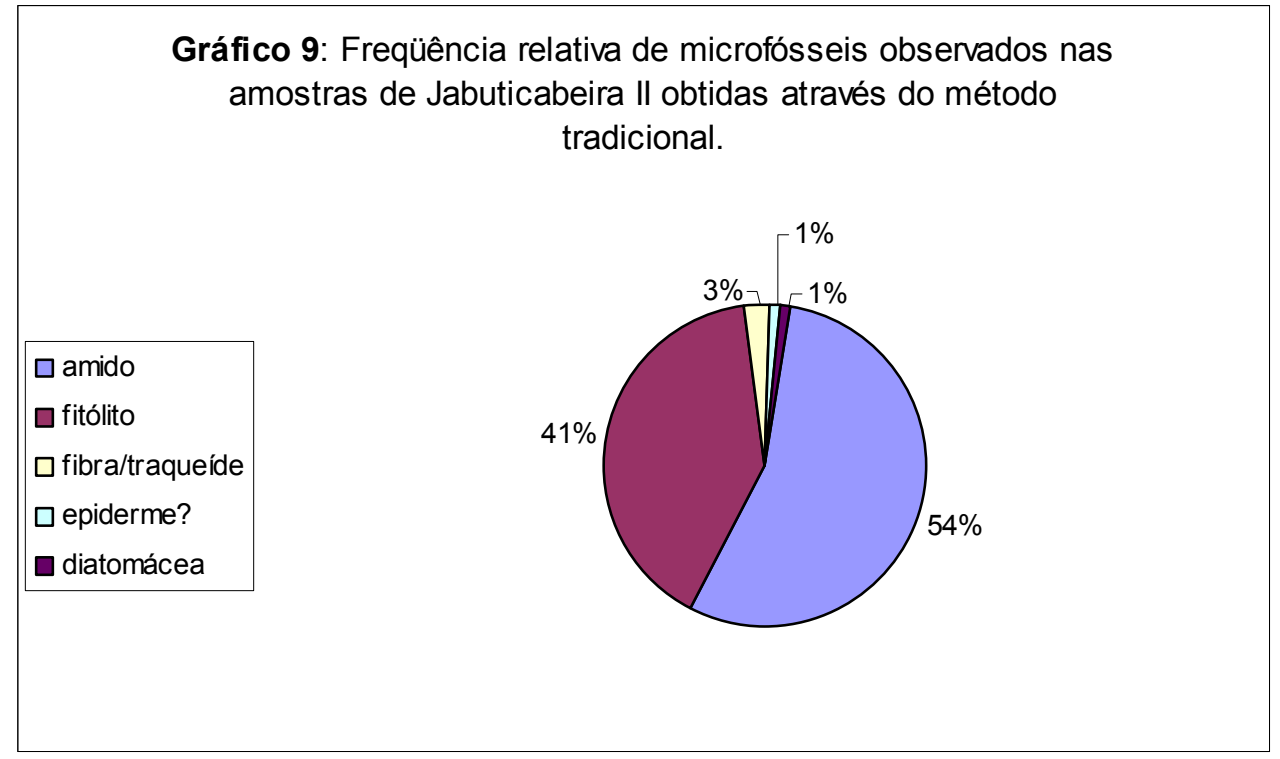




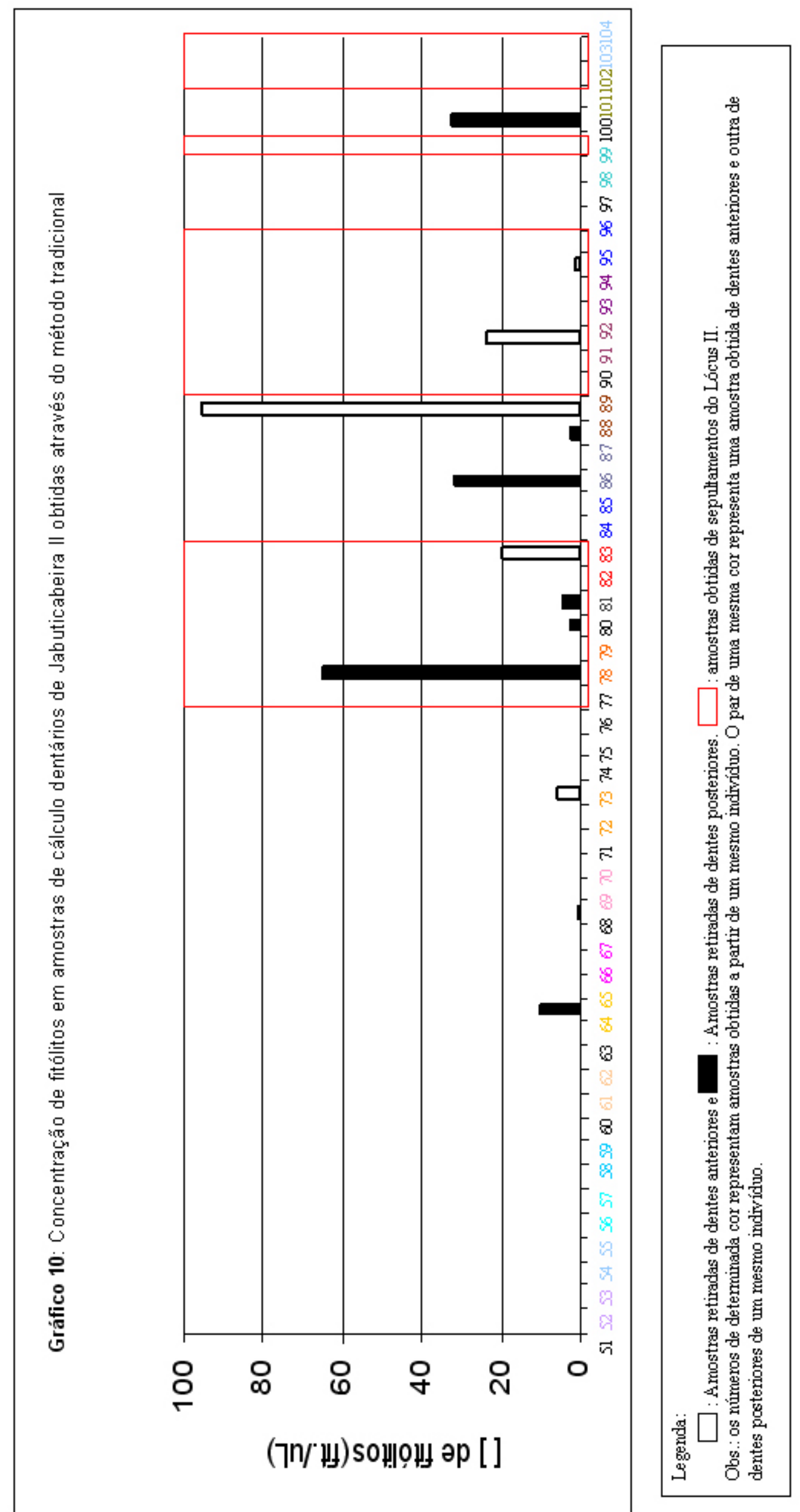



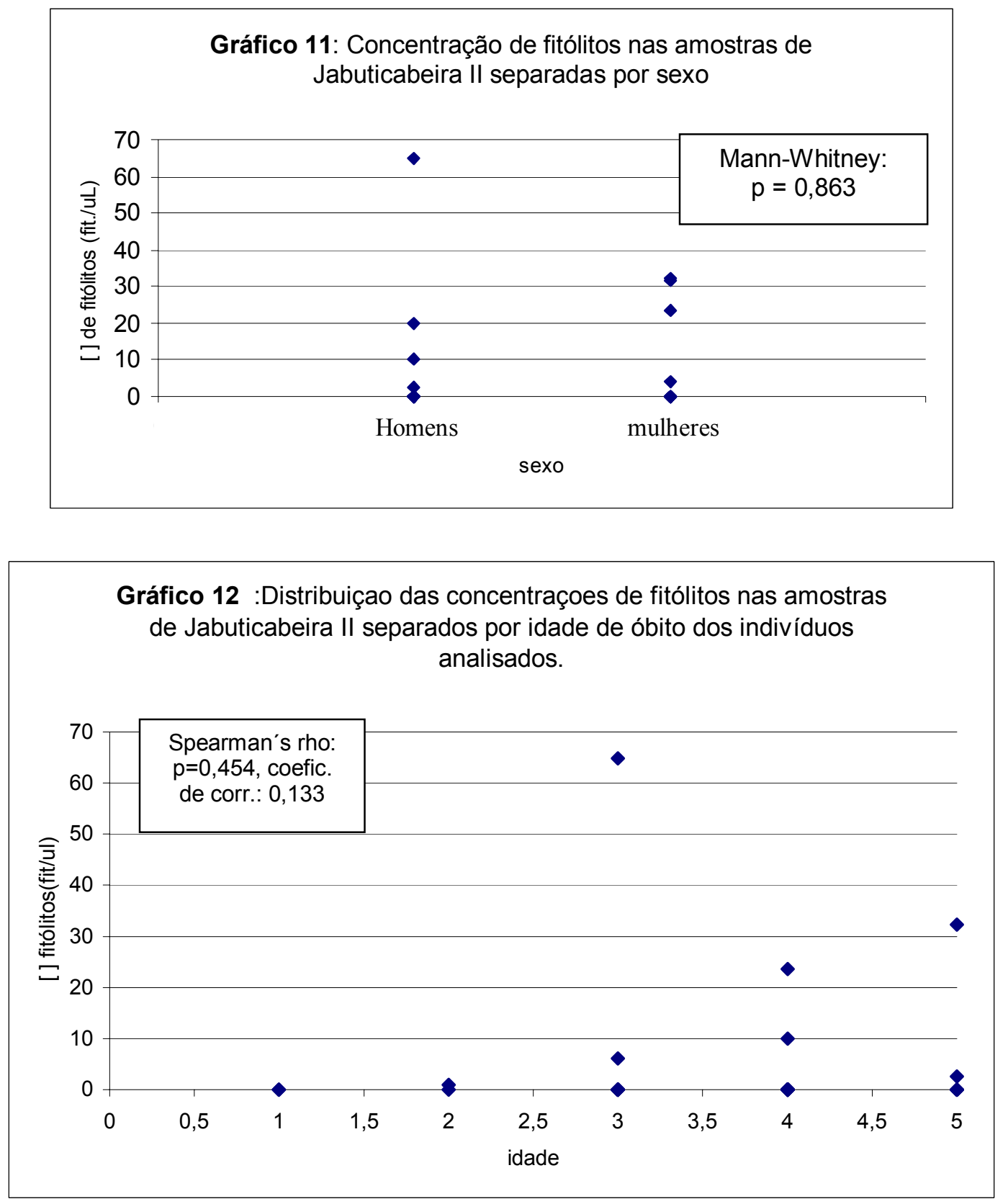

Legenda: $1=$ criança, $2=$ juvenil, $3=$ adulto jovem, 4= adulto médio, 5= adulto velho. 

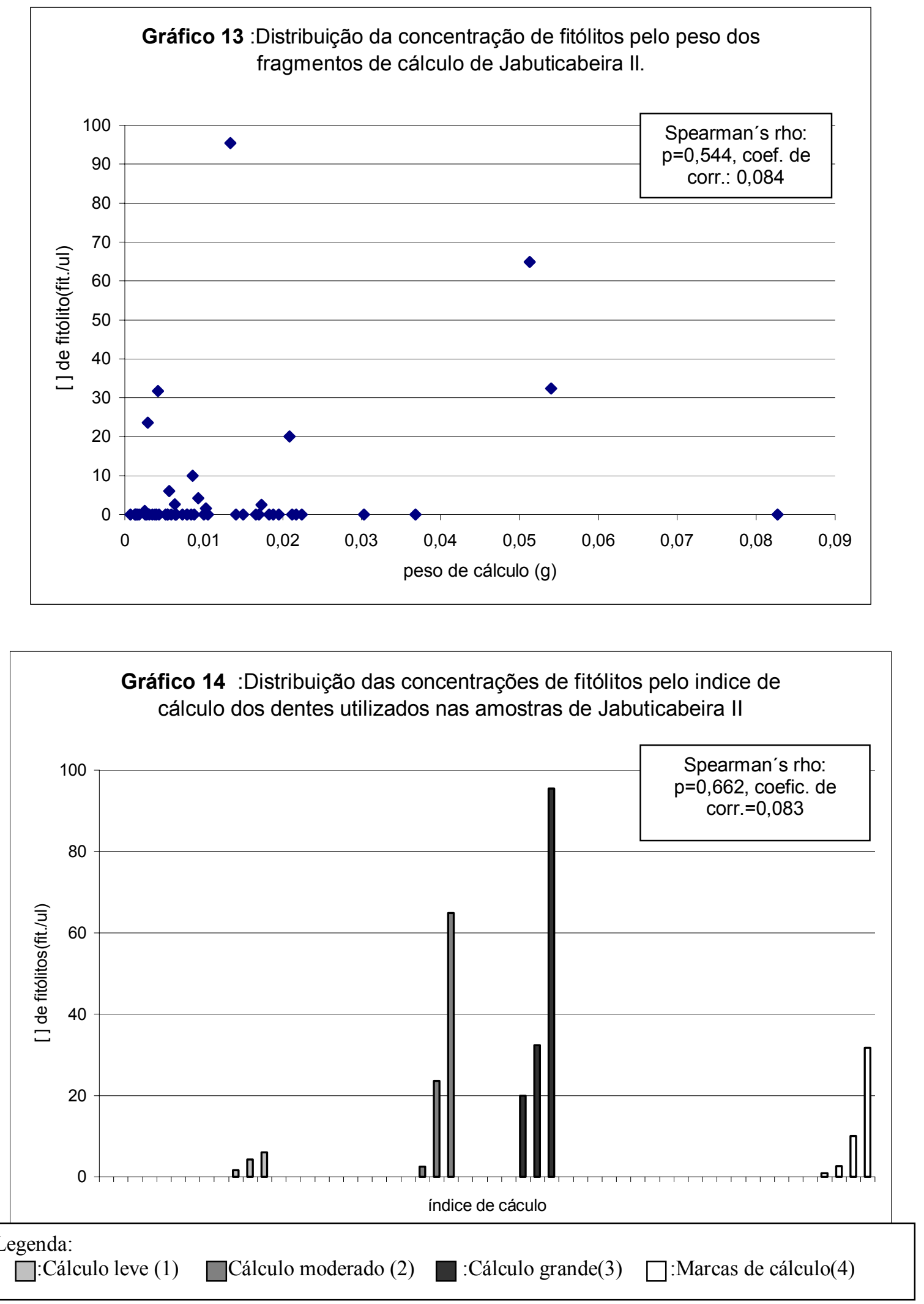


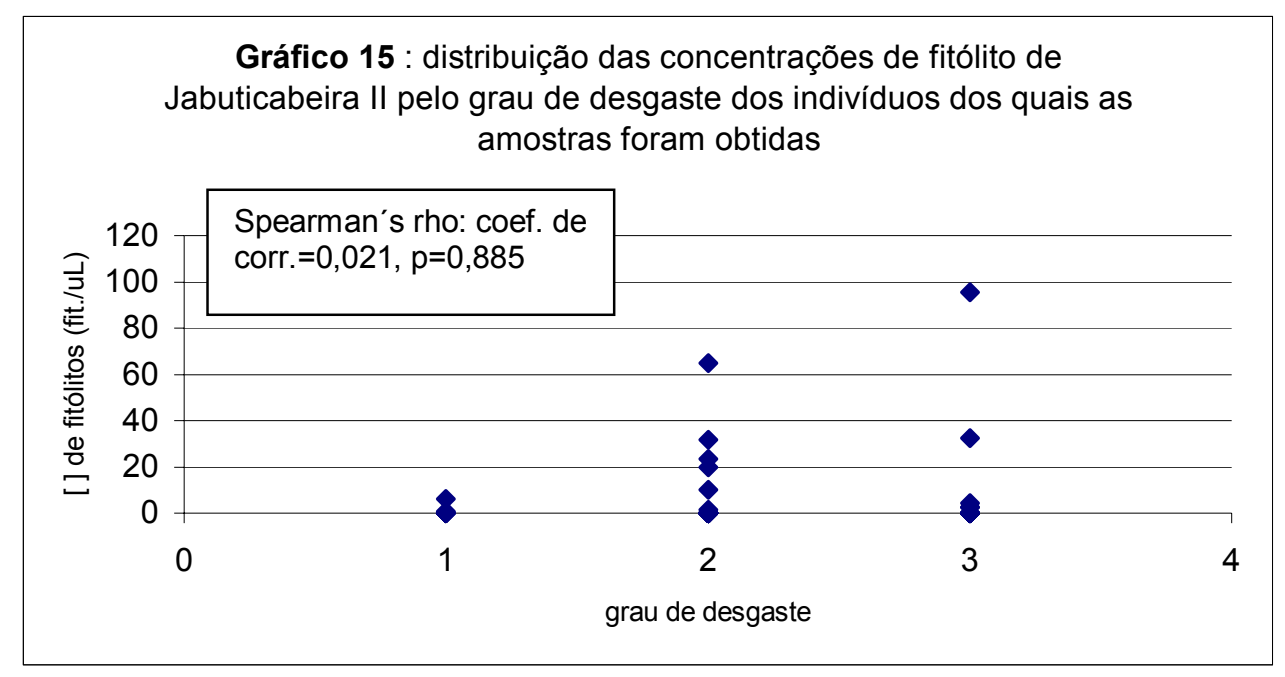

\begin{tabular}{|l|c|c|}
\hline \multicolumn{2}{|c|}{$\begin{array}{c}\text { Tabela 5: Resultados obtidos nos testes de correlação de Spearman's rho, realizados para as } \\
\text { variáveis: peso dos fragmentos de cálculo, idade de óbito e índice de cálculo e concentração de } \\
\text { fitólitos em Jabuticabeira II. }\end{array}$} \\
\hline \multicolumn{2}{|c|}{ Pares de variáveis } & \multicolumn{2}{c|}{ resultado } \\
\hline Concentração de fitólitos x Idade & coeficiente de correlação & valor do p \\
\hline Peso x Idade & 0,133 & 0,454 \\
\hline Peso x Concentração de fitólitos & 0,440 & $0,008^{*}$ \\
\hline Concentração de fitólitos x índice de cálculo & 0,084 & 0,544 \\
\hline Índice de cálculo x idade & 0,083 & 0,662 \\
\hline Índice de cálculo x peso & 0,320 & 0,157 \\
\hline
\end{tabular}




\begin{tabular}{|c|c|c|}
\hline & teste & resultados \\
\hline [] $x$ sexo & Mann-Whitney & $\begin{aligned} & \mathrm{P}=0,321 ; \\
& \text { sum of ranks: } \mathrm{male}=38,50 \text { and female }=39,50\end{aligned}$ \\
\hline [] $\mathrm{x}$ idade de óbito & Spearman's Rho & $\mathrm{p}=0,765 ;$ coeficiente de correlação $=0,109$ \\
\hline [ ] L2 x [ ] outros Lóci & Mann-Whitney & $\begin{array}{c}\mathrm{p}=0,489 ; \\
\text { sum of ranks: } L 2=396,50 \text { and outros loci }=1034,50\end{array}$ \\
\hline 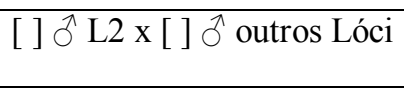 & Mann-Whitney & $\begin{array}{c}\mathrm{p}=0,568 ; \\
\text { sum of ranks: lócus2 }=37,50 \text { e outros loci }=98,50\end{array}$ \\
\hline [] ] + L2 x [] + outros Lóci & Mann-Whitney & $\begin{array}{c}\mathrm{p}=0,174 \\
\text { sum of ranks: lócus2 }=56,50 \text { and outros loci }=153,50\end{array}$ \\
\hline
\end{tabular}

\begin{tabular}{|l|c|c|}
\hline \multicolumn{2}{|c|}{ Tabela 7: Resultados obtidos nos testes estatísticos para as concentrações de fitólito das amostras de } \\
cálculo dental do Lócus 2 de Jabuticabeira II.
\end{tabular}




\section{2 - "Dental Wash"}

Nem todos os dentes de sambaquieiros apresentam fartos depósitos de cálculo dentário. Assim, houve a necessidade de se desenvolver um método alternativo de recuperação de microfósseis a partir de pequenas marcas de cálculo. A lavagem de micro-resíduos a partir de vasilhames de cerâmica constituiu a base para elaboração deste método alternativo (Bryant \& Morris 1986; Pearsall 2003 a,b).

Diferente do que se acreditou inicialmente, um tipo de técnica de lavagem dos dentes para recuperação de resíduos vegetais de cálculo dentário já havia sido descrito anteriormente por Middleton \& Rovner (1994). Entretanto, há algumas importantes diferenças entre o método utilizado aqui e o método desses pesquisadores. Enquanto aqueles autores aplicaram a lavagem em dentes de animais, aqui a lavagem foi aplicada em dentes humanos. Além disso, Middleton \& Rovner (1994) utilizaram uma concentração de $10 \%$ de ácido clorídrico para garantir a dissolução de depósitos grossos de cálculo de dentes de herbívoros, objetivando a recuperação de fitólitos, enquanto no presente trabalho foi utilizado o mesmo ácido em concentração de apenas $2 \%$, já que o objetivo era lavar depósitos finos de cálculo de dentes humanos, com a preocupação de não danificar o esmalte. Por fim, e mais importante, o objetivo principal do presente trabalho é quantificar os microfósseis aderidos ao cálculo dentário, e esse tipo de abordagem não havia sido realizada até o presente momento.

De início, foram realizadas as primeiras tentativas de desenvolvimento e adaptação do "dental wash" e, em um projeto piloto, aplicou-se o novo método em alguns dentes de dois sepultamentos de Jabuticabeira II, o 3B e o 12C. Esse método pareceu eficaz para a recuperação de micro restos vegetais inicialmente e foi celebrado como uma importante ferramenta capaz de contornar o problema de falta de informações a respeito, especialmente, da dieta vegetal em sítios onde não há macro-restos botânicos (Boyadjian et al, 2007a). Através desse novo método, foram obtidas altas concentrações de grãos de amido e baixas concentrações de fitólitos, além de um fragmento de diatomácea. Além disso, os resultados obtidos com a amostra controle indicaram que os microfósseis encontrados no experimento não eram oriundos de contaminação (Boyadjian et al, 2007a).

Por outro lado, notou-se que a lavagem com ácido clorídrico poderia causar danos ao material arqueológico, especialmente se o mesmo já se apresentasse em más condições de preservação. De fato conclui-se, que seria melhor utilizar o "dental wash" 
com cautela, enquanto os "efeitos colaterais" do método não fossem avaliados de forma sistemática e a sua eficácia não fosse realmente afirmada.

No entanto, para se comprovar a eficácia do método "dental wash" desenvolvido neste trabalho, se faziam necessários alguns testes, cujos resultados serão discutidos a seguir.

\subsection{1 - Testes do Dental Wash: Comparabilidade:}

Para que fosse possível realizar o teste de comparabilidade, conforme especificado em Material e Métodos, o "dental wash" foi aplicado nos mesmos dentes de indivíduos de Jabuticabeira II dos quais haviam sido obtidos, previamente, os fragmentos de cálculo para a análise tradicional. Foi possível aplicar o "dental wash" em quase todos os dentes utilizados para o método tradicional, pois, após a retirada mecânica do cálculo espesso como um todo, restam marcas finas de cálculo nos locais onde este estava mais fortemente aderido ao dente. As únicas exceções foram dentes que se encontravam: a) originalmente muito danificados e que, portanto, poderiam ser destruídos caso a lavagem fosse aplicada e b) dentes fortemente aderidos ao alvéolo de forma que não podiam ser mergulhados individualmente na solução de ácido clorídrico até a junção cementoesmalte.

Foram obtidas amostras de 30 indivíduos de Jabuticabeira II mediante a nova metodologia do "dental wash" (14 amostras provenientes de homens, 15 de mulheres e 15 de indivíduos com sexo indeterminado, num total de 44 amostras). Estas amostras possuem os mesmos números que as amostras correspondentes para o método tradicional, mas são marcadas com “ ' ", como pode ser visto na primeira coluna da Tabela 8.

Nessas amostras foram observados, ao todo: 58 grãos de amido (sendo que destes, 3 eram grãos de amido compostos, observados nas amostras 77, 78 e 88), 22 fitólitos e 14 fibras vegetais/traqueídes. Novamente, deve-se deixar claro aqui, que a coluna fibras/traqueídes se refere a estruturas vegetais outras que não grãos de amido ou fitólitos. Entretanto fibras e traqueídes são estruturas diferentes que,foram computadas como um mesmo grupo pois foram observados raramente. As concentrações de cada tipo de microfóssil observado nas amostras encontram-se na Tabela 8. Da mesma forma como ocorreu com as amostras obtidas através do método tradicional, foi encontrada uma estrutura não identificada (Figura $11^{*}$ ) e alguns fragmentos escuros (conforme definição 
de Piperno, 2006). Estes poderiam estar relacionados ao preparo de alimentos através da utilização de fogo (Wesolowski, 2007), o que justificaria a observação de muitos grãos de amido modificados. Por outro lado estes fragmentos escuros poderiam ser provenientes de restos de fogueiras rituais (Edwards et al, 2001), como discutido anteriormente (Tópico 4.1.1.5, sobre amido modificado)

Embora tenham sido observados diferentes micro-restos botânicos nas amostras provenientes do "dental wash", para a realização do teste de comparabilidade optou-se por utilizar apenas as concentrações de grãos de amido para as análises estatísticas. Isso porque, dentre todos os microfósseis encontrados, os grãos de amido eram aqueles que puderam ser diagnosticados com maior acuidade, além de serem as estruturas mais freqüentes.

\subsubsection{1 - Verificando a possibilidade de comparação:}

Há diferenças importantes entre os resultados obtidos através do método tradicional e o "dental wash" (Tabela 9 e Gráfico 16) entretanto, não se observa um padrão claro. Análises exploratórias foram realizadas entre ambos os métodos antes de se testar as diferenças entre as concentrações de cada tipo de amostra.

De início, acreditou-se que as diferenças entre os resultados obtidos através do método tradicional e o "dental wash" pudessem ter sido ocasionadas por diferenças nos números de esporos de licopódio observados nas amostras obtidas através dos dois métodos. Isso se justifica pelo do fato de que, durante o processamento das amostras tradicionais, foi adicionado somente um tablete de esporo de licopódio em cada microtubo de centrífuga, enquanto nas amostras de "dental wash" foram acrescentados 2 tabletes em cada tubo de centrífuga. Entretanto, enquanto o microtubo de centrífuga apresentava volume de $2 \mathrm{ml}$ de solução, o tubo utilizado para a lavagem, apresentava $12 \mathrm{ml}$. Tal fator poderia estar contribuindo para uma diferença de concentração entre as amostras, já que a fórmula de concentração leva em conta o número de esporos de licopódio, e a concentração final do microfóssil será proporcional ao número destes esporos. Os números obtidos de cada microfóssil, bem como de esporos de licopódio em cada amostra, para ambos os métodos se encontra na Tabela 10.

Portanto foi testado, inicialmente, o número de esporos de licopódio observados em ambos os tipos de amostras. Havia praticamente o dobro do número de esporos de licopódio observados nas amostras tradicionais em comparação com as obtidas através 
do "dental wash", sendo esta diferença estatisticamente significativa (Mann-Whitney: $p=0,002-$ Figura 16).

Porém, os testes estatísticos não indicaram correlação entre o número de esporos de licopódio e a concentração de amido para nenhum dos dois métodos (Spearman's rho: método tradicional: $p=0,541$; coeficiente de correlação=-0,086; método wash: $p=0,290$; coeficiente de correlação=-0,163, Gráficos 17 e 18, excluindo-se a amostra 83 discrepante). Quando testados os números de esporos de licopódio contra o número de grãos de amido observados nas amostras do "dental wash" (Gráfico 19) não é observada correlação estatisticamente significativa (Spearman's rho: $p=0,791$, coeficiente de correlação= 0,042). Estes resultados demonstram que, apesar de haver diferença quanto ao número de tabletes de licopódio adicionados durante a preparação das amostras utilizando o método tradicional e o "dental wash", isto não afeta o teste de comparabilidade dos métodos.

Por outro lado, detectou-se correlação positiva entre o número de esporos de licopódio e o número de grãos de amido das amostras do método tradicional (Spearman's rho: $p=0,027$, coeficiente de correlação=0,300 - Gráfico 20). Esta correlação pode ser decorrente do poder aglutinante dos esporos de licopódio (Reinhard et al, 2001).

Testou-se, também, se havia correlação entre o número de grãos de amido e as concentrações de amido obtidas nas amostras em cada um dos métodos (Gráficos 21 e 22). O resultado do teste estatístico indicou haver correlação positiva para ambos os métodos (Sperman's rho: método tradicional: $p=0,000$, coeficiente de correlação $=0,808$; método "wash": $p=0,000$, coeficiente de correlação=0,944). Novamente, ambos os testes foram realizados excluindo-se os "outliers" de cada um dos tipos de amostra.

Assim, com base nestes dados conclui-se que, enquanto o número de esporos de licopódio não interfere de forma significativa nos resultados, o número de grãos de amido observado nas amostras (obtidas através de ambos os métodos) interfere diretamente nas concentrações de grãos de amido (quanto maior o número de grãos, maior a concentração). De acordo com estes resultados, finalmente pode ser testada, com mais segurança, a diferença das concentrações de grãos de amido entre as amostras de ambos os métodos aplicados para cálculos dentários provenientes de Jabuticabeira II (Gráfico 16). Estes dados são apresentados e discutidos a seguir. 
4.2.1.2 - Comparação das concentraç̃es entre ambos os métodos:

Embora através do Gráfico 16 possa parecer que as concentrações de grãos de amido obtidas para cada par de amostras sejam muito diferentes, esta diferença não chega a ser estatisticamente significativa (teste de Wilcoxon: $p=0,242, z=-1,169$ ). Os métodos tradicional e "dental wash" são, portanto, comparáveis quanto a concentração de grãos de amido. Assim sendo, pode se prosseguir com uma comparação mais aprofundada dos métodos.

\subsubsection{1 - Comparações entre dentição anterior e posterior}

Da mesma forma como realizado para o método tradicional (Tópico 4.1.1.1), investigou-se as diferenças de concentrações de amido entre a dentição anterior e posterior para as amostras de "dental wash" de Jabuticabeira II. Entretanto, assim como para o método tradicional, as diferenças de concentração de amido entre a os dois tipos de dentição não atingem significância estatística (Mann-Whitney: $p=0,176$ ). Inclusive, quando são comparadas as concentrações de amido de dentes anteriores entre as amostras de ambos os métodos e de dentes posteriores, também entre os métodos, os testes estatísticos não demonstraram diferença significativa (Teste de Wilcoxon: dentição anterior entre os métodos: $p=0,158, z=-1,412$; dentição posterior entre os métodos: $\mathrm{p}=0,657, \mathrm{z}=-0,444)$.

Para o método tradicional, a explicação para estes resultados apóia-se no fato de que não há diferença significativa de peso de cálculo entre amostras de dentes anteriores e posteriores. Para o "dental wash", embora não seja possível quantificar o peso dos fragmentos do cálculo remanescente nos dentes, pode ser constatado, visualmente, que há, aproximadamente, a mesma quantidade de cálculo restando nos dentes após a retirada dos fragmentos de cálculo para o método tradicional, não havendo grandes diferenças entre os dentes anteriores e posteriores. Isto resultaria na semelhança das concentrações de amido entre dentes posteriores e anteriores, também detectável através do "dental wash". 


\subsubsection{2 - Sexo e idade}

Tanto para as amostras obtidas através do método tradicional de obtenção de cálculo (vide Tópico 4.1.1.2 - Comparação entre sexos), quanto para as amostras do "dental wash", não se detectou diferença das concentrações de amido entre os sexos (Mann-Whitney: $p=0,385$ - Gráfico 23), sugerindo, mais uma vez, não haver distinção na dieta entre os sexos em Jabuticabeira II.

Tampouco foi demonstrada correlação entre as concentrações de amido e as idades de óbito dos indivíduos quanto ao "dental wash" (Gráfico 24, Spearman's rho: $p=0,719$, coeficiente de correlação=0,074), assim como ocorreu com as amostras obtidas através do método tradicional (vide Tópico 4.1.1.3). Este resultado pode estar relacionado à quantidade de cálculo restante nos dentes após a retirada dos fragmentos para o processamento tradicional. Após o destacamento dos fragmentos, sobram apenas finas marcas de cálculo em todos os dentes utilizados para a obtenção da amostra, independentemente da idade do indivíduo do qual estes dentes provêm. Então, possivelmente não há diferença entre indivíduos de diferentes idades quanto ao montante dos depósitos de cálculo restantes nos dentes, o que faria com que as concentrações de amido não variassem conforme o aumento de idade.

Em suma, os resultados de todos os testes realizados confirmam a comparabilidade do método tradicional de obtenção de microfósseis de cálculo dentário com o método "dental wash", demonstrando haver eficácia do método alternativo. Assim, o "dental wash" pode se considerado tão eficiente quanto o método tradicional, no que tange a concentração e distribuição de microfósseis. Portanto, este método pode ser utilizado em dentições que apresentam apenas marcas de cálculo, quando o intuito é a recuperação de microfósseis para reconstrução de paleodieta. Entretanto, faz-se necessário demonstrar, ainda, até que ponto o método pode ser prejudicial ao material arqueológico.

\subsection{2 -Testes do Dental Wash: Efeitos sobre o Microdesgaste (MEV):}

Durante o projeto piloto (Boyadjian et al, 2007a) e a preparação das amostras para execução do teste de comparabilidade entre os método tradicional e o "dental wash", notou-se que os dentes apresentavam uma leve alteração na coloração e, especialmente, no brilho após a lavagem com ácido clorídrico. Aventou-se a possibilidade do "dental wash" causar danos ao material arqueológico, especialmente se o mesmo já 
apresentasse más condições de preservação. No intuito de avaliar o grau de destruição causado pelo "dental wash" alguns dentes foram submetidos a varreduras sistemáticas sob o Microscópio eletrônico de varredura (MEV) antes e após a lavagem com ácido clorídrico (vide Tópico 3.6.1 de Material e Métodos).

Através da comparação das imagens obtidas antes e após a lavagem dos dentes, observou-se que o "dental wash" a) elimina camadas de sedimento e matriz aderidas ao esmalte, evidenciando sulcos e depressões antes encobertos (Figura 17); b) elimina camadas superficiais de esmalte da coroa do dente, evidenciando as microestruturas do esmalte (camada prismática) e a da dentina (canalículos) (Figura 17), c) aumenta levemente a espessura de fissuras (Figura 17), principalmente em dentes já friáveis, d) suaviza estriações e depressões necessárias para avaliações de microdesgaste (Figura18) (Boyadjian et al, 2007b).

Dessa forma, pelas evidências obtidas até o presente momento, o "dental wash" se mostrou eficaz na recuperação de micro-restos vegetais a partir de exíguas marcas de cálculo. Contudo, deve haver muita cautela na escolha do material no qual será utilizado esse método, visto que ele é prejudicial, principalmente, para as análises de microdesgaste dentário.

\subsection{3-Resumo:}

Em suma, com relação aos testes realizados para a verificação da eficácia e do efeito do método de "dental wash", pode-se afirmar que:

Assim como nas amostras de Jabuticabeira II obtidas através do método tradicional de processamento de cálculo dentário, foram obtidos grãos de amido, fitólitos, fibras/traqueídes, fragmentos escuros e, inclusive, grãos de amido modificados nas amostras do mesmo sítio obtidas através de "dental wash", sugerindo, de início, que os resultados pudessem ser comparáveis para estes dois métodos.

As análises exploratórias relacionando número de esporos de licopódio, número de grãos de amido e concentrações de grãos de amido demonstraram que havia a possibilidade de se realizar testes estatísticos de comparação mais específicos.

Não foi demonstrada diferença significativa entre as concentrações de amido das amostras obtidas através de "dental wash" e do método 
tradicional, o que indica que ambos os métodos produzem resultados comparáveis.

- Testes de comparação das concentrações de amido obtidas para amostras da dentição anterior com as da dentição posterior, e de comparação entre os sexos, demonstraram, assim como ocorreu para as amostras obtidas através da técnica tradicional, que também não há diferença significativa entre estas variáveis quando obtidas através do "dental wash". Isto sugere, mais uma vez, a comparabilidade dos resultados obtidos através dos dois métodos.

Embora o "dental wash" tenha se mostrado eficiente para a recuperação de microfósseis dentais, e os resultados obtidos através dele tenham se mostrado comparáveis com aqueles obtidos a partir dos mesmos dentes através da técnica tradicional, as análises das imagens captadas com o MEV indicam que esta técnica pode provocar danos à superfície dos dentes, prejudicando, especialmente, análises de microdesgaste. 


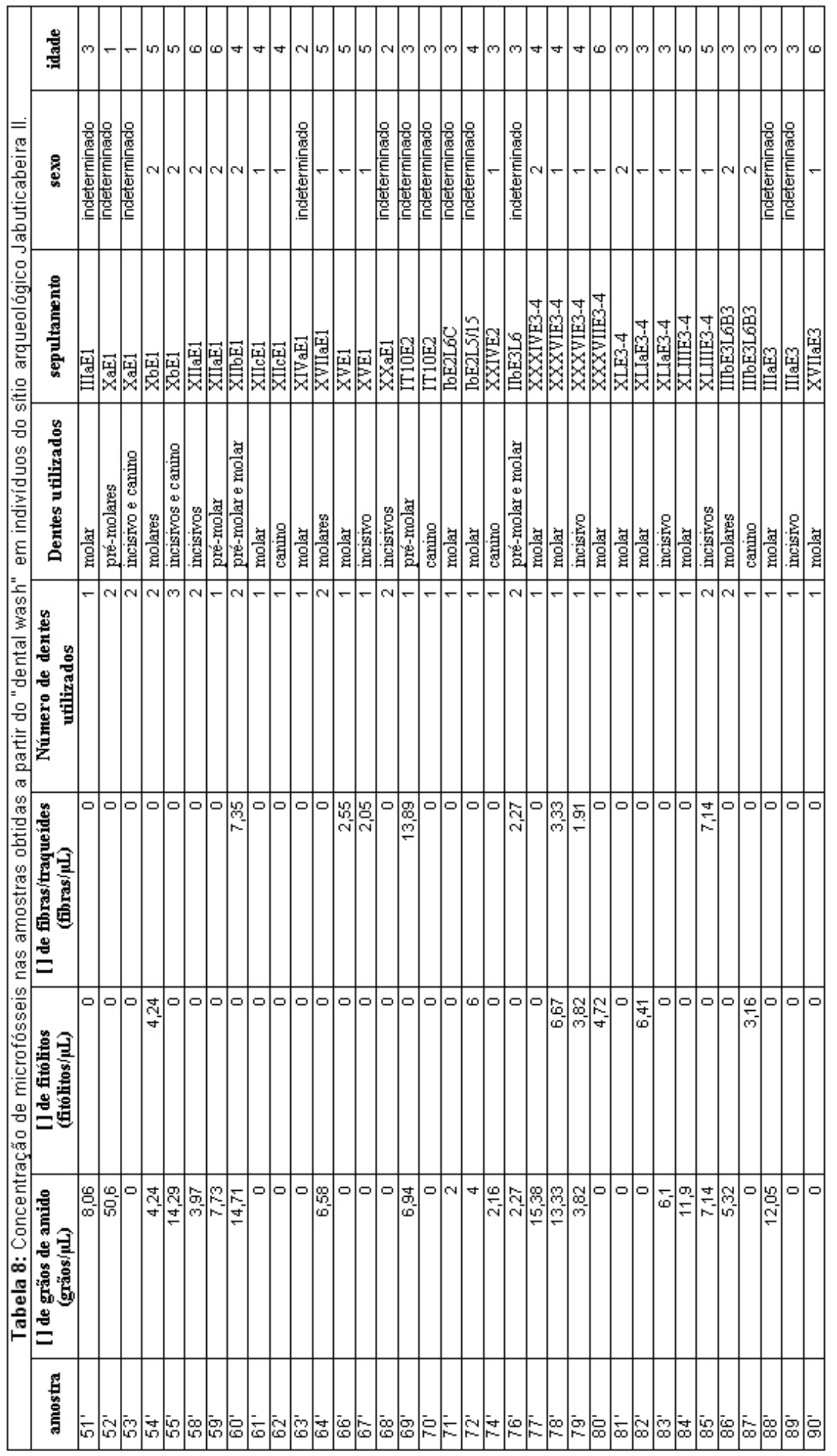




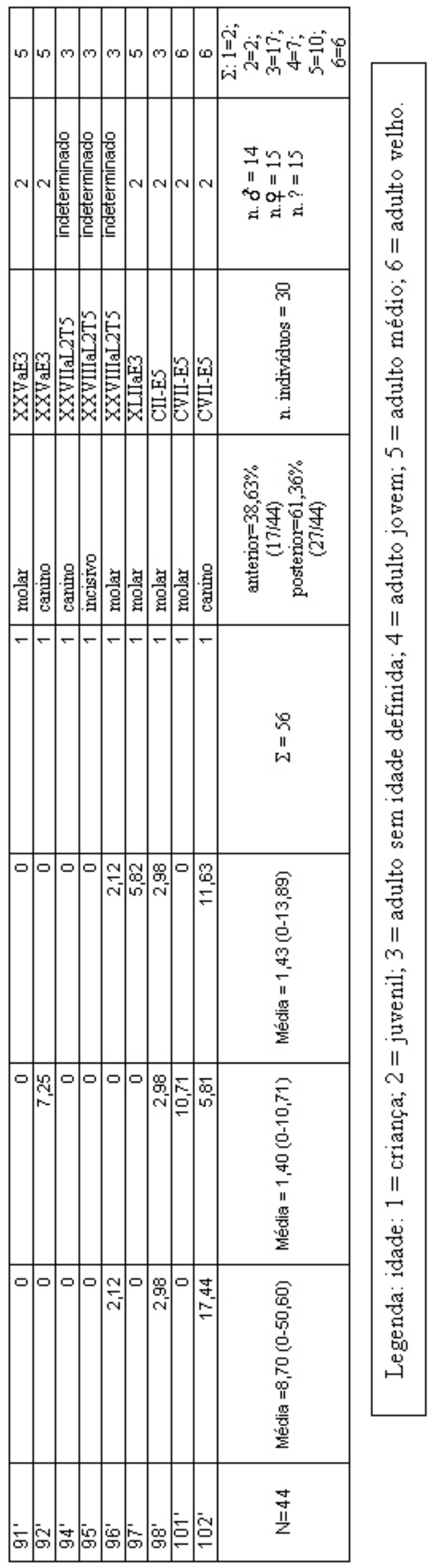




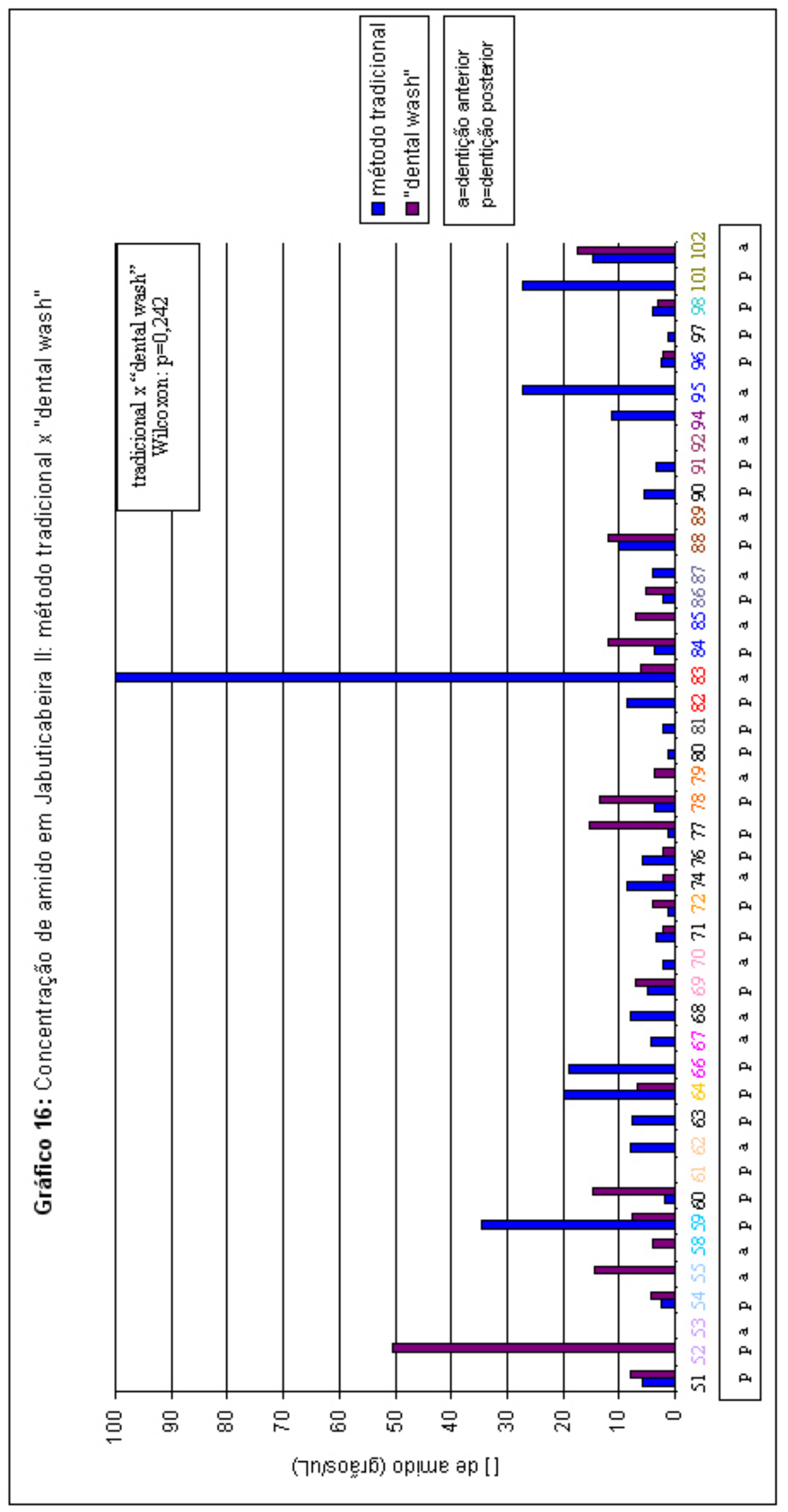




\begin{tabular}{|c|c|c|c|c|c|c|}
\hline \multirow[b]{2}{*}{ amostras } & \multicolumn{2}{|c|}{$\begin{array}{l}\text { [ ] de grãos de amido } \\
\text { (grãos/ } / \mu \mathrm{L})\end{array}$} & \multicolumn{2}{|c|}{ [ ] de fitólitos (fitólitos $/ \mu \mathrm{L}$ ) } & \multicolumn{2}{|c|}{ [ ] de fibras (fibras $/ \mu L)$} \\
\hline & Tradicional & "Dental wash" & tradicional & "Dental wash" & tradicional & "Dental wash" \\
\hline $51 / 51^{\prime}$ & 5,81 & 8,06 & 0 & 0 & 0 & 0 \\
\hline $52 / 52^{\prime}$ & 0 & 50,6 & 0 & 0 & 0 & 0 \\
\hline $53 / 53^{\prime}$ & 0 & 0 & 0 & 0 & 0 & 0 \\
\hline $54 / 54^{\prime}$ & 2,55 & 4,24 & 0 & 4,24 & 0 & 0 \\
\hline $55 / 55^{\prime}$ & 0 & 14,29 & 0 & 0 & 0 & 0 \\
\hline $58 / 58^{\prime}$ & 0 & 3,97 & 0 & 0 & 0 & 0 \\
\hline $59 / 59^{\prime}$ & 34,48 & 7,73 & 0 & 0 & 0 & 0 \\
\hline $60 / 60^{\prime}$ & 1,84 & 14,71 & 0 & 0 & 0 & 7,35 \\
\hline $61 / 61^{\prime}$ & 0 & 0 & 0 & 0 & 0 & 0 \\
\hline $62 / 62^{\prime}$ & 7,94 & 0 & 0 & 0 & 3,97 & 0 \\
\hline $63 / 63^{\prime}$ & 7,58 & 0 & 0 & 0 & 0 & 0 \\
\hline $64 / 64^{\prime}$ & 20 & 6,58 & 10 & 0 & 0 & 0 \\
\hline $66 / 66^{\prime}$ & 18,87 & 0 & 0 & 0 & 4,72 & 2,55 \\
\hline $67 / 67^{\prime}$ & 4,39 & 0 & 0 & 0 & 0 & 2,05 \\
\hline $68 / 68^{\prime}$ & 8,09 & 0 & 0,9 & 0 & 0 & $\frac{2,0}{0}$ \\
\hline $69 / 69^{\prime}$ & 4,93 & 6,94 & 0 & 0 & 0 & 13,89 \\
\hline $70 / 70^{\prime}$ & 2,15 & 0 & 0 & 0 & 0 & 0 \\
\hline $71 / 71^{\prime}$ & 3,45 & 2 & 0 & 0 & 0 & 0 \\
\hline $72 / 72^{\prime}$ & 1,13 & 4 & 0 & 6 & 0 & 0 \\
\hline $74 / 74^{\prime}$ & 8,66 & 2,16 & 0 & 0 & 0 & 0 \\
\hline $76 / 76^{\prime}$ & 5,92 & 2,27 & 0 & 0 & 0 & 2,27 \\
\hline $77 / 77^{\prime}$ & 1,24 & 15,38 & 0 & 0 & 0 & 0 \\
\hline $78 / 78^{\prime}$ & 3,82 & 13,33 & \begin{tabular}{|c|}
64,88 \\
\end{tabular} & 6,67 & 1,91 & 3,33 \\
\hline $79 / 79^{\prime}$ & 0 & 3,82 & 0 & 3,82 & 0 & 1.91 \\
\hline $80 / 80^{\prime}$ & 1,3 & 0 & 2,6 & 4,72 & 0 & 0 \\
\hline $81 / 81^{\prime}$ & 2,12 & 0 & 4,24 & 0 & 0 & 0 \\
\hline $82 / 82^{\prime}$ & 8,52 & 0 & $\begin{array}{r}0 \\
\end{array}$ & 6,41 & 0 & 0 \\
\hline $83 / 83^{\prime}$ & 100 & 6,1 & 20 & 0 & 0 & 0 \\
\hline $84 / 84^{\prime}$ & 3,79 & 11,9 & 0 & 0 & 3,79 & 0 \\
\hline $85 / 85^{\prime}$ & 0 & 7,14 & 0 & 0 & 5,43 & 77,14 \\
\hline $86 / 86^{\prime}$ & 2,12 & 5,32 & 31,78 & 0 & 0 & 0 \\
\hline $87 / 87^{\prime}$ & 3,88 & 0 & 0 & 3,16 & 0 & 0 \\
\hline $88 / 88^{\prime}$ & 10,2 & 12,05 & 2,55 & 0 & 2,55 & 0 \\
\hline $89 / 89^{\prime}$ & 0 & 0 & 95,45 & 0 & 2,27 & 0 \\
\hline $90 / 90^{\prime}$ & 5,43 & 0 & 0 & 0 & 1,81 & 0 \\
\hline $91 / 91^{\prime}$ & 3,49 & 0 & 0 & 0 & 0 & 0 \\
\hline 92/92' & 0 & 0 & \begin{tabular}{|l|}
23,58 \\
\end{tabular} & 7,25 & 0 & 0 \\
\hline 94/94' & 11,28 & 0 & 0 & 0 & 0 & 0 \\
\hline $95 / 95^{\prime}$ & 27,07 & 0 & 1,59 & 0 & 0 & 0 \\
\hline $96 / 96^{\prime}$ & 2,5 & 2,12 & 0 & 0 & 0 & 2,12 \\
\hline $97 / 97^{\prime}$ & 1,18 & 0 & 0 & 0 & 0 & 5,82 \\
\hline 98/98' & 3,84 & 2,98 & 0 & 2,98 & 0 & 2,98 \\
\hline 101/101' & 27,21 & 0 & 32,31 & 10,71 & 0 & 0 \\
\hline 102/102' & 14,71 & 17,44 & 0 & 5,81 & 0 & 11,63 \\
\hline
\end{tabular}




\begin{tabular}{|c|c|c|c|c|c|c|c|c|}
\hline \multirow[b]{2}{*}{ amostras } & \multicolumn{2}{|c|}{$\begin{array}{l}\text { n. de esporos de } \\
\text { licopódio }\end{array}$} & \multicolumn{2}{|c|}{ n. de grãos de amido } & \multicolumn{2}{|c|}{ n. de fitólitos } & \multicolumn{2}{|c|}{ n. de fibras } \\
\hline & Tradicional & $\begin{array}{l}\text { "Dental } \\
\text { wash" }\end{array}$ & Tradicional & $\begin{array}{l}\text { "Dental } \\
\text { wash" }\end{array}$ & Tradicional & $\begin{array}{l}\text { "Dental } \\
\text { wash" }\end{array}$ & tradicional & $\begin{array}{l}\text { "Dental } \\
\text { wash" }\end{array}$ \\
\hline $51 / 51^{\prime}$ & 43 & 31 & 1 & 1 & 0 & 0 & 0 & 0 \\
\hline $52 / 52^{\prime}$ & 50 & 84 & 0 & 17 & 0 & 0 & 0 & 0 \\
\hline $53 / 53^{\prime}$ & 26 & 36 & 0 & 0 & 0 & 0 & 0 & 0 \\
\hline $54 / 54^{\prime}$ & 98 & 59 & 3 & 1 & 0 & 1 & 0 & 0 \\
\hline $55 / 55^{\prime}$ & 20 & 35 & 0 & 2 & 0 & 0 & 0 & 0 \\
\hline $58 / 58^{\prime}$ & 52 & 63 & 0 & 1 & 0 & 0 & 0 & 0 \\
\hline $59 / 59^{\prime}$ & 29 & 97 & 4 & 3 & 0 & 0 & 0 & 0 \\
\hline $60 / 60^{\prime}$ & 136 & 34 & 1 & 2 & 0 & 0 & 0 & 1 \\
\hline $61 / 61^{\prime}$ & 56 & 56 & 0 & 0 & 0 & 0 & 0 & 0 \\
\hline $62 / 62^{\prime}$ & 63 & 49 & 2 & 0 & 0 & 0 & 1 & 0 \\
\hline $63 / 63^{\prime}$ & 33 & 100 & 1 & 0 & 0 & 0 & 0 & 0 \\
\hline $64 / 64^{\prime}$ & 50 & 76 & 4 & 2 & 2 & 0 & 0 & 0 \\
\hline $66 / 66^{\prime}$ & 53 & 98 & 4 & 0 & 0 & 0 & 1 & 1 \\
\hline $67 / 67^{\prime}$ & 57 & 122 & 1 & 0 & 0 & 0 & 0 & 2 \\
\hline $68 / 68^{\prime}$ & 278 & 38 & 9 & 0 & 1 & 0 & 0 & 0 \\
\hline $69 / 69^{\prime}$ & 152 & 36 & 3 & 1 & 0 & 0 & 0 & 2 \\
\hline 70/70' & 464 & 43 & 4 & 0 & 0 & 0 & 0 & 0 \\
\hline $71 / 71^{\prime}$ & 362 & 125 & 5 & 1 & 0 & 0 & 0 & 0 \\
\hline $72 / 72^{\prime}$ & 222 & 125 & 1 & 2 & 0 & 3 & 0 & 0 \\
\hline $74 / 74^{\prime}$ & 202 & 116 & 7 & 1 & 0 & 0 & 0 & 0 \\
\hline $76 / 76^{\prime}$ & 169 & 110 & 4 & 1 & 0 & 0 & 0 & 1 \\
\hline $77 / 77^{\prime}$ & 202 & 65 & 1 & 4 & 0 & 0 & 0 & 0 \\
\hline 78/78' & 131 & 75 & 2 & 4 & 33 & 2 & 1 & 1 \\
\hline 79/79' & 212 & 131 & 0 & 2 & 0 & 2 & 0 & 1 \\
\hline $80 / 80^{\prime}$ & 192 & 53 & 1 & 0 & 2 & 1 & 0 & 0 \\
\hline $81 / 81^{\prime}$ & 118 & 75 & 1 & 0 & 2 & 0 & 0 & 0 \\
\hline $82 / 82^{\prime}$ & 88 & 117 & 3 & 0 & 0 & 3 & 0 & 0 \\
\hline $83 / 83^{\prime}$ & 25 & 41 & 10 & 1 & 2 & 0 & 0 & 0 \\
\hline $84 / 84^{\prime}$ & 66 & 21 & 16 & 1 & 0 & 0 & 1 & 0 \\
\hline $85 / 85^{\prime}$ & 46 & 35 & 0 & 1 & 0 & 0 & 1 & 1 \\
\hline $86 / 86^{\prime}$ & 118 & 47 & 1 & 1 & 1 & 0 & 0 & 0 \\
\hline 87/87' & 129 & 79 & 2 & 0 & 0 & 1 & 0 & 0 \\
\hline $88 / 88^{\prime}$ & 98 & 83 & 4 & 4 & 1 & 0 & 1 & 0 \\
\hline $89 / 89^{\prime}$ & 110 & 67 & 0 & 0 & 42 & 0 & 1 & 0 \\
\hline 90/90' & 138 & 30 & 3 & 0 & 0 & 0 & 1 & 0 \\
\hline 91/91' & 215 & 37 & 3 & 0 & 0 & 0 & 0 & 0 \\
\hline 92/92' & 159 & 69 & 0 & 0 & 15 & 2 & 0 & 0 \\
\hline 94/94' & 266 & 52 & 12 & 0 & 0 & 0 & 0 & 0 \\
\hline 95/95' & 157 & 77 & 17 & 0 & 1 & 0 & 0 & 0 \\
\hline 96/96' & 100 & 118 & 1 & 1 & 0 & 0 & 0 & 1 \\
\hline 97/97' & 211 & 43 & 1 & 0 & 0 & 0 & 0 & 1 \\
\hline 98/98' & 65 & 84 & 1 & 1 & 0 & 1 & 0 & 1 \\
\hline 101/101' & 147 & 70 & 16 & 0 & 19 & 3 & 0 & 0 \\
\hline 102/102' & 17 & 43 & 1 & 3 & 0 & 3 & 0 & 1 \\
\hline Total $=44$ & 5625 & 3045 & 150 & 58 & 121 & 22 & 8 & 14 \\
\hline
\end{tabular}


Figura 16: média e desvio padrão do número de esporos de licopódio nas amostras de ambos os métodos em Jabuticabeira II

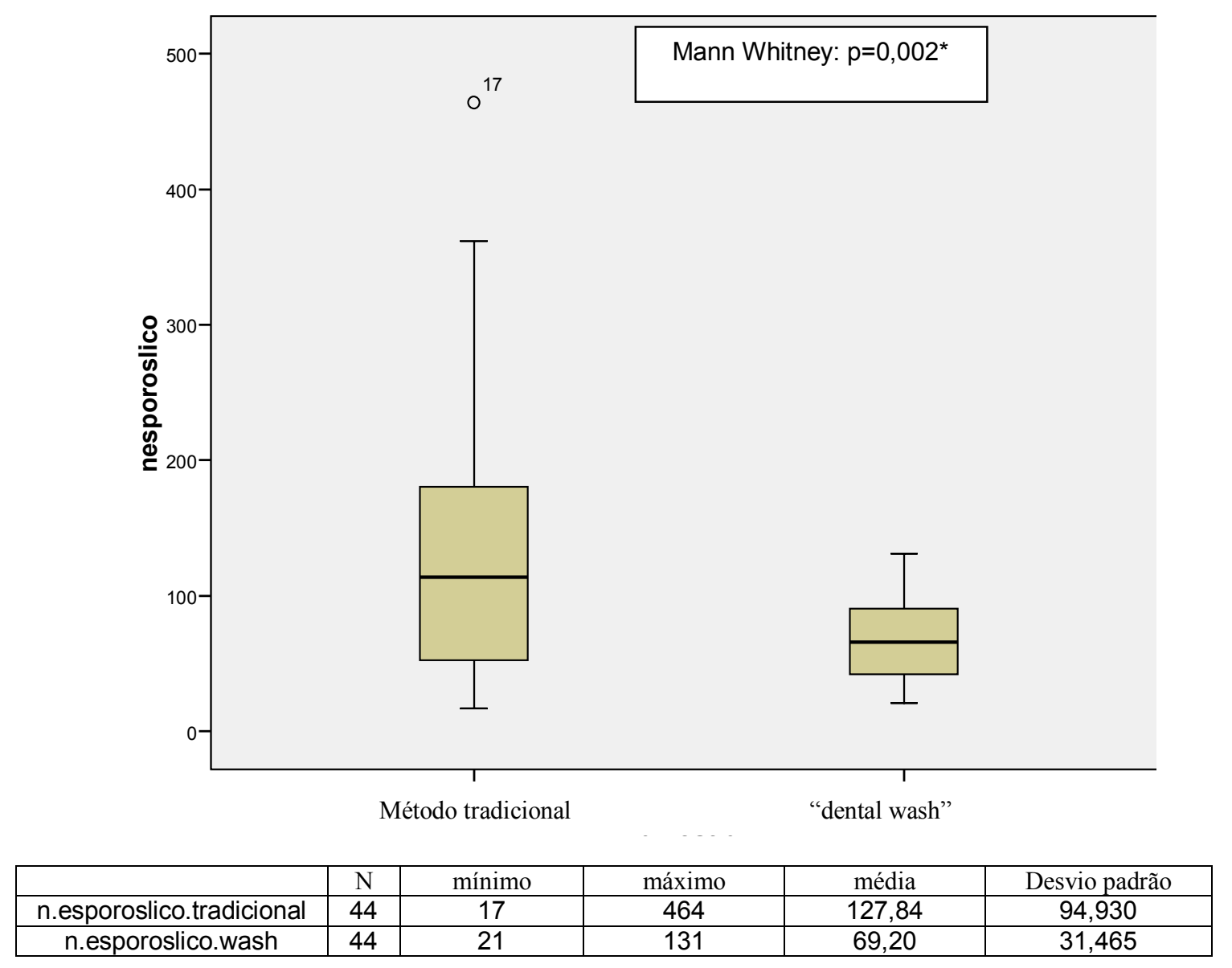


Gráfico 17: Distribuição do número de esporos de licopódio pela concentração de amido - método tradicional

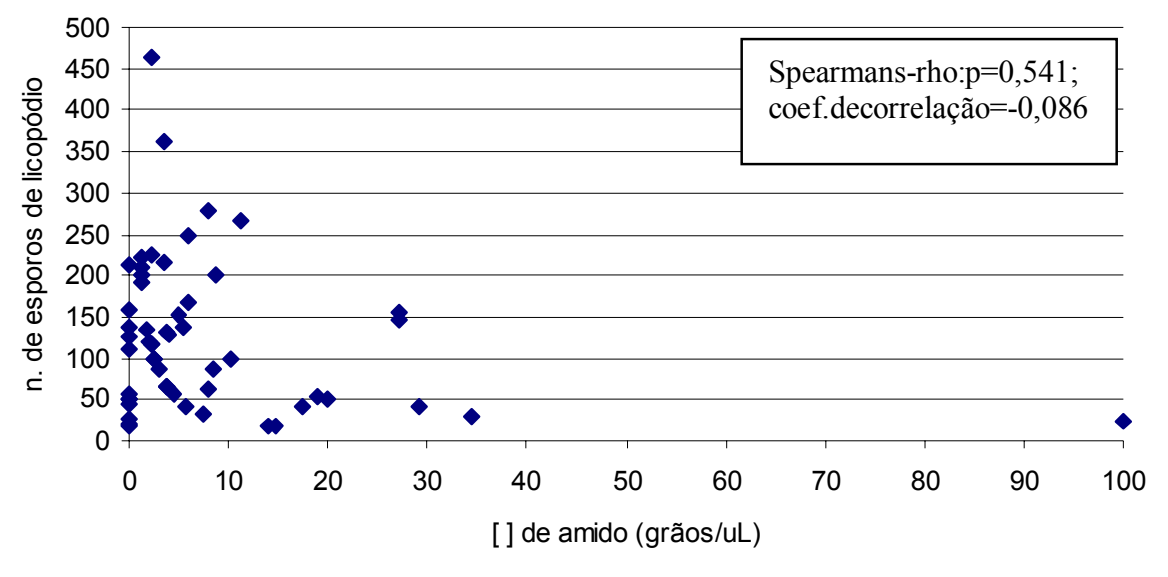

Gráfico 18: Distribuição do número de esporos de licopódio pela concentraçao de amido - "dental wash"

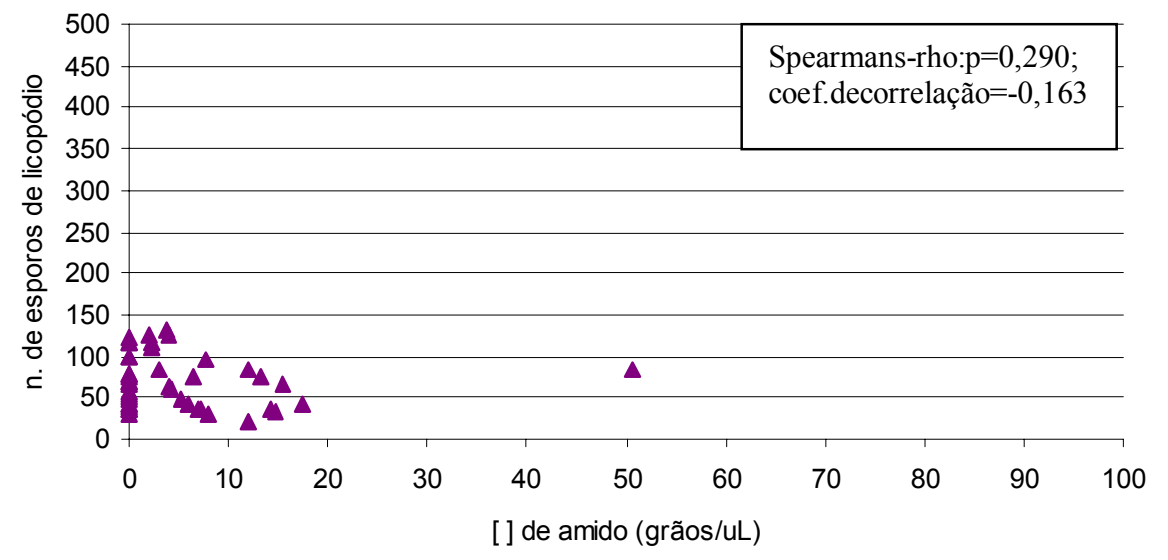



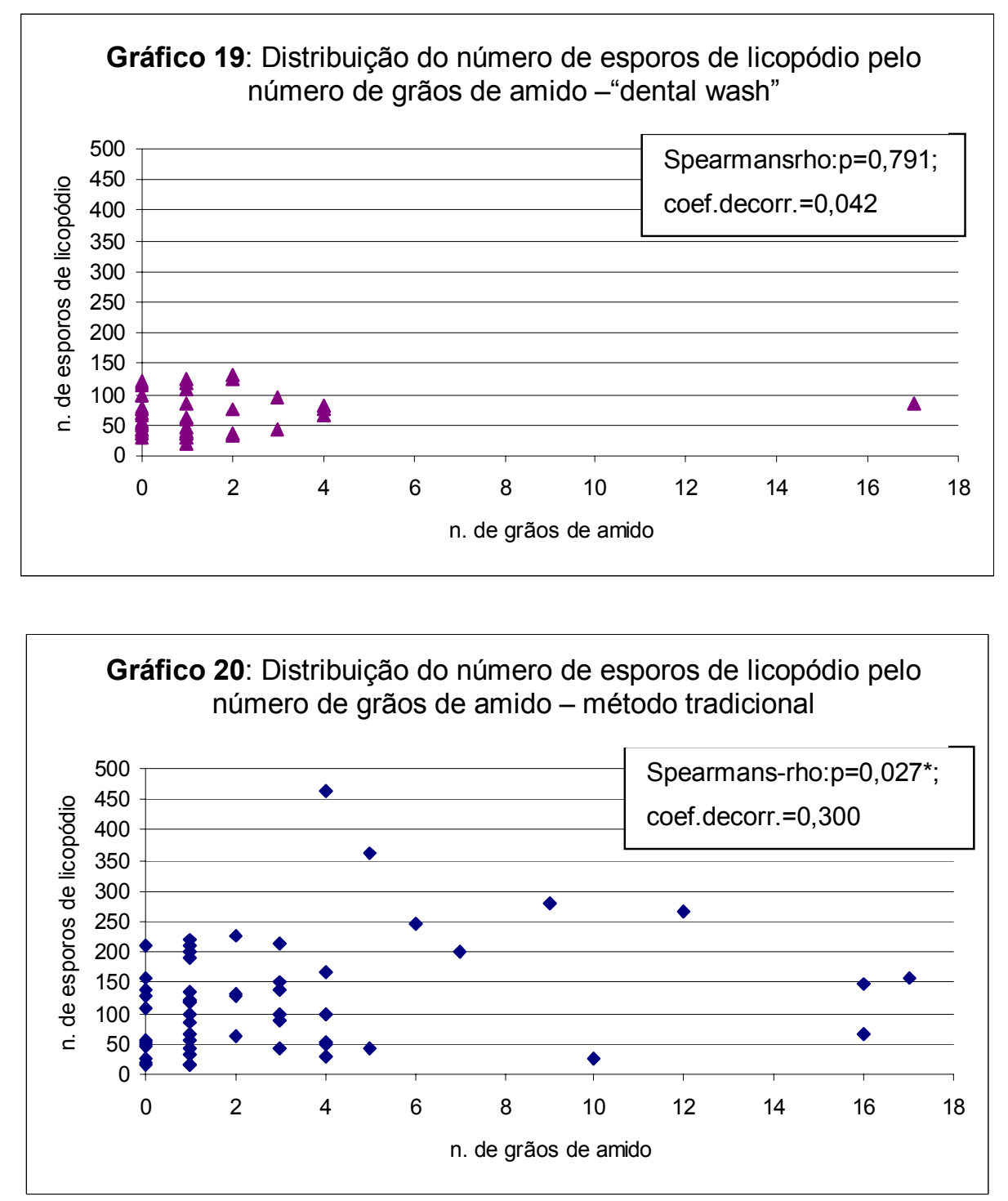

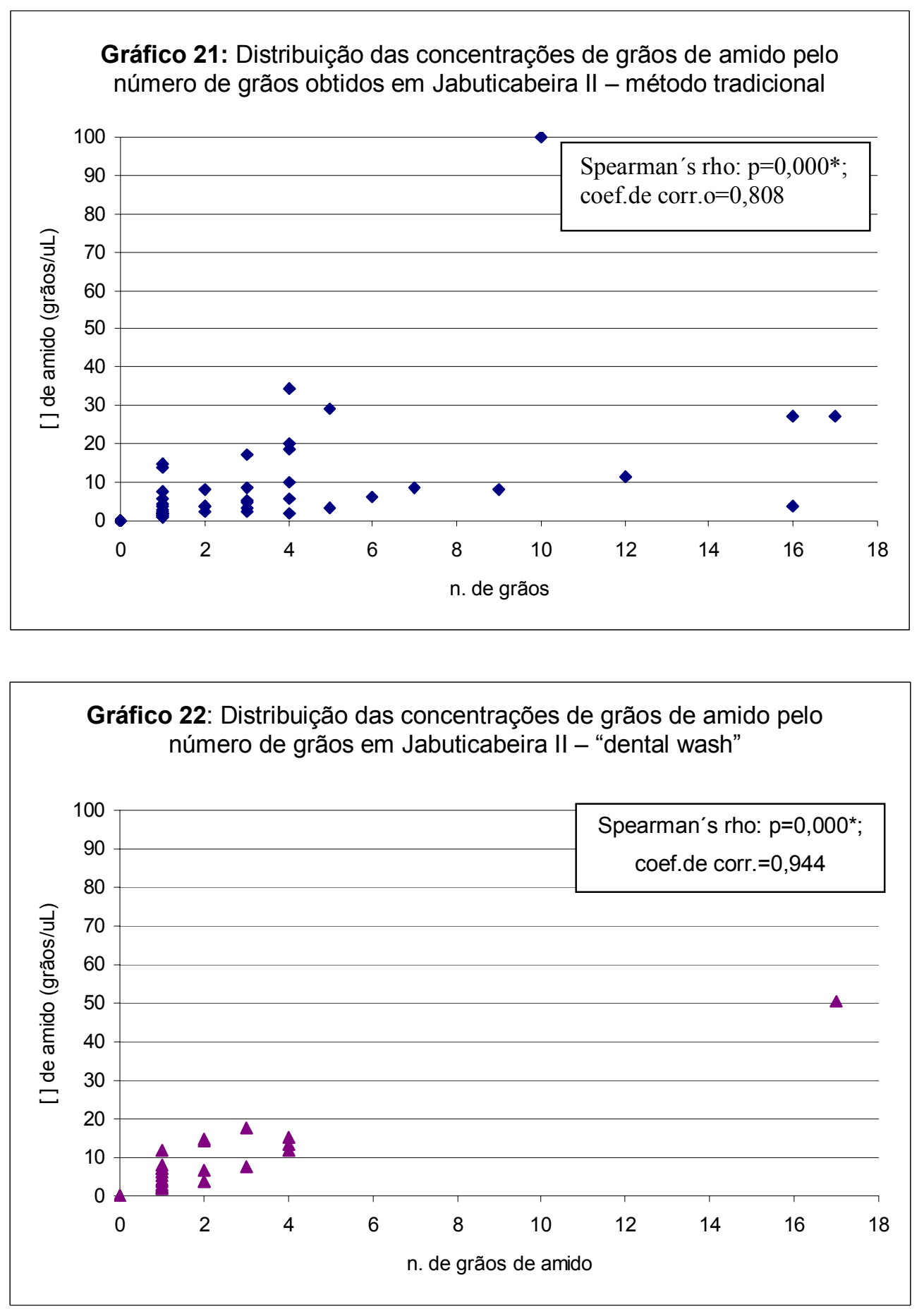


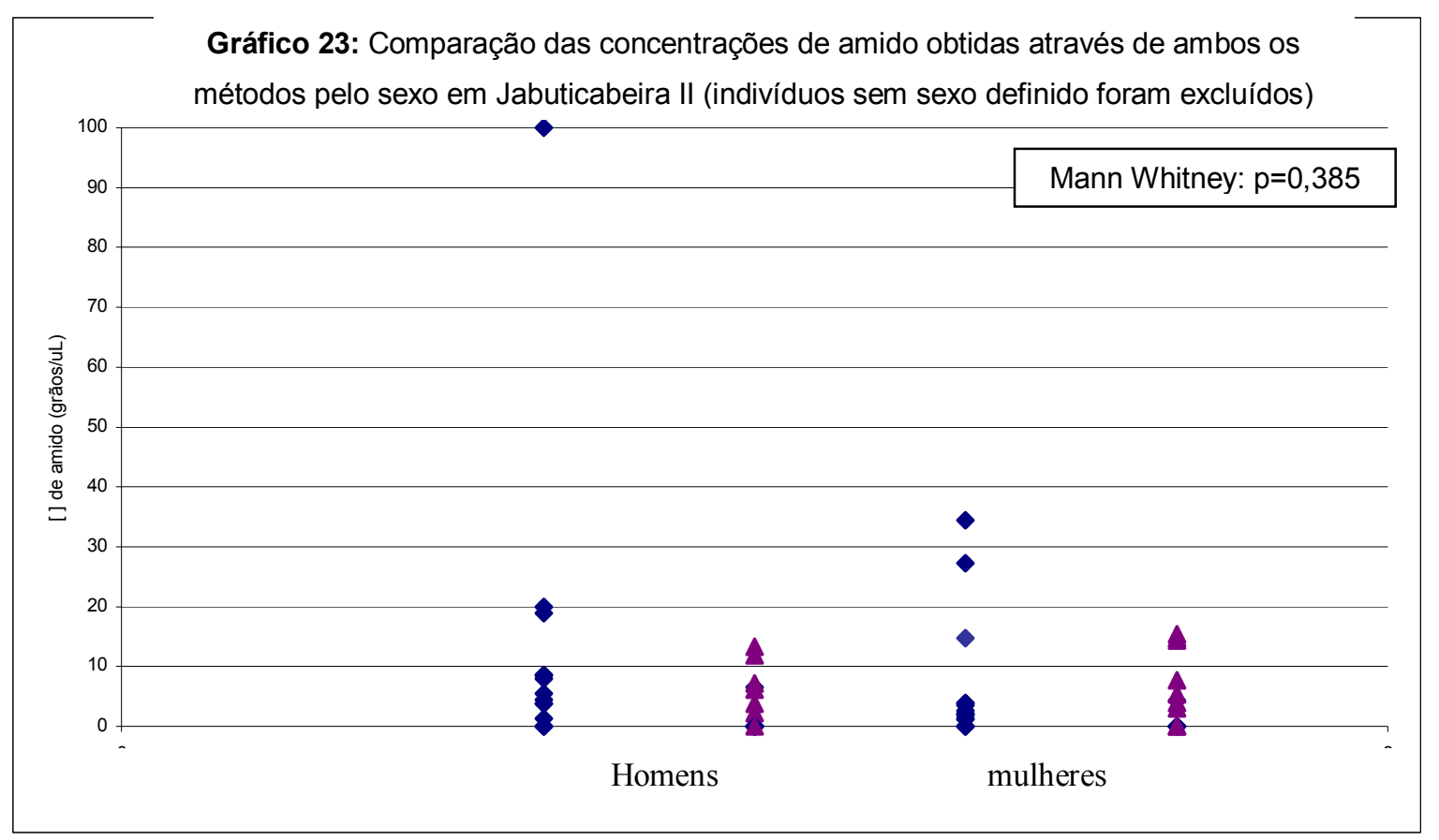

Legenda: - método tradicional \ "dental wash"

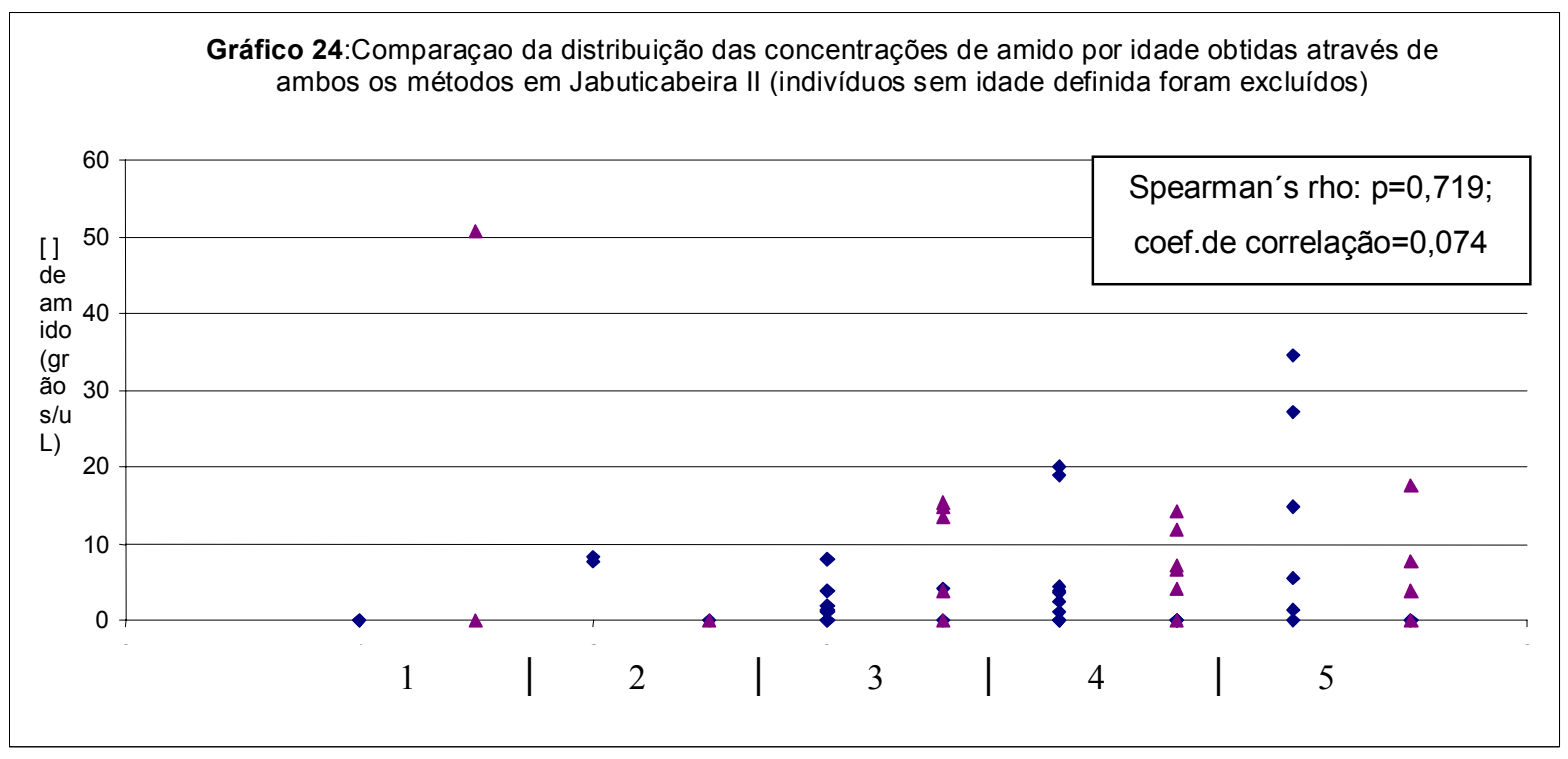

Legenda: 1 = criança, 2 = juvenil, 3 = adulto jovem, 4 = adulto médio, 5= adulto velho.

• método tradicional \ "dental wash" 


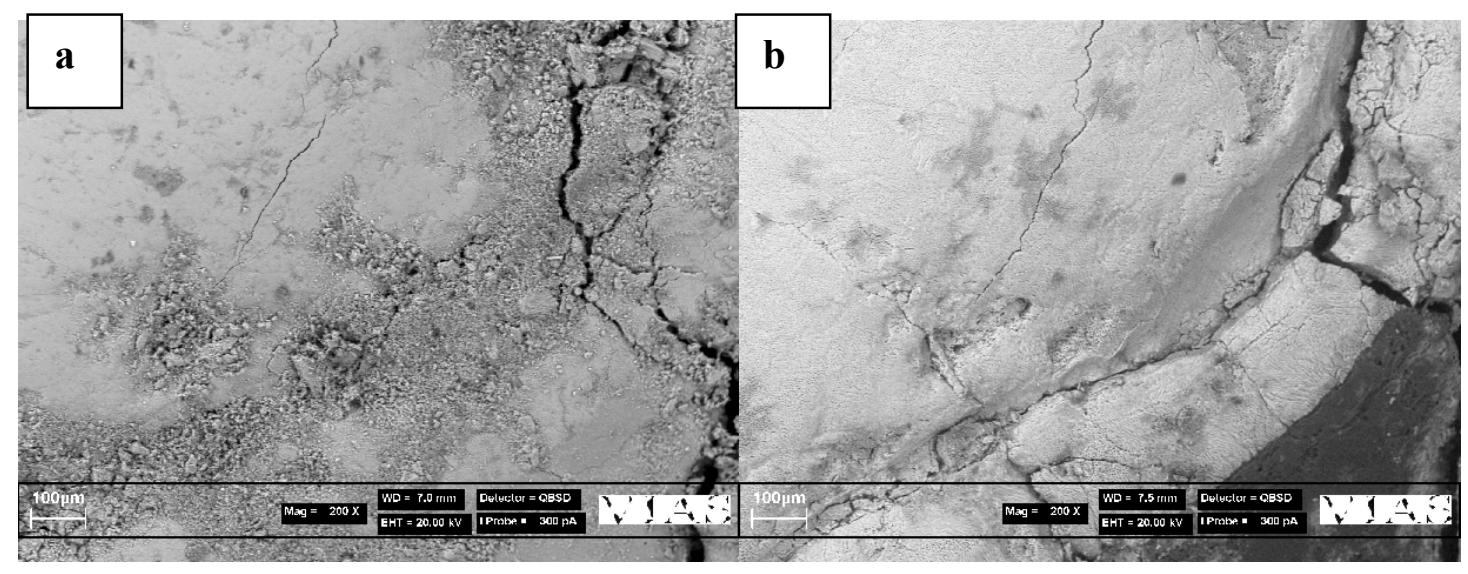

Figura 17 : Efeitos do "dental wash": imagens obtidas sob MEV a)antes e b) após a lavagem, evidenciando o aparecimento das depressões sobre as quais se depositava camada de cálculo dentário e a ultra estrutura de esmalte (área clara - imagem b) e dentina (área escura - imagem b).

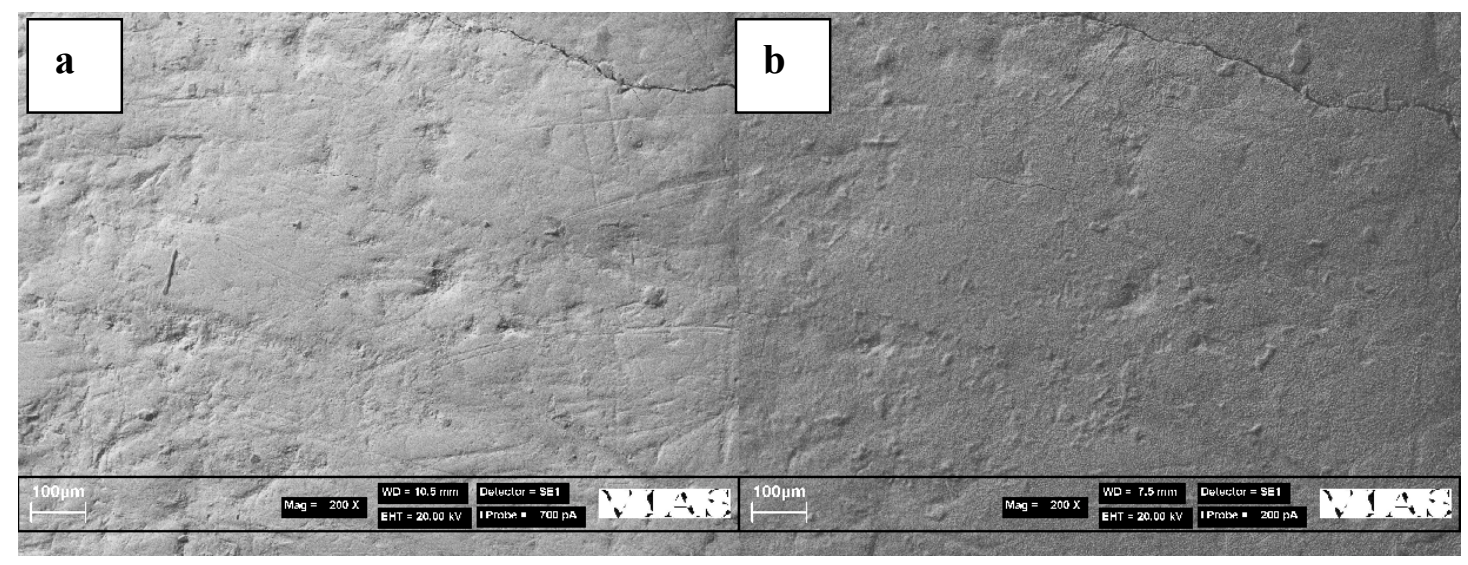

Figura 18 : Efeitos do "dental wash": imagens obtidas sob MEV a)antes e b) após a lavagem, evidenciando o desaparecimento de marcas de microdesgaste. 


\section{3 - Análise de Cálculo em Moraes ("dental wash")}

Tendo em vista os resultados obtidos com o teste de comparação entre o método tradicional e o "dental wash" para recuperação de microfósseis a partir de cálculo dentário em material proveniente de Jabuticabeira II, passa-se a analisar e discutir os dados obtidos através do "dental wash" em indivíduos exumados do sambaqui fluvial Moraes.

Foram obtidas 32 amostras, sendo 5 provenientes de indivíduos do sexo masculino, 8 de mulheres e 19 de indivíduos não avaliáveis quanto ao sexo. Para a aplicação do "dental wash" houve preferência de escolha por dentes menos danificados tafonomicamente, já que o método se mostrou prejudicial para dentes friáveis (Boyadjian et al, 2007a, b). Assim como em Jabuticabeira II, alguns indivíduos apresentavam a dentição bastante completa, o que possibilitou a obtenção de amostras duplas em 6 indivíduos, sendo uma delas obtida a partir de dentes anteriores e outra a partir de dentes posteriores (Tabela 11 e Gráfico 25). Entretanto, em três casos a lavagem foi realizada com dentes anteriores e posteriores em conjunto (denominadas de amostras mistas) para salvaguardar a obtenção de um volume mínimo necessário para análise (amostras 27, 37 e 38). Isso foi preciso já que apenas poucos dentes estavam conservados nestes três indivíduos e estes apresentavam marcas de cálculo ínfimas. Estas três amostras foram, portanto, excluídas para as análises de diferença de concentração de amido e fitólito entre dentes anteriores e posteriores.

Nas 32 amostras obtidas através do "dental wash", foram observados $\mathbf{2 1 0}$ grãos de amido e 17 fitólitos. Não foi encontrado em Moraes nenhum outro tipo de microfóssil além dos dois citados. Algumas das imagens obtidas dos microfósseis mais interessantes observados nestas amostras encontram-se nas Figuras 19 e 20. Dentre elas se encontram fotografias de grãos de amido com formatos peculiares, fitólitos e estruturas ainda não identificadas, algumas das quais podem, inclusive, não ser microfósseis, mas sim, artefatos.

\subsection{1 - Amido:}

Conforme consta da Tabela 11 e do Gráfico 25, as concentrações de amido variam muito entre as amostras (de 0 a 791,66 grãos/ $\mu$ ). A amostra 12 apresentou uma concentração extremamente elevada de grãos de amido (791,66 grãos/ $\mu$ l), muito destoante das demais. Isso deve ter ocorrido porque tal amostra foi a única que 
apresentou contagem do número de esporos de licopódio menor do que a do número dos microfósseis (12 esporos de licopódios e 38 grãos de amido), resultando em concentração muito elevada de grãos de amido quando se utiliza a fórmula descrita nos Métodos. Isso pode ser decorrência do fato de se ter utilizado cola hidrossolúvel para a curadoria destes dentes. Ao imergir estes dentes no ácido clorídrico a cola dissolveu-se e evitou a diluição dos tabletes de licopódio. Cogitou-se ainda que a cola poderia ser composta por amido, entretanto a análise de uma lâmina confeccionada com solução simples dessa mesma cola não revelou sequer um grão de amido.

De qualquer forma, uma investigação mais detalhada das fichas individuais e do material de campo do sepultamento do qual provém essa amostra, teve que ser realizada, em busca de alguma informação que pudesse ser válida para se formular uma hipótese a respeito da grande quantidade de grãos de amido. Contudo, não foi obtida nenhuma informação mais específica a esse respeito (entretanto, vide Tópico 6 - Limitações do trabalho).

Uma identificação preliminar realizada a partir da comparação dos grãos de amido observados em Moraes e aqueles publicados por Torrence e Barton (2006), Zeder e colaboradores (2006) e Wesolowski, (2007) sugere que a maioria dos grânulos sejam de Dioscorea sp (inhames) e da família Araceae. Há, ainda, alguns grãos de Ipomoea batatas (batata doce). Os grãos de amido de Dioscorea sp e Ipomoea batatas indicam claramente o uso de órgãos de reserva como alimento em Moraes. Já na família Araceae, existem plantas que são utilizadas como alimento, como é o caso de Colocasia esculenta (taro) embora existam algumas espécies que sejam utilizadas para fins medicinais, como a Philodendron bipinnatifidum (Balbach, 1979). Como não foi possível identificar o gênero destes grãos, não se pode sugerir se plantas da família Araceae eram utilizadas como alimento ou para outros fins.

\subsubsection{1 - Sexo e idade}

Os Gráficos 26 e 27 representam, respectivamente, a distribuição das concentrações de grãos de amido quanto ao sexo e quanto a idade dos indivíduos analisados. Os indivíduos com sexo e idade indeterminados foram excluídos. Embora os valores mais altos de concentração de amido estejam entre as amostras masculinas, essa diferença não é estatisticamente significativa (Mann-Whitney $p=0,921$ ), excluindo-se os

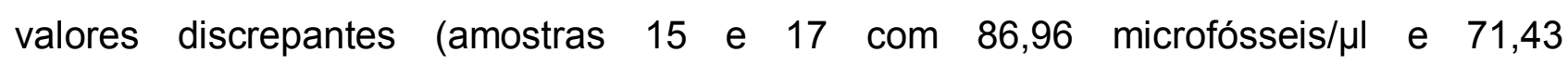




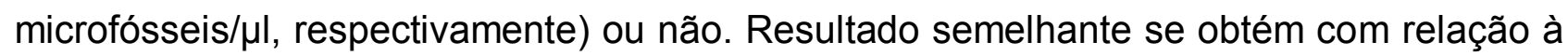
idade. Embora o Gráfico 27 acuse uma diminuição na concentração total de amido com o aumento da idade (excetuando-se a amostra 8 , pertencente a um juvenil com a maior concentração de amido observada para Moraes, ou não), esse aumento não é estatisticamente significativo (Spearman's rho $p=0,977$; coeficiente de correlação $=-$ $0,007)$.

\subsubsection{2 - Comparações entre dentição anterior e posterior}

Em concordância com os resultados obtidos para Jabuticabeira II (Tópico 4.1.1.1), em Moraes também não se constatou diferença significativa de concentração de grãos de amido entre amostras provenientes de dentes anteriores e posteriores (Mann-Whitney: $p=0,390$ ), excluindo-se as amostras discrepantes.

\subsubsection{3 - Concentração de amido versus cáries}

Uma vez que se admite, na maioria dos trabalhos, que dietas ricas em carboidratos propiciam, em conjunção com outros fatores, o aparecimento de cáries, procurou-se testar a relação dos grãos de amido encontrados nas amostras com a presença de cáries, já que diferentemente de Jabuticabeira II, a freqüência desta patologia dentre os indivíduos de Moraes é alta (atingindo 46,15\% dos indivíduos). Entretanto, através da Tabela 12 e do Gráfico 28, as maiores concentrações de amido não correspondem, necessariamente, aos indivíduos com maior número de cáries, como seria esperado. Assim, o número de indivíduos com cáries em cujos dentes foram encontrados grãos de amido, não é significativamente maior do que nos indivíduos sem cáries (Chi-quadrado $=0,3678$, $p=0,5442$ ). Também não foi constatada relação entre o aumento de cáries e o aumento de concentração de amido tanto para o conjunto dos indivíduos analisados (coeficiente de correlação $=0,039, p=0,847$ ), quanto somente para os indivíduos com cáries (coeficiente de correlação = - 0,248; $p=0,392$ ). Nota-se, ainda, que a concentração de grãos de amido variou bastante, mesmo entre os indivíduos sem cáries ou com apenas uma única cárie. Curiosamente, entre aqueles indivíduos sem cáries encontram-se as maiores concentrações de grãos de amido (excluindo-se o sepultamento VIIlb com duas cáries, correspondente a amostra 12, que possui uma concentração exorbitante de grãos de amido). 
Essa ausência de associação e correlação entre concentração de amido e número de cáries pode ser reflexo de diferentes dietas dentro de um mesmo grupo, quando se parte do princípio que, já de saída, existiam outros fatores que propiciavam o aparecimento e desenvolvimento das lesões cariosas em Moraes (haja visto a freqüência alta da patologia para o grupo). Essas diferenças estariam promovendo uma concentração diferente de grãos de amido e outros micro-resíduos no cálculo dentário. Por outro lado, concentrações distintas podem, também, advir de sazonalidade de certos recursos alimentares, como foi observado para outros sambaquis (Beck, 1972; Bandeira, 1992). Além disso, uma subsistência baseada em proteína animal leva a um aumento na alcalinidade do $\mathrm{pH}$ da boca, promovendo uma mineralizaçao mais rápida da placa (Kleinberg, 1961; Jin e Yip, 2002). Assim, formar-se-iam depósitos de cálculo mais pesados, mas menos densos em micro resíduos (Wesolowski, 20007).

Embora a ingestão de alimentos amiláceos parece ter sido significativa (a julgar pelas altas concentrações de amido e o alto índice de cáries) em Moraes, diferenças na proporção da ingestão de proteína animal podem ter modulado a quantidade de retenção dos grânulos na matriz do cálculo. Isso levaria, portanto, às diferenças de concentração deste microfóssil, tanto em indivíduos com cáries quanto em indivíduos sem cáries, como discutido adiante (Tópico 4.4.1).

\subsubsection{4 - Grãos de amido modificados em Moraes}

Assim como em Jabuticabeira II, também foram encontrados grãos de amido modificados em Moraes, embora em menor quantidade. Enquanto em Jabuticabeira II foram observados 37 grãos modificados em 15 amostras, em Moraes foram observados apenas 11 grãos modificados em 7 amostras (Tabela 13). O fato de haver grãos de amido modificados em Moraes, caso não sejam resultado de processos tafonômicos, é um indício de que estes sambaquieiros também preparavam previamente tubérculos ou raízes (Torrence e Barton, 2006; Wesolowski, 2007), assim como sugerido para Jabuticabeira II. No entanto, devido à diferença nas quantidades obtidas deste tipo de amido entre os dois sítios, pode-se aventar a possibilidade de que uma proporção menor de alimentos de origem vegetal tenha sido preparada mediante a ação do calor em Moraes do que em Jabuticabeira II. Assim como os resultados zooarqueológicos sugerem que a caça em Moraes teria sido diversificada, talvez a variação de espécies e modos de consumo de vegetais também teria sido variado. 
Em concordância com o observado para Jabuticabeira (Tópico 4.1.1.5), não se encontrou diferença significativa entre os sexos quanto ao número de grãos de amido modificados e não modificados $\left(X^{2}=1,8601, p=0,1726\right.$; $p$ Fischer $\left.=0,2409\right)$. Isso sugere não ter havido diferença no modo de preparo de alimentos amiláceos ingeridos por homens e mulheres em Moraes.

\subsection{2 - Fitólitos:}

Em Moraes foram observados muito mais grãos de amido (93\%dos microfósseis observados) do que fitólitos (apenas 7\% do microfósseis - Gráfico 29). A maioria (76,92\%) dos indivíduos de Moraes apresentou exclusivamente grãos de amido e nenhum fitólito em sua dentição, com exceção das amostras 12, 13, 38, 39 e 47 (pertencentes a distintos indivíduos e apresentando baixas concentrações de fitólitos, salvo a amostra $12 \mathrm{com}$ 187,5 fitólitos $/ \mu \mathrm{L}$ ) (Tabela 11). Este valor discrepante poderia refletir uma baixa contagem de esporos de licopódio, que acabou por aumentar muito a concentração de amido e fitólitos, como foi discutido anteriormente na seção sobre amido em Moraes (Tópico 4.3.1). O mesmo tipo de fitólito foi observado nas amostras 12, 38 e 39 e outros dois tipos, bem distintos e ainda não identificáveis, foram evidenciados nas amostras 13 e 47 .

Assim como realizado para o sambaqui Jabuticabeira II de Santa Catarina, foram procuradas informações complementares a respeito dos indivíduos em cujas amostras de cálculo foram observados fitólitos. Todavia, a documentação de campo e de laboratório é muito pouco informativa. Portanto, não há informação adicionais que sejam relevantes para explicar essas concentrações de fitólitos em apenas algumas poucas amostras.

De qualquer forma, estes dados sugerem, assim como em Jabuticabeira II, que havia uma maior utilização de órgãos vegetais de reserva, em relação a outros órgãos vegetais, ricos em fitólitos.

Apenas 5, dentre as 32 amostras de Moraes (15,62\%) apresentaram fitólitos (Gráfico 30). Como esperado, devido a esse reduzido número de amostras contendo fitólitos, alguns dados serão apresentados apenas sob a forma de freqüências relativas e discutidos a seguir. 


\subsubsection{1 - Sexo e idade}

Para a realização de testes de associação com sexo versus concentração de fitólitos, tiveram de ser eliminados todos os indivíduos sem sexo determinado, resultando em 13 amostras (sendo 5 de homens e 8 de mulheres) (Gráfico 31 e Tabela 11). Como, entretanto, apenas $7,7 \%$ das amostras com sexo definido apresenta fitólitos (o que corresponde a apenas uma mulher), não fazia sentido aplicar o teste de comparação das concentrações entre os sexos. No entanto, havia possibilidade de se comparar o número de amostras com e sem fitólitos entre os sexos, mas o resultado não foi estatisticamente significativo $\left(X^{2}=0,6771, p=0,4106\right.$; $p$ Fisher=1,0000).

O Gráfico 32 sugere uma diminuição da concentração de fitólitos com o aumento da idade. Entretanto, como o tamanho da amostra é extremamente reduzido (apenas 3 amostras com fitólitos e com idade determinada, sendo 2/3 correspondentes a crianças e 1/3 a juvenis), o teste estatístico tornou-se inviável. Além disso, a verificação desta tendência somente faria algum sentido se houvessem, também, indivíduos mais velhos com fitólitos na dentição.

\subsubsection{2 - Comparações entre dentição anterior e posterior}

Problemas amostrais também prejudicaram as análises sobre a concentração de fitólitos na dentição anterior versus dentição posterior (Gráfico 30). De início, excluindo-se as 3 amostras mistas, elimina-se, automaticamente, uma das amostras que apresentavam fitólitos (amostra 38). As 4 amostras restantes com fitólitos, entretanto, são provenientes da dentição posterior. Além disso, uma destas é a amostra com concentração discrepante de 187,5 fitólitos/ul e que, portanto, deve ser excluída de qualquer análise estatística, restando apenas 3 amostras com fitólitos e provenientes da dentição posterior. Evidentemente, uma análise estatística aqui não seria adequada.

\subsubsection{3 - Fitólitos versus desgaste dentário}

O grau de desgaste dentário pode estar relacionado à presença de partículas abrasivas no bolo alimentar, incluindo fitólitos (Armitage, 1975; Middleton, 1990, 1992; Ciochon et al, 1990; Danielson e Reinhard, 1998). Portanto, buscou-se verificar uma possível relação entre a concentração destes microfósseis e o desgaste dentário médio 
dos indivíduos provenientes de Moraes. Porém, de acordo com o Gráfico 33 e o teste de Spearman (coeficiente de correlação=-0,320, p=0,074) não há correlação significativa entre estas variáveis.

No mais, é importante notar que, além do tamanho amostral ser pequeno, visto que o número de amostras com fitólitos é reduzido, o que pode estar provocando um enviesamento dos resultados, o desgaste dentário dos indivíduos de Moraes não é tão intenso quanto o de Jabuticabeira II e, portanto, talvez os (poucos) fitólitos mastigados não sejam os responsáveis diretos pelo desgaste. Entretanto, um estudo sistemático do desgaste dentário dos indivíduos deste sítio arqueológico se faz necessário.

\subsection{3 - Peso e índice de cálculo:}

Em contraste com Jabuticabeira II, as análises de fitólitos e amido com relação ao peso dos fragmentos e ao índice de cálculo não podem ser realizadas para Moraes. Isso decorre do fato dessas amostras terem sido obtidas através do "dental wash", justamente por que o depósito de cálculo era tão reduzido a ponto de impossibilitar qualquer quantificação.

\subsection{4 - Resumo:}

Em suma, com relação às análises do conteúdo presente nos remanescentes de cálculo dentário de Moraes, pode-se afirmar que:

A proporção de grãos de amido (93\% dos microfósseis observados) foi muito superior à proporção de fitólitos $(7 \%)$ encontrados nas amostras de Moraes. Enquanto grãos de amido encontravam-se distribuídos entre todas as 32 amostras, fitólitos se concentraram em apenas 5 delas. Isso demonstra um aporte expressivo de alimentos amiláceos na dieta da maioria dos indivíduos, em contraste com um baixo consumo de vegetais ricos em fitólitos, concentrado em apenas poucos indivíduos construtores de Moraes.

Não foi demonstrada diferença das concentrações de amido entre os sexos, o que sugere que não havia, em Moraes, diferenças entre os sexos quanto à alimentação. Da mesma forma, não foi observada correlação entre concentração deste micro-resto vegetal e a idade de óbito dos 
indivíduos analisados. Isso pode ser explicado, pois, como há variações na formação, compactação, composição e velocidade de mineralização dos depósitos de cálculo, além de haver variações na dieta entre os indivíduos e ao longo da vida de cada indivíduo, os tipos e quantidades de microfósseis que se aderem a estes depósitos podem variar entre os indivíduos e ao longo da vida de cada um;

Assim como para Jabuticabeira II, não houve significância estatística das diferenças de concentração entre amostras oriundas da dentição anterior e da posterior.

Houve ausência de associação e correlação entre concentração de amido e número de cáries em Moraes, o que poderia ser reflexo de diferentes dietas dentro de um mesmo grupo, quando se parte do princípio que, já de saída, existiam outros fatores que propiciavam o aparecimento e desenvolvimento de lesões cariosas em Moraes. Essas diferenças estariam promovendo concentrações diferentes de grãos de amido e outros micro-resíduos no cálculo dentário entre os indivíduos deste sítio.

Neste sambaqui fluvial também foram observados grãos de amido modificados nas amostras de cálculo dentário, o que sugere que, o grupo humano associado a este sítio preparava alimentos de origem vegetal antes de seu consumo.

Devido ao diminuto tamanho amostral, não foi possível avaliar diferenças de concentração de fitólitos quanto ao sexo e nem se havia correlação da concentração com a idade de óbito

Pelo mesmo motivo, também não foi possível testar estatisticamente se diferenças de concentração de fitólitos ocorrem nas amostras provenientes da dentição anterior em relação àquelas obtidas a partir da dentição posterior.

Não foi encontrada correlação entre as concentrações de fitólitos e o desgaste dentário das amostras oriundas de Moraes, o que leva a crer que, o desgaste dentário destes indivíduos não tivesse relação com a presença de fitólitos nos vegetais consumidos. No entanto, como o tamanho amostral é muito reduzido, não se pode excluir totalmente a idéia de que fitólitos tenham contribuído para o desgaste dental. 
As variáveis peso e índice de cálculo não puderam ser testadas para Moraes, visto que os dentes provenientes deste sítio apresentavam apenas marcas de cálculo, não sendo possível quantificar o montante de cálculo dissolvido com a aplicação do método da lavagem dos dentes ("dental wash"). 

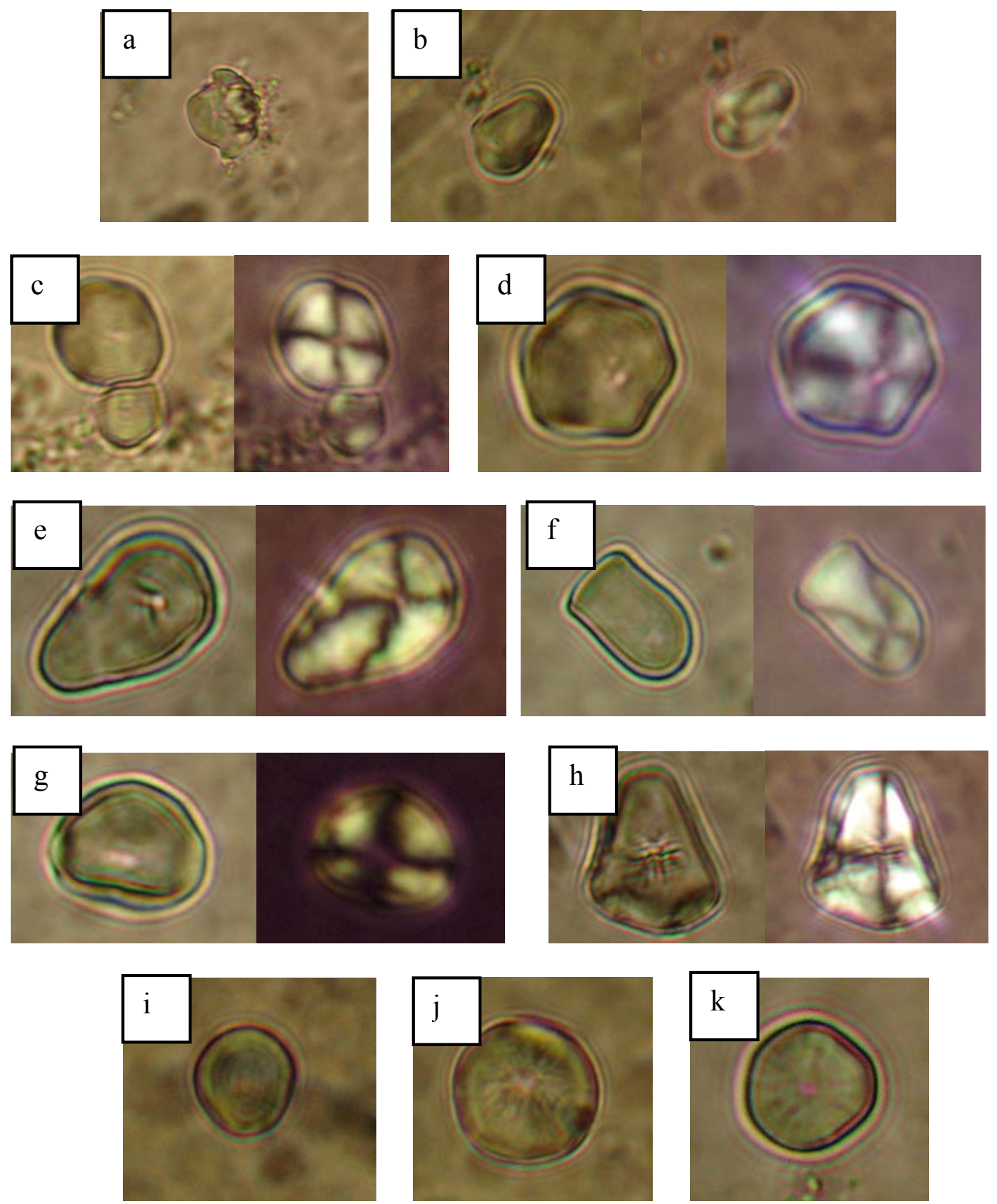

Figura 19: tipos de grãos de amido encontrados nas amostras obtidas através do "dental wash" do sítio arqueológico Moraes: a) grão com formato peculiar; b-h) grãos de diferentes tipos observados sem e com luz polarizada; i) grão em que é possível observar as linhas de deposição ao redor do hilo; j, k) grãos com ornamentação. Aumento de 400x.

Obs.: nenhum desses grãos foi identificado ainda. Nessa figura não há escala porque quando as amostras foram analisadas o Laboratório de Antropologia Biológica ainda não possuía o retículo para mensuração em seu microscópio óptico. 

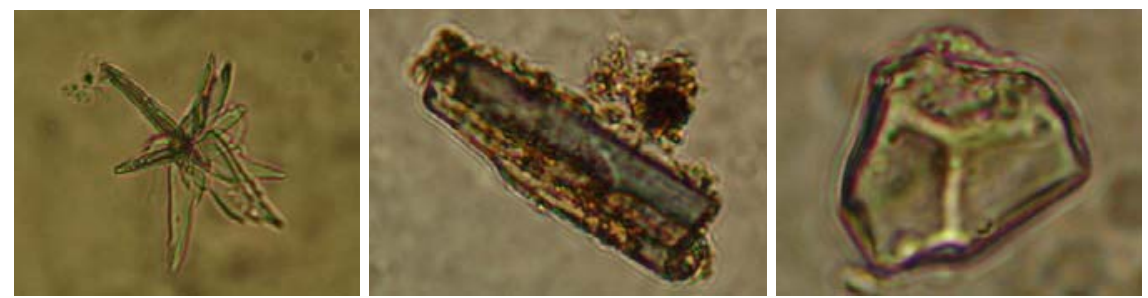

Figura 20: fitólitos (ainda não identificados) encontrados nas amostras obtidas através do "dental wash", em Moraes. Aumento de 400x

Obs.: Na figura não há escala porque quando essas amostras foram analisadas o Laboratório de Antropologia Biológica ainda não possuía o retículo para mensuração em seu microscópio óptico. 


\begin{tabular}{|c|c|c|c|c|c|c|c|}
\hline amostra & 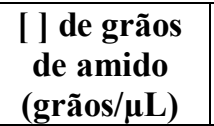 & $\begin{array}{l}\text { [ ] de fitólitos } \\
\text { (fitólitos/ } \boldsymbol{\mu L} \text { ) }\end{array}$ & $\begin{array}{c}\text { No. de } \\
\text { dentes } \\
\text { utilizados } \\
\end{array}$ & Dentes utilizados & sepultamento & sexo & idade \\
\hline 8 & 148,35 & 0 & 1 & Canino & IIIa & Indeterminado & 2 \\
\hline 9 & 35,21 & 0 & 3 & Pré-molares e molar & IIIa & Indeterminado & 2 \\
\hline 10 & 41,67 & 0 & 2 & Molares & $\mathrm{V}$ & mulher & 4 \\
\hline 12 & 791,66 & 187,5 & 2 & Molares & VIIIb & Indeterminado & 3 \\
\hline 13 & 22,96 & 5,1 & 2 & Pré-molares & VIa & mulher & 2 \\
\hline 14 & 10,27 & 0 & 1 & Incisivo & VII & homem & 5 \\
\hline 15 & 86,96 & 0 & 2 & Molares & VII & homem & 5 \\
\hline 17 & 71,43 & 0 & 2 & Molares & Ixa & homem & 5 \\
\hline 19 & 8,77 & 0 & 2 & Incisivos & XIII & mulher & 5 \\
\hline 20 & 0 & 0 & 1 & Molar & XIII & mulher & 5 \\
\hline 23 & 13,89 & 0 & 2 & Molares & Xva & Indeterminado & 3 \\
\hline 24 & 3,62 & 0 & 2 & Incisivos & XVII & mulher & 5 \\
\hline 25 & 7,69 & 0 & 2 & Molares & XVII & mulher & 5 \\
\hline 27 & 12,5 & 0 & 3 & Molar e incisivos & XVIII & homem & 4 \\
\hline 29 & 13,97 & 0 & 2 & Molares & XXV & mulher & 4 \\
\hline 30 & 25,86 & 0 & 2 & Caninos & XXV & mulher & 4 \\
\hline 31 & 40,62 & 0 & 2 & Molares & XXVIIa & Indeterminado & 2 \\
\hline 32 & 10,27 & 0 & 2 & Molares & XXVIIb & Indeterminado & 3 \\
\hline 34 & 20,49 & 0 & 2 & Incisivos & XXVIIb & Indeterminado & 3 \\
\hline 35 & 8,43 & 0 & 2 & Molares & XXXVa & homem & 3 \\
\hline 36 & 2,14 & 0 & 2 & Molar e pré-molar & XXXVb & Indeterminado & 1 \\
\hline 37 & 7,57 & 0 & 2 & Molar e incisivo & XXXVIIa & Indeterminado & 4 \\
\hline 38 & 8,62 & 8,62 & 5 & Canino e molares & XXXVIIb & Indeterminado & 1 \\
\hline 39 & 8,06 & 8,06 & 3 & \begin{tabular}{|l|}
$\begin{array}{l}\text { Molar e pré- } \\
\text { molares }\end{array}$ \\
\end{tabular} & XIIb & Indeterminado & 3 \\
\hline 40 & 0 & 0 & 1 & Molar & NP590 QF22 & Indeterminado & 3 \\
\hline 41 & 7,94 & 0 & 2 & Incisivos & F25 NPd806 & Indeterminado & 1 \\
\hline 42 & 6,58 & 0 & 1 & Molar & NP360.superfície & Indeterminado & 3 \\
\hline 43 & 1,85 & 0 & 1 & Molar & F16 NP1140? & Indeterminado & 1 \\
\hline 44 & 6,17 & 0 & 1 & Molar & E16 NP1481 & Indeterminado & 3 \\
\hline 45 & 0 & 0 & 2 & Molares & F25 NP789 & Indeterminado & 3 \\
\hline 46 & 3,47 & 0 & 2 & Molar e pré-molar & \begin{tabular}{|l|} 
E16 NP1487 \\
\end{tabular} & Indeterminado & 3 \\
\hline 47 & 8,2 & 4,1 & 2 & molares & II & Indeterminado & 1 \\
\hline $\mathbf{N}=32$ & $\begin{array}{c}\text { Média=44,85 } \\
(0-791,66)\end{array}$ & $\begin{array}{c}\text { Média }=6,67(0- \\
187,50)\end{array}$ & $\Sigma=63$ & $\begin{array}{c}\text { anterior }=21,87 \% \\
(7 / 32) \\
\text { posterior }=65,75 \% \\
(22 / 32) \\
\text { mista }=9,37 \%(3 / 32) \\
\end{array}$ & $\begin{array}{c}\text { n. indivíduos }= \\
26\end{array}$ & $\begin{array}{c}\text { n. } \hat{\jmath}=5 \\
\text { n. } \stackrel{+}{=}=8 \\
\text { n. } ?=19\end{array}$ & $\begin{array}{c}\Sigma: 1=5 ; \\
2=4 ; \\
3=11 ; \\
4=5 ; 5=7\end{array}$ \\
\hline
\end{tabular}

Legenda: idade: $1=$ criança; $2=$ juvenil; $3=$ adulto sem idade definida; $4=$ adulto jovem; $5=$ adulto médio 


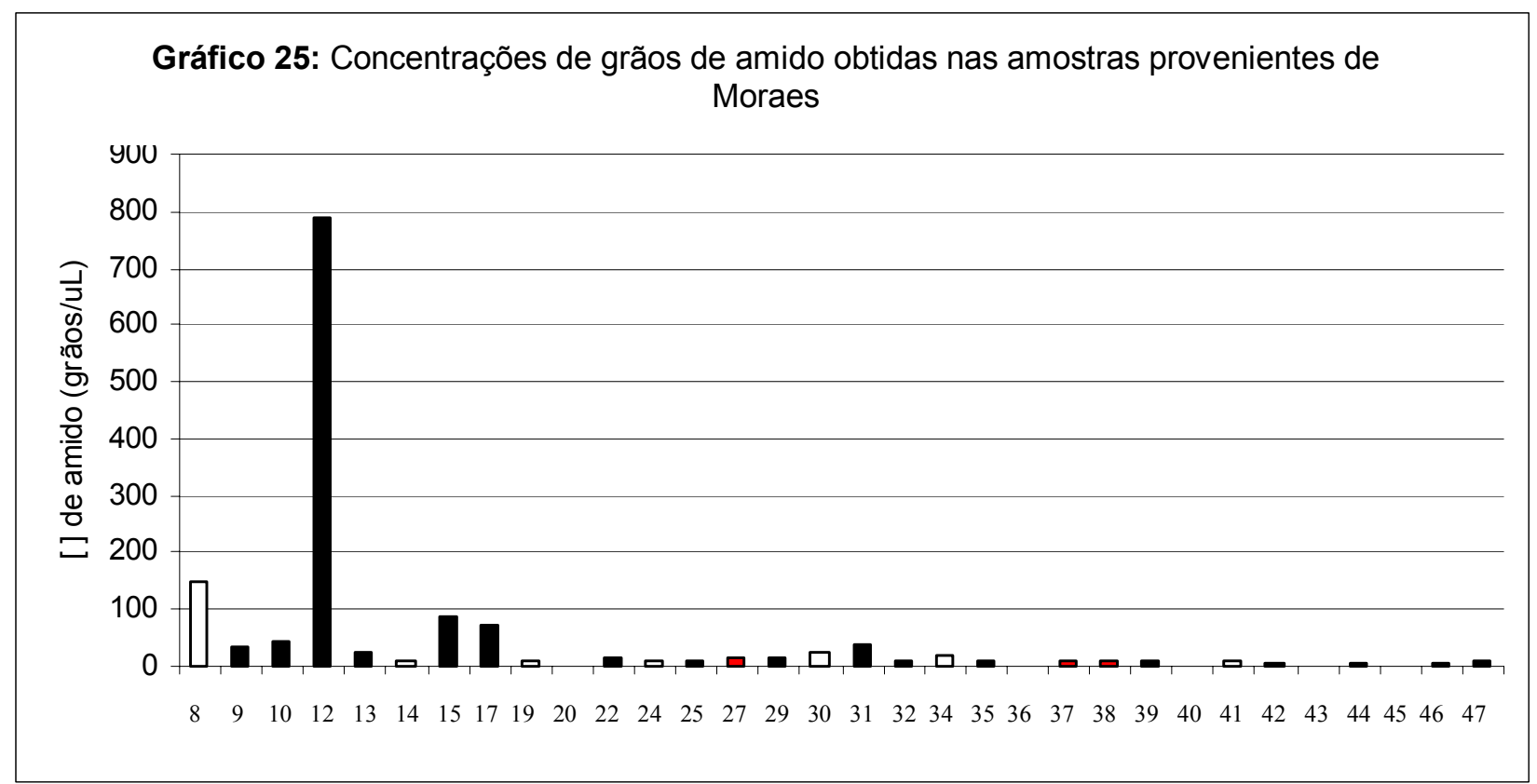

Legenda:

$\square$ : Amostras retiradas de dentes anteriores e de ambas as dentições.

Amostras retiradas de dentes posteriores.

amostras obtidas com dentes

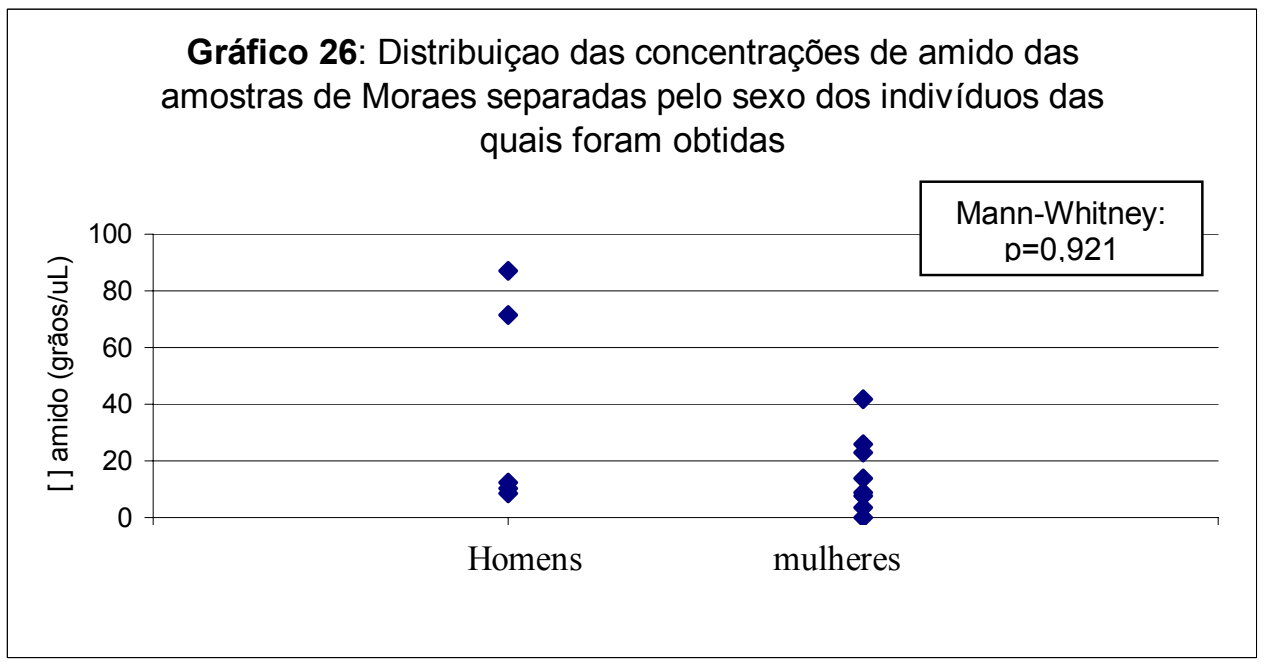




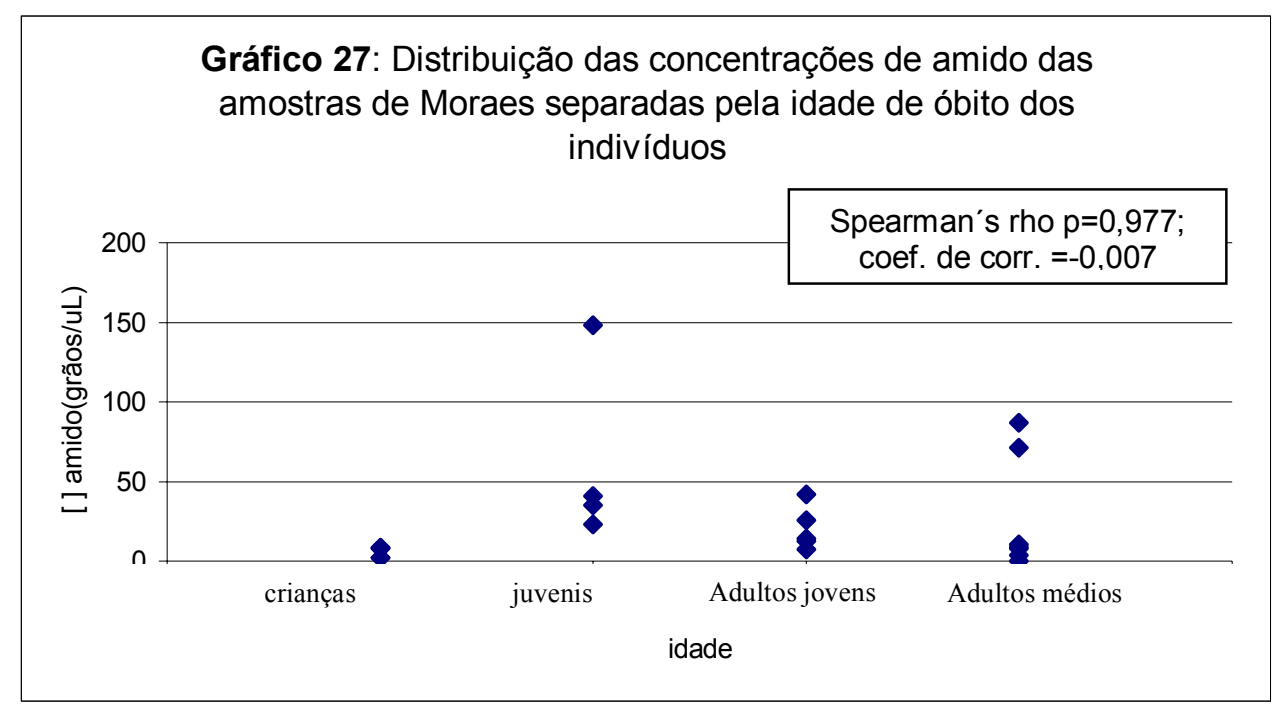

\begin{tabular}{|c|c|c|}
\hline \multicolumn{3}{|c|}{$\begin{array}{c}\text { Tabela 12: concentração de grãos de amido e } \\
\text { número de cáries nos dentes dos sepultamentos } \\
\text { analisados em Moraes }\end{array}$} \\
\hline sepultamento & Número de cáries & $\begin{array}{c}\text { [ ] de grãos de } \\
\text { amido } \\
\text { (grãos/ } / \mu \mathrm{L})\end{array}$ \\
\hline IIIIa & 0 & 148,35 \\
\hline IIIa & 0 & 35,21 \\
\hline $\mathrm{V}$ & 0 & 41,67 \\
\hline Via & 0 & 22,96 \\
\hline VII & 0 & 10,27 \\
\hline VII & 0 & 86,96 \\
\hline XVIII & 0 & 12,5 \\
\hline $\mathrm{XXXVb}$ & 0 & 2,14 \\
\hline XXXVIIb & 0 & 8,62 \\
\hline XIIb & 0 & 8,06 \\
\hline NP590 QF22 & 0 & 0 \\
\hline F25 NPd806 & 0 & 7,94 \\
\hline NP360.superfície & 0 & 6,58 \\
\hline F16 NP1140? & 0 & 1,85 \\
\hline E16 NP1481 & 0 & 6,17 \\
\hline E16 NP1487 & 0 & 3,47 \\
\hline Xva & 1 & 13,89 \\
\hline XXV & 1 & 13,97 \\
\hline XXV & 1 & 25,86 \\
\hline XXVIIa & 1 & 40,62 \\
\hline XXXVIIa & 1 & 7,57 \\
\hline F25 NP789 & 1 & 0 \\
\hline VIIIb & 2 & 791,66 \\
\hline XVII & 2 & 3,62 \\
\hline XVII & 2 & 7,69 \\
\hline Ixa & 3 & 71,43 \\
\hline XXXVa & 4 & 8,43 \\
\hline XXVIIb & 7 & 10,27 \\
\hline XXVIIb & 7 & 20,49 \\
\hline XIII & 8 & 8,77 \\
\hline XIII & 8 & 0 \\
\hline II & 11 & 8,2 \\
\hline
\end{tabular}




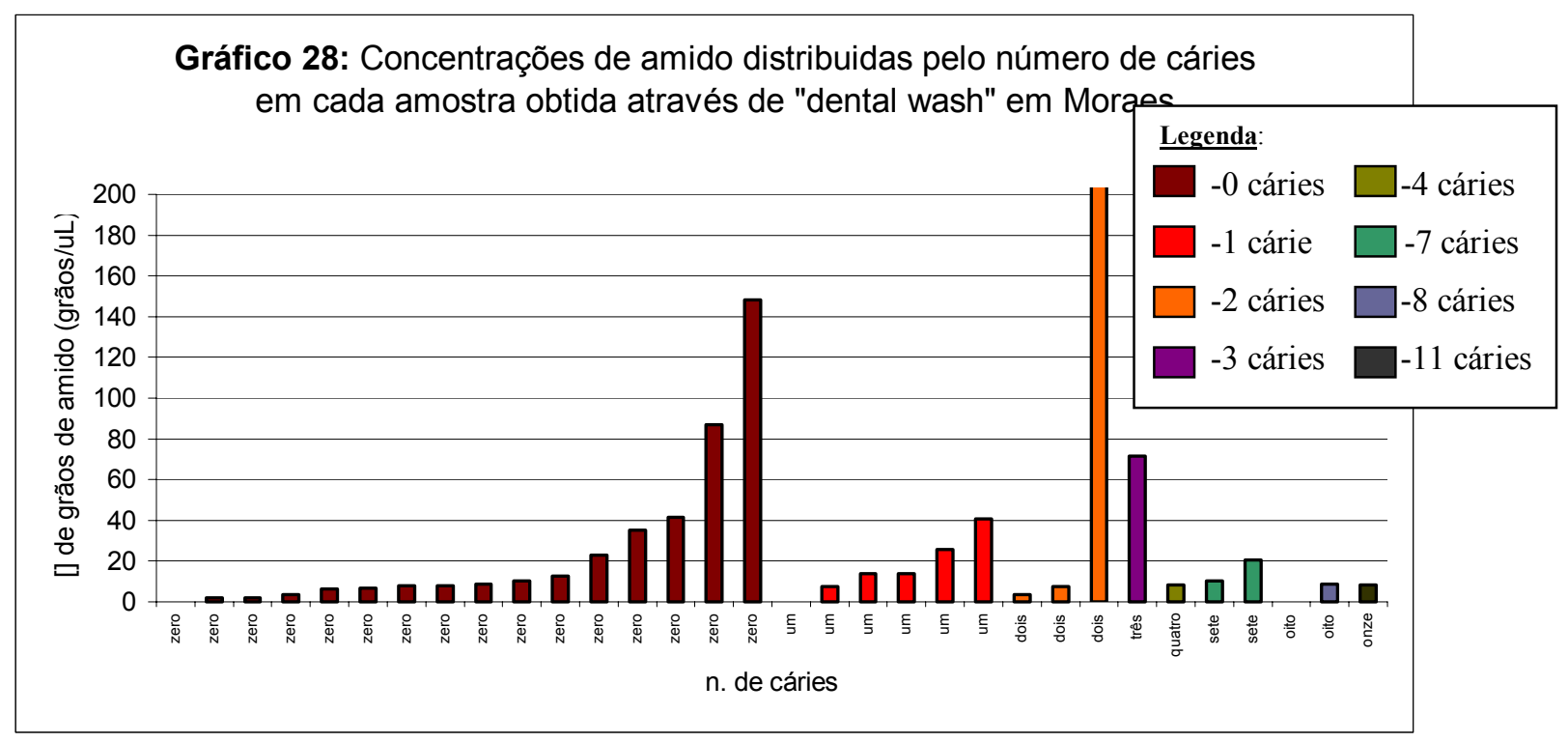

\begin{tabular}{|c|l|cr|}
\hline \multicolumn{2}{|c|}{ Tabela 13: Amostras de Moraes em que foram observados grãos de amido } \\
modificados
\end{tabular}

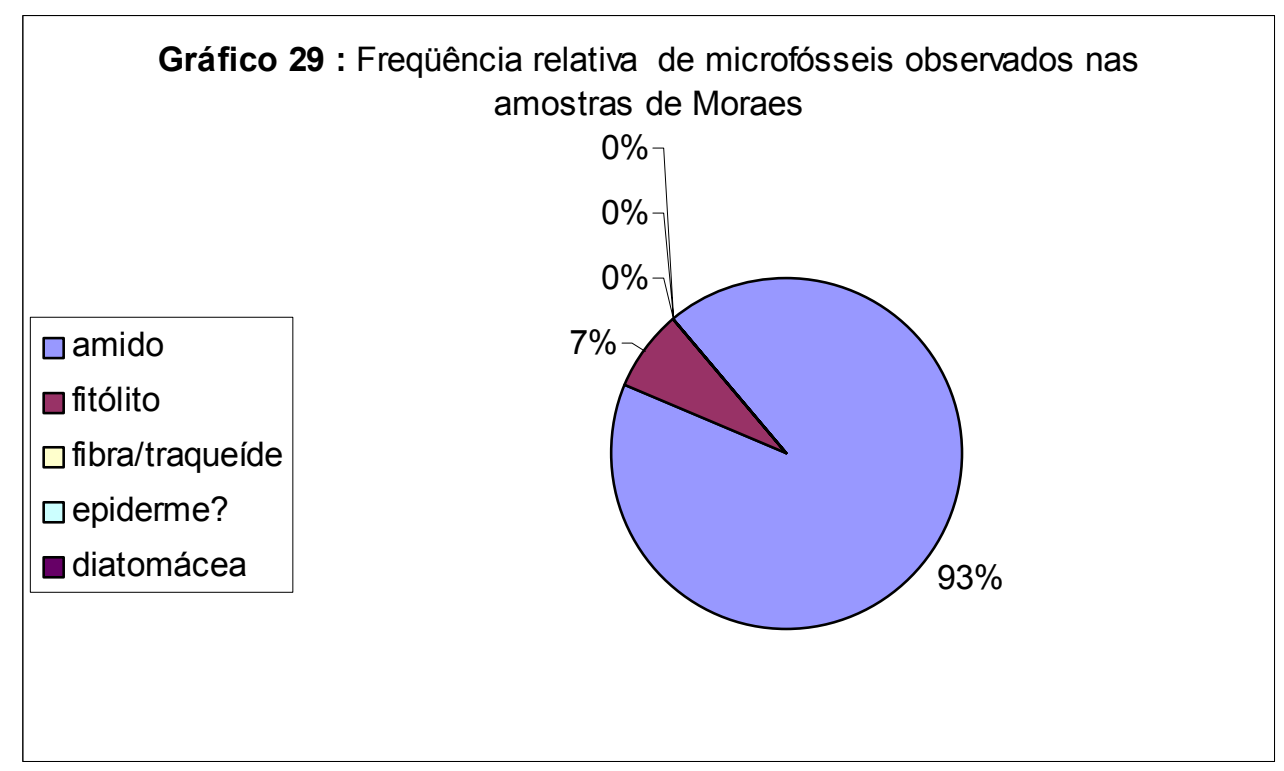




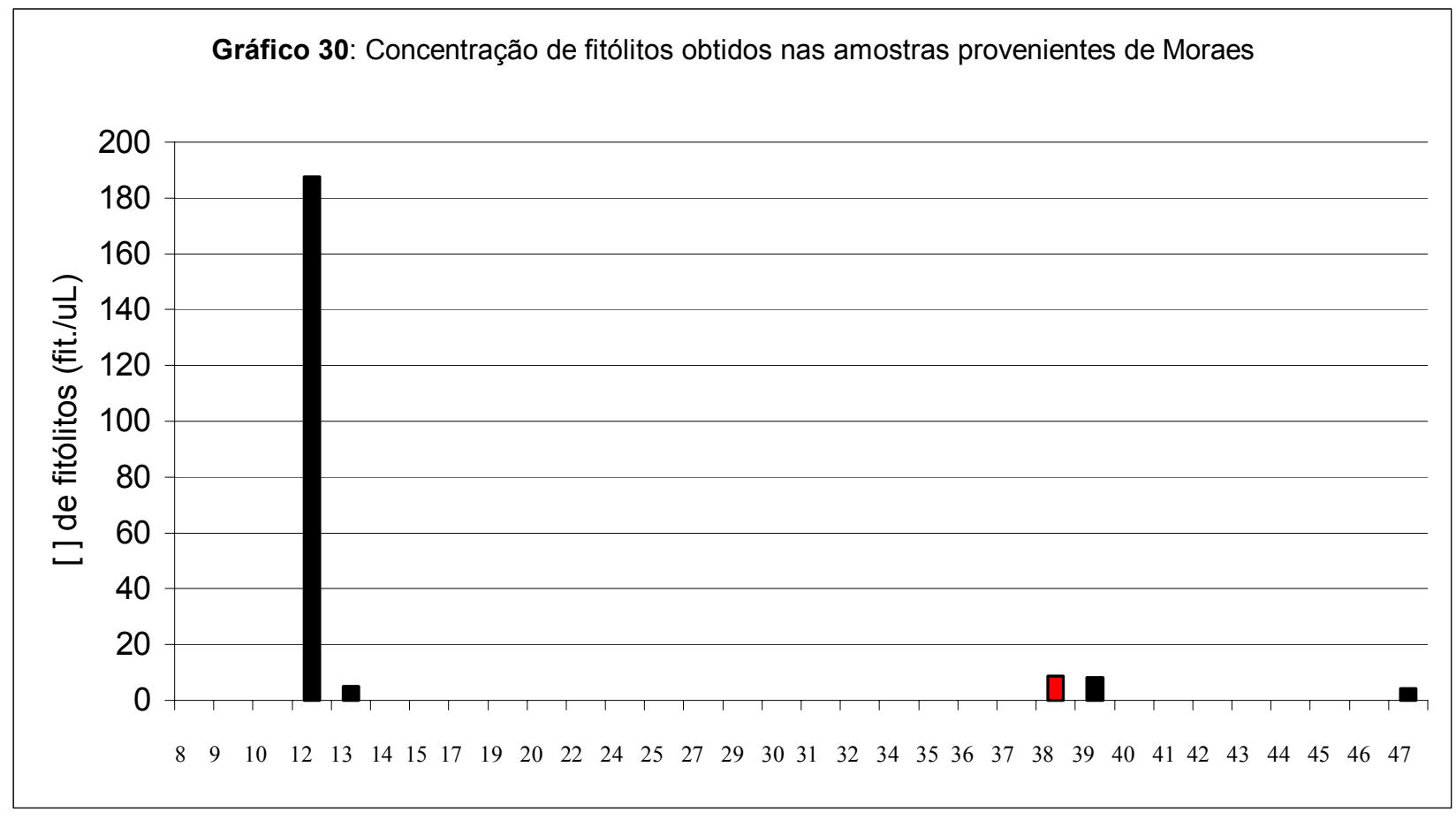

Legenda:

: Amostras retiradas de dentes posteriores $\square$ : amostras obtidas com dentes de ambas as dentições.

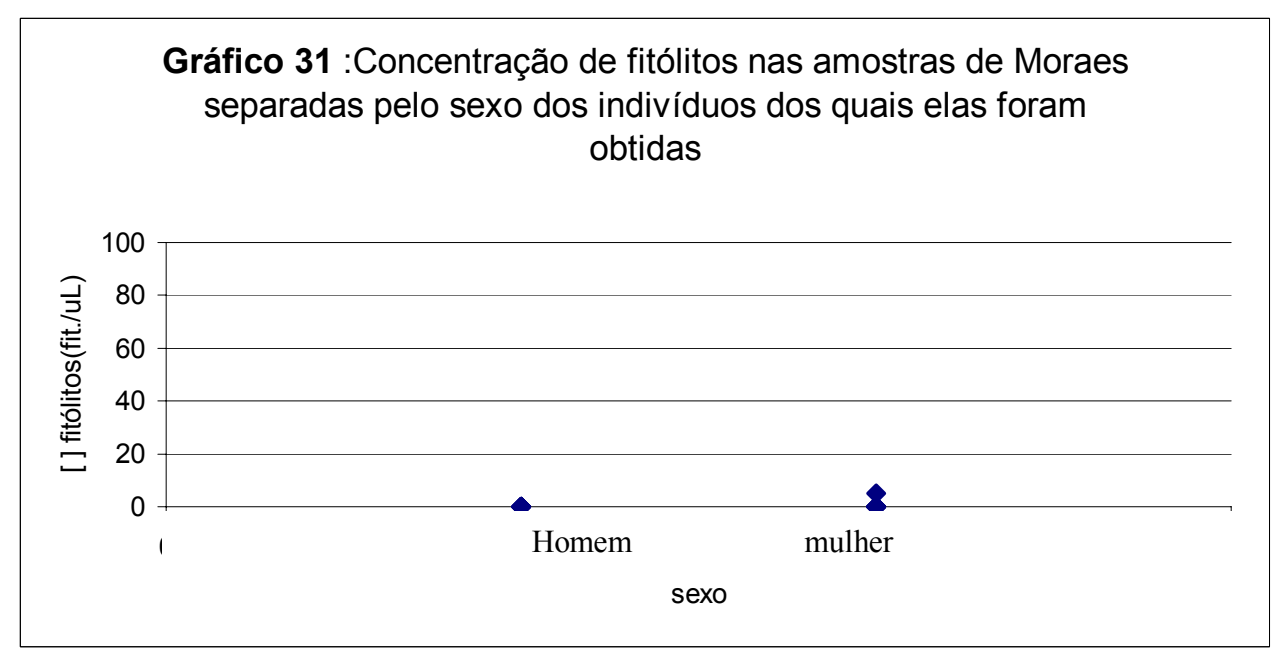



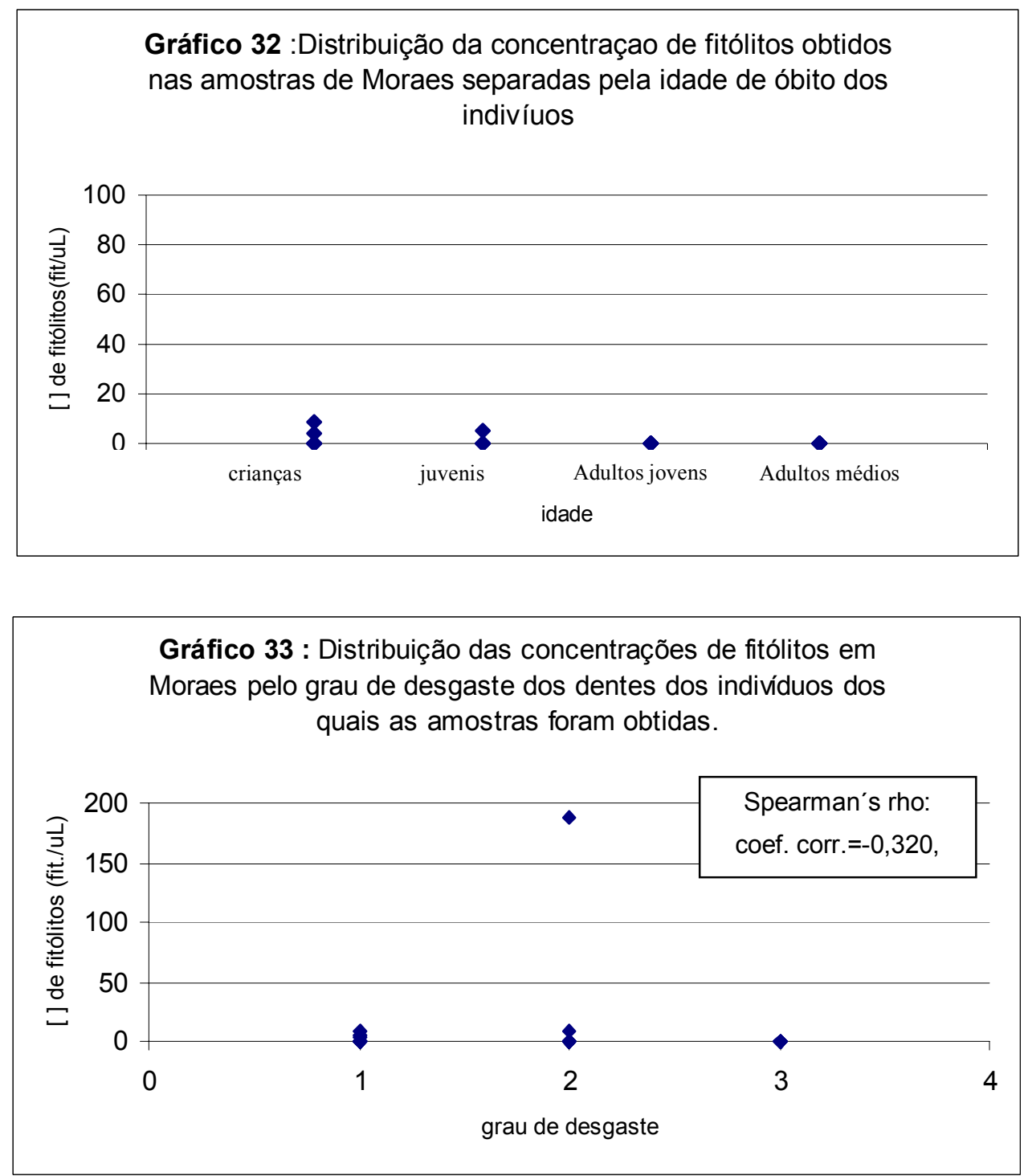


\section{4 - A dieta vegetal dos sambaquieiros de Moraes e Jabuticabeira II}

Uma vez constatada a comparabilidade entre o método tradicional (utilizado para obtenção de cálculo dentário dos indivíduos de Jabuticabeira II) e o "dental wash" (aplicado às dentições provenientes de Moraes), e descritas as características próprias para cada sítio, passa-se a discutir semelhanças e diferenças de dieta vegetal entre esses dois grupos sambaquieiros.

\subsection{1 - Concentrações de microfósseis, cáries, formação dos depósitos de cálculo:}

Tanto em Moraes, quanto em Jabuticabeira II, o número total de grãos de amido obtido nas amostras é expressivo, sugerindo um aporte de alimentos amiláceos importante para ambos os sítios. Isso está em conformidade com resultados recentes obtidos sobre outros sambaquis da região sul do país (Wesolowski, 2007). Porém, ao contrário do que se acreditava, até recentemente, sambaquis com cerâmica não apresentam freqüências ou concentrações maiores de grãos de amido do que sambaquis "pré-cerâmicos" (Wesolowski, 2007), assim como também não há maior freqüência de cáries em indivíduos provenientes de sambaquis ceramistas em comparação àqueles que não apresentam evidências de cerâmica (Wesolowski, 2000).

Enquanto em Moraes a proporção de fitólitos ( $7 \%$ do total de microfósseis obtidos) observados no total das amostras de cálculo é muito menor do que a proporção de grãos de amido (93\%) (Gráfico 29), em Jabuticabeira Il a proporção de fitólitos e grãos de amido é equilibrada ( $41 \%$ e $54 \%$ respectivamente, Gráfico 9). Entretanto, é interessante notar que, apesar do número total de fitólitos em Jabuticabeira II ser próximo do número total de grãos de amido, os fitólitos apresentam-se concentrados em apenas poucas amostras ( $24 \%$ do total de amostras), enquanto o amido está presente em $78 \%$ das amostras. Em Moraes, de forma semelhante, os fitólitos também se concentram em poucas amostras (16\%), enquanto os grãos de amido são observados em 93\% delas.

Assim sendo, as análises estatísticas não demonstraram diferença significativa das concentrações de fitólitos entre os dois sítios (Mann-Whitney: $p=0,344$ ) mesmo sem a exclusão das amostras discrepantes de Moraes (amostras 78 e 89 em questão). Também não é significativa a diferença entre número de amostras com e sem fitólitos de Jabuticabeira II e Moraes $\left(X^{2}=0,8667, p=0,3519\right.$; $\left.p F i s h e r=0,4202\right)$. Portanto, a proporção 
de fitólitos em Jabuticabeira II resulta muito alta mas está concentrada em uma parcela pequena das amostras e dos indivíduos analisados.

Já a concentração média de grãos de amido é significativamente maior em Moraes do que em Jabuticabeira II (Mann-Whitney $p=0,001$, excluindo-se os "outliers" de ambos os sítios, ou seja amostra 83 em Jabuticabeira II e amostras 8 e 12 em Moraes), conforme consta nos Gráficos 1 e 25 e nas Tabelas 1 e 11.

Uma possível explicação para o reduzido número de amostras com fitólitos enquanto a maioria delas contém grãos de amido, tanto em Jabuticabeira II quanto em Moraes, é necessária. Poderia se aventar a possibilidade destes sambaquieiros se valerem mais de vegetais contendo fitólitos de oxalato de cálcio (plantas da família Moraceae, por exemplo - Piperno, 2006) do que de vegetais com fitólitos de sílica. Sendo os fitólitos de oxalato de cálcio destruídos pelo ácido clorídrico durante o processamento para obtenção dos micro-resíduos a partir de cálculo dentário (Pearsall, 2000), a categoria fitólitos estaria, então, sub-representada artificialmente. Corroborando com essa interpretação, observam-se nas imagens obtidas através do microscópio eletrônico de varredura para o indivíduo do sepultamento XLla de Jabuticabeira II (Figura 15), estruturas semelhantes a fitólitos. Entretanto, as imagens ao MEV foram realizadas apenas em um dente de um único indivíduo, sendo este, um dos indivíduos em cuja amostra foram observados fitólitos. É possível que, se dentes de outros indivíduos fossem observados sob MEV, não seriam observados fitólitos.

Entretanto, Wesolowski (2007), valendo-se igualmente de técnicas a base de ácido clorídrico, observou freqüências mais altas de fitólitos em vários dos sambaquis da região sul por ela estudados, que, inclusive, encontravam-se em paleoambiente comparável ao de Jabuticabeira II. Portanto, a interpretação mais plausível para a escassez de fitólitos deste estudo não seria a utilização de $\mathrm{HCl}$ para obtenção das amostras, mais sim, uma dieta vegetal baseada, principalmente, em raízes e tubérculos, órgãos vegetais que, em geral, não contem fitólitos (Gott et al, 2006) e que são extremamente ricos em grãos de amido. Isso seria o caso, especialmente em Moraes. No entanto, deveria estar ocorrendo, também, uma diferenciação na dieta, com alguns indivíduos alimentando-se de grandes quantidades de (ou ingerindo com maior freqüência) órgãos vegetais ricos em fitólitos como folhas, caules, entre outros (Fox \& Pérez-Pérez, 1994), haja visto a distribuição desequilibrada das concentrações de fitólitos das amostras provenientes de ambos os sítios. 
De fato, evidências de tubérculos foram encontradas tanto em Jabuticabeira II, quanto em outros sambaquis costeiros da região sudeste do Brasil (Scheel-Ybert et al, 2003). Todos os tubérculos encontrados eram de monocotiledôneas e, embora alguns tenham sido identificados como Dioscorea sp (inhames) com ricos órgãos de reserva (Scheel-Ybert et al, 2003), outras espécies muito provavelmente também foram utilizadas. No mais, tubérculos foram encontrados em quase todos os estratos destes sítios, o que sugere uma larga utilização destas espécies pelos sambaquieiros da região sul e sudeste. Soma-se a isso o fato de que, em Jabuticabeira II, em torno de $10 \%$ dos artefatos líticos encontrados eram utilizados para o processamento de vegetais (Scheel-Ybert et al, 2003), porcentagem semelhante à encontrada em vários outros sambaquis (Beck, 1972; Garcia, 1972; Kneip, 1994; Uchoa, 1973). Tais evidências, assim como as evidências de grãos de amido modificados corroboram a hipótese de larga utilização de vegetais, especialmente ricos em amido, na dieta dos sambaqueiros estudados, sendo alguns destes alimentos, inclusive, processados antes de seu consumo.

Em paralelo a isso, também se observa uma freqüência significativamente maior de cáries em Moraes (18,00\%, Eggers et al, 2003a) do que em Jabuticabeira II (0,44\%, Okumura \& Eggers, 1995). Esta discrepância, além de ser observada para ambas as coleções osteológicas, como um todo, também foi verificada para as amostras de indivíduos estudados no presente trabalho (46,15\% dos indivíduos analisados de Moraes apresentam cáries, enquanto em Jabuticabeira II isto ocorre em apenas 5,88\%). Uma vez que alimentos amiláceos podem ser cariogênicos (Lingström et al, 2000), esses resultados corroboram com a interpretação de que os indivíduos de Moraes consumiam alimentos cariogênicos com maior freqüência e/ou intensidade que os indivíduos provenientes de Jabuticabeira II, visto que a concentração de amido em Moraes é significativamente maior do que em Jabuticabeira II.

Por outro lado, muitos fatores influenciam na forma e na freqüência com que a cárie acomete os indivíduos, e a dieta representa apenas um deles (Tayles et al, 2000, Wesolowski, 2007). Dietas ricas em carboidratos normalmente causam um aumento na freqüência de cáries (Cohen \& Armelagos, 1984; Klinberg, 2002 Turner II, 1979). Entretanto, existem alimentos que provocam efeito cariostático. A dieta marinha, por exemplo, pode ser vista como uma proteção contra lesões cariosas (Steckel \& Rose, 2002), como foi discutido anteriormente (Tópico 1.3.1.2). De fato, a subsistência dos indivíduos de Jabuticabeira II baseava-se, principalmente, em recursos marinhos e estuarinos (Klökler, 2000; Eggers et al, 2007). 
Outro fato que deve ser levado em consideração no intuito de explicar a baixa freqüência de cáries em Jabuticabeira II, apesar do importante aporte amiláceo, é o intenso desgaste dentário observado neste grupo. Os diversos fatores que provocam o desgaste, especialmente os relacionados à dieta (partículas duras presentes no bolo alimentar como fitólitos, areia e fragmentos de conchas), diminuem o relevo da superfície oclusal, impedindo a instalação das bactérias, além de poder, inclusive, levar à eliminação da própria lesão cariosa (Mendonça de Souza, 1995; Wesolowski, 2007). O próprio consumo de alimentos vegetais resistentes e ainda crus podem provocar abrasão dos dentes (Pearsall, 2000). Em Jabuticabeira II, como foi demonstrado, não há associação significativa entre desgaste dentário e presença de fitólitos, nem entre fibras e desgaste para-mastigatório, o que tornaria a utilização dos dentes como ferramentas para produção de artefatos menos provável. No entanto, ainda, há a possibilidade destes indivíduos terem feito uso dos dentes para descascar órgãos vegetais de reserva com epiderme resistente (como é o caso da mandioca) provocando desgaste (Pearsall, 2000), sem ocorrer agregação significativa de fitólitos ou fibras no cálculo dentário.

Além do desgaste dos dentes, até mesmo o próprio cálculo dentário (severo em Jabuticabeira II) poderia promover uma espécie de barreira protetora contra a ação danosa das bactérias cariogênicas (Greene et al, 2005). Diferenças no processo de mineralização da placa dentária estão relacionadas a uma maior ou menor ingestão de proteína animal. Quanto maior a proporção protéica na dieta, mais alcalino se torna o pH da boca, o que promove o aumento da precipitação de cálcio, levando a um processo mais rápido de mineralização da placa dentária (Kleinberg, 1961; Jin e Yip, 2002). Este processo, por sua vez, promoveria a formação de cálculos mais pesados, mas menos densos em micro resíduos (Wesolowski, 2007), já que, devido à velocidade de mineralização, poucos deles ficariam retidos na matriz. Já a menor ingestão de proteínas e aumento da ingestão de alimentos amiláceos tornam a mineralização da placa mais lenta, formando cálculos mais leves e com mais micro resíduos.

De acordo com estas observações, portanto, a baixa incidência de cáries em Jabuticabeira II, em comparação com a altíssima incidência de lesões cariosas em Moraes, deve ser resultado de diferenças quanto a) abrasividade da dieta (sendo ela muito maior em Jabuticabeira II do que em Moraes, mesmo não tendo relação, ao menos para estes sítios, com a presença de fitólitos nos cálculos dentários), b) a quantidade e qualidade do aporte protéico (mais recursos marinhos e, portanto, maior ingestão de flúor e cálcio em Jabuticabeira II do que em Moraes), e c) diferenças na velocidade e no 
acúmulo de cálculo dentário (muito maior em Jabuticabeira II e que, portanto, atuaria contra a formação de cáries nos indivíduos deste sítio).

De acordo com essas inferências, interpreta-se que houvesse uma importante ingestão de alimentos amiláceos em ambos os sítios aqui analisados. No entanto, as diferenças da velocidade de mineralização da placa dentária, ocasionada por diferenças na ingestão de proteínas, estariam contribuindo para haver uma maior concentração de grãos de amido nas amostras de Moraes (que teria uma dieta pobre em proteína marinha, o que é consistente com a localização do sítio e com os achados zooarqueológicos (Figuti, 2004), em comparação com Jabuticabeira II. Em contrapartida, o alto consumo protéico em Jabuticabeira II diminuiria a capacidade de retenção de microfósseis, incluindo amido, no cálculo dentário, em comparação com Moraes.

No entanto, enquanto em Jabuticabeira II há grandes depósitos de cálculo, o que corrobora a hipótese levantada, em Moraes restam apenas fragmentos de cálculo, sendo impossível avaliar se os depósitos originais eram grande ou pequenos, pesados ou leves.

Além disso, nos resultados apresentados no presente trabalho, diferentemente das concentrações de amido, as concentrações de fitólitos não diferem significativamente entre os dois sítios estudados, o que iria contra a idéia de que haveria uma preservação menor de microfósseis em Jabuticabeira II, devido a maior velocidade de mineralização da placa dentária. Ainda, e mais importante, foi demonstrada, aqui, uma correlação positiva dos pesos dos fragmentos de cálculo com a concentração de grãos de amido obtidas nas amostras em Jabuticabeira II, o que contradiz os dados obtidos por Wesolowski em sua tese (Wesolowski, 2007). Além do mais, outros autores acreditam que a maior ingestão de proteínas acarreta numa menor formação de cálculo dentário (Greene et al, 2005), ao contrário do que ela sustenta.

Para além das cáries e do desgaste dentário, existem outras patologias e características dentárias como abscessos, doença periodontal, hipoplasia linear do esmalte, que apresentam intensa relação com a dieta, apesar de sempre haver uma grande complexidade de fatores envolvidos na etiologia e desenvolvimento das mesmas (Larsen, 1997). Embora este trabalho trate da utilização de vegetais pelos construtores dos sambaquis, especialmente no que concerne sua dieta, alguns aspectos sobre patologia oral dos indivíduos analisados não constam dos objetivos e, portanto, não foram abordados. Planeja-se um estudo mais detalhado a esse respeito para que seus resultados, somados com aqueles apresentados aqui, tragam informações valiosas para a 
reconstrução dos hábitos alimentares e da subsistência dos pescadores-caçadorescoletores destes sambaquis.

\subsection{2 - Diferenças entre sexos e idade de óbito quanto à alimentação:}

Uma questão intrigante deste trabalho é a observação de fitólitos em apenas algumas poucas amostras, enquanto grãos de amido foram registrados para praticamente todas as amostras, tanto em Jabuticabeira II quanto em Moraes. A priori, isso sugere diferenças na alimentação entre os indivíduos (hipótese mais plausível das levantadas aqui). Assim, é necessário testar se esta diferença se dá por distinções alimentares entre homens e mulheres.

Para cada um dos sítios em separado, os resultados obtidos indicaram não haver diferença entre os sexos quanto às concentrações de amido e fitólitos. Também aqui se verificou não haver diferença significativa tanto para homens, quanto para mulheres, entre as concentrações de amido das amostras do sambaqui catarinense e do sambaqui paulista (Mann-Whitney: homens - $p=0,144$; mulheres $-p=0,055$ ).

Também não se encontrou diferença significativa de concentração de fitólitos tanto para homens, quanto para mulheres, entre os sítios (Mann-Whitney: homens - $p=0,244$; mulheres - $p=0,594)$. Entretanto, estes resultados devem ser vistos com cautela, já que as amostras para fitólitos são reduzidas. Assim passou-se a verificar a diferença do número de amostras masculinas com e sem fitólitos e o número de amostras femininas com e sem fitólitos entre os sítios. Entretanto, os resultados também não foram significativos (homens - $X^{2}=1,438, \quad p=0,231 ;$ pFisher=0,535; mulheres - $X^{2}=0,219, \quad p=0,640$; pFisher=1,000). A partir destes testes é possível afirmar que, muito provavelmente, não havia distinção entre a utilização dos recursos alimentares vegetais entre homens e mulheres em ambos os sítios, e nem entre os sítios.

Embora tenha sido objetivo do presente trabalho estudar a relação entre idade de óbito e concentração de microfósseis, não se obteve resultados informativos. Assim, não foi demonstrada relação estatisticamente significativa entre a idade de óbito dos indivíduos e as concentrações de amido tanto para Jabuticabeira II quanto para Moraes, nem entre idade e concentração de fitólitos para o primeiro sítio. Estes dados sugerem que não há aumento gradativo da quantidade de microfósseis ao longo do tempo, como poderia se imaginar (Greene et al, 2005). Essa ausência de relação entre microfóssies e 
idade talvez ocorra, como já havia sido discutido, por diferenças na dieta entre os indivíduos e, até, ao longo da vida de cada indivíduo.

Infelizmente, devido ao diminuto tamanho amostral, nenhum teste estatístico pode ser realizado para se verificar a relação entre as concentrações de fitólitos e idade em Moraes.

\subsection{3 - Outros microfósseis vegetais:}

Além dos grãos de amido e fitólitos, outras categorias de microfósseis foram observadas nas amostras de cálculo provenientes de Jabuticabeira II(Tabela 1), fato que não ocorreu em Moraes. Entretanto, a freqüência desse achado foi tão reduzida que impossibilitou qualquer interpretação contundente. De posse da coleção de referência de microfósseis vegetais provenientes da flora regional, a identificação destas raras evidências será possível, eventualmente acrescentando novas informações sobre o uso de vegetais desses grupos pré-históricos brasileiros.

\section{$\underline{4.5}$ - Paleodieta sambaquieira}

Resultados recentes demonstraram evidências da exploração de plantas para as mais diversas funções em sambaquis (Scheel-Ybert, 2000; 2001; Scheel-Ybert et al, 2003). Dentre estas evidências, a presença de grandes quantidades de grãos de amido no cálculo dentário (Boyadjian, et al, 2007a; Wesolowski, 2007) torna indiscutível o consumo de alimentos ricos em carboidratos na dieta de todos os grupos sambaquieiros estudados mais detalhadamente.

Enquanto para o grupo de Moraes um aporte amiláceo importante era esperado, devido à alta freqüência de cáries (Eggers et al, 2003a), para o grupo costeiro que construiu o sambaqui cemitério Jabuticabeira II, com baixo índice de cáries (Okumura \& Eggers, 2005), esse resultado foi surpreendente.

Uma identificação preliminar realizada a partir da comparação com a literatura (Torrence e Barton, 2006; Wesolowski, 2007; Zeder et al, 2006) sugere que, dentre os grãos de amido analisados em Jabuticabeira II e Moraes, haviam grânulos compatíveis com Dioscorea sp (inhames), com a família Araceae e com Ipomoea batatas (batata doce). Os grânulos de amido de Dioscorea sp e Ipomoea batatas indicam claramente o uso de órgãos de reserva como alimento, entretanto, embora atualmente hajam alguns 
gêneros de Araceae que são utilizados na alimentação (taro), há aqueles para fins medicinais (Balbach, 1979).

A presença de grãos de amido modificados no cálculo dentário de ambos os sítios estudados aqui, e naqueles analisados por Wesolowski (2007), inclusive, sugere que órgãos vegetais de reserva não só eram consumidos, como também eram preparados previamente antes da ingestão do alimento. Além disso, embora não seja possível determinar, até o presente momento, se os micro vestígios observados provinham de vegetais cultivados ou apenas coletados, visto que ainda não se pode realizar uma identificação mais segura destas partículas, há indícios que sugerem o manejo ou cultivo incipiente de algumas espécies em sambaquis da região Sul e Sudeste do país (ScheeYbert, et al 2003).

Embora ocorra um grande aporte de alimentos vegetais amiláceos em ambos os sítios, os dados indicam que alguns poucos indivíduos destes sambaquis tinham uma alimentação vegetal mais diversificada, consumindo, inclusive porções vegetais ricas em fitólitos, além dos tubérculos e raízes. Contudo, essa distinção entre os indivíduos no que concerne à dieta não se relaciona aos sexos.

Os resultados apresentados aqui não corroboraram a hipótese de que havia distinção entre o grupo sepultado no Lócus 2 e os demais lóci de Jabuticabeira II, nem entre os indivíduos do próprio Lócus 2. Portanto, também no âmbito da dieta vegetal, não é possível afirmar que as pessoas exumadas deste Lócus faziam parte de um grupo de afinidade.

Finalmente, com base nas evidências apresentadas aqui e em alguns outros trabalhos (Bandeira, 2004; Garcia, 1972; Scheel-Ybert 2000, 20001; Scheel-Ybert et al 2003; Tenório, 1991; Wesolowski, 2007), fica claro que a utilização de vegetais por sambaquieiros, inclusive no que concerne sua dieta, era expressiva. Portanto, apesar de ter sido sempre frisada a interpretação de que estes grupo estivessem adaptados a um modo de vida baseado em recursos aquáticos (especialmente marinhos para aqueles da costa), é necessário enfatizar, também, sua dependência em recursos vegetais, e, inclusive, deve ser levada em conta a possibilidade de manejo e cultivo de algumas espécies. Assim, o modelo sobre subsistência neste tipo de sítio arqueológico deve ser repensado e, não mais se deve limitar as discussões apenas ao aspecto protéico (de origem animal) da dieta. 


\section{Conclusões}

Tendo em vista os objetivos pretendidos, pode-se concluir a respeito dos resultados obtidos neste trabalho que:

* O método alternativo ("dental wash") desenvolvido para evitar perda de informação sobre paleodieta em contextos com pouca preservação de cálculo dentário se mostrou eficaz para a recuperação de microfósseis. Os resultados obtidos a partir dos mesmos indivíduos utilizando-se o método alternativo e o tradicional são semelhantes. Portanto, é possível comparar resultados obtidos através do método tradicional (neste caso, aplicado à coleção de Jabuticabeira II) com aqueles obtidos pelo método alternativo (utilizado na série osteológica de Moraes). No entanto, a técnica do "dental wash" deve ser empregada com critério e cautela, visto que pode causar danos à estrutura do dente, prejudicando análises de microdesgaste dentário.

* O grande número de grãos de amido, distribuído entre praticamente todas as amostras, e a concentração de fitólitos em poucas delas, tanto em Jabuticabeira II quanto em Moraes, levam a crer que a dieta vegetal dos grupos relacionados a estes sambaquis baseava-se, principalmente, em órgãos de reserva, ricos em amido e pobres em fitólitos. Entretanto, alguns poucos indivíduos em ambos os sítios parecem ter se alimentado de uma maior diversidade de vegetais, incluindo aqui aqueles ricos em fitólitos.

* No cálculo dentário dos indivíduos de ambos os sítios foram encontrados muitos grãos de amido com características diversas, além de grãos de amido modificados, o que indica o preparo de parte dos alimentos ricos em carboidratos.

* A concentração média de grãos de amido significativamente maior em Moraes do que em Jabuticabeira II pode ser interpretada à luz da maior freqüência de cáries observada dentre os construtores do primeiro em relação aos do segundo sitio. Isso sugere que o aporte amiláceo teria sido maior em Moraes.

* A ausência de correlação entre a concentração de amido e o número de cáries dentre os indivíduos de Moraes, por outro lado, reflete a complexidade da relação causal entre quantidade e freqüência de amido consumido e desenvolvimento de cáries. 
Sugere-se, também, que em Jabuticabeira e Moraes havia influência de outros fatores (como proporção e qualidade do aporte protéico e abrasividade da dieta como um todo) na modulação do desenvolvimento da lesão cariosa.

* Não havendo diferença nas concentrações de amido e fitólitos, nem tampouco de peso dos fragmentos de cálculo entre homens e mulheres, sugere-se não haver distinção no aporte vegetal da dieta entre os sexos em ambos os sambaquis.

* Somente em Jabuticabeira II foram encontradas fibras, traqueídes, fragmentos escuros e diatomáceas. Os primeiros dois tipos de microfóssil sugerem que, em Jabuticabeira II, houve um consumo mais variado de alimentos de origem vegetal que em Moraes. Os fragmentos escuros podem ser indício de combustível para produção de fogo ou, alternativamente, indicariam preparo de vegetais para o consumo alimentar. Por fim, as diatomáceas são mais um indício de que o aporte protéico dos indivíduos de Jabuticabeira II seja de origem aquática. Contudo, mais análises, em um número maior de amostras, se fazem necessárias para testar a veracidade destas afirmações.

* Não foi obtida evidência alguma de que fitólitos (em ambos os sítios) ou fibras (em Jabuticabeira II) fossem responsáveis pelo desgaste dentário (tanto de origem mastigatória, quanto aquele causado pelo uso dos dentes como ferramenta). Como este resultado provém de um número reduzido de amostras, não se pode excluir totalmente o uso dos dentes como ferramenta para produção de artefatos como cestaria e cordas, assim como para auxiliar em atividades cotidianas, como no arremesso de redes durante a pesca.

* Finalmente, para Jabuticabeira II, não se encontrou diferenças significativas de número, proporção ou concentração de grãos de amido entre os indivíduos do Locus 2 e os demais. Desta maneira, não se confirma a hipótese de que o Lócus 2 representa um grupo de afinidade, que se diferenciasse dos demais indivíduos deste sítio arqueológico devido a ausência de diferenças na dieta vegetal. 


\section{Limitações do Trabalho}

Como todo trabalho, este também apresenta limitações. Uma parte das limitações está atrelada à própria natureza, em geral, fragmentária, incompleta e mal preservada do material arqueológico. Este fato, embora tenha sido contornado parcialmente através do desenvolvimento de um método alternativo de recuperação de microfósseis (através do "dental wash"), impossibilitou análises multivariadas em geral e limitou testes estatísticos em certos casos.

A má preservação do material arqueológico, provocada por fatores tafonômicos, estocásticos e inerentes à escavação, em geral, é agravada quando os esqueletos são retirados do sítio, transportados ou acondicionados em laboratório de forma inadequada e sem os devidos cuidados (Mendonça de Souza, 1995). Estas condições ruins de preservação, aqui especialmente relacionadas ao material osteológico humano, limita drasticamente as possibilidades de determinação de sexo e idade, assim como as tentativas de diagnósticos diferenciais. Resultado disso são tamanhos amostrais reduzidos que limitam o poder interpretativo do bioarqueólogo. Este panorama se aplica, no contexto do presente trabalho, principalmente à coleção do sambaqui fluvial Moraes, onde o sexo não pode ser estimado em $60 \%$ e a idade em 35\% dos indivíduos.

Entretanto, não é somente a má conservação e preservação das coleções osteológicas que restringem as interpretações do bioarqueólogo. A ausência do mesmo em campo e a atenção dos arqueólogos escavadores voltada a outros aspectos que excluem os remanescentes humanos, prejudicam a qualidade de informação e documentação obtidas in loco. Desta maneira, fichas e diários de campo, croquis, mapas estratigráficos e análises osteológicas preliminares acabam acrescentando pouco às análises realizadas em laboratório. Este tipo de limitação impossibilitou encontrar explicações para o fato de fitólitos estarem concentrados em apenas alguns dos indivíduos, tanto de Jabuticabeira II, quanto de Moraes. Contudo, algumas informações essenciais para estas investigações não puderam ser obtidas, também, porque alguns estudos complementares sobre os esqueletos e os sítios, como análises de microfósseis vegetais do solo, análise do padrão de sepultamento, entre outros, ainda não foram realizados.

Os problemas enfrentados com relação à interpretação de resultados provenientes de Moraes se estenderam, também, ao fato da devolução da coleção osteológica ao Museu de Arqueologia e Etnologia ter sido exigida antes do prazo previsto. Em 
conseqüência, ao contrário do planejado, houve a necessidade de antecipar a aplicação do método "dental wash" em Moraes, mesmo antes de terem sido iniciados os testes de comprovação de comparabilidade.

Outro problema enfrentado se refere a impossibilidade da realização do teste de confiabilidade do "dental wash". Este problema advém de vicissitudes enfrentadas durante as etapas de escavação. Originalmente, planejava-se testar se os microfósseis encontrados no cálculo dentário pudessem ser provenientes de contaminação do solo. Teriam sido necessárias amostras de sedimento coletadas em regiões adjacentes aos dentes dos indivíduos a serem escavados em Jabuticabeira II. Entretanto, isso não foi possível devido à redução do número de esqueletos escavados nas últimas etapas de campo, à má preservação de mandíbulas e maxilas nos poucos sepultamentos evidenciados e a condições climáticas que impediram a permanência em campo (como um ciclone extratropical ocorrido na etapa de escavação do ano de 2005). Portanto, o teste de confiabilidade teve que ser protelado.

Apesar disso, é interessante notar que, embora este teste ainda não tenha sido realizado, muitos dos microfósseis encontrados nas amostras obtidas através do "dental wash", em Jabuticabeira II, estavam aderidos a estruturas semelhantes à matriz de cálculo, como acontece quando são observadas lâminas de amostras obtidas através do método tradicional. Isso leva a crer que tais microfósseis não seriam provenientes do solo do sítio adjacente aos dentes dos indivíduos, mas sim, provenientes dos restos de cálculo que ainda estavam aderidos ao esmalte dentário. Entretanto, somente após todos os testes terem sido realizados será possível afirmar se o "dental wash" é um método realmente viável e se sua eficácia compensa, inclusive, os danos causados.

Finalmente, embora o objetivo principal do presente trabalho tenha sido a quantificação dos tipos de microfósseis, somente poucos deles puderam ser atribuídos a algum táxon. A identificação segura dos micro-restos não é possível, ainda, devido à falta de coleções de referências e chaves de identificação destas partículas vegetais para as plantas da região estudada. Até o momento, consequentemente, a identificação destas partículas baseou-se, apenas, em semelhanças de morfologia detectadas em figuras e imagens obtidas através da literatura, o que não é o ideal, mesmo por que, muitos desses trabalhos enfocam regiões fitogeográficas distintas daquelas em que es inserem os sítios arqueológicos abordados no presente trabalho.

Contudo, essa deficiência será sanada em breve, através da elaboração de uma chave de identificação e um gabarito comparativo das plantas características das regiões 
de inserção destes sambaquis. Esta ferramenta fornecerá dados concretos para que se possa, finalmente, compreender quais eram as espécies consumidas na dieta alimentar de populações pretéritas que habitavam o sul e sudeste do Brasil. 


\section{Considerações Finais}

Além das dificuldades encontradas com a preservação do material arqueológico, devido aos próprios efeitos tafonômicos, deve-se lembrar que é necessário que sejam tomados cuidados durante o acondicionamento e tratamento do material em campo e durante o processo de curadoria. Para as análises de micro-resíduos vegetais, por exemplo, dados de extrema valia podem ser perdidos caso o sedimento obtido em campo seja mal acondicionado, porque estes resíduos (especialmente amido e grãos de pólen) podem deteriorar-se significativamente quando sujeitos a ação de microorganismos, umidade e calor. No mais, muitas vezes, o cálculo dentário é perdido com o excesso de escovação (indevida) dos dentes, durante o processo de curadoria. Portanto, em campo, além de arqueólogos, deve haver a presença de outros profissionais ligados à arqueologia como bioantropólogos, paleobotânicos, paleoparasitólogistas, para que sejam localizados, escavados e acondicionados os diferentes tipos de vestígios arqueológicos da forma mais adequada, a fim de se otimizar o poder informativo sobre estas populações pretéritas.

Quanto ao método alternativo ("dental wash") desenvolvido e testado no presente trabalho, uma vez que ele se mostrou eficaz para a recuperação de microfósseis a partir de marcas ínfimas de cálculo dentário, mas altera substancialmente a superfície dental impedindo análises de microdesgaste, sugere-se sua aplicação somente sob as seguintes condições:

- Que sejam selecionados para aplicação do "dental wash" apenas dentes que já foram analisados previamente quanto à morfologia, paleopatologia e ao microdesgaste e cujas imagens e informações foram devidamente registradas e;

- que sejam submetidos ao "dental wash" apenas dentes que serão utilizados posteriormente, para as análises destrutivas como as de isótopos estáveis ou de recuperação de DNA antigo.

Por fim, um dos objetivos principais de estudos futuros será a confecção de uma coleção de referência para grãos de amido e fitólitos das regiões sul e sudeste do Brasil, especialmente da costa. Isso possibilitará a identificação das partículas observadas no cálculo dentário das coleções estudadas aqui e essa identificação poderá, inclusive, ser extendida para micro-resíduos vegetais de artefatos líticos e cerâmicos, sedimentos, coprólitos, e cálculo dentário de outros sítios da região. 


\section{Resumo}

A análise de microfósseis vegetais é extremamente útil para a recuperação de informações acerca da utilização de plantas por grupo humanos do passado, especialmente em sítios arqueológicos em que os macro-restos botânicos são raros, como é o caso dos sambaquis. Estes micro-restos podem ser obtidos a partir de sedimento, coprólitos, utensílios de pedra ou cerâmica, assim como de cálculo dentário (tártaro). Durante a mastigação e a utilização dos dentes como ferramentas, micro partículas provenientes do alimento ou da matéria prima utilizada, como grãos de amido, fitólitos, fibras, ficam retidas na matriz do cálculo, podendo ali permanecer protegidas por milhares de anos. O tratamento químico do cálculo permite a recuperação destes microfósseis, que, uma vez quantificados e identificados, fornecem dados valiosos para a reconstrução de hábitos e dieta. Entretanto, existem sítios em que, além da má preservação dos macro-restos vegetais, restam apenas escassas marcas de cálculo dentário aderidos aos dentes, impedindo a obtenção de fragmentos de cálculo e conseqüentemente a recuperação dos microfósseis.

A utilização de recursos vegetais pelos grupos construtores de sambaquis constitui uma área do conhecimento ainda pouco explorada. Dentre os sambaquieiros há aqueles com depósitos fartos de cálculo dentário, como é o caso em Jabuticabeira II (SC), mas também há aqueles que apresentam somente reduzidos depósitos de cálculo, como é o caso em Moraes (SP). Assim, os objetivos deste trabalho foram: processar e analisar quantitativamente o conteúdo do cálculo dentário de indivíduos de Jabuticabeira II; desenvolver e testar um método alternativo que permitisse a recuperação de microfósseis a partir de marcas de cálculo dentário ("dental wash”); aplicar este método alternativo nos indivíduos de Moraes e comparar os resultados obtidos entre os dois sítios.

Através dos resultados obtidos concluiu-se que:

- O método "dental wash" é eficiente para a recuperação de micro partículas a partir de marcas exíguas de cálculo dentário, e seus resultados são comparáveis àqueles obtidos através da técnica tradicional. Contudo, o "dental wash" pode tornar os dentes mais friáveis, prejudicando análises morfológicas e de microdesgaste.

- Foram observados grãos de amido em praticamente todas as amostras de Jabuticabeira II e Moraes, enquanto fitólitos somente foram encontrados em poucas delas. Isso indica um importante aporte de alimento amiláceo em ambos os sítios, enquanto que apenas 
alguns indivíduos consumiam uma dieta mais diversificada, constituída em parte de vegetais ricos em fitólitos.

- Grãos de amido modificados (em ambos os sítios) e fragmentos escuros de origem vegetal (somente em Jabuticabeira II) indicam o preparo de alimentos através de cocção, maceração, abrasão.

- A concentração média dos grãos de amido significativamente maior nas amostras de Moraes em comparação com Jabuticabeira II sugere que o aporte amiláceo tivesse sido maior em Moraes, o que é confirmado indiretamente através da maior freqüência de cáries.

-Não parece ter havido distinção no aporte vegetal da dieta entre os sexos, já que não houve diferença das concentrações de amido e fitólitos entre homens e mulheres de Jabuticabeira II e Moraes. 


\section{Abstract}

The analysis of vegetal microfossils is paramount for the recovery of informations about plant use in past human groups, especially in archaeological contexts where macro remains are poorly preserved (as in shellmounds or sambaquis). Micro remains can be recovered from sediments, coprolites, stone artefacts, pottery, as well as from dental calculus. During the mastication and the use of the teeth as tools, micro particles like starch grains, phytoliths and fibers, become trapped in the dental calculus matrix. Chemical processing of dental calculus permits the extraction of microfossils. Quantification and identification allows reconstruction of habits and diet of past human groups. However, there are sites in which the calculus deposits do not preserve well enough to be processed using the traditional method.

The plant use by Brazilian shellmound groups is still an underexplored matter. Among these there are groups like Jabuticabeira II (SC) with large deposits of dental calculus, where the traditional method can be applied, as well as others with just faint dental calculus marks, like Moraes (SP).

Therefore, the aims of this work are to: process and analyse dental calculus contents from Jabuticabeira II individuals; develop and test a new method for the recovery of microfossils form cryptic dental calculus marks (dental wash); apply the dental wash in Moraes teeth; and, finally, to compare the results between both sites.

The data obtained permit the following conclusions:

-The dental wash technique is efficient for the recovery of microfossils from faint dental calculus marks and the results are comparable to those obtained by the traditional method. However, dental wash can preclude morphological and microwear analyses.

- Starch grains were observed in almost all samples from both sites but the phytoliths were obtained only from few of them. This indicates that the vegetal diet in these sites was based mainly in storage organs of plants where only few individuals had a more diverse food intake, consuming also vegetal parts rich in phytoliths.

- Modified starch grains found in both sites and dark plant fragments (charcoal) found only in Jabuticabeira II suggest food preparation.

- The significant higher concentrations of starch grains in Moraes than in Jabuticabeira II, suggests that the intake of carbohydrate rich food was higher in Moraes. Indeed, this is corroborated by a much higher caries rates in the latter site. 
-The absence of differences of starch and phytolith concentrations between men and women suggest that there was no distinction in the plant food consumed between the sexes. 


\section{Apêndice}

\section{Protocolo 1: Dissolução do Cálculo Dentário}

- Coloque os fragmentos de cálculo em um eppendorf de $2 \mathrm{ml}$ junto com um tablete de Lycopodium;

- Complete o volume do eppendorf com ácido clorídrico $(\mathrm{HCl} 10 \%)$ aos poucos, para evitar extravasamento do material, devido à efervescência, e espere até que o tablete seja dissolvido;

- Centrifugue, em 500 RPM, por 5 minutos;

- Decante o $\mathrm{HCl}$ até sobrar só o precipitado e complete o volume com água destilada (lavagem com água destilada);

- Centrifugue por mais 5 minutos, em 500 RPM;

- Repita a lavagem com água destilada e a centrifugação;

- Decante a água e transfira o precipitado para um outro recipiente fazendo enxágüe com etanol $100 \%$.

\section{Protocolo 2: "Dental Wash"/ Lavagem dos Dentes}

- Coloque os dentes soltos em um béquer com $50 \mathrm{~mL}$ de água destilada, por 3-5 minutos para deixar que a água penetre;

- Retire os dentes da água e coloque-os em um béquer com ácido clorídrico ( $\mathrm{HCl} 2 \%$ ), de modo que apenas a coroa fique imersa no ácido, por 5 minutos.

- Escove esses dentes com uma escova de dentes comum nova, para garantir que a maioria dos resíduos dos microfósseis se desprendam e mergulhe suas cerdas no ácido;

- Retire os dentes do béquer e despeje o ácido com os resíduos em um tubo de centrífuga;

- Enxágüe o béquer com água destilada e despeje essa água no tubo de centrífuga, para que algum resíduo que tenha sobrado no béquer não seja descartado; 
- Adicione 2 tabletes de Lycopodium sp. no tubo, espere dissolver e, então, centrifugue por 2 minutos, em 1500 RPM;

- Finalmente, decante o $\mathrm{HCl}$, preencha o tubo com água destilada, agite o precipitado com a ajuda de um bastão de vidro e centrifugue novamente na mesma velocidade pelo mesmo tempo.

- Retire a água destilada, coloque um pouco de etanol (100\%) e transfira o material para um outro recipiente fechado.

Ficha utilizada para catalogação dos microfósseis observados:

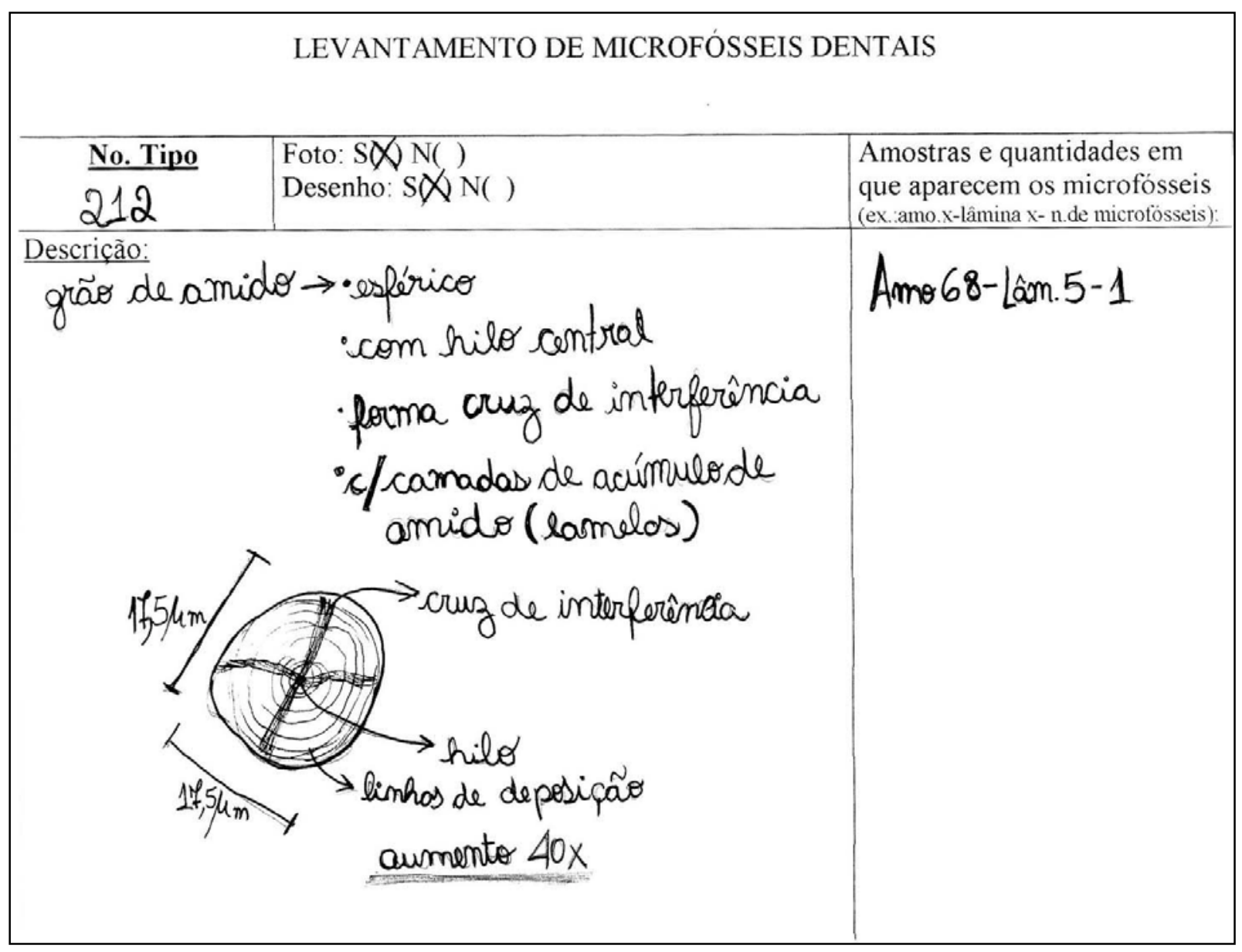




\section{Referências Bibliográficas}

Adde SMdiSS, Duarte CA. O papel do cálculo dentário na cárie e doença periodontal. Revista da Associação Paulista de Cirurgiões Dentistas. 1990; 44(6): 313-316.

Alcorn JB. The scope and aims of ethnobotany in a developing world. In: Schultes RE, von Reis S. Ethnobotany: Evolution of a Discipline. Timber Press, Oregon, EUA. 1995.

Ânerud $\AA$, Löe $\mathrm{H}$, Boysen $\mathrm{H}$. The natural history and clinical course of calculus formation in man. Journal of Clinical Periodontology. 1991; 18:160-170.

Angulo JR, Lessa G. The Brazilian sea level curves: a critical review with emphasis on the curves from the Paranaguá and Cananéia regions. Marine Geology. 1997; 140:141-166.

Anneroth G, Eneroth CM, Isacsson G, Lundiquist PG. The ultrastructure of salivary calculi. Scandinavian Journal of Dental Research. 1977.

Armitage PL. The extraction and identifivation of opal phytoliths from the teeth of ungulates. J Archaeol Sci 1975; 2: 187-197.

Babot MDP. Damage on starch from processing andean food plants. In: Torrence $\mathrm{R}$, Barton $\mathrm{H}$; organizadores. Ancient Starch Research. Walnut Creec: Leaf Coast press. 2006. p66-67.

Balbach A. A flora nacional na medicina doméstica: plantas medicinais 2.. A edificação do lar, Rio de Janeiro. 1979. $6^{\text {a }}$. ed.

Baker G. Fossil Opal-phytoliths. Micropaleontology. 1960a; 6:79-85 Appud Piperno DR. Phytolith Analysis: An Archaelogical and Geological Perspective. Academic Press Inc. USA. 1988.

Baker G. Phytoliths in some Australian dusts. Proceedings of the Royal Society of Victoria 1960b; 72:21-40. Appud Piperno DR. Phytolith Analysis: An Archaelogical and Geological Perspective. Academic Press Inc. USA. 1988.

Bandeira DR. Mudança na estratégia de subsistência do sítio arqueológico Enseada I: um estudo de caso. [ dissertação de Mestrado]. Florianópolis: Universidade Federal de Santa

Catarina; 1992. 127p.

Bandeira DR Ceramistas pré-colonias da baía da Babitonga, SC : Arqueologia e etnicidade. [Tese de doutorado]. Campinas Universidade: Estadual de Campinas; 2004. 257p.

Bartolomucci LBG. Variabilidade biológica entre sambaquieiros: um estudo de morfologia dentária. [dissertação de Mestrado]. São Paulo: Instituto de Biociências da Universidade de São Paulo. 2006. 105p.

Barreto CNGB. A ocupação pré-Colonial do Vale do Ribeira de Iguape, SP: Os Sítios Concheiros do Médio Curso. [dissertação de mestrado]. São Paulo: FFLCH -USP; 1988.

Beck A. A variação no conteúdo cultural dos sambaquis. Litoral de Santa Catarina. [tese de doutorado] São Paulo: Universidade de São Paulo; 1972.

Beck A, Sambaquis: tecnologia e subsistência. Anais do Museu de Antropologia UFSC. 1978; 10(11):124138.

Beck W, Torrence R. Starch Pathways. In:Torrence R, Barton H. (eds.) Ancient Starch Research. Walmut Creek: Leaf Coast Press, California; 2006. p58-60

Bernimoulin JP. Recent Concepts in Plaque Formation. Journal of Clinical Periodontology. 2003; 30 (Suppl. 5): 7-9.

Bissa WM, Ybert JP, Catharino ELM, Kutner M. Evolução paleoambiental na planície costeira do baixo 
ribeira durante a ocupação sambaquieira. Revista do Museu de Arqueologia e Etnologia da USP. São Paulo. 2000; 10:89102.

Boyadjian $\mathrm{CH}$, Eggers S. A Exostose Auditiva como Marcador de Atividade Gênero-Específica em Populações Construtoras dos Sambaquis. $10^{\circ}$ Simpósio Internacional de Iniciação Científica (SIICUSP), Ribeirão Preto, São Paulo. 2002.

Boyadjian $\mathrm{CH}$, Eggers S. Exostose Auditiva como Marcador de Atividade em Populações Construtoras dos Sambaquis. $11^{\circ}$ Simpósio Internacional de Iniciação Científica (SIICUSP), Ribeirão Preto, São Paulo. 2003a.

Boyadjian $\mathrm{CH}$, Eggers $\mathrm{S}$. A exostose auditiva como marcador de atividade em populações construtoras dos sambaquis. In: Arqueologia da América Latina. XII congresso da Sociedade de Arqueologia Brasileira; São Paulo, 2003. Abstracts. Sociedade de Arqueologia Brasileira; 2003b

Boyadjian CHC, Okumura MMM, Eggers, S. A Influência Ambiental na Formação das Exostoses do Meato Auditivo Externo: Um Estudo Comparativo nos Grupos Pré-históricos da Costa Brasileira. Anais do XIII Congresso da Sociedade de Arqueologia Brasileira. Revista SAB. 2005.

Boyadjian CHC, Eggers S, Reinhard K. Dental Wash: A Problematic Method for Extracting Microfossils from Teeth. Journal of Archaeological Science. 2007; 34(10): 1622-1628.

Boyadjian, CHC, Kucera M, Pany D, Reinhard K, Eggers S. In: XIV Congresso da Sociedade de Arqueologia Brasileira. Florianópolis, Santa Catarina, 2007b. Abstracts Sociedade de Arqueologia Brasileira.

Boyadjian $\mathrm{CH}$, Perrotta R, Reinhard KJ, Eggers S. Microfossils in dental calculus and sediments from a Brazilian sehllmound: what do they reveal about diet and plant management?. Symposium "Bioarchaeology from the midst of Shells" (org:E Cunha, S Mendonça, S Eggers). XV Congress of the International Union for Prehistoric and Protohistoric Sciences, Lisboa. 2006

Bryant VMJ. Prehistoric Diet in Southwest Texas: The Coprolite Evidence. American Antiquity. 1974; 39:407420.

Bryant VMJ, Morris DP.. Uses of Ceramic Vessels and Grinding Implements: The Pollen Evidence. In: Morris DP. Archeological Investigations at Antelope House. National Park Service Publications in Archaeology no. 19. National Printing Office, Washington, D.C; 1986. pp. 489-500.

Brothwell DR. Digging up bones. Londres: Oxford University Press; 1981. 200p.

Calippo FR. Os sambaquis submersos de Cananéia: um estudo de caso de arqueologia subaquática. [dissertação de Mestrado] Universidade de São Paulo, São Paulo. 2004.

Canis FM, Kramer GM, Pameijer CM. Calculus attachment: Review of the literature and new findings. Journal of Periodontology. 1979; 50(8):406-15.

Ciochon RL, Piperno DR, Thompson RG. Opal phytoliths found on the teeth of the extinct ape Gigantopithecus blacki:implications for paleodietary studies. Proc Natl Acad Sci 1990; 87: 8120-4

Cohen MN, Armelagos GJ. Paleopathology at the origins of agriculture. Nova York: Academic Press; 1984. $615 p$.

Cortella AR, Pochettino ML. Starch Grain Analysis as a Microscopic Diagnostic Feature in the Identification of Plant Material. Economic Botany. 1994; 48(2):171-181.

Danielson DR, Reinhard KJ. Human Dental Microwear Caused by Calcium Oxalate Phytoliths in Prehistoric Diet of the Lower Pecos Region, Texas. American Journal of Physical Anthropology. 1998; 107:297-304.

De Blasis PAD, Fish SK, Gaspar MD, Fish PR. Some References for the Discussion of Complexity among the Sambaqui Moundbuilders from the Southern Shores of Brazil. Revista de Arqueologia Americana.1998; 15: 75-105.

De Blasis Gaspar MD, Giannini PC, Figuti L, Eggers S, Scheel-Ybert R, Afonso MC, Farias DF, Kneip A, Mendonça $A B$, Ybert JP, Klökler D, Sawakuchi A, Barbosa PN, Bendazzoli C, Ribeiro FVA, Ariza M. 
Processos formativos nos Sambaquis do Camacho, SC: Padrões funerários e atividades cotidians. Relatório final FAPESP; São Paulo. 2004.

De Blasis P, Kneip A, Schee-Ybert R, Giannini PC, Gaspar MD. Sambaquis e paisagem: Dinâmica natural e arqeuologia regional no litoral do sul do Brasil. Arqueologia Suramericana/Arqueologia Sul-Americana. 2007; 3(1): 29-61.

De Masi MA.Prehistoric hunter-gathers mobility on the Southern Brazilian coast: Santa Catarina Island.[Teses de doutorado] Stanford: Universidade de Stanford; 1999.

Dent VE, Marsh PD. Evidence for a Basic Plaque Microbial Community on the Tooth Surfaces of Animals. Archives of Oral Biology. 1981; 26:171-79.

Dickau R, Ranere J, Cooke RG. Starch grain evidence for preceramic dispersals of maize and root drops into tropical dry and humid forests of Panamá.

Dimbleby GW. The Palynology of Archaeological Sites. Academic Press, London. 1985.

Dillehay TD, Rossen J, Andres TC, Williams DE. Preceramic adoption of peanut, squash and cotton in Northern Peru. Science. 2007; 316:1890-1893.

Epstein E. The Anomaly of Silicon in Plant Biology. Procedings of the National Academy of Sciences USA. 1994; 91:11-17. Appud: Piperno DR. Phytoliths: A Comprehensive Guide for Archaeologists and Paleoecologists. Altamira Press, New York. 2006. 238p.

Eggers S. Riverine versus Coastal Shellmounds in Brasil. Symposium "Bioarchaeology from the midst of Shells" (org:E Cunha, S Mendonça, S Eggers). XV Congress of the International Union for Prehistoric and Protohistoric Sciences, Lisboa. 2006.

Eggers S, Plens CR, Filippini J, Wesolowski V, Petronilho C; Boyadjian CH, Bartoloucci R, Giardini LB. Bioarqueologia dos sambaquis fluviais do Vale do Ribeira. In: XII Congresso da Sociedade de Arqueologia Brasileira, São Paulo. Revista SAB. 2003a.

Eggers S, Filippini J, Wesolowski V, Petronilho CC, Boyadjian CH, Bartolomucci R, Giardini LB. Bioarqueologia dos sambaquis fluviais do Vale do Ribeira. Anais do XII Congresso da Sociedade de Arqueologia Brasileira. [CD-rom]. 2003b

Eggers, S. Okumura, M.M.M. Boyadjian, C.H.C. 2006. Auditory exostoses as an aquatic activity marker: a comparative analysis between coastal and inland skeletal remains from tropical and subtropical regions in Brazil. 16th Palaeopathology Association Meeting Europe, Santorini.

Edwards HGM, Farwell DW, Faria DLA, Monteiro AMF, Afonso MC, DeBlasis P, Eggers, S. Raman spectroscopic study of 3000 year-old human skeletal remains from a sambaqui, Santa Catarina, Brazil.Journal of Raman Spectroscopy. 2001;32:17-22.

Esau K. Vascular Differentiation in Plants. 1965. Apud: Pearsall DM. Paleoethnobotany: A Handbook of Procedures. New York: Academic Press. Second Edition. 2000.

Ferreira CS, Carvalho ME. Diafanização de esfregaços de fezes. Revista de Saúde Pública, São Paulo. 1972; 6 (1).

Figuti, L. O homem pré-histórico, o molusco e o sambaqui: considerações sobre a subsistência dos povos sambaquieiros. Revista do Museu de Arqueologia e Etnologia 1993; 3: 67-80.

Figuti L. Os Sambaquis Fluviais do Vale do Ribeira. In: XII Congresso da Sociedade de Arqueologia Brasileira; São Paulo, 2003. Abstracts. Sociedade de Arqueologia Brasileira; 2003. p44-45.

Figuti L. Investigações Arqueológicas e Geofísicas dos sambaquis fluviais do vale do Ribeira de Iguape, Estado de São Paulo. Relatório Final de Atividades de Projeto Temático (FAPESP no. 99/12684-2) 2004. 
Filippini J. Biodistância entre sambaquieiros fluviais e costeiros: Uma abordagem não-métrica craniana entre três sítios fluviais do vale do Ribeira - SP (Moraes, Capelinha e Pavão XVI) e três costeiros do sul e sudeste do Brasil (Piaçagüera, Jabuticabeira II e Tenório). [dissertação de Mestrado] Museu de Arqueologia e Etnologia da USP. 2004.

Filippini J, Eggers S. Testando a proximidade biológica entre sambaquieiros fluviais (Vale do Ribeira, SP) e costeiros (litoral sul e sudeste) do Brasil. In: XIII Congresso da Sociedade de Arqueologia Brasilieira. Campo Grande - MT. Abstracts. Soceidade de Arqueologia Brasileira. 2005.

Filippini J, Eggers S. Distância Biológica entre Sambaquieiros Fluviais (Moraes - Vale do Ribeira - SP) e Construtores de Sítios Litorâneos (Piaçagüera e Tenório - SP e Jabuticabeira II -SC). Revista do Museu de Arqueologia e Etnologia da USP n.15/16. 2005/2006.

Fish SK, De Blasis PAD, Gaspar MD, Fish PR. Eventos Incrementais na Construção de Sambaquis, Litoral Sul do Estado de Santa Catarina. Revista do Museu de Arqueologia e Etnologia 2000; 10: 69-87.

Fox CL, Juan J, Albert R. Phytolith Analysis on Dental Calculus, Enamel Surface and Burial Soil: Information About Diet and Paleoenvironmet. American Journal of Physical Anthropology. 1996; 101:101-114.

Fox CL, Pérez-Pérez A. Dietary Information through the Examination of Plant Phytoliths on the Enamel Surface of Human Dentition. Journal of Archaeological Science. 1994; 21:29-34.

Garcia CR Estudo comparativo das fontes de alimentação de duas populações préhistóricas do litoral paulista. [Tese de Doutorado]. São Paulo: Instituto de Biociências; Universidade de São Paulo; 1972.

Gaspar MD. Considerations of the Sambaquis of the Brazilian Coast. Antiquity. 1998; 72: 592-615.

Gaspar MD, Afonso M, De Blasis P, Eggers S, Figuti L, Fish P, Fish S, Klökler DM, Lahr MM, Morley E. Uma Breve História do Projeto de Pesquisa "Padrão de Assentamento e Formação de Sambaquis: Arquelogia e Preservação em Santa Catarina".Ver. CEPA, Santa Cruz do Sul. 1999; 23:108-117.

Gill ED. Stability of Biogenetic Opal. Science. 1967; 158-810.

Greene TR, Kuba CL, Irish JD. Quantifying Calculus: A Suggested New Approach for Recording an Important Indicator of Diet and Dental Health. HOMO-Journal of Comparative Humen Biology. 2005; 56: 119132.

Giardini LB, Eggers S. Variações morfológicas dentárias em sambaquieiros.. In: XII congresso da Sociedade de Arqueologia Brasilieira, 2003, São Paulo. Anais do XII Congresso da Sociedade de Arqueologia Brasileira.

Gott B, Barton H, Samuel D, Torrence R. Byology of Starch in: Torrence R, Barton H. Ancient Starch Research. Left Coast Press Inc. Califonia. 2006; pp 35-45.

Hazen SP. Supragingival Dental Calculus. Periodontology 2000. 1995; 8: 125-136.

Helbaek H. The Domestication of Food Plants in the Old World. Science. 1959; 130:365-372.

Hillson S. Dental Anthropology. Cambridge: Cambridge University Press; 1996.

Hodson MJ, Sangster AG, Parry DW. An Ultrastructural Study on the Development of Silicified Tissues in the Lemma of Phalaris canariensis L. Proceedings of the Royal Society of London. 1984; B222:413-425. Appud Piperno DR. Phytolith Analysis: An Archaelogical and Geological Perspective. Academic Press Inc. USA. 1988.

Iriarte J, Holst I, Marozzi O, Listopad C, Alonso E, Rinderknecht A, Montan J. Evidence for cultivar adoption and emerging complexity during the mid-holocene in the La Plata basin. Nature. 2004; 432:614-617.

Jin Y, Yip H-K. Supragingival Calculus: Formation and Control. Critical Review in Oral Biology \& Medicine. 2002; 13(5): 426-441. 
Jones RL, Hay WW, Beavers AH. Microfossils in Wisconsin Loess and Till from Western Illinois and Eastern Iwoa. Science. 1963; 140:1222-1224.

Kani T, Kani M, Moriwaki Y, Doy Y. Microbeam X-ray Diffraction Analysis of Dental Calculus. Journal of Dental Research. 1983; 62 (2).

Kelly RL. The Foraging Spectrum: Diversity in Hunter-Gatherer Lifeways. Smithsonian Institution Press. Washington. 1995. 446pps.

Kleinberg I. Studies on dental plaque I. the effect of different concentrations of glucose on the $\mathrm{pH}$ of dental plaque in vivo. J Dent Res 1961; 40: 1087 - 1111.

Kleinberg I. A mixed-bacteria ecological approach to understanding the role of oral bacteria in dental caries causation: an alternative to Streptococcus mutans and specificplaque hypothesis. Crit Rev Oral Biol Med 2002; 13: 108-25.

Kleinberg I, Jenkis GN, Denepitiya L, Cjatterjee R. Diet and dental plaque. In Fergunson DB, editor. The environment of the teeth. Nova York: Kargel; 1981. p. 88-107.

Klökler DM. Construindo ou Deixando um Sambaqui? Análise de sedimentos de um sambaqui do litoral meridional brasileiro: processos formativos, região de Laguna, SC. [dissertação de Mestrado] Museu de Arqueologia e Etnologia da USP. São Paulo. 2000.

Klökler DM. Vida Ritual dos Sambaquieiros. In: Arqueologias da América Latina. XII Congresso da Sociedade de Arqueologia Brasileira. São Paulo: Sociedade de Arqueologia Brasileira. 2003; p29.

Kneip LM. Cultura material e subsistência das populações pré-históricas de Saquarema, RJ. Documento de Trabalho, sér. Arqueologia. 1994; 2:1-120.

Lalueza C, Pérez-Pérez A. The Diet of Neanderthal child Gibraltar 2(Devil's Tower) through the Study of Vestibular Striation Pattern. Journal of Human Evolution. 1993; 24:29-41.

Larsen CS. Bioarchaeology: interpretting behavior from the human skeleton. Cambridge:

Cambridge University Press, 1997.

Larsen MJ, Jensen AF, Madsen DM, Pearce EFI. Individual Variations of pH, Buffer Capacity and Concentrations of Calcium and Phosphate in Unstimulated Whole Saliva. Archives of Oral Biology. 1999; 44:111-117.

Lehninger AL, Nelson DL, Cox MN. Principles of Biochemistry. Second Edition. Worth Publisher Inc. New York. 1993.

Leyden BW, Brenner M, Dahlin BH. Cultural and Climatic history of Cobá, a lowland Maya city in Quintana Roo, Mexico. Quaternary Research. 1998; 49:111-122.

Lima TA. Em busca dos frutos do mar: Os pescadores-coletores do litoral centro-sul do Brasil. Revista USP 1999-2000; 44: 270-327.

Lima TA; Macario KD; Anjos RM; Gomes PRS; Coimbra MM; Elmore D. The antiquity of the prehistoric settlement of the central-south Brazilian coast. Radiocarbon. 2002; 44:733-738.

Lingström P, Van Houte J, Kashket S. Food starches and dental caries. Crit Rev Oral Biol Med 2000; 11: 366-80.

Loy TH. Methods in the Analysis of Starch Residues on Prehistoric Stone Tools. In: Hather JG. Tropical Archaeobotany: Applications and New Developments. 1994; pp 86-114. Routledge, London. Appud Pearsall DM, Paleoethnobotany: A Handbook of Procedures. New York: Academic Press. Second Edition. 2000.

MacPhee T, Cowley G. Essentials of Periodontology and Periodontics. Blackwell Scientific Publications. Oxford. Second edition. 1975. Appud: Middleton WD, Rovner I. Extraction of opal phytoliths from herbivore dental calculus. Journal of Archaeological Science. 1994; 21, 469-473. 
Mandel ID. Effects of dietary modifications on caries in humans. J Dent Res 1970; 6 Suppl: 120111.

Mendonça de Souza SMF. Estresse, doença e adaptabilidade: Estudo comparativo de dois grupos préhistóricos em perspectiva biocultural. [Tese de Doutorado] Rio de Janeiro: Escola Nacional de Saúde Pública, Fundação Oswaldo Cruz; 1995.

Middleton W. An improved method for extraction of opal phytolith from cervid dental tartar. The Phytolitarien newsletter 1990; 6: 2-5.

Middleton WD, Rovner I. Extraction of opal phytoliths from herbivore dental calculus. Journal of Archaeological Science. 1994; 21, 469-473.

Moss GE. The Microscopy of Starch. In: Radley JA. Examination and Analysis of Starch and Starch Products. Applied Science, London. 1976.

Okuda A, Takahashi E. The Effect of Various Amounts of Silicon Supply on the Growth of the Rice Plant and Nutrient Uptake, Part 3. Journal of the Science of Soil and Manure, Japan. 1961; 32:533-37. Appud Piperno DR. Phytoliths: A Comprehensive Guide for Archaeologists and Paleoecologists. Altamira Press, New York. 2006; 238p.

Okumura MMM, Neves WA. Afinidades biológicas de grupos pré-históricos do vale do rio ribeira do Iguape (SP): uma análise preliminar. Revista de Antropologia (FFLCH-USP). 2005; 48:525-558.

Okumura MMM, Eggers S The People of Jabuticabeira II: Reconstruction of the Way of Life in a Brazilian Shellmound. International Journal of Osteoarchaeology. Homo. 2005; 55:263-281.

Okumura MMM, Boyadjian $\mathrm{CH}$, Eggers $\mathrm{S}$. Is auditory exostosis a good aquatic activity marker? $1^{\text {st }}$ Palaeopathology Association Meeting in South America, Rio de Janeiro. 2005.

Okumura MMM, Boyadjian CH, Eggers S. a. Auditory Exostosis as an Aquatic Activity Marker: A Comparison of Coastal and Inland Skeletal Remains from Tropical and Subtropical Regions of Brazil. American Journal of Physical Anthropology. 2007.

Okumura MMM, Boyadjian CH, Eggers S. b. Is Cold Water Sufficient to Trigger Auditory Exostosis? Ear Nose and Throat Journal. No prelo.

Okumura MMM, Boyadjian $\mathrm{CH}$, Eggers S. Análise da Exostose do Meato Auditivo Externo como um Marcador de Atividade Aquática em Restos Esqueletais Humanos da Costa e do Interior do Brasil. Revista de Arqueologia, USP. São Paulo. Brasil. 2005/6; 15/16.

Pearsall DM. Phytolith Analysis of Vessels 2, 4 and 9. In: Markman CW. Putney Landing: Archaeologycal Investigations at a Havana-Hopewell Settlement on the Mississippi River, west-central Illinois. Northern Illinois University Department of Anthropology Report of Investigations 15. 1987; p 416-420.

Pearsall DM. Paleoethnobotany: A handbook of procedures. Nova York: Academic Press; 2000.

Perry C, Man S, Williams RJP, Watt F, Grime GW, Takacs J. A Scanning Electron Microprobe Study of Microhairs from the Lemma of the Grass Phalaris canariensis L. Proceedings of the Royal Society of London. 1984; B222:439-455. Appud Piperno DR. Phytolith Analysis: An Archaelogical and Geological Perspective. Academic Press Inc. USA. 1988.

Perrotta R, Eggers S. Horticultura em Sambaqui? XIII Congresso da Sociedade de Arqueologia Brasilieira. Campo Grande , MT. 2005.

Petronilho CC. Comprometimento Articular Como um Marcador de Atividade em um Grande SambaquiCemitério. [dissertação de mestrado] Instituto de Biociências da Universidade de São Paulo. 2005.

Petronilho CC, Eggers S. Articular degeneration and other activity markers in the sambaqui Jaboticabeira II. $1^{\text {st }}$ Palaeopathology Association Meeting in South America. Rio de Janeiro. 2005.

Perry L, Sndweiss DH, Piperno DR, Redemaker K, Malpass MA, Umire A, de la Vera P. Early Maze Agriculture and Interzonal Interaction in Southern Peru. Nature. 2006; 440:76-79. 
Piperno DR. Phytolith Analysis: An Archaeological and Geological Perspective. Academic Press. San Diego, USA. 1988.

Piperno DR. Paleothnobotany in the Newtropic from the microfossils: New Insights into Ancient Plant Use and Agricultural Origins in the Tropical Forest. Journal of World Prehistory. 1998; 12 n. 4.

Piperno DR. Phytoliths: A Comprehensive Guide for Archaeologists and Paleoecologists. Altamira Press, New York. 2006; 238p.

Piperno DR, Holst I. The Presence of Starch Grains on Prehistoric Stone Tools from the Humid Neotropics: Indications of Early Tuber Use and Agriculture in Panama. Journal of Archaeological Science. 1998; 25: 765776.

Piperno DR, Pearsall DM. The Nature and Status of Phytolith Analysis. In: Pearsall DM, Piperno DR. Current Research in Phytolith Analysis: Applications in Archaeology and Paleoecology. MASCA Research Papers in Science and Archaeology. University Museum of Archaeology and Anthropology, University of Pennsylvania, Philadelphia. 1993; 10:9-18

Piperno DR, Ranere AJ, Holst I, Hansel P. Starch Grains Reveal Early Root Crop Horticulture in the Panamian Tropical Forest. Nature. 2000; 407:894-897.

Piperno DR, Weiss E, Holst I, Nadel D. Processing of Wild Cereal Grains in the Upper Paleolithic Revealed by Starch Grain Analyis. Nature. 2004; 430:670-673.

Poff AM, Pearce EIF, Larsen MJ, Cutress T. Human Supragingival In Vivo Calculus Formation in Relation to Saturation of Saliva with Respect to Calcium Phosphates. Archives of Oral Biology. 1997; 42(2): 93-99.

Pough FH, Janis CM, Heiser JB. A Vida dos Vertebrados, third ed., Editora Ateneu São Paulo, São Paulo, Brazil. 2003.

Prous A. Arqueologia Brasileira. Brasília: Editora Universidade de Brasília. 1991.

Rapp GJ, Mulholland SC. Phytolith Systematics: Emergence Issues. Plenum Press. New York. 1992. 345p.

Reinhard KJ. The Utility of Pollen Concentration in Coprolite Analysis: Expanding upon Dean's Comments. Journal of Ethnobiology.1993; 9:31-44.

Reinhard, K.J.; Mendonça de Souza, S.F.; Rodrigues, C.; Kimerle, E.; Dorsey-Vinton, S. Microfossils in dental calculus: A new perspective on diet and dental disease. In Willians E, editor. Human remain: Conservation, retrieval and analysis. Proceedings of a conference held in Willianburg, VA, nov 1999. BAR International Series 934, pp113-118; 2001.

Samuel D. Modified Starch. In: Torrence R, Barton H. Ancient Starch Research. Left Coast Press Inc. Califonia. 2006; p35-45.

Sandweiss DH. Small is big: The Microfossil Perspective on Human-Plant Interaction. Proceedings of the National Academy of Sceinces of the United States of America (PNAS). 2007; 104(9):3021-3022.

Sangster AG. Silicon Distribution and Anatomy of the Grass Rhyzome, with Special Reference to Miscanthus sacchariflorus (maxim.) Hackel. Annals of Botany. 1985; 55:621-634. Appud Piperno DR. Phytolith Analysis: An Archaelogical and Geological Perspective. Academic Press Inc. USA. 1988.

Sangster AG, Hodson MJ, Tubb HJ. Silicon Deposition in Higher Plants. In: Datnoff IE, Snyder GH, Korndorfer GH. Silicon in Agriculture. Elsevier Scienc. Amsterdam. 2001; p85-113. Appud Piperno DR. Phytoliths: A Comprehensive Guide for Archaeologists and Paleoecologists. Altamira Press, New York. 2006. 238p.

Scarre S. The World Transformed: From Foragers and Farmers to States and Empires In: Scarre C. The Human Past: World Prehistory \& Development of Human Societies. Thames and Hudson Ltd.London. 2005. p.176-199

Scott GR, Turner II CG. Dental anthropology. Ann Rev Anthropol 1988; 17: 99-126. 
Scheel-Ybert R. 2000. Vegetation stability in the Southeastern Brazilian coastal area from 5500 to $1400{ }^{14} \mathrm{C}$ yr BP deduced from charcoal analysis. Review of Palaeobotany and Palynology. 2000; 110:111-138.

Scheel-Ybert R. Man and vegetation in the Southeastern Brazil during the Late Holocene. Journal of Archaeological Science. 2001; 28(5): 471-80.

Scheel-Ybert R, Eggers S, Wesolowski V, Petronilho CC, Boyadjian CH, DeBlasis PAD, Barbosa-Guimarães M, Gaspar MD. Novas perspectivas na reconstituição do modo de vida dos sambaquieiros: uma abordagem multidisciplinar. Revista de Arqueologia. 2003; 16:109-137.

Schimitz PI. As tradições ceramistas do planalto sul-brasileiro. Documentos, Inst. Anchietano de Pesquisas. 1988; 2:75-130.

Shafer HJ, Holloway RG. Organic Residue Analysis in Determining Stone Tool Function. In: Hayden B. Lithic Use-Wear Analysis. Academic Press. New York. 1979; p385-389.

Shannon JC, Garwood DL. Genetics and Physiology of Starch Development. In: Whistler RL, BrMiller JN, Paschal EF. Starch, Chemistry and Technology, second ed. Academic Press. Orlando. 1984; p26-85.. Appud Gott B, Barton H, Samuel D, Torrence R. Byology of Starch In: Torrence R, Barton H. Ancient Starch Research. Left Coast Press Inc., Califonia. 2006. p35-45.

Steckel RH, Rose JC. The backbone of History: Health and Nutrition in the Western Hemisphere. Cambridge University Press. 2002.

Storto C, Eggers S, Lahr MM. Estudo Preliminar das Paleopatologias da População do Sambaqui Jaboticabeira II, Jaguaruna, SC. Revista do Museu de Arqueologia e Etnologia/USP. 1999; n.9.

Tayles N, Domett K, Nelsen K. Agriculture and Dental Caries ? The Case of Rice in Prehistoric Southeast Asia. World Archaeology. 2000; 32(1): 68-83.

Tenório CM. A importância da coleta de vegetais no advento da agricultura. [Dissertação de Mestrado]. Rio de Janeiro: Universidade Federal do Rio de Janeiro; 1991.

Tiburtius G; Bigarella JJ; Bigarella IK Nota prévia sobre a jazida paleoetnográfica de Itacoara, Joinville, Santa Catarina. Ciência e Cultura 1951; 3: 267-8.

Torrence R. Starch and Archaeology. In:Torrence R, Barton H. Ancient Starch Research. Leaf Coast Press, California. 2006.

Torrence R, Barton H. Ancient Starch Research. Leaf Coast Press, California. 2006.

Turner II CG. Dental anthropological indications of agriculture among the Jomon people of central Japan. Am J Phys Anthropol 1979; 51: 619-36.

Uchôa DP Arqueologia de Piaçaguera e Tenório : análise de dois tipos de sítios précerâmicos do litoral paulista [Tese de doutorado].Rio Claro: Faculdade de Filosofia, Ciências e Letras de Rio Claro; 1973.

Vickers W. The Faunal Componentes of Lowland South America Hunting Kills. Interciência. 1984; 9(6):366376. Appud Figuti L. O Homem Pré-histórico, o Molusco e os Sambaquis: considerações sobre a subsistência dos povos sambaquieiros. Revista do Museu de Arqueologia e Etnologia. 1993; 3: 67-80.

Vickers, W. Game Depletion Hypothesis of Amazonian Adaptation: Data from a Native Community. Science.1988; 239:1521-1522.

Villers RL, López FRM, Barrera A. La unidad de habitación tradicional campesina y el manejo de recursos bióticos en el area Maya Yucatanense. Biotica. 1981; 6:293-322. Apud: Alcorn JB. The Scope and Aims of Ethnobotany in a Developing World. In: Schultes Re, von Reis S Ethnobotany: Evolution of a Discipline. Timber Press, Oregon USA. 1995.

Walker AC, Hoeck HN, Perez L. Microwear of mammalian teeth as an indicator of diet. Science 1978; p908910. 
Warnock P, Reinhard KJ. Methods of Extracting Pollen and Parasite Eggs from Latrine Soils. Journal of Archaeological Science. 1992; 19:261-264.

White GE. Dental caries: a multifactorial disease. Springfield: Charles C. Thomas Editor. 1975.

Wittmack L. Our Present Knowledge of Ancient Plants. Transactions of the Academy of Sceince of St. Louis. 1905;15:1-15. Apud Torrence R, Barton H. Ancient Starch Research. Leaf Coast Press, California. 2006.

Wesolowski V. A prática da horticultura entre os construtores de sambaquis e acampamentos litorâneos da região da Baía de São Francisco, Santa Catarina: Uma abordagem bio-antropológica. [Dissertação de mestrado]. Faculdade de Filosofia, Letras e Ciências Humanas, Universidade de São Paulo; 2000.

Wesolowski V. Cáries, desgaste, cálculos dentários e micro-resíduos da dieta entre grupos pré-históricos do litoral norte de Santa Catarina: É possível comer amido e não ter cárie? [ Tese de Doutorado] Fundação Oswaldo Cruz. Escola Nacional de Saúde Pública Sérgio Arouca. 2007. 192p.

Zarrillo S, Kooyman B. Evidence for berry and maize processing on the canadian plains from starch grain analysis. American Antiquity. 2006;71(3):473-499.

Zeder MA, Bradley DG, Emshwiller E, Smith BD. Documenting Domestication: New Genetic and Archaeological paradigms. University of California Press. 2006. 